\title{
Estudo do ruído de rodagem estrutural através da análise dos caminhos de transferência de energia - TPA
}

Dissertação de mestrado apresentada ao Programa de Pós Graduação em Engenharia Mecânica da Escola de Engenharia de São Carlos da Universidade de São Paulo, para a obtenção do título de Mestre em Engenharia Mecânica.

Área de concentração:

Dinâmica das Máquinas e Sistemas

Orientador: Prof. Dr. Leopoldo P. R. de Oliveira

Este exemplar trata-se da versão corrigida. A versão original encontra-se disponível junto ao departamento de Engenharia Mecânica da EESC-SP.

São Carlos 
AUTORIZO A REPRODUÇÃO E DIVULGAÇÃO TOTAL OU PARCIAL DESTE TRABALHO, POR QUALQUER MEIO CONVENCIONAL OU ELETRÔNICO, PARA FINS DE ESTUDO E PESQUISA, DESDE QUE CITADA A FONTE.

Ficha catalográfica preparada pela Seção de Tratamento da Informação do Serviço de Biblioteca - EESC/USP análise dos caminhos de transferência de energia - TPA / César Helou Teodoro da Silva ; orientador Leopoldo P. R. de Oliveira. -- São Carlos, 2011.

Dissertação (Mestrado-Programa de Pós-Graduação em Engenharia Mecânica e Área de Concentração Dinâmica das Máquinas e Sistemas) -- Escola de Engenharia de São Carlos da Universidade de São Paulo, 2011.

1. Dinâmica veicular. 2. Ruído de rodagem. 3. Rumble. 4. Análise dos caminhos de transferência de energia. 5. TPA. 6. NPA. 7. Interação pneu/pavimento. 8. Chassis. 9. Vibrações. 10. Ruído interno veicular. 11. FRF. I. Título. 


\section{FOLHA DE JULGAMENTO}

Candidato(a): Engenheiro CÉSAR HELOU TEODORO DA SILVA.

Dissertação defendida e julgada em 31/05/2011 perante a Comissão Julgadora:

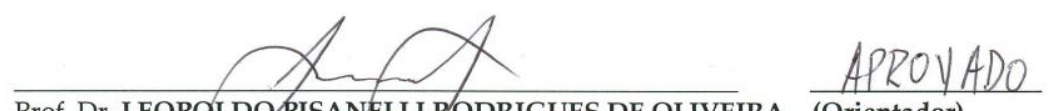

Prof. Dr. LEOPOLDO/PISANELLI RODRIGUES DE OLIVEIRA - (Orientador)

(Escola de Engenharia de São Carlos/USP)

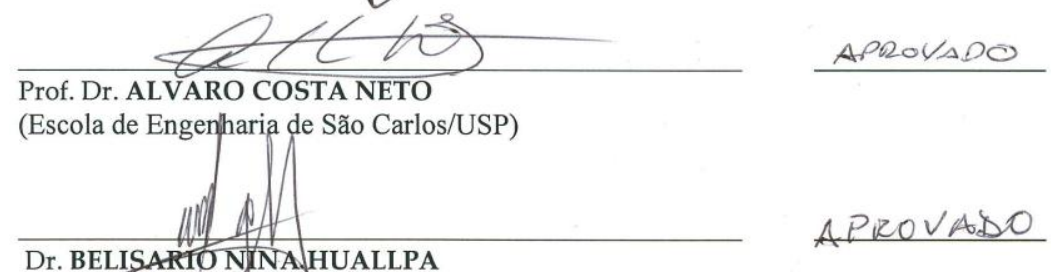

(Ford Motor Company)

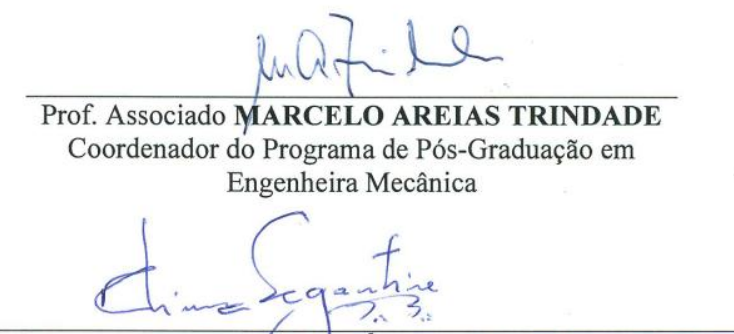

Prof. Associado PAULO CÉSAR LIMA SEGANTINE Presidente da Comissão da Pós-Graduação da EESC 


\title{
Agradecimentos
}

\author{
Á Aline pelo incentivo e força, aos meus amigos pela torcida e paciência, á minha \\ família pela educação e apoio, e principalmente ao meu Pai, pelo seu carinho, dedicação \\ e exemplos, e á minha Mãe, pela sua garra, incentivos e renúncias. Á Deus pela minha \\ saúde, por sempre mostrar a porta estreita e pela fé que me motiva a percorrer os \\ caminhos para minha reforma e sonhos.
}


"A vida é como andar de bicicleta. Para manter seu equilibro você deve continuar em movimento."

Albert Einstein 


\section{Resumo}

da Silva, C.H.T., Estudo do ruído de rodagem estrutural através das análises dos caminhos de transferência de energia - TPA. 2011, 139 p. Dissertação (Mestrado) Escola de Engenharia de São Carlos da Universidade de São Paulo, 2011.

Os ruídos, vibrações e asperezas de rodagem veicular (do acrônimo em inglês Road $N V H$ ), presentes de $20 \mathrm{~Hz}$ até $1000 \mathrm{~Hz}$ aproximadamente, originam-se das vibrações e propagações acústicas dos pneus ao interagir com as superfícies. Nestas fontes de ruído, ambas as vias de contribuições estruturais e aéreas, são relevantes para o refinamento veicular. Constantes são os esforços para estudar o veículo como um conjunto de caminhos de transferência entre a dinâmica dos pneus até o conforto dos passageiros. Sendo assim, o tratamento dos mecanismos que geram e propagam o ruído e vibração à cabine está avançando, graças aos testes e análises sistemáticas, fundamentadas na teoria de Análises dos Caminhos de Transferências de energia (TPA do inglês transfer path analysis). O objetivo deste trabalho é apresentar um estudo de um caso de Road NVH utilizando o TPA em veículo protótipo. Neste tema, é investigado o nível de ruído de rodagem em torno de $180 \mathrm{~Hz}$, semelhante ao efeito de roncar (rumble, na expressão em inglês). Este ruído permanece presente no protótipo, em diversos tipos de pista e velocidades, porém em apenas um modelo de pneu (batizado de modelo “A”), entre os diversos testados. Das avaliações subjetivas prévias, defini-se que o foco das investigações são as contribuições estruturais da suspensão dianteira. Usando o TPA para demonstrar os caminhos críticos na formação do rumble, aplicou-se o método da matriz inversa para o calculo das forcas, considerando os seguintes pontos: buchas do braço de controle do A-Arm e de ligação da carroceria com a parte superior da suspensão dianteira (fig. 4.6 - tipo Mc Pherson). Foram obtidas experimentalmente as vibrações dos lados ativos e passivos destes pontos, nas condições de rolagem e as funções de resposta vibracionais e acústica do ponto, no laboratório. Após a correlação do ruído interno calculado com o medido, concluiu-se que o rumble deste caso foi gerado pela baixa eficiência de isolação das vibrações radiais nas buchas anteriores e pela força lateral do pneu "A". Por fim, propostas de bucha e pneu são apresentadas em termos das novas forças e respostas acústicas transmitidas, para minimizar o rumble.

Palavras chaves: Ruído de rodagem, rumble, análise dos caminhos de transferência de energia, TPA, NPA, interação pneu/pavimento, chassis, vibrações, ruído interno veicular, FRF. 


\section{Abstract}

da Silva, C.T.H., Structure-borne road noise study using transfer path analysis, TPA. 2011, 139 p. Master Thesis - São Carlos School of Engineering, University of São Paulo, 2011.

The road noise, vibration and harshness (Road NVH) present from $20 \mathrm{~Hz}$ to $1000 \mathrm{~Hz}$ approximately, begins from the tires vibration and acoustic propagation and their interactions with the road surfaces. In these noise sources, both structural-borne and airborne noise contributions are relevant to vehicle refinement. The constant efforts to study the vehicle as a set of transfer paths from tires dynamic behavior to passenger comfort to the final passenger comfort perception. Thus the treatment of generation and propagation mechanisms, have being forward thanks to the systematic tests and proceedings based on the transfer path analysis theory (TPA). The purpose of this work is to present a case study of Road $N V H$, using TPA in prototype vehicle. On this theme, it is investigated a higher noise level around $180 \mathrm{~Hz}$, on the rumble narrow band. This noise remains in the prototype during several types of tracks and speeds conditions, whenever only a tire model, named as sample "A", is used, despites all tires tested. From the previous subjective evaluation, the focus of the investigation is defined to be structure-borne of the front suspension. Using TPA to demonstrate the critical paths to rumble, it was applied the matrix inversion method to force calculation, considering the follow points: A-Arm type lower control arm bushings and top mounts of front suspension (picture 4.6 - Mc Pherson type). The vibration in the active and passive side of these points during test conditions and the FRFs driving points and body sensitivity for a target microphone were obtained experimentally. After correlation between internal road noise calculated and the measured, it was concluded the Rumble of this case had been formed by low radial vibration isolation of the front bushings and due lateral forces of tire "A". At last, the bushing and tire proposals are presented in terms of new transmitted forces and acoustical responses, to minimize the rumble.

Key words: Road NVH, rumble, transfer path analysis, TPA, NPA, tire/road interaction, chassis, vibration, vehicle internal noise, FRF; 


\section{Sumário}

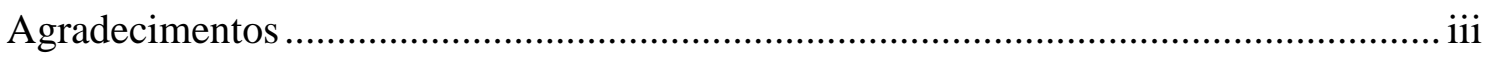

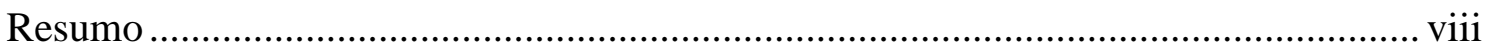

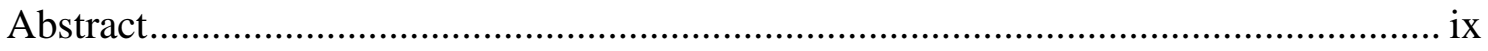

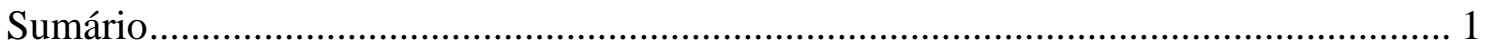

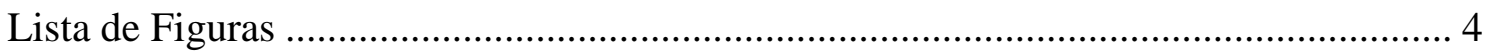

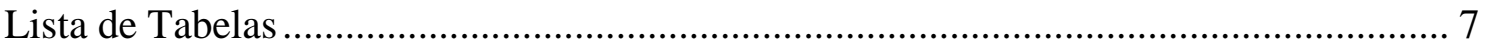

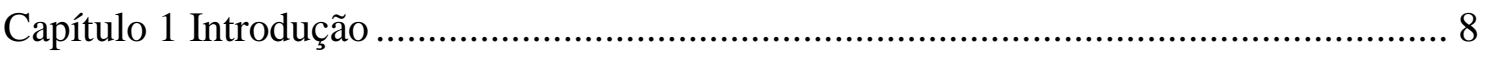

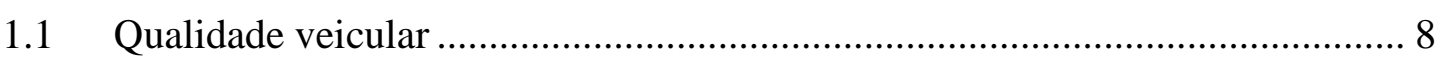

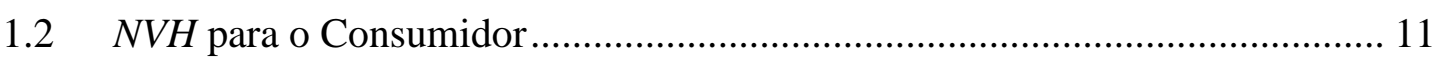

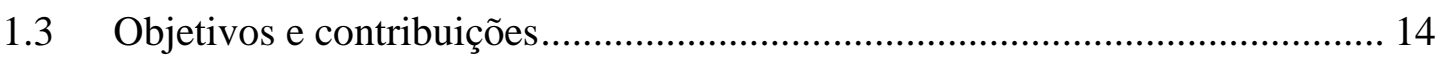

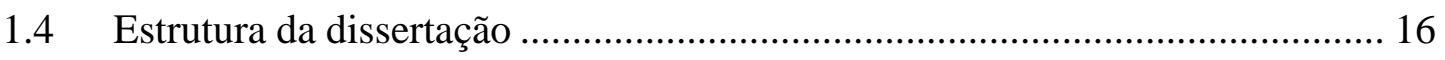

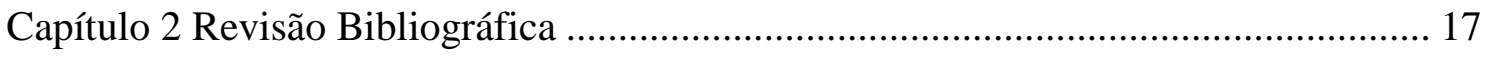

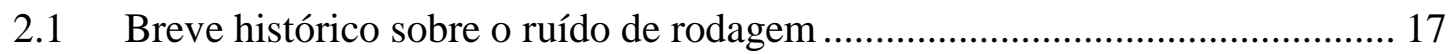

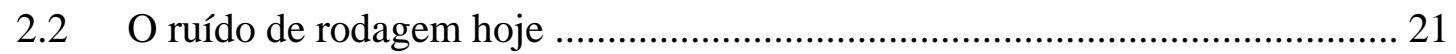

2.3 Balanço e contribuições de $N V H$.................................................................. 23

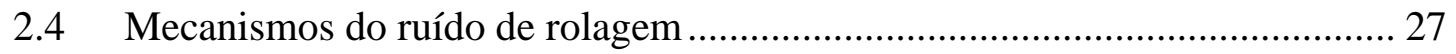

2.4.1 Influência das superfícies ............................................................. 28

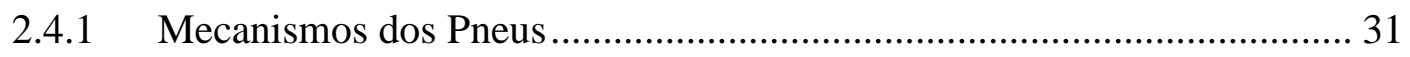

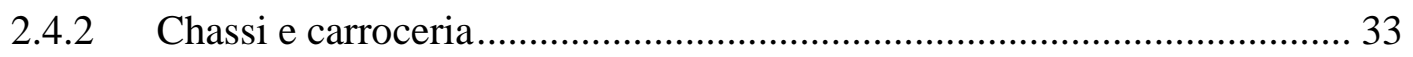

2.5 Estado da arte em análises do ruído interno de rodagem ............................... 36

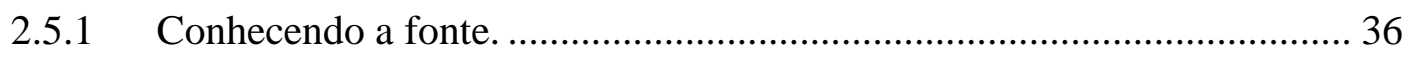

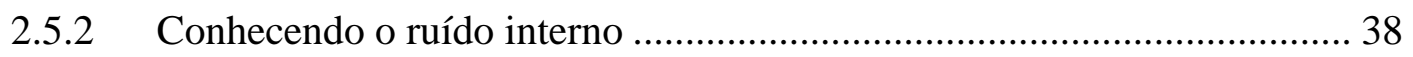

2.5.3 Os caminhos das fontes para o ruído interno, TPA............................... 39

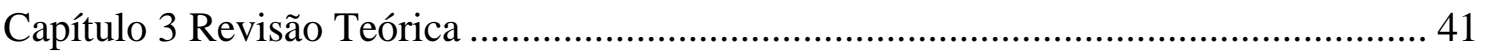

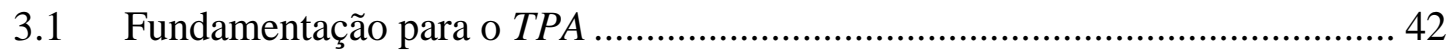


3.1.1 Lei da Reciprocidade - sistemas SISO e MIMO em múltiplos GDF ........ 44

3.1.2 Análises de sinais: relações entrada/saída de sistemas lineares ............... 46

3.1.3 Função de coerência da FRF ............................................................ 54

3.1.4 Vibração - Fase \& Coerência de fase .................................................... 58

3.2 Medindo os caminhos de transferência de energia ....................................... 60

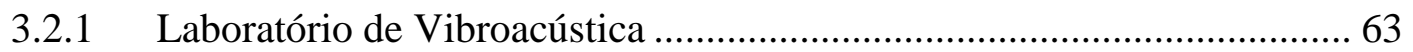

3.2.2 Testes em pistas, dinamômetros e bancadas.............................................. 66

3.3 Métodos para determinação das forças operacionais.................................... 69

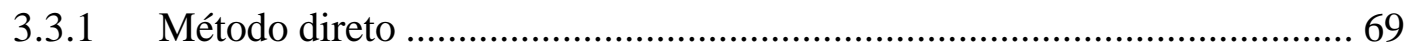

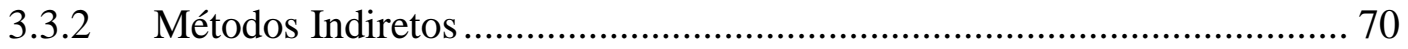

3.4 Métodos para determinação das velocidades de volume operacionais ............ 72

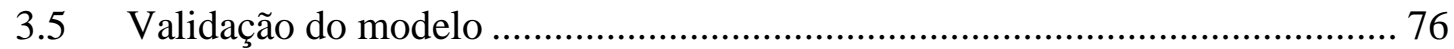

3.6 TPA de Múltiplas referências - Road TPA …................................................ 77

3.6.1 Técnicas de coerência parcial ............................................................. 78

3.6.2 Análise virtual de coerência ............................................................. 79

3.6.3 Análise de Componentes Principais: .................................................. 80

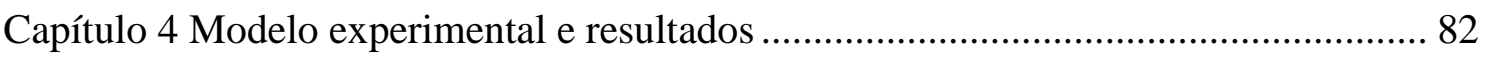

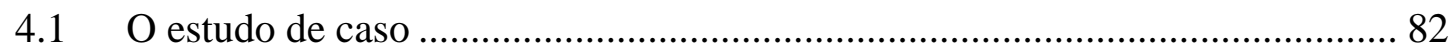

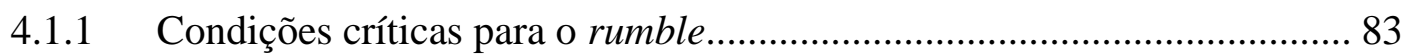

4.1.2 Avaliações subjetivas e otimizações do TPA …...................................... 87

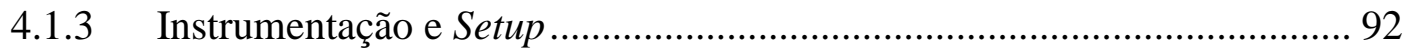

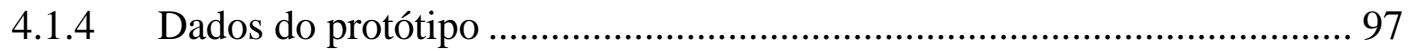

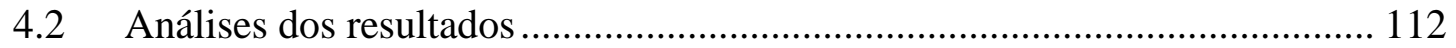

4.2.1 Correlação experimental entre ruído medido e o TPA …....................... 112

4.2.2 Eficiências dos caminhos na absorção de energia ................................ 115

4.2.3 Calculo das forças de entrada no chassi ............................................. 119

4.2.4 Calculo das respostas acústicas da carroceria................................... 121 
4.3 Modificações propostas e resultados

4.3.1 Análise das forças na bucha anterior, ponto 3

4.3.2 Análises da contribuição do ruído na bucha anterior, ponto 3

4.3.3 Resultado final para o rumble. 130

Capítulo 5 Conclusões e desenvolvimentos futuros 131

5.1 Conclusões do estudo de caso 131

5.2 Próximos passos. 134

5.3 Tendências para Road TPA 134

Bibliografia 136 


\section{Lista de Figuras}

FIGURA 1.1: MODELO KANO PARA DEFINIÇÃO DA QUALIDADE DOS ATRIBUTOS NA VOZ DO CONSUMIDOR .........................9

FIGURA 1.2: NíVEIS DE PRESSÕES SONORAS E DIRETRIZES ESTABELECIDAS PELA OMS, OECD E CONAMA .....................12

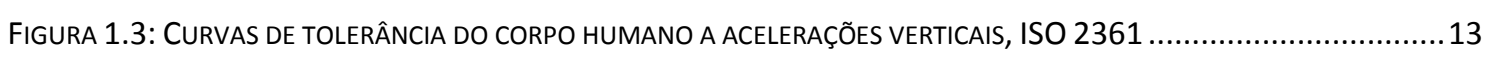

FIGURA 2.1: OS PRIMEIROS MODELOS DE VELOCÍPEDES NO MUNDO, A PARTIR DO SÉCULO XIX ...................................18

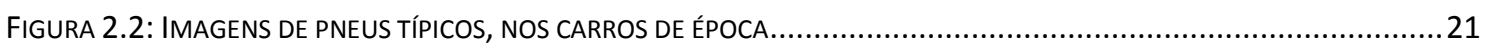

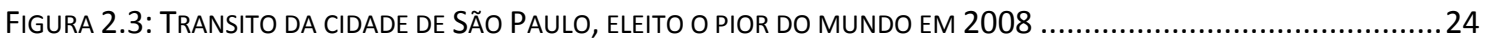

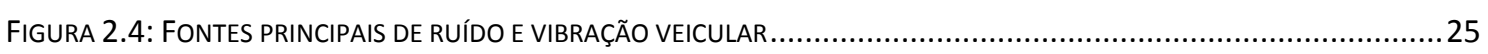

Figura 2.5: EVOLUÇÃo dOS NÍVEIS DE RUÍdO DE PT VS. PNEUS (SANDBERG, ULF; EJSMONT, JERZY A., 2002) .................26

FIGURA 2.6: EXEMPLO DAS CONTRIBUIÇÕES DO RUÍDO NO INTERIOR DE UM VEÍCULO A 70 KM/H, ASFALTO LISO ................27

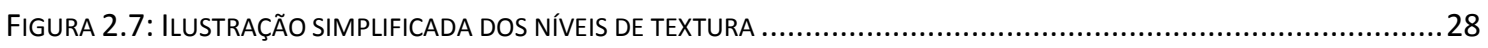

FIGURA 2.8: ESCALAS MICRO E MACRO ESTRUTURAS DE DIFERENTES SUPERFÍCIES DE RODAGEM ..................................29

FIGURA 2.9: CARACTERÍSTICAS DE ABSORÇÃO ACÚSTICA DE UMA SUPERFÍCIE POROSA................................................30

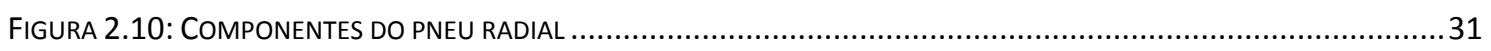

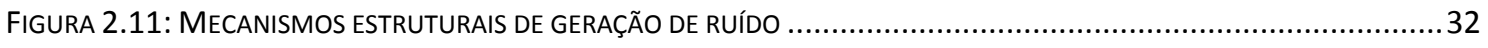

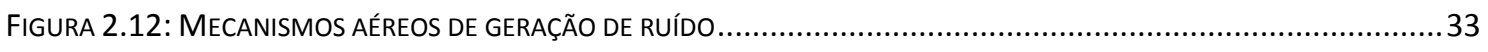

FIGURA 2.13: VISÃO GERAL PARA IDENTIFICAÇÃO DO PROBLEMA NA ANÁLISE DO RUÍDO DE RODAGEM..............................35

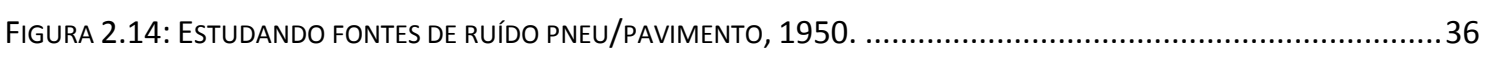

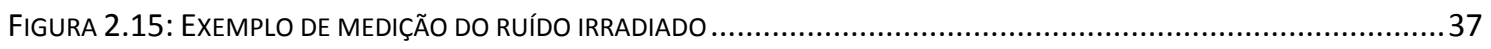

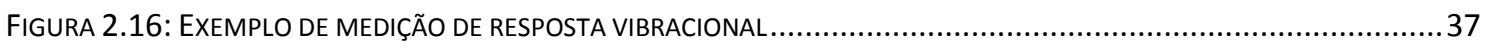

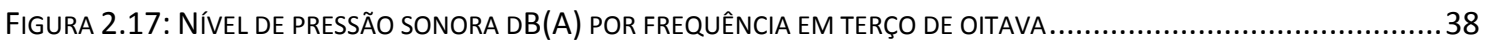

FIGURA 2.18: EXEMPLO DE ANALISE DE TPA COM OS CAMINHOS CRÍTICOS EM MIC1 E MIC3 ….................................40

FIGURA 3.1: RESPOSTAS EM FUNÇÃO DAS CARACTERÍSTICAS DO MEIO TRANSMISSOR E DA FONTE (LMS) ..........................4

FIGURA 3.2: EXEMPLOS DE CAMINHOS DE TRANSFERÊNCIAS ESTRUTURAIS EM UM VEÍCULO .......................................4

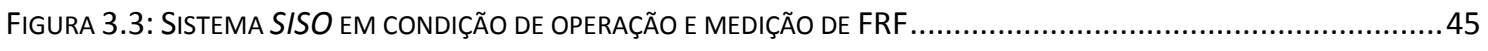

FIGURA 3.4: SINAL DE ENTRADA INDICANDO UMA DAS ENTRADAS E RESPECTIVA RESPOSTA .......................................47

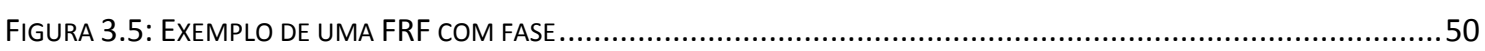

Figura 3.6: Modelos DE SISTEMAS LINEARES INPUT-OUTPUT. (A) CONVOLUÇão NO DOMÍNIO DO TEMPO. (B)

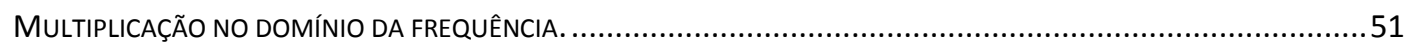

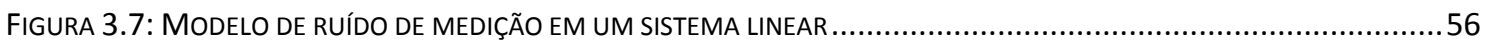

FIGURA 3.8: ILUSTRAÇÃO DE UMA FRF E SUA FUNÇÃO DE COERÊNCIA (LMS) .....................................................5

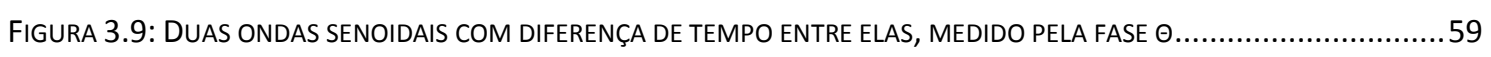

FIGURA 3.10: REPRESENTAÇÃO DE UM SISTEMA COM PARTE ATIVA E PASSIVA ...............................................61 
FIGURAS 3.11 (A) E (B): FoRd FIESTA APOIAdO EM COLCHÕES DE AR - CONDIÇÃO LIVRE-LIVRE DE CARREGAMENTO............64

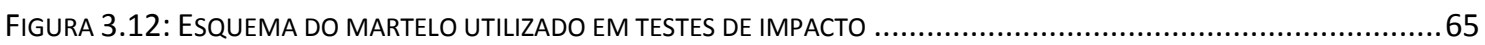

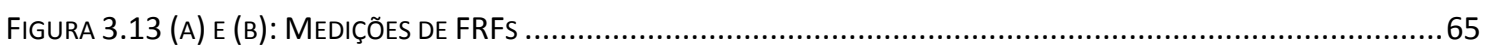

FIGURA 3.14 (A) E (B): EXEMPLOS DE SUPERFÍCIES COM RUGOSIDADES E RESPOSTAS DE RUÍDOS DISTINTOS, SP-280..........67

FigURA 3.15: MUdANÇA PARA SUPERfíCIE MENOS RUGOSA, SP-280, KM 80, SENTIDO SÃo PAULO ..............................67

FIGURA 3.16 (A) E (B): ACELERÔMETROS NOS LADOS ATIVOS E PASSIVOS DAS ENTRADAS DE FORÇAS ..............................68

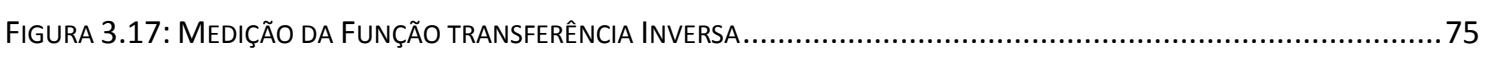

FIGURA 3.18: TRANSFORMAÇÃO EM REFERENCIA ORTOGONAL PARCIALMENTE COERENTE ...........................................79

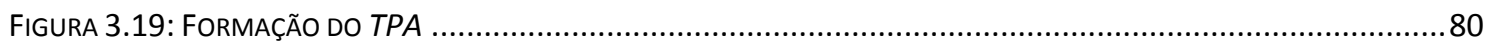

FIGURA 4.1: PRESSÃO SONORA NO INTERIOR DO VEICULO PARA TRÊS MODELOS DE PNEUS, PISTA LISA Á 20 KM/H .............84

FIGURA 4.2: RUÍDO INTERNO COM O PNEU “A” EM DIVERSAS VELOCIDADES, PISTA LISA...........................................84

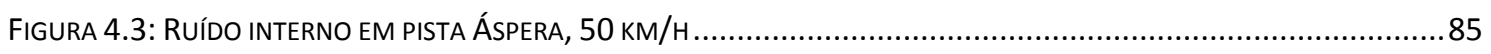

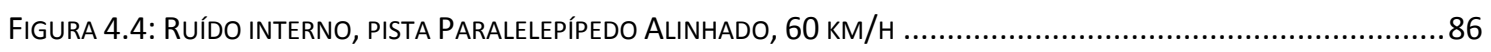

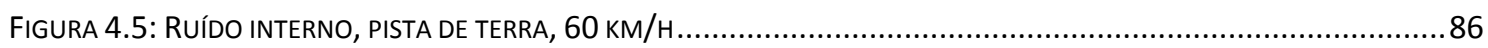

FIGURA 4.6:- PONTOS DE ENTRADA DE FORÇA CONSIDERADOS PARA O TPA …....................................................90

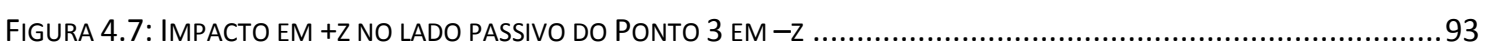

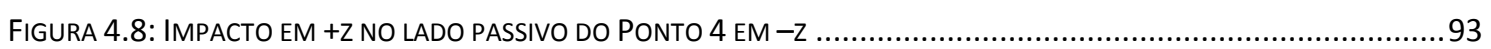

FIGURA 4.9: IMPACTO EM +Z NO LADO PASSIVO DA TORRE DA SUSPENSÃO EM -Z ..........................................93

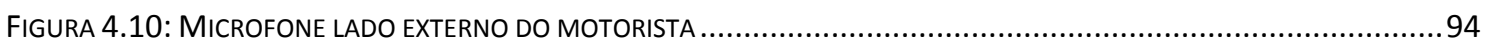

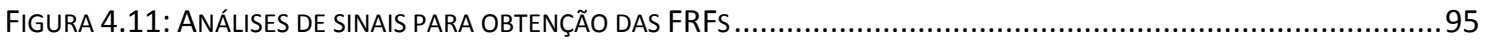

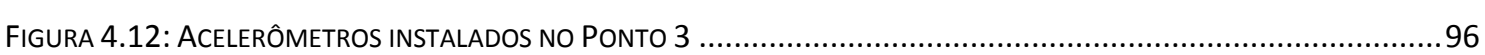

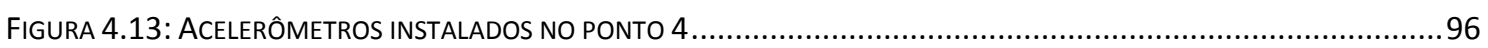

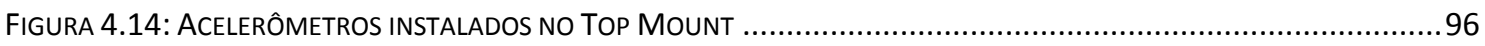

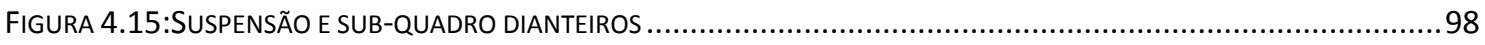

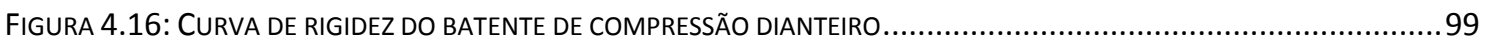

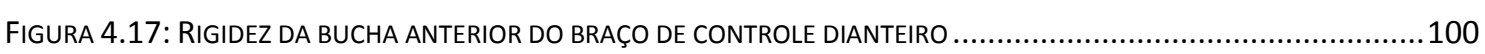

FIGURA 4.18: RIGIDEZ DA BUCHA POSTERIOR DO BRAÇO DE CONTROLE DIANTEIRO...............................................100

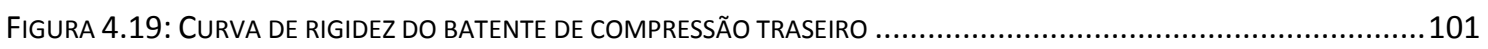

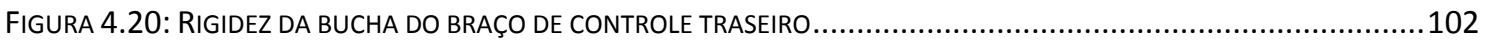

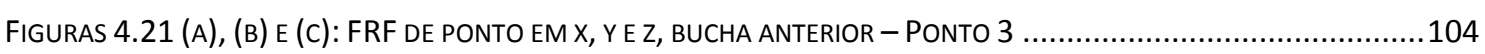

FIGURAS 4.22 (A), (B) E (C): FRF PARA SENSIBILIDADE ACÚSTICA EM X, Y E Z, BUCHA ANTERIOR - PONTO 3 ....................105

FigURAS 4.23 (A), (B) E (C): FRF DE PONTO EM X, Y E Z, BUCHA POSTERIOR - PONTO 4 .......................................107

FiguRAS 4.24 (A), (B) E (C): FRF PARA SENSIBILIDADE ACÚSTICA EM X, Y E Z, BUCHA POSTERIOR - PONTO 4 .................108

FIGURAS 4.25 (A), (B) E (C): ): FRF DE PONTO EM X, YE Z, TOP MOUNT …...................................................110

FIGURAS 4.26 (A), (B) E (C): FRF PARA SENSIBILIDADE ACÚSTICA EM X, Y E Z, TOP MOUNT ....................................111

FIGURA 4.27:- CORRELAÇÃO dO NÍVEL DE PRESSÃO SONORA MEDIDA VS. CALCULADO, PISTA LISA @ 20 KM/H ..............113

FIGURA 4.28: CORRELAÇÃO DOS CAMINHOS PARA O RUMBLE, PISTA LISA @ 20 KM/H...........................................113

FIGURA 4.29: CORRELAÇÃO dOS CAMINHOS PARA O RUMBLE, PISTA LISA @ 60 kM/H..........................................114 
FiguRA 4.30: CoRRELAÇÃo dOS CAMINHOS PARA O RUMBLE, PISTA ÁSPERA @ 50 KM/H

Figuras 4.31 (A), (B) E (C): Velocidades nOS LAdOS ATIVOS E PASSIVOS MEDIDOS NAS BUCHAS PONTO 3, 4 E TOP MOUNT

RESPECTIVAMENTE. 116

FiguRAS 4.32 (A), (B) E (C): RELAÇÃO ATIVO/PASSIVO REFERENTE O TRABALHO DAS BUCHAS NA ISOLAÇÃO DE VIBRAÇÕES 118

FIGURA 4.33: FORÇAS DE ENTRADA MEDIDO PELO TPA 119

FiguRAS 4.34 (A), (B) E (C): ForÇAS DE ENTRADA NAS BUCHAS DA SUSPENSÃO DIANTEIRA ..... 121

FiguRAS 4.35 (A), (B) E (C): RESPOSTAS ACÚSTICAS DOS CAMINHOS DAS BUCHAS

FIGURAS 4.36 (A), (B), (C) E (D): COMPARAÇÃO DAS RESPOSTAS DAS FORÇAS PARA SOLUÇõES PROPOSTAS - RESULTANTE, X, Y E Z RESPECTIVAMENTE.

FiguRA 4.37 (A), (B), (C) E (D): COMPARAÇÃO DAS RESPOSTAS DE RUÍDO PARA SOLUÇÕES PROPOSTAS - RESULTANTE, Z,Y E Z RESPECTIVAMENTE .129

FIGURA 4.38: RUÍDO INTERNO MEDIDO PARA AS PROPOSTAS QUE ATENUAM O RUMBLE 130 


\section{Lista de Tabelas}

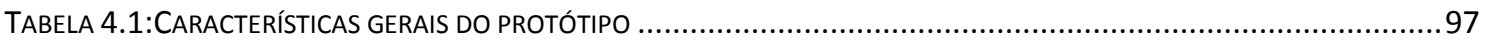

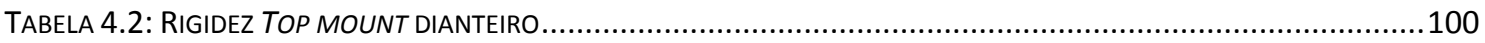

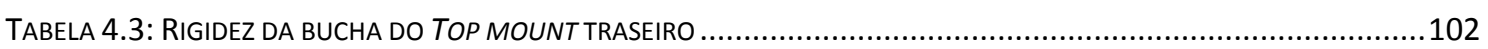




\section{Capítulo 1}

\section{Introdução}

O ruído, vibração e aspereza veicular ( $N V H$ do acrônimo em inglês) ganha destaque nas últimas décadas como fator de qualidade e diferencial de satisfação para os usuários de veículos automotores. Sua importância aumenta juntamente com o crescimento da densidade do tráfego e o aumento nas distancias dos bairros residenciais dos centros comerciais e industriais (Research for a quiter europe in 2020: Updated strategy paper of CALM network, 2007). As consequências são os maiores tempos de exposição nos níveis de ruído e vibração no interior do veículo, trazendo novas considerações quanto aos efeitos na saúde, satisfação pessoal e produtividade econômica (K.R. Stassen; P. Collier; R. Torfs, 2008), (J. Lambert, 2000). Além dos veículos com apelos visuais, sustentáveis em seu amplo sentido, dinamicamente seguro e confortável, constantes investimentos são feitos pela indústria automobilística para os ganhos do refinamento no $N V H$ veicular com o mínimo impacto em peso e custo.

\subsection{Qualidade veicular}

$\mathrm{Na}$ tentativa de contabilizar o que é qualidade e principalmente medir quanto investimento é necessário para alcançá-lo, em todos os seguimentos de veículos, diversas pesquisas de satisfações são realizados, nos diferentes nichos de mercados. Como exemplo destes estudos para descrever sentimentos em termos objetivos, pode-se 
citar a teoria do Modelo Kano (Kano, Noriaki, 1984), no qual se baseia no desenvolvimento de produtos e satisfação do consumidor, criado nos anos 80 pelo professor Noriaki Kano. Neste modelo, conforme a figura 1.1, Kano classifica as emoções em cinco grupos principais de qualidade (atraentes, unidimensionais, "precisa ser", esperado e reverso), sendo estes dependentes do tempo e oferta de mercado.

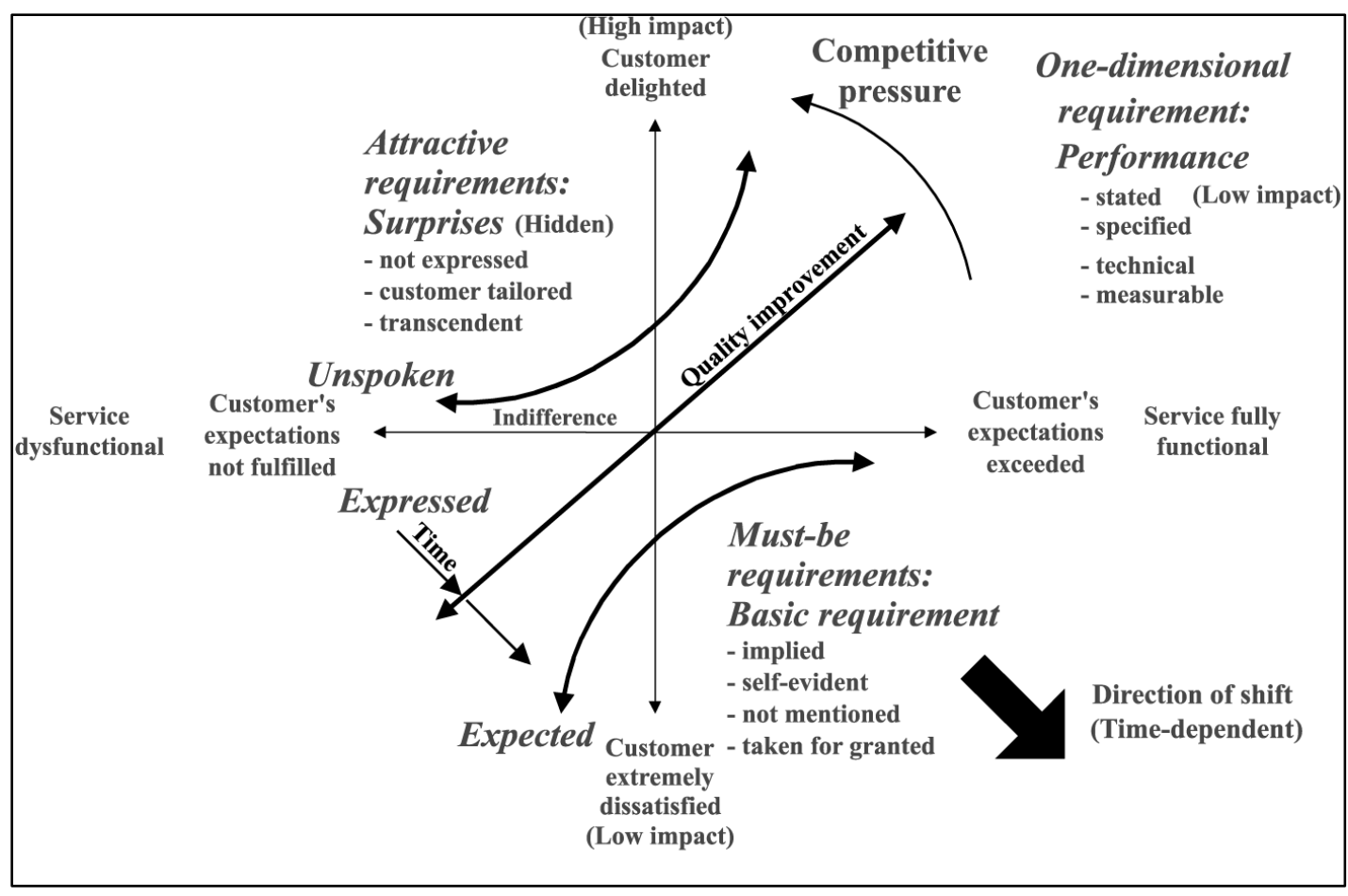

Figura 1.1: Modelo Kano para definição da qualidade dos atributos na voz do consumidor

Nos moldes deste modelo, a qualidade do $N V H$ veicular poderia ser exemplificada classificando as emoções como: Algo surpreendente e empolgante, uma qualidade sonora ao acelerar. Algo que já é esperado ou mandatório seria um baixo ruído de rodagem e de vento. E algo que irrita e não pode acontecer, são os rangidos e batidas ao trafegar com o veículo.

Nos pilares que definem os confortos dinâmicos, táteis e psicoacústicos, há dois pontos complexos que impactam na robustez e no custo do refinamento do projeto. Primeiramente, os níveis e a qualidade dos balanços das fontes de $N V H$ sendo, de um modo geral, as três principais: motorização, pneu/rodagem, ruído de vento ou 
aerodinâmico. Também são importantes os confortos dinâmicos longitudinais (ride), manobrabilidade (steering), dirigibilidade e estabilidade direcional (handling).

Focando em $N V H$, nas últimas décadas, grandes reduções de ruído na cabine do veículo foram alcançadas refinando componentes de motorizações e aerodinâmica da carroceria. Como consequência, existem atualmente dificuldades em manter o ruído de pneu/rodagem em balanço com as demais fontes (W. Hendricx; D. Vandenbroeck, 1993). Tanto para os nichos de baixo custo quanto para os segmentos mais sofisticados o ruído de rodagem começa a se sobressair sobre o de motorização desde baixas velocidades, a partir de $40 \mathrm{~km} / \mathrm{h}$. Seu efeito pode se tornar relativamente menor ao ruído aerodinâmico apenas nas altas velocidades, como em rodovias, dependendo do asfalto utilizado.

Apesar do ruído de pneu/rodagem ser exaustivamente estudado por décadas, parte dos fenômenos de geração de ruído percebido dentro do veiculo ainda não são totalmente compreendidos, sendo que as interações entre padrões de pneus e tipos de superfícies (continuas e descontinuas), ainda não foram estudadas em detalhes. Esta dificuldade está associada à alta complexidade dos projetos de pneumáticos e dos diferentes tipos de misturas de asfaltos/concretos dos pavimentos (Sandberg, Ulf; Ejsmont, Jerzy A., 2002). A redução do ruído de rodagem como um todo deveria necessariamente ocorrer integrando trabalhos entre os construtores de pneus, pavimentos e veículos. Os compromissos de baixo ruído devem ser assumidos considerando também, as complexas relações entre a resistência ao rolamento, durabilidade, aderência no molhado, conforto, dirigibilidade, estabilidade e manobrabilidade.

Desta maneira, faz-se necessário interpretar as respostas do ruído de rodagem com maior profundidade por duas frentes principais: Por parte dos fabricantes de pneus, conhecendo por completo seus mecanismos geradores e amplificação de ruído no design do pneumático; Pelo fabricante automotivo, ao investigar os fatores que influenciam as funções de transferência de energia do pneu, em forma de vibração e ruído para o veículo, tema em foco nesta dissertação. 


\subsection{NVH para o Consumidor}

A percepção subjetiva dos motoristas e passageiros é cada vez mais afetada pelas características de ruído, vibração e aspereza dos veículos. Tamanho é o impacto que o atributo $N V H$ pode causar no consumidor, que alguns fabricantes já utilizam a qualidade de NVH como estratégia de marketing a anos. Como exemplo, podem-se citar as motos da Harley-Davidson, empresa americana que faz questão de manter a qualidade sonora do seu motor de dois cilindros em V, que consagrou a marca (Marshall Brain, 2010).

Contudo, antes da busca pela qualidade sonora, a interação entre os pneus e os pavimentos, numa ampla faixa de velocidades, deve atender a requisitos mínimos de contribuição do ruído externo e interno do veículo, em toda a faixa de frequência audível. No caso do ruído de rodagem, o excesso afeta a saúde dos ocupantes pelo aspecto do cansaço mental e estresse durante a viagem. A figura 1.2 ilustra os níveis de ruídos e os efeitos no ser humano, classificados e descritos pela Organização Mundial de Saúde, OMS, Organização de Cooperação e Desenvolvimento Econômico, OECD, e Conselho Nacional do Meio Ambiente, CONAMA (CETESB, 2004).

As sensações táteis de vibrações nos assentos, encostos, volante e em alguns casos, alavanca de cambio, também são importantes na percepção do motorista. Dependendo das amplitudes e suas frequências, essas vibrações aceleram o nível de cansaço e desconforto em seu aspecto físico, também reduzindo a intenção de permanência e uso do veículo. Para a maioria das superfícies de rodagem, a interação entre os pneus e pavimentos se torna a maior fonte das vibrações, as quais são transmitidas pela suspensão para a carroceria. A figura. 1.3 mostra a relação dos limites de tempo para exposição de vibração ortogonal a superfícies, segundo a norma ISO 2631. 


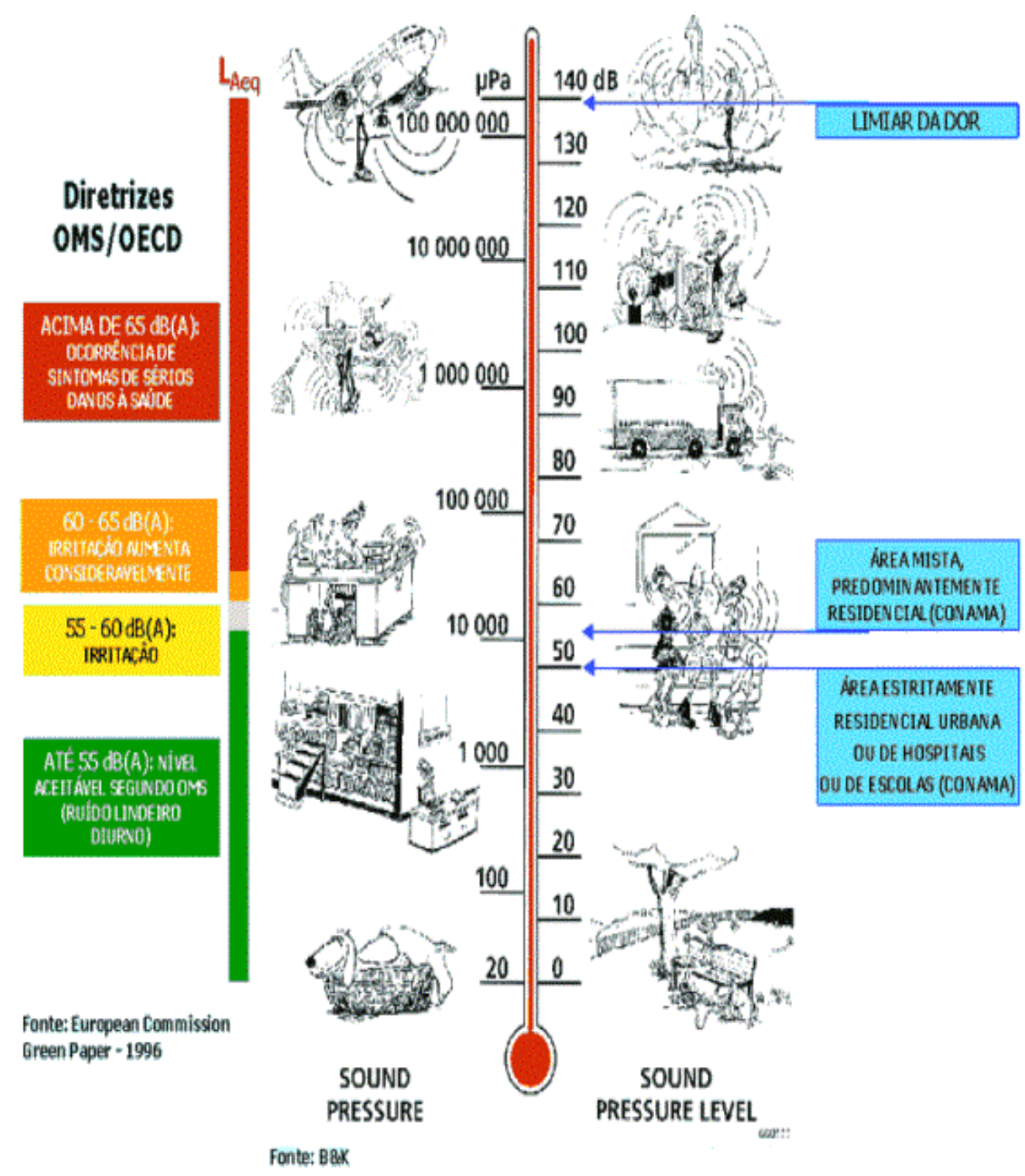

Figura 1.2: Níveis de pressões sonoras e diretrizes estabelecidas pela OMS, OECD e CONAMA

A aspereza veicular é a percepção subjetiva do transiente entre vibração e ruído. Ao rodar sobre superfícies mais ásperas ou rugosas, ou seja, com micro ou macrotexturas mais irregulares, as combinações dos níveis de vibrações e ruídos também somam os efeitos de incômodos físicos e mentais dentro de um veículo. 


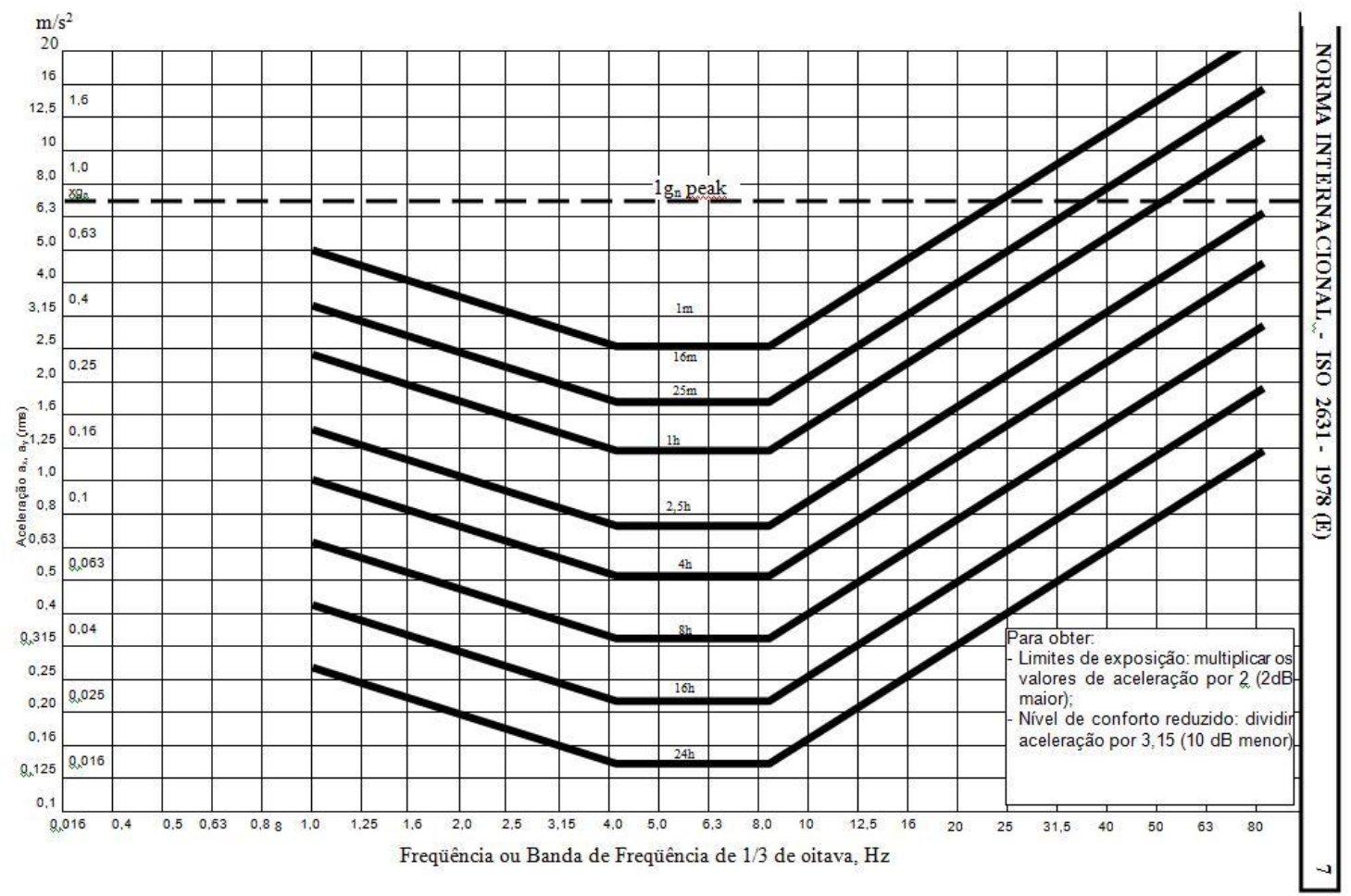

Figura 1.3: Curvas de tolerância do corpo humano a acelerações verticais, ISO 2361

Do ponto de vista do fabricante de veículos, as melhorias nos níveis, qualidade e balanço das respostas de $N V H$ requerem um entendimento aprofundado das fontes e também dos caminhos das transmissões vibracionais (estruturais) e acústicas (aéreas) da energia propagada pelo veículo.

Graças aos avanços dos métodos experimentais e numéricos de pelo menos duas décadas (H. Van der Auweraer, 2007), o tempo de abordagem para uma Análise dos Caminhos de Transferência de Energia, do inglês Transfer Path Analysis ou TPA, para o desenvolvimento de novos produtos, vem caindo consideravelmente. 


\subsection{Objetivos e contribuições}

Conforme será revisado no capitulo dois, a crescente preocupação para os problemas associados com o ruído de trafego tem levado à demanda por carros, pneus e superfícies mais silenciosas. Apesar de o pneu ser alvo de estudos por séculos, ainda há deficiências em prever fielmente e controlar o ruído da interação pneu superfície. Simultaneamente, a qualidade vibroacústicas do veículo vem se tornando uma característica importante.

Para as montadoras, as sensibilidades do veículo ao ruído de rodagem, em diversos tipos de superfícies e velocidades, demandam maior trabalho da engenharia no refinamento de sistemas de chassis e carroceria. O conhecimento multidisciplinar das complexas relações entre vibroacústica, dinâmica veicular e durabilidade, resulta na evolução das tecnologias de experimentação e modelagem matemática.

Recentemente, os métodos de TPA, aplicados em Road NVH, se tornam ferramentas cada vez mais importante para compreender de maneira profunda a sensibilidade acústica dos veículos, as forças dos pneus transmitidas através dos chassis, bem como ao ruído propagado pelos próprios pneus. Desta maneira o ruído global calculado, correlacionado com o ruído de rodagem global medido, tem o potencial para definir as estratégias dos caminhos de contribuições de absorção, transmissibilidade e sensibilidade dos veículos, aplicados a diversas condições de pavimentos e velocidades.

Os fundamentos teóricos destes métodos, se empregados na prática de forma correta durante a preparação das instrumentações, simulações matemáticas e análises, permitem o mapeamento de todos os fenômenos em banda larga e tons da rodagem por cada caminho ou componente. Tanto para simples investigações de rigidez de buchas quanto para investigações de arquiteturas de suspensão ou carroceria, a aplicação do TPA permite quantificar as contribuições de cada subsistema para o ruído/vibração veicular, e desta forma, estudar a vibração e o ruído de cada um dos componentes, que impactam no fenômeno rumble do ruído. 
Baseado na importância do atributo de ruído de rodagem e também nos fundamentos da análise dos caminhos de transferência de energia, os objetivos desta dissertação são:

- Aplicar os fundamentos dos métodos de TPA para investigar experimentalmente as contribuições estruturais de ruído na faixa de rumble durante a rolagem dos pneus em um veículo de passageiros;

- Correlacionar o ruído interno calculado com o ruído interno global;

- Decompor o ruído de rodagem em termos de caminhos de sensibilidade acústica da carroceria e forças atuantes nos componentes do chassi;

- Do TPA, analisar as eficiências das isolações de vibrações nas buchas dos braços e batentes dos amortecedores da suspensão dianteira;

- Identificar a causa da formação do fenômeno de banda estreita de rodagem em evidencia neste o estudo de caso, conhecido como ronco, do inglês rumble na literatura automobilística;

- Com os caminhos de ruído quantificados, demonstrar os resultados das possíveis soluções do estudo de caso.

Esta dissertação visa contribuir para o entendimento das seguintes questões de Road $N V H$ :

- Apresentar o TPA como o estado da arte em ferramenta de análise dos caminhos de transmissão de $N V H$ para resolução de problemas de campo e desenvolvimento de novos produtos;

- Revisar os fenômenos geradores e amplificadores de ruído de rodagem veicular pelas fontes (pneus) e transmissibilidade (chassi/carroceria);

- Demonstrar a importância do TPA para $N V H$ na concepção de componentes transparentes a dinâmica veicular e durabilidade.

O ruído calculado e correlacionado com a medição real, obtido sistematicamente por testes em laboratório e pista, permite a identificação individual dos caminhos de transmissão mais críticos e consequentemente, a correta visualização das melhores estratégias de absorção, transmissibilidade e sensibilidade táctil e acústica do veículo.

Este cenário propicia um estudo real para aplicação do TPA, em uma condição hipotética de configuração de pneu e protótipo. Os resultados obtidos não representam dados de veículos de produção no presente ou futuro. 


\subsection{Estrutura da dissertação}

Capitulo 2: A revisão bibliográfica se inicia com o histórico da preocupação do homem ao ruído de rodagem, de acordo com evolução dos meios de transporte. Apresenta a situação atual quanto aos balanços e meios de propagações nos veículos de passeios. Identifica os mecanismos que influenciam na geração e propagação do ruído de rodagem. Por fim revisa como são realizadas as medições de ruído em pneus e apresenta o que hoje é considerado o estado da arte em metodologia de experimentação, o TPA, para o entendimento dos caminhos do ruído no veículo.

Capitulo 3: Os fundamentos do TPA são apresentados. São abordadas as teorias de reciprocidade no SISO e $M I M O$ em sistemas de múltiplos GDL, e de analise de sinais, coerência e fase em FRFs, que fundamentam as análises dos caminhos de transferência de energia. Os procedimentos de laboratório e em pistas são detalhados ao se identificar a sistemática de testes envolvidos. Os métodos de TPA comuns na indústria automobilística são apresentados. E finalmente, também é citada a importância dos efeitos de acoplamentos cruzados das vibrações para correlação entre ruído calculado e o medido.

Capitulo 4: Apresenta-se o cenário do estudo de caso com as primeiras avaliações subjetivas e objetivas realizado em um protótipo. Mostra-se a preparação dos testes e as instrumentações envolvidas. As análises dos sinais medidos em laboratório e em pista. Os racionais e cuidados para as otimizações das rotinas de testes. A aplicação do método da matriz inversa do TPA e particularidades para simplificação dos cálculos em termos de energia. Por final, a apresentação dos resultados em termos de ruído $(\mathrm{dB}(\mathrm{A}))$, sensibilidade acústica (P/F), FRF de ponto ou point mobility (v/F), forças (F) e vibrações de operação (v).

Capitulo 5: São apresentados as conclusões do estudo de caso e das simplificações do uso do método de TPA. Ressaltam-se mais uma vez a importância das análises de coerência e fases, para o cálculo das contribuições do ruído. Por último as recomendações do uso da ferramenta nas tendências de mercado dos veículos. 


\section{Capítulo 2}

\section{Revisão Bibliográfica}

Os fenômenos relacionados ao ruído de rodagem se iniciam como respostas do veículo às interações pneus/pavimento. O presente capítulo tem como objetivo apresentar uma revisão da literatura disponível que apresenta aspectos relevantes para o desenvolvimento deste trabalho. Está subdividida nos seguintes tópicos: Histórico que motivou a invenção e os desenvolvimentos de pneu, seu design estrutural atual e mecanismos geradores e amplificadores do ruído. Por fim o estado da arte nas análises de Road NVH: os métodos de TPA como ferramenta eficaz na compreensão dos caminhos de transferência formadores do $N V H$ global do veículo.

\subsection{Breve histórico sobre o ruído de rodagem}

As rodas de madeira, recobertas por ligas de aço ou ferro, das carruagens e carroças, juntamente com a batida dos cascos dos animais nas pavimentações e paralelepípedos há dois mil anos atrás, eram as maiores contribuições de ruído nas áreas urbanas em todo período pré-motorização, sendo os Romanos os primeiros a se incomodarem (Sandberg, Ulf; Ejsmont, Jerzy A., 2002).

O primeiro meio de transporte humano a fazer uso do principio das duas rodas, o draisine (Laufmachine, termo em alemão para Máquina de passeio) foi inventado pelo 
barão alemão Karl Von Drais, considerado o precursor da bicicleta moderna, imagem 11 da figura 2.1, do site Baron von Draisâ€ $€^{\mathrm{TM}}$ Bicycle (Museun, 2006). Foi apresentado no verão de 1817, em Mannheim, Alemanha e em Paris, Fraça em 1818.

\section{VELOCIPEDE.}

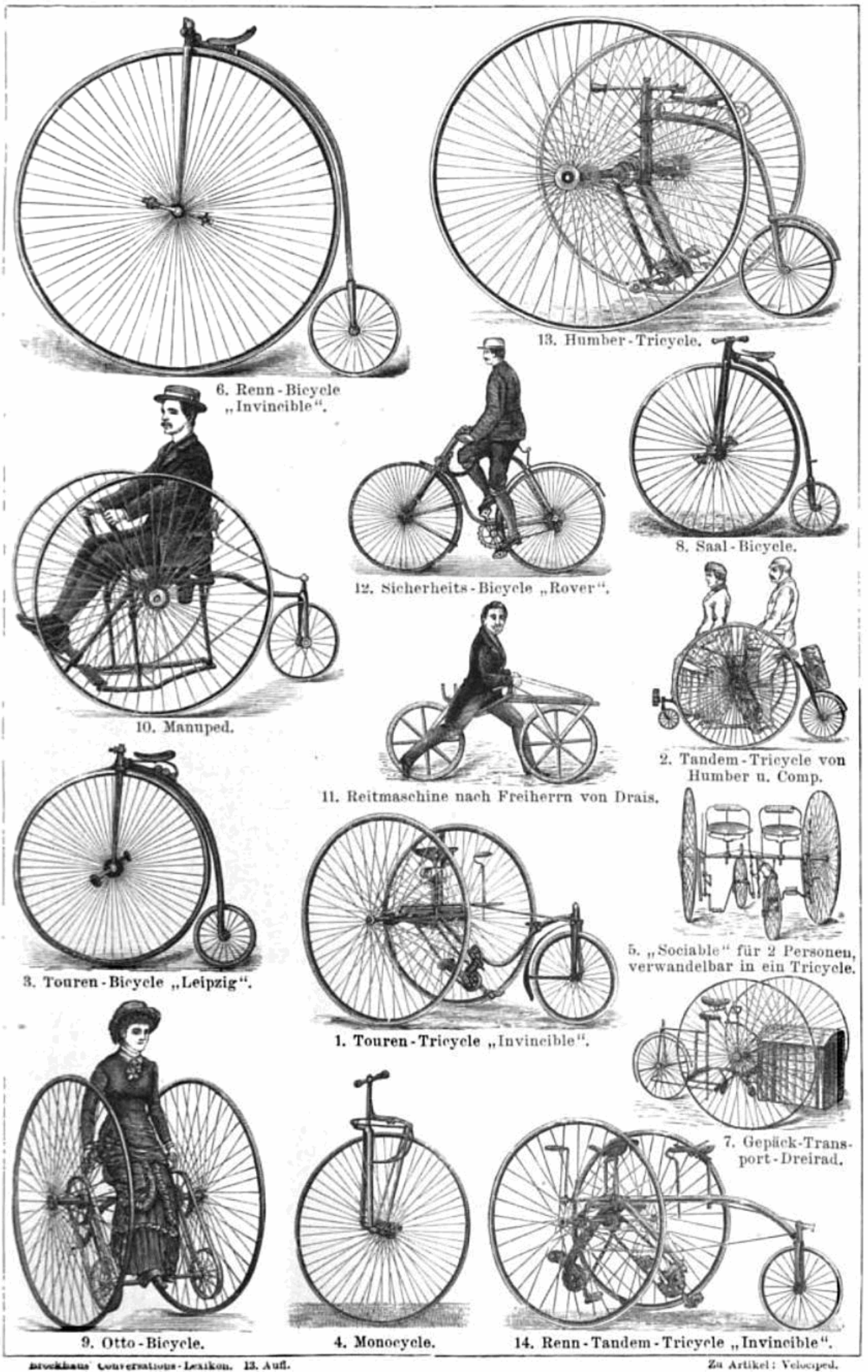

Figura 2.1: Os primeiros modelos de velocípedes no mundo, a partir do século XIX 
O velocípede (expressão em latim para "pé rápido") é o primeiro termo cunhado pelo francês Nicéphore Niépce em 1818 para descrever a sua versão do Laufmaschine, ou a popular bicicleta. Esta expressão é usada hoje como um termo coletivo para os diferentes sucessores da bicicleta (monociclo, a própria bicicleta ou diciclo, o triciclo e quadriciclo) desenvolvidos entre 1817 e 1890. As bicicletas ganharam os primeiros mecanismos de pedais a partir de 1869. Com o aumento da velocidade e os problemas de estabilidade e conforto nas pistas irregulares, logo ganhou o nome de Boneshaker, referencia em inglês para o "Agitador de ossos" (Museun, 2006).

Nos primeiros velocípedes a pedais, os pneus ainda eram as mesmas rodas de madeiras envoltas por bandas de aços usadas nas carruagens e carroças. Naturalmente, o aço foi substituído por borracha sólida e cubos com rolamento de esferas para diminuir os esforços e o desconforto. Como evolução natural, as rodas aumentaram de tamanho para que fosse possível vencer irregularidades de superfícies e aumentar a velocidade, limitado na época ao tamanho das pernas. Assim, surgem os penny-farthings (imagens 3, 6 e 8 da figura 2.1). Em novas tentativas de suavizar o passeio, os pneus de borracha com um núcleo oco também foram usados nesses modelos (Herlihy, 2004).

Em 1839, Charles Goodyear descobre, experimentalmente, o processo de vulcanização, melhorando as propriedades mecânicas da borracha natural ao aquecê-la misturada com enxofre. Sua primeira aplicação foi usada em Springfield, Massachusetts, em 1841. Tomas Hancock usou essencialmente o mesmo processo um ano depois, na Inglaterra. Em 1845, Goodyear anuncia o processo comercial da vulcanização. Em 1846 o Escocês Robert Willian Thomson (Thomson, 1846) inventa e patenteia o pneu inflável na França e um ano depois, nos Estados Unidos. Porém, somente em 1887, com a criação de um prático pneu de borracha inflável, do veterinário Irlandês John Boyd Dunlop, o pneumático foi de fato produzido comercialmente, com o intuito de redução do ruído e vibração de rodagem. Sua motivação era diminuir as dores de cabeça do seu filho ao andar de triciclo, nas ruas irregulares de Belfast onde moravam, na capital da Irlanda do Norte. Dá-se a ele o credito por demonstrar que o pneu poderia suportar desgastes mantendo sua resistência mecânica (Dunlop, John Boyd, 2009), (Scotland, Virtual, 2009).

Paralelo ao desenvolvimento dos pneumáticos, os pneus sólidos de borracha também sofreram uma breve evolução, tendo as patentes dadas a projetos distintos do Sr. John 
M. Dunlop em 1852, (sem relação encontrada com John Boyd Dunlop), e Sr. Thomson em 1867 (Scotland, Virtual, 2009). Em 1861, modelos de pneus sólidos já eram montados nas carroças Inglesas. Contudo, as limitações do modelo sólido eram as dificuldades e o tempo necessário para a montagem do pneu nas rodas. Estes modelos de pneus são importantes de serem lembrados, devido ao fato da primeira indústria a introduzir os pneus sólidos, por volta de 1880, se chamar Noiseless Tyre Co., do inglês Pneus Sem Ruídos, em Londres. Entre os fatos apresentados, as evidencias sugerem que o ruído e a vibração de rodagem já eram assuntos importantes, antes mesmo da existência do automóvel (Sandberg, Ulf; Ejsmont, Jerzy A., 2002).

Ainda nesta época, antes de 1900, de transformar um veículo pedalado por homens em uma carroça com tração própria, já desafiava inventores, físicos, químicos, engenheiros e entusiastas, até que, entre diversas invenções, a patente do que se conhece como carro moderno é obtido em 1885, pelo engenheiro alemão Karl Bens. Não se sabe dizer quanto das primeiras carroças motorizadas a vapor usaram pneus de borracha solido ou pneumáticos. Sabe apenas que a evolução do automóvel começou e em paralelo, o desenvolvimento dos pneus.

Em resumo, desde que iniciou se a comercialização do automóvel como um bem de consumo, diversas tecnologias ligadas á mobilidade foram aprimoradas para atender as demandas do publico. O primeiro processo de produção em grande escala foi lançado por Ransom Olds em sua fábrica Oldsmobile em 1902. Mas tarde, no inicio de 1914, este conceito de linha de produção-fabricação de automóveis foi expandido por Henry Ford (Georgano, 2000). Nesta fase um dos marcos principais, relevante nos projetos de pneumático e que afetam o ruído de rodagem, foi a implementação do pneu radial, projetado em 1913-14 na Inglaterra, seguido desde então de inúmeras patentes em aplicações específicas.

Assim, o pneu inflável como conhecemos foi inicialmente adaptado para bicicletas, depois a carruagens puxadas por cavalos e, após alguns anos, aos carros, caminhões e demais meios de transportes. Ao longo deste tempo comprova-se que a preocupação do homem com o ruído, vibração e conforto durante a rodagem.

A figura 2.2 ilustra exemplos de diversos pneumáticos utilizados nos automóveis de 1920 a 1982 (Sandberg, Ulf; Ejsmont, Jerzy A., 2002). 


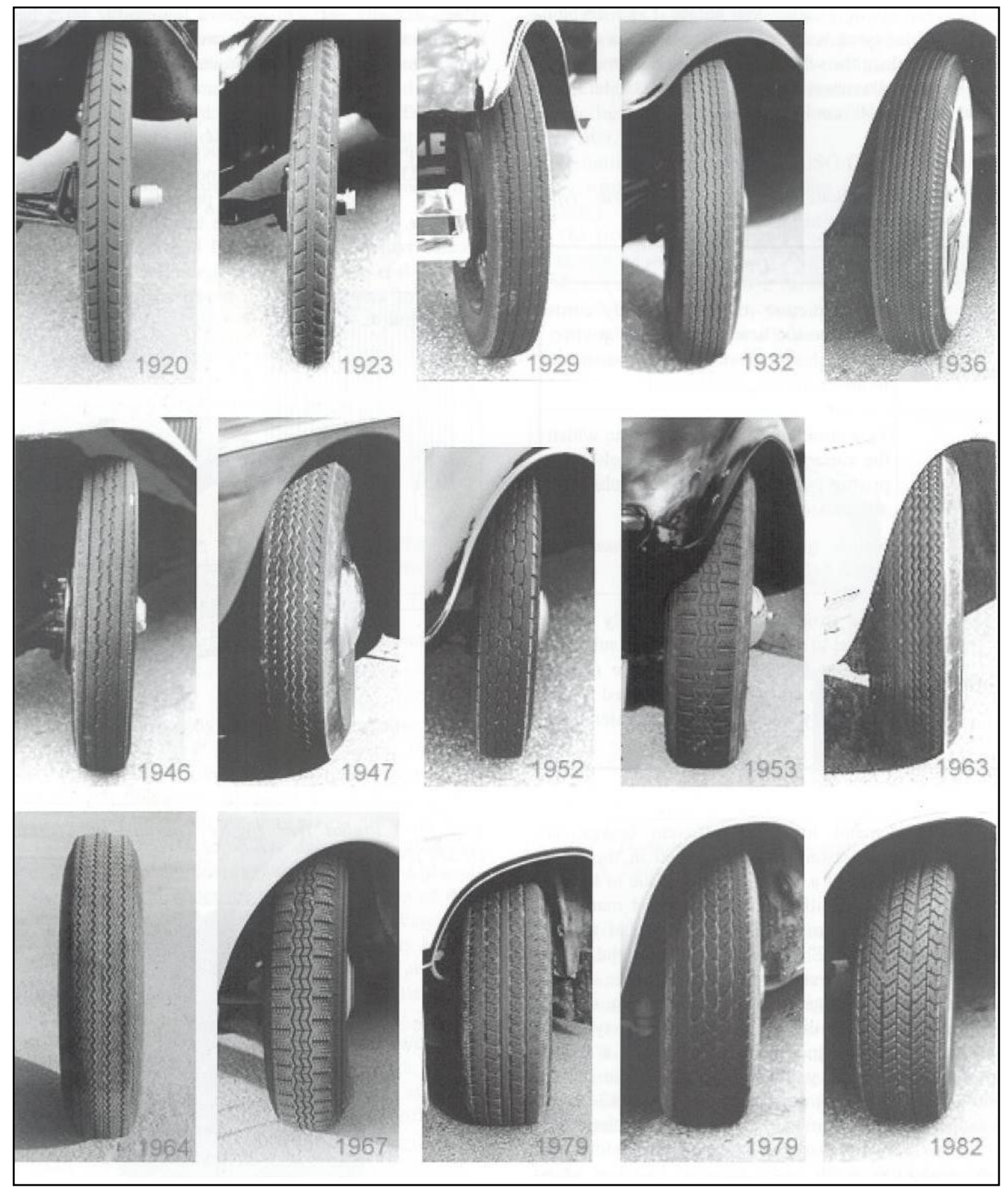

Figura 2.2: Imagens de pneus típicos, nos carros de época

\subsection{0 ruído de rodagem hoje}

$\mathrm{O}$ ruído de rodagem é fundamentalmente um fenômeno de banda larga, acoplado a efeitos de banda estreita e/ou tonais (K. Ichiro ; U. Sagiri, 2005). Partes destes tons 
estão relacionadas às características construtivas do veículo e permanecem fixas a uma determinada frequência. Outros são dependentes da velocidade do veículo e, em geral, estão relacionados às características dos pneus. Conhecer as características de propagações dos caminhos do ruído de banda larga e dos tons de rodagem em relação a sua fonte e transmissibilidade no veículo torna-se vital ao trabalho de refinamento e é o tema abordado nesta dissertação.

Como o ruído pode se propagar por diferentes caminhos, é comum fazer a primeira distinção entre as contribuições aéreas e estruturas. Esta distinção é baseada na natureza da geração e propagação do ruído. A maior parte dessas transmissões não é puramente acústica ou estrutural, mas sim uma composição de ambos com alternância das predominâncias ao longo do espectro de frequência. Os estudos sobre o ruído de rodagem são abordados segundo as divisões:

Ruído de rodagem externo (foco das normas e diretrizes dos órgãos ambientais do governo) - Ruído da interação pneu/pavimento que um observador escuta fora do veículo dividido nos dois tipos de contribuições:

- Ruído de rodagem estrutural externo: Esta parcela é relacionada às vibrações estruturais do pneu, gerados pela interação pneu/pavimento durante 0 movimento. Diferentes tipos de ondas estruturais propagam pelo corpo do pneu e irradiado pela superfície externa da carcaça.

- Ruído de rodagem aéreo externo: Esta parcela origina-se dos distúrbios de pressões no ar em volta do pneu, como resultando da interação do mesmo com a superfície e também a reflexão do ruído pelo pavimento, caixa de rodas e assoalho.

Ruído de rodagem interno - Ruído da interação pneu/pavimento que um observador escuta dentro do veículo dividido nos dois tipos de contribuições:

- Ruído de rodagem estrutural interno: Esta parcela é relacionada às vibrações estruturais do pneu, gerados pela interação pneu/pavimento durante o movimento. A energia vibracional gerada é transmitida através da suspensão para a carroceria do veículo. A sensibilidade do veículo às vibrações nas 
estruturas, chapas e janelas da carroceria resulta no ruído irradiado no interior da cabine.

- Ruído de rodagem aéreo interno: Esta parcela origina-se do ruído de rodagem aéreo externo, audíveis dentro do veículo. As ondas sonoras que se originam da interação entre pneu e pavimentos são propagados pelo ar através de furos, janelas e painéis da carroceria. Existem dois caminhos (efeitos) pelos quais o ruído aéreo pode ser transmitido para os passageiros. Primeiramente, atravessam os painéis e janelas do veículo, pela lei de massa, causam irradiação sonora no interior da cabine. Segundo, o ruído pode entrar na cabine em regiões com pouca vedação entre chapas internas e externas ao ambiente como, por exemplo, perímetro de portas e janelas, coluna de direção e passagem de chicotes (vazamento sonoro).

Nas arquiteturas veiculares atuais, em seus diversos seguimentos, a maior parte do ruído de rodagem interno tende a se propagar via contribuição estrutural, por diversos fatores a serem abordados no capitulo 2 (Sandberg, Ulf; Ejsmont, Jerzy A., 2002) e (Kindt, 2009). Esta dissertação foca na aplicação dos fundamentos de TPA no ruído de rodagem estrutural interno, exemplificado através de um estudo de caso.

\subsection{Balanço e contribuições de $\mathrm{NVH}$}

Com o aumento do número de proprietários de veículos e a mobilidade crescente, mais tempo é gasto no transito, como mostra a figura 2.3 o cenário da mobilidade nos centros urbanos (Time, 2008). Isto levou a uma crescente demanda por conforto, incluindo o conforto tátil e acústico. 


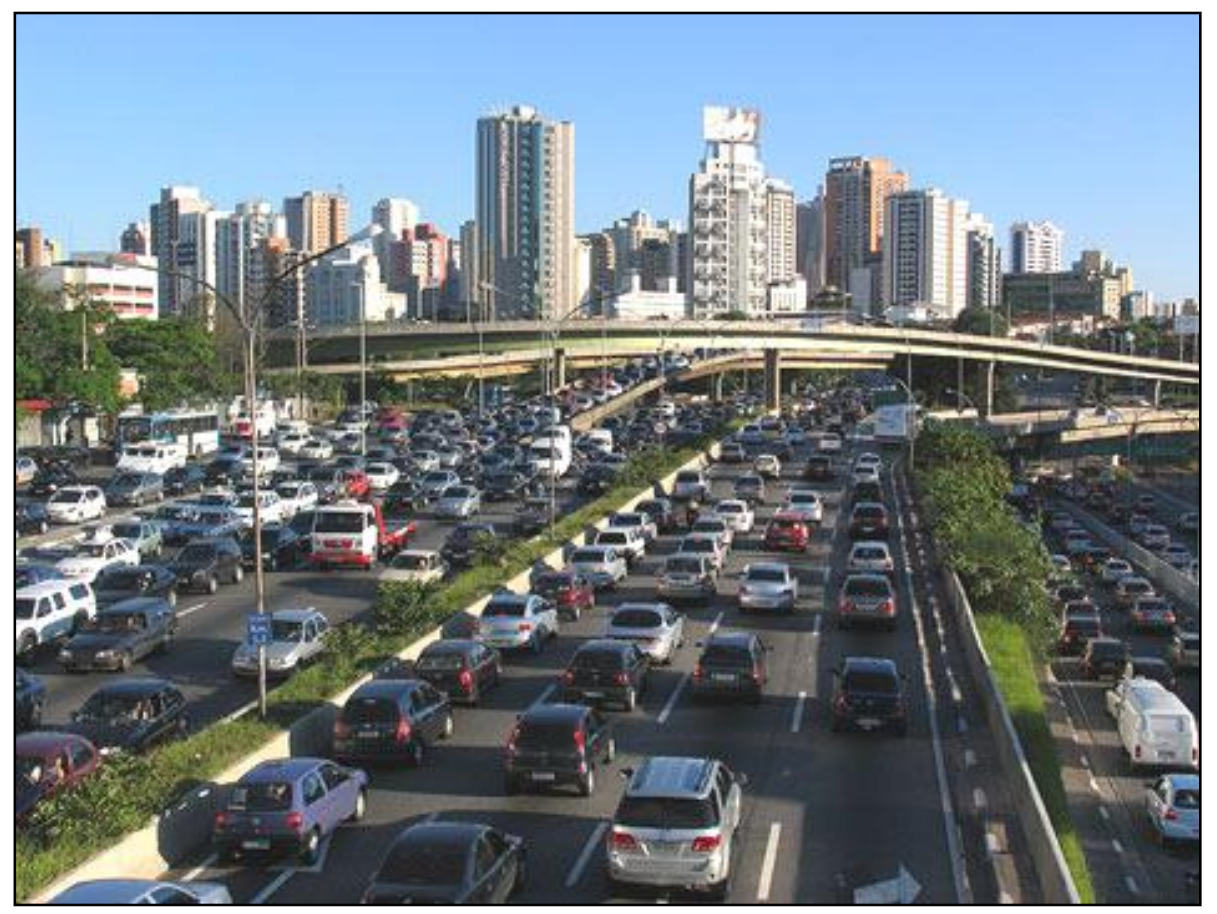

Figura 2.3: Transito da cidade de São Paulo, eleito o pior do mundo em 2008

Além de segurança, durabilidade e valor agregado ao bem, os consumidores, motoristas e passageiros, agora esperam que os carros sejam lisos e silenciosos, isto é, sem vibrações e com as fontes de ruídos reduzidas e balanceadas. Diversas pesquisas de mercado e mídias especializadas mostram que o refinamento veicular se torna cada vez mais importante e elemento fundamental para a diferenciação dos produtos, sendo o conforto acústico um dos principais critérios para a escolha de um modelo visto como moderno e de qualidade. $\mathrm{O}$ acerto na concepção do produto e o compromisso com ao bem estar social fortalecem a marca do construtor e promovem o atrativo emocional e a fidelidade dos consumidores.

À medida que se aumentam as conscientizações sobre poluição sonora, principalmente nos centros urbanos, esforços são direcionados para produzir carros mais silenciosos, seja pelas pressões naturais do mercado competitivo, seja pela imposição de legislações específicas. A origem do ruído e vibração em veículos pode ser dividida em três fontes principais: motorização (Powertrain), rodagem/pneus (Road) e de vento ou aerodinâmico (Wind). A figura 2.4 (Digimods) editado pelo autor ilustra as fontes a seguir. 


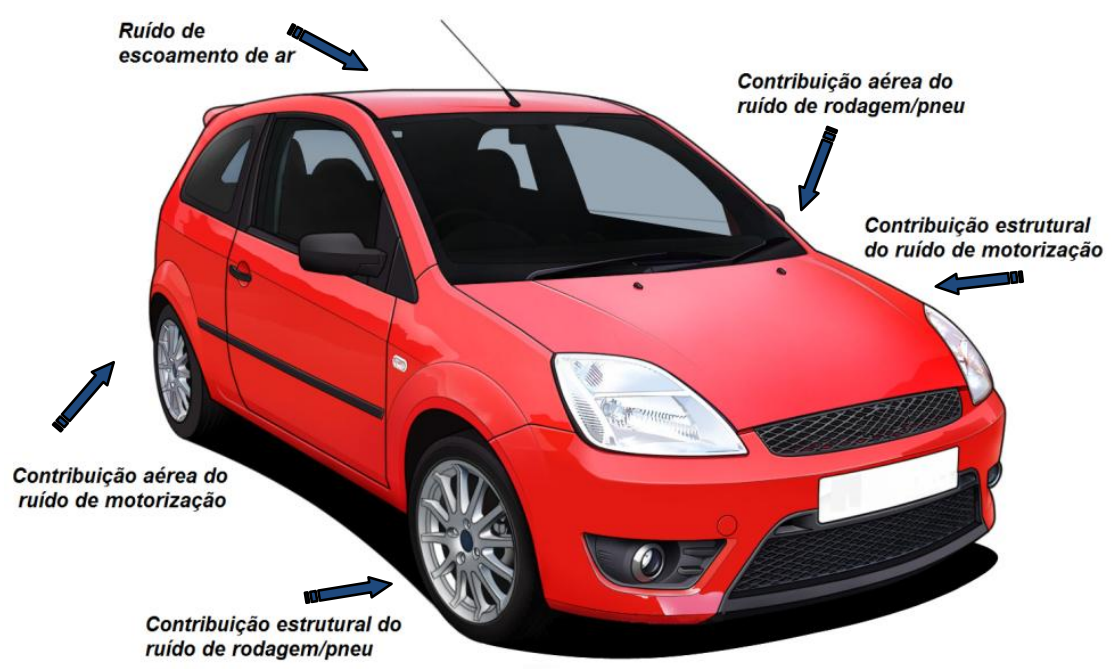

Figura 2.4: Fontes principais de ruído e vibração veicular

O nível e balanço da contribuição de cada fonte dependem, a princípio, do segmento do modelo, tipo de carroceria, peso e acabamento. Ainda, problemas de nível e/ou balanço ocorrem, em um veículo específico, em determinada velocidade e rotação do motor. Desde o século $\mathrm{XX}$, os esforços para reduzir as fontes de ruído e vibrações das motorizações, tornando-os energeticamente mais eficientes e agradáveis, resultaram na melhoria do aproveitamento térmico da combustão, aperfeiçoamento de componentes dos motores, transmissões, coxins, filtros de ar e sistemas de escapamentos.

Conforme Hendricx e Vandenbroeck (Vandenbroeck, 1993), os autores mencionam a alta expectativa dos consumidores e os avanços nos motores de 6,8 e 12 cilindros. Como exemplo, é citado melhorias nas contribuições estruturais devido a reduções na vibração dos motores 6 cilindros, tração traseira, após a adoção de massas passivas nos semi eixos e melhorias no design do eixo cardã. Consequentemente, com a redução dos ruídos de terceira ordem, as contribuições das fontes, antes secundárias, se sobressaíram.

Em velocidades mais altas, o desenvolvimento dos processos de manufatura e concepção de projeto aerodinâmico mais eficiente em túneis de vento e simulações, juntamente com sistemas de vedações e isolação do ruído aéreo, trouxeram importantes reduções nos níveis de ruído desta fonte, principalmente nos carros mais luxuosos. Estes desenvolvimentos fizeram com que atualmente predomine o ruído de rodagem (figura 2.5). 


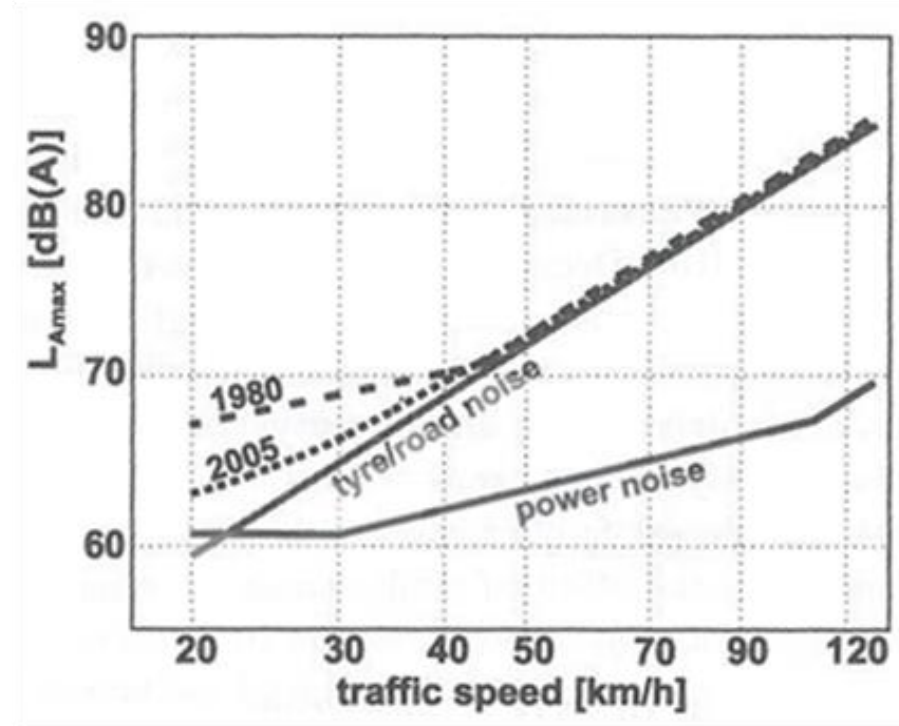

Figura 2.5: Evolução dos níveis de ruído de PT vs. Pneus (Sandberg, Ulf; Ejsmont, Jerzy A., 2002)

Conforme discutido na introdução, o ruído de rodagem é fundamentalmente um fenômeno de banda larga, acoplado a efeitos de banda estreita ou tonais. Partes destes tons estão relacionadas às características construtivas do veículo e permanecem fixas a uma determinada frequência. Outros são dependentes da velocidade do veículo e, em geral, estão relacionados às características dos pneus. Podem ser propagados via contribuições estruturais ou aéreas.

Neste contexto, grandes conquistas foram alcançadas entre construtores e fornecedores. Os pneus também melhoraram quanto à frenagem, tratividade, dirigibilidade, conforto e eficiência de rolagem. Contudo, segundo (Sandberg; Ejsmont, 2002), pouco mudou ao longo das décadas quanto aos impactos ambientais e ao ruído irradiado dos pneus.

Da parte estrutural, os conceitos de chassis mais eficientes e otimizados zelam pelas relações entre $N V H$ e dinâmica veicular. Porém o resultado final do conforto ainda depende do pneu, de suas características construtivas, da uniformidade de produção e de como se dá a geração de forças para ruído estrutural. A figura 2.6 ilustra um exemplo das três fontes principais de ruídos, sendo o ruído de rodagem subdividido entre contribuições aéreas e estruturais. O nível de pressão sonora relativo às influencias de cada fonte são apresentadas em função da frequência. Para as contribuições de rodagem/pneus, mostra-se a relevância da contribuição estrutural para baixas frequências e a contribuição aérea nas mais altas. Em particular, o exemplo trata de um veículo a $70 \mathrm{~km} / \mathrm{h}$ em uma pista de asfalto de baixa rugosidade (Kindt, 2009). 


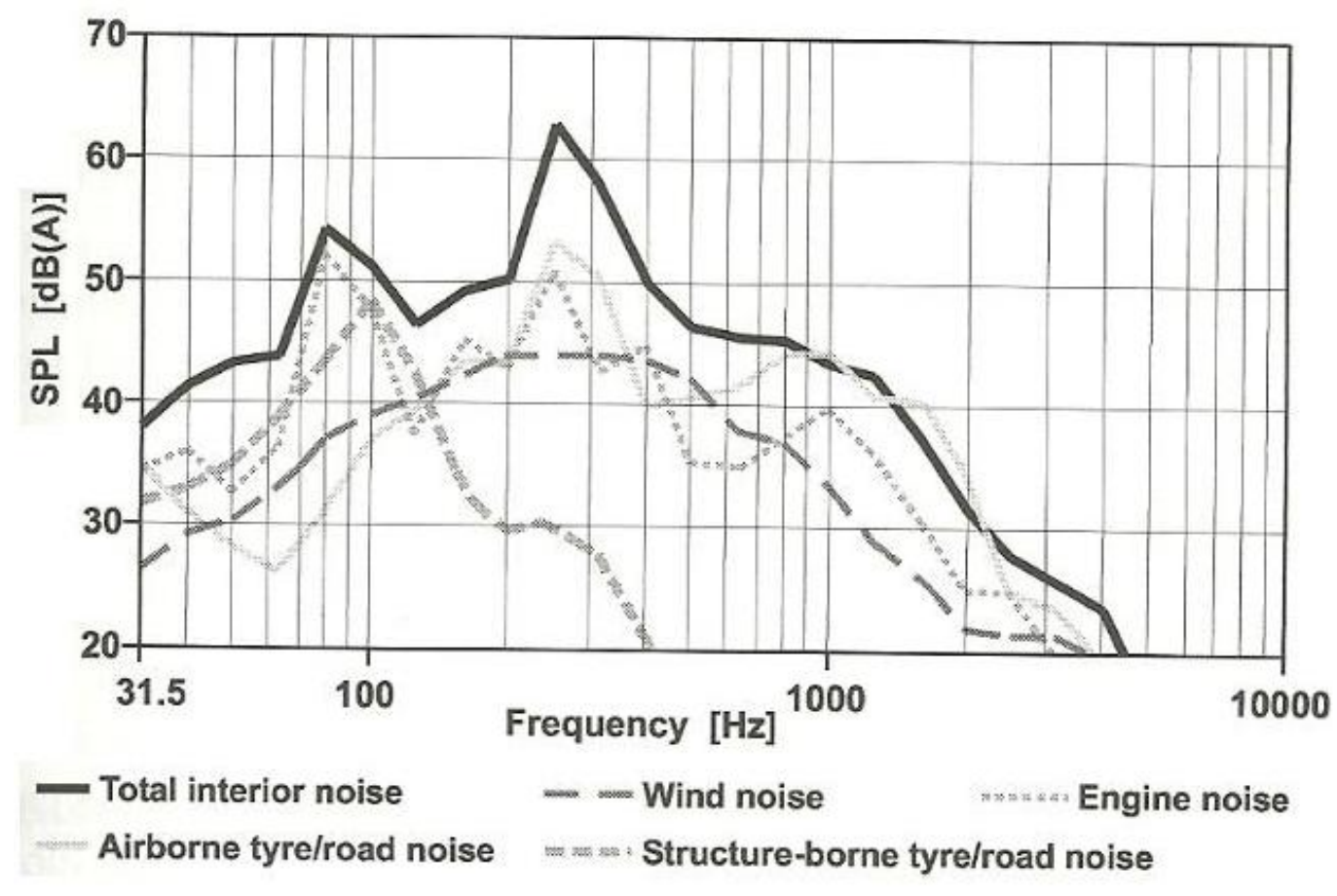

Figura 2.6: Exemplo das contribuições do ruído no interior de um veículo a $70 \mathrm{~km} / \mathrm{h}$, asfalto liso

A contribuição do ruído estrutural, a ser estudado neste trabalho, se origina da interação pneus/pavimento, causando vibração mecânica nos pneus, cubos de rodas, suspensão, carroceria e resultam em vibrações e ruídos sentidos no interior do veículo. Estas vibrações atuam até aproximadamente $450 \mathrm{~Hz}$. Acima deste valor, a predominância altera-se para a contribuição aérea, tornando-se cada vez mais difícil separar os efeitos de ruído de rodagem com o de vento pela carroceria do veículo.

\subsection{Mecanismos do ruído de rolagem}

A seguir, apresenta-se um sumário dos fatores que influenciam no ruído de rodagem. 


\subsubsection{Influência das superfícies}

A maior parte das superfícies é composta de agregados (chippings) que permanecem juntos por um elemento de ligação (binder). Os tipos e tamanhos destes agregados, em conjunto com suas distribuições pelo elemento de ligação, possuem uma grande influencia para a interação entre pneu e pavimento (Sandberg, Ulf; Ejsmont, Jerzy A., 2002).

As principais funções das pistas de rodagem são: distribuição dos carregamentos dos veículos, fornecimento de tração suficiente entre pneus e pista sob quaisquer condições climáticas, com drenagem adequada da água, baixo desgaste (superfície e pneu) e de forma lisa/suave e silenciosa. Atualmente uma grande variedade de asfaltos e concretos de rodagem pode ser encontrada nas vias dos centros urbanos e rodovias. Entre os diferentes tipos, as características de textura, porosidade e absorção acústica, além de conflitantes, variam e são de grande relevância para as reações dinâmicas do pneu.

\section{Textura}

A figura 2.7 (Sandberg, Ulf; Ejsmont, Jerzy A., 2002) ilustra as micro e macro escalas da textura em diferentes pavimentos de rodagem.

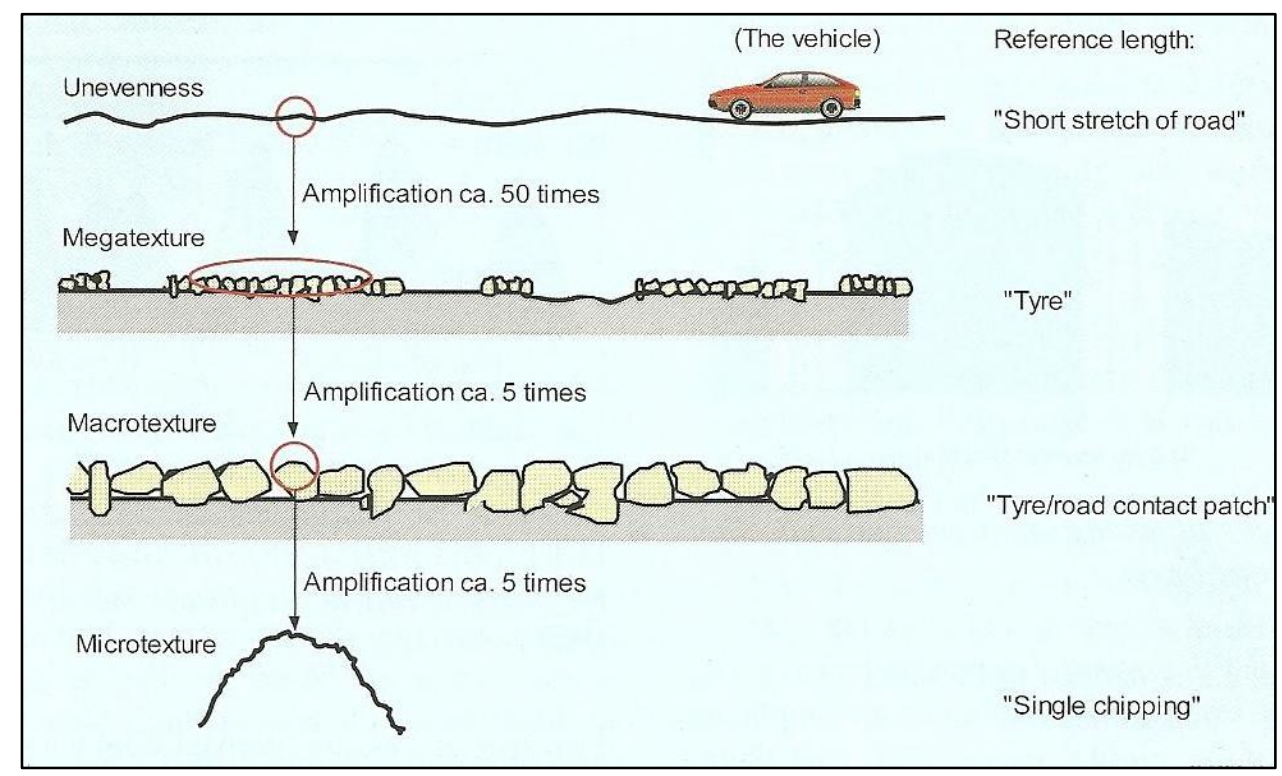

Figura 2.7: Ilustração simplificada dos níveis de textura 
A microtextura esta relacionada à rugosidade dos agregados, enquanto que os tamanhos dos agregados determinam os valores de macrotextura. A escala de mega-textura, também referenciado como nível irregularidades, caracteriza o tipo de superfície de rodagem, como por exemplo, pistas de paralelepípedos (belgian blocks).

Assim, a textura da superfície de rodagem descreve com qual extensão o comprimento de onda da superfície se difere de outra perfeitamente plana e lisa. Dependendo do comprimento do perfil de elevação dos desvios, conforme a figura 2.8 (Kindt, 2009), a escala da textura é definida entre microtextura (comprimento de onda $<0.5 \mathrm{~mm}$ ), macrotextura (comprimento de onda entre $0.5 \mathrm{~mm}$ e $50 \mathrm{~mm}$ ) e megatextura (comprimento de onda $>50 \mathrm{~mm}$ ).

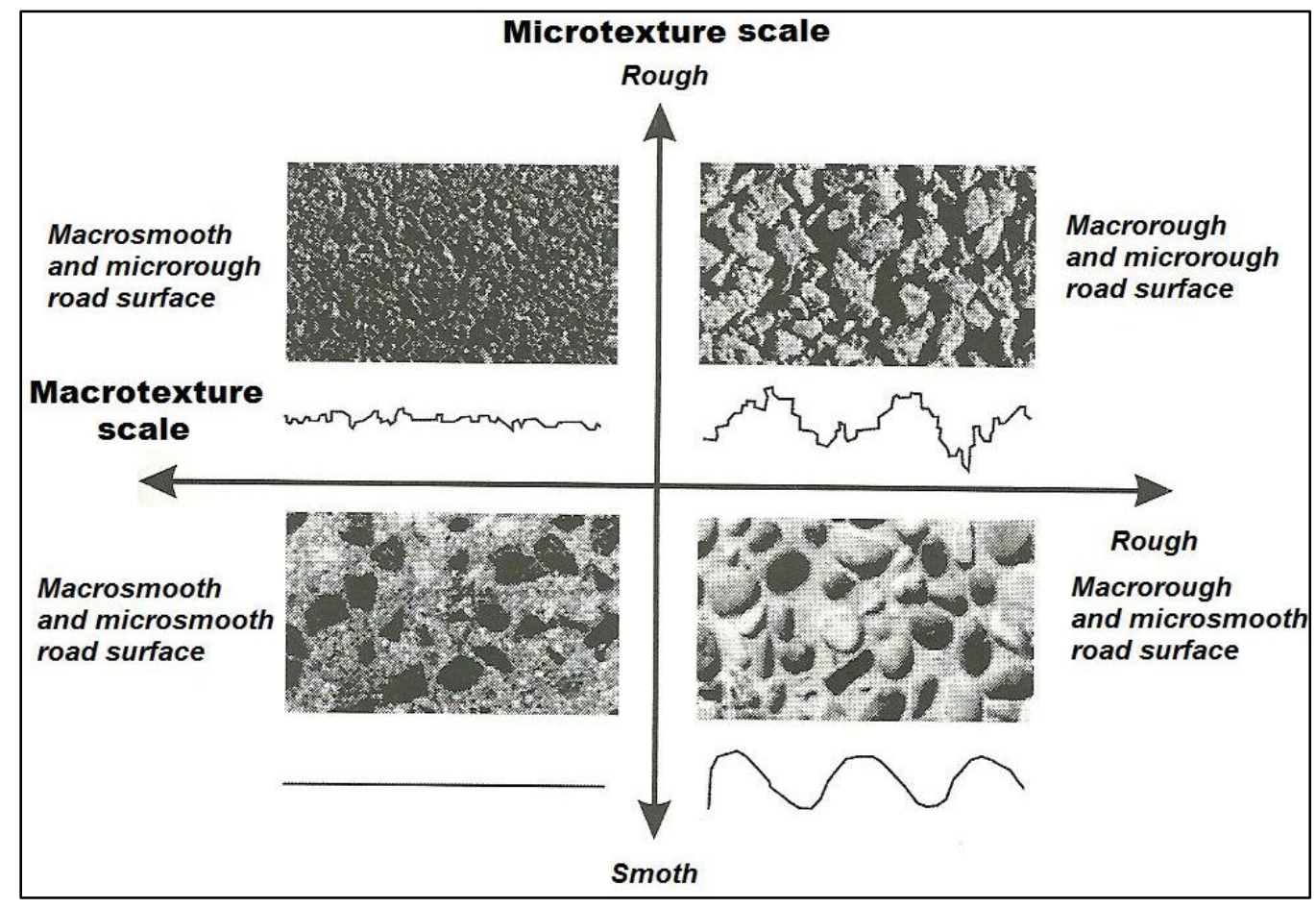

Figura 2.8: Escalas micro e macro estruturas de diferentes superfícies de rodagem

Na prática, tais perfis podem ser descritos medindo o eixo vertical ao longo do eixo longitudinal da pista com ajuda das análises das suas propriedades estatísticas da densidade espectral (Power Spectral Density - PSD). 


\section{Porosidade}

O termo porosidade se refere ao ar existente nos agregados do pavimento. Além da drenagem da água na superfície, os poros também proporcionam a drenagem do ar nas interações entre o pneu e a superfície de rodagem. Esta propriedade reduz significativamente certos fenômenos dos mecanismos de geração de ruído a serem vistos a seguir.

\section{Absorção acústica}

Absorção acústica é a propriedade da superfície de rodagem que está fortemente relacionada com as características de porosidade. O nível de porosidade proporciona à superfície a capacidade de absorção acústica, a qual influencia na reflexão e propagação do ruído de rodagem e também de motorização. A figura 2.9 (Kindt, 2009) mostra uma curva de absorção acústica para uma superfície asfáltica porosa com 23,1\% de espaços vazios e camada de $67 \mathrm{~mm}$ de espessura.

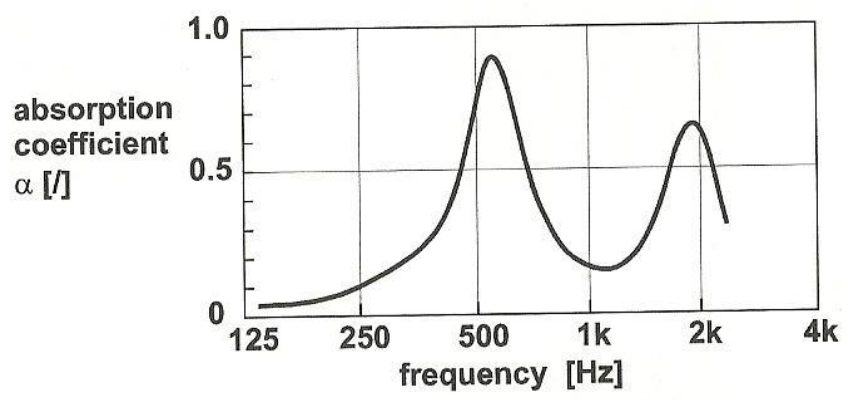

Figura 2.9: Características de absorção acústica de uma superfície porosa

A frequência do pico de absorção acústico está relacionada à espessura e densidade da camada porosa. Conforme a porosidade aumenta, a largura dos picos também aumenta. A altura dos picos de absorção acústica está relacionada com as características de resistência ao fluxo de ar dos poros do pavimento. 


\subsubsection{Mecanismos dos Pneus}

Os pneumáticos são crucias na interação com os pavimentos e na geração de forças de controle para o movimento do veículo. Os principais requerimentos estão associados à: direção segura, dirigibilidade e estabilidade direcional, conforto, eficiência (resistência ao rolamento, peso e custo) e impactos ambientas (ruído irradiado e re-uso ou reciclagem da carcaça). A figura 2.10 apresenta de uma forma geral como é formada a estrutura de um pneu radial (EUROPEAN TYRE SCHOOL).

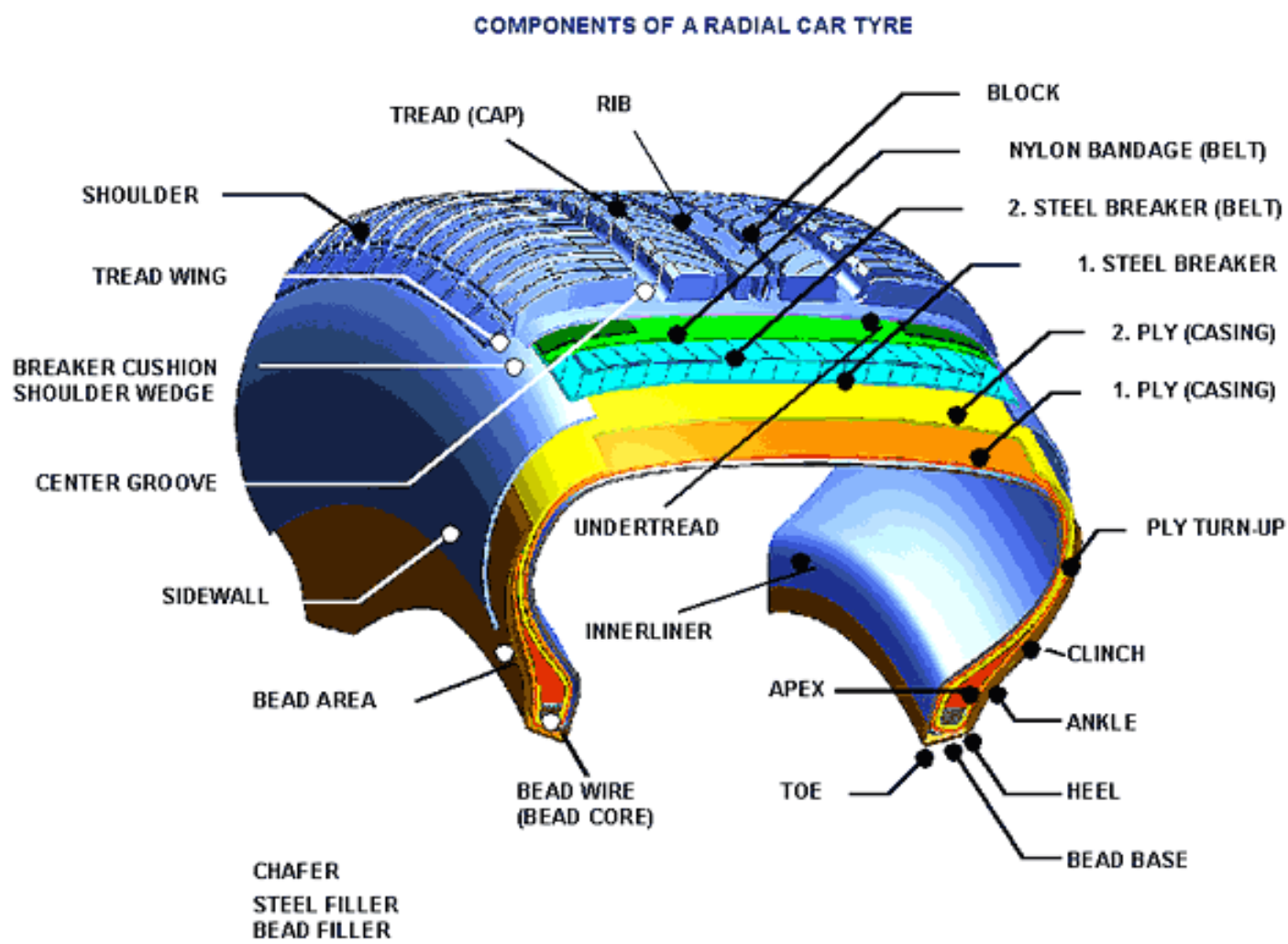

Figura 2.10: Componentes do pneu radial

As forças de um pneu são distribuídas na superfície de contato com a superfície e geram as resultantes normais e de cisalhamento de tensões. A pressão de distribuição não é uniforme e varia nas direções x e y (lateral e longitudinal, respectivamente). Durante a rolagem, a distribuição não é simétrica em y, tendendo a ser maior na região a frente do contato. 
Devido aos comportamentos visco elásticos não lineares de deformação, os mecanismos de geração de fricção (histerese e adesão) formam as forças de cisalhamento trativas e laterais do contato pneu pavimento (Gillespie, 1992).

As características mecânicas dos componentes que constituem o pneu, juntos resultam nas forças de interação entre o pneumático as superfícies. Neste comportamento dinâmico, ocorrem também os fenômenos vibracionais e acústicos que geram e propagam o $\mathrm{NVH}$ de rodagem. Os mecanismos de geração de ruído aceitos atualmente na literatura, classificados como de natureza estrutural e aéreo, são apresentados a seguir.

\section{Mecanismos de geração do ruído estrutural}

São divididos entre mecanismos de vibrações com maior predominância entre as direções radiais e tangenciais. A parcela predominantemente radial esta associada aos impactos da banda de rodagem, da textura da pista e deflexões de rolagem. Já na parte onde predominam as vibrações tangenciais, ocorrem os mecanismos de adesões stickslip e stick-snap, conforme figura 2.11 (Sandberg, Ulf; Ejsmont, Jerzy A., 2002).
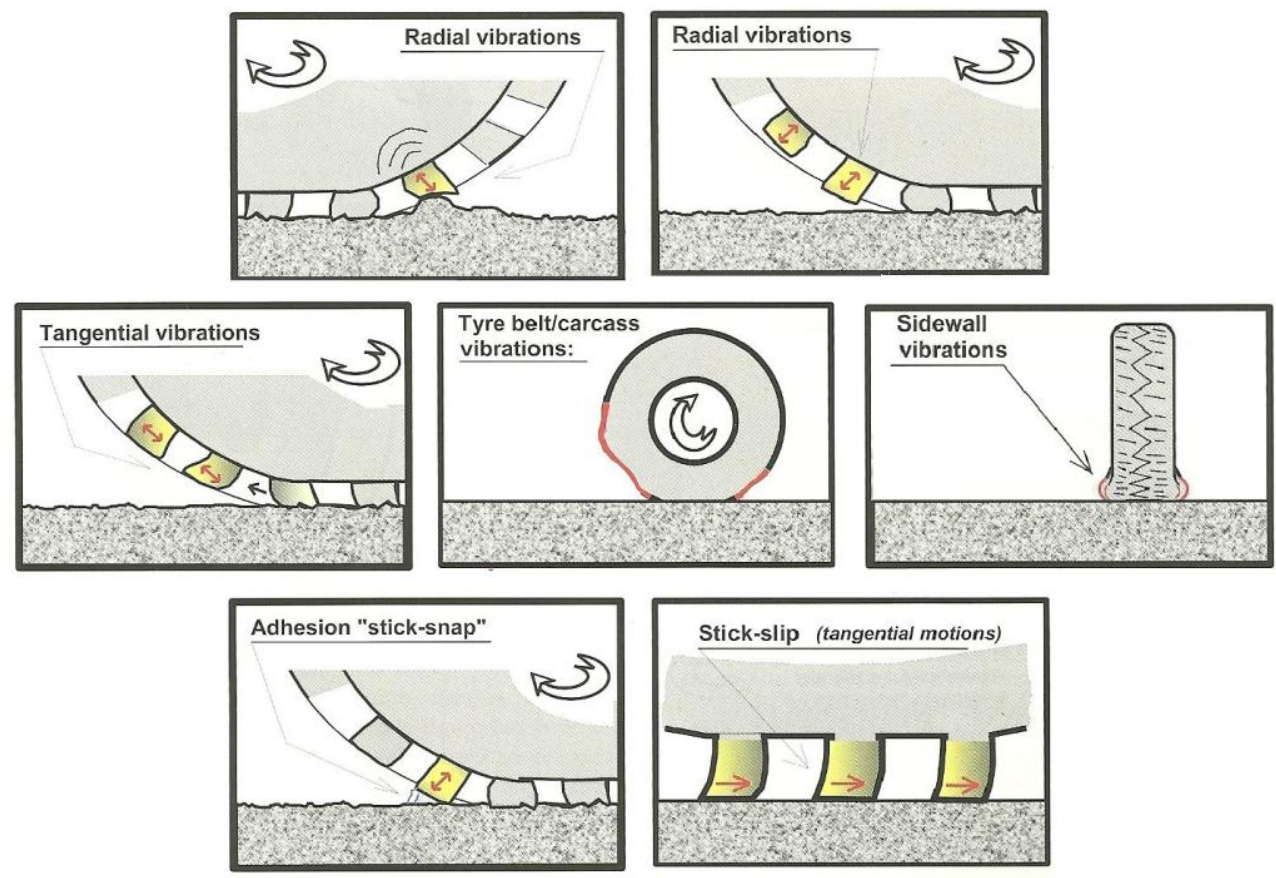

Figura 2.11: Mecanismos estruturais de geração de ruído 


\section{Mecanismos de geração do ruído aéreo}

São basicamente os mecanismos de deslocamento de ar classificados como efeitos de turbulência, bombeamento, ressonância na banda de rodagem em contato com o solo e ressonância de Helmholtz, que também trata do efeito do ar nos espaços dos desenhos da banda de rodagem, ilustrado a seguir na figura 2.12 (Sandberg, Ulf; Ejsmont, Jerzy A., 2002).
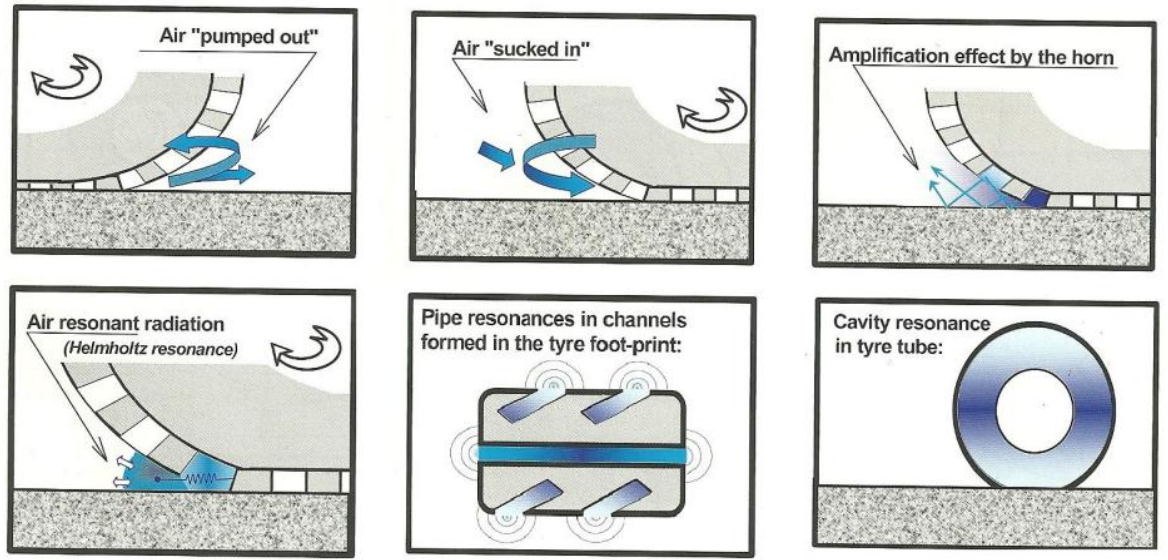

Figura 2.12: Mecanismos aéreos de geração de ruído

Dentre todos os mecanismos revisados previamente, alguns dos efeitos são capazes de amplificar ou atenuar as propagações acústicas e estruturais. São cinco efeitos hoje identificados: horn (buzina ou megafone), impedância acústica (relacionada a efeitos de porosidade e propagação de ruído na superfície), impedância mecânica (relacionada a efeitos de textura versus rigidez do pneu) e ressonância de pneus (mecânica através das vibrações das cintas e acústica pela circulação dos gradientes de pressões de ar internamente no pneu).

\subsubsection{Chassi e carroceria}

Conforme visto, os mecanismos de geração, amplificação e transferência de vibrações e ruído de rodagem podem ser estudados por engenheiros civis, fabricantes de pneumáticos e também construtores automotivos, cada qual responsável por parte dos 
mecanismos que formam o ruído. Encontrar a melhor relação entre especificações de superfícies, pneus, veículos e custos, é tarefa complexa no desenvolvimento do produto final.

Focando na construção de veículos, os projetos de chassi e carroceria são fundamentais para atenuar as propagações acústicas e estruturais dos pneus e demais fontes, promovendo a melhor função transferência dos atributos de conforto na percepção dos passageiros.

Para as propagações acústicas, de médias $(\sim 450 \mathrm{~Hz})$ para altas frequências, estuda-se o uso de vedações, forrações e painéis com características de absorção e perda de transmissibilidade acústica, com melhor relação desempenho versus peso e custo.

Já para médias á baixas frequências, tem-se a preocupação no tratamento do ruído estrutural. A atenuação deve ser feita refinando-se as características mecânicas de todo o chassi e a carroceria. Observa-se o conceito da suspensão, rigidez de buchas e batentes, subquadro e rigidez dos pontos de ancoragem entre o chassi e a carroceria. As características construtivas destes componentes, previamente estabelecidas no inicio do projeto, estão diretamente ligadas às respostas dinâmicas vertical, longitudinal e lateral do veículo e a sensibilidade acústica na formação do ruído estrutural.

Para avaliar cada componente e como os mesmos contribuem para o ruído, existem análises que, apesar de não serem obrigatórios, são complementares ao uso do TPA. Como exemplo de métodos, pode ser citado: análises modais, análise de formas operacionais (ou Operational Shape Analisys), análises de coerências, decomposição de componentes principais e análises de TPA com múltiplas referências (Katrien Wyckaert, Herman Van der Auweraer, 1995). A figura 2.14 mostra o uso destes métodos, para a abordagem e identificação do caminho crítico para contribuição do ruído de rodagem. 


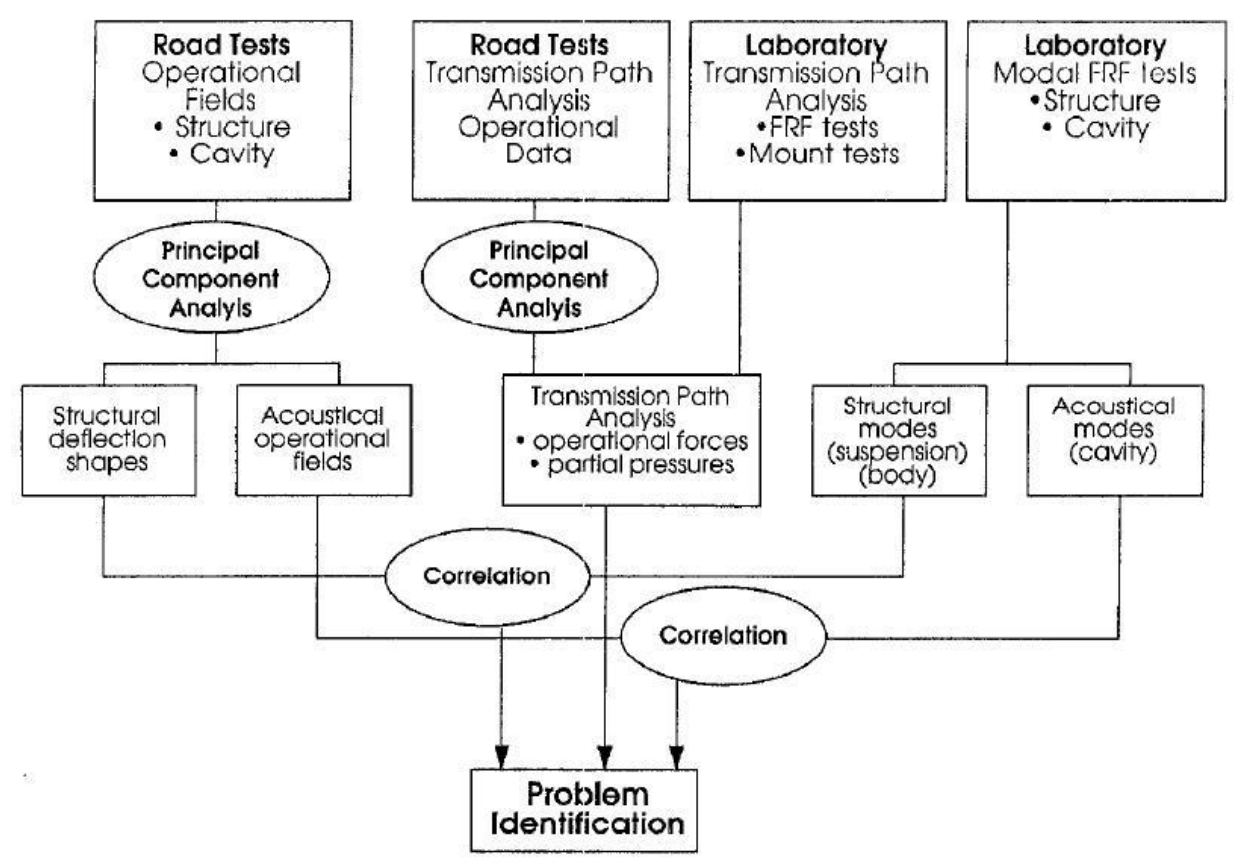

Figura 2.13: Visão geral para identificação do problema na análise do ruído de rodagem

Com a proposta da rotina de testes usando o $T P A$, as interações entre o projeto de suspensões, carroceria, pneus e pavimentos podem agora serem visualizados com maior profundidade. A seguir, serão demonstrados exemplos distintos de como o ruído interno pode ser acessado. Primeiramente, é mostrada uma medição comum de ruído de rodagem em pista, usando dois microfones apenas. Em seguida, mostras-se o potencial investigativo de uma análise de $T P A$, no qual se utilizam microfones, acelerômetros, testes em pista e laboratório.

Nesta nova metodologia, será possível explicar, e até prever matematicamente, a distribuição e nível da energia sonora por contribuições individuais entre os possíveis caminhos de propagação no veículo. 


\subsection{Estado da arte em análises do ruído interno de rodagem}

A seguir, apresenta-se um sumário dos fatores que motivam o uso do TPA.

\subsubsection{Conhecendo a fonte.}

Os métodos para investigação dos mecanismos de geração e propagação de ruídos de rodagem evoluíram ao longo dos anos, em conjunto com os projetos de pneus. A figura 2.15 curiosamente ilustra um estudo de fontes de ruído de pneu/pavimento, utilizando um estetoscópio em um laboratório provido de dinamômetro. Trabalho realizado por um engenheiro da Dunlop próximo do ano de 1950 e por razoes de segurança, não era recomendado pelos autores (Sandberg, Ulf; Ejsmont, Jerzy A., 2002).

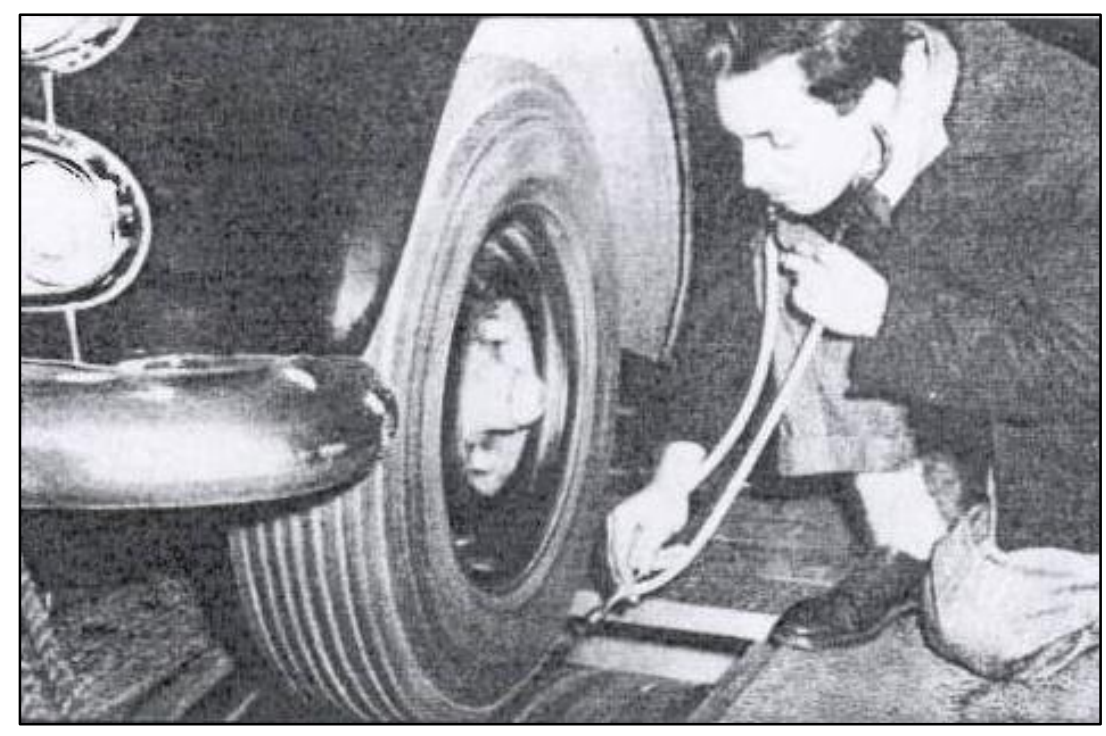

Figura 2.14: Estudando fontes de ruído pneu/pavimento, 1950. 
$\mathrm{Na}$ busca por compreender o pneu como fonte de ruído e vibração, muitas foram as mudanças em termos de procedimentos de teste, tecnologias de instrumentação e análises . Apenas como exemplo, a figura 2.16 (Ejsmont, 2005) mostra os preparativos para medições de ruído irradiado em um trailer construído pela Universidade Tecnológica de Gdansk, na Polônia, ano 2000. Este equipamento simula um ambiente sem reflexões de ruído (semi - anecóico), possibilitando criar torques de frenagens e aceleração, utilizando um sistema de transmissão e realiza variação do ângulo de deriva (Slip angle).
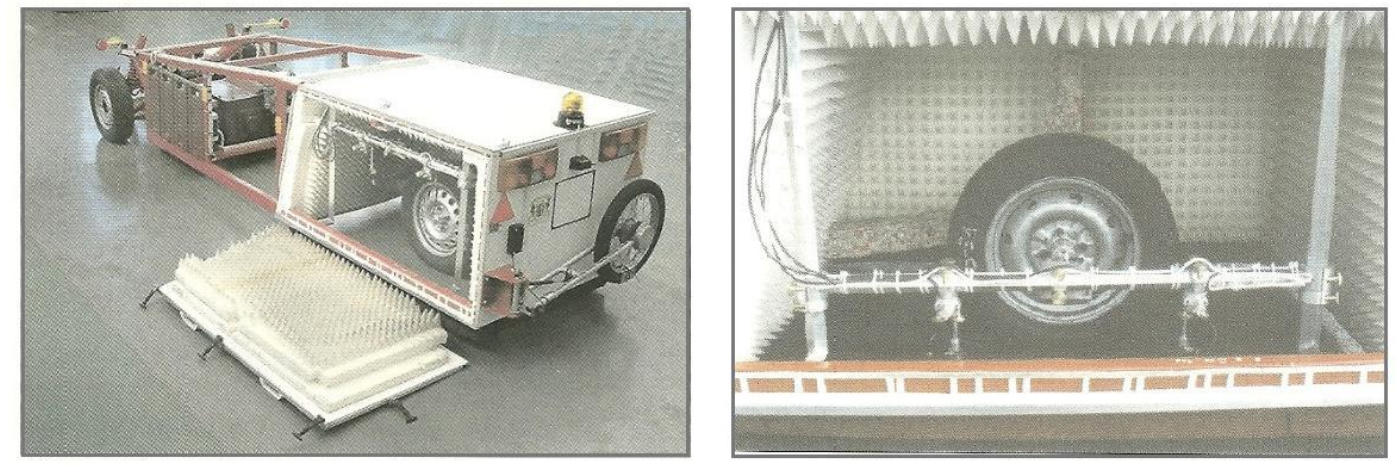

Figura 2.15: Exemplo de medição do ruído irradiado

Outro exemplo possível de encontrar em diversos artigos e livros é o uso da analise modal operacional, considerando o carregamento do veículo, figura 2.17 (Kindt, 2009).

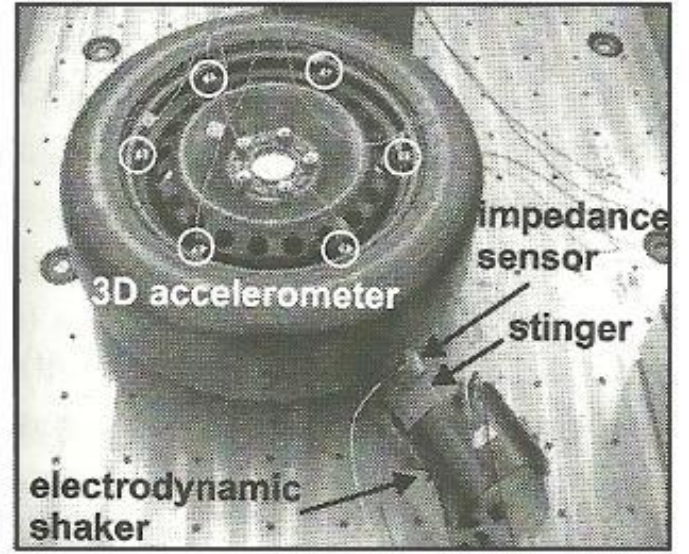

(a) unloaded tyre

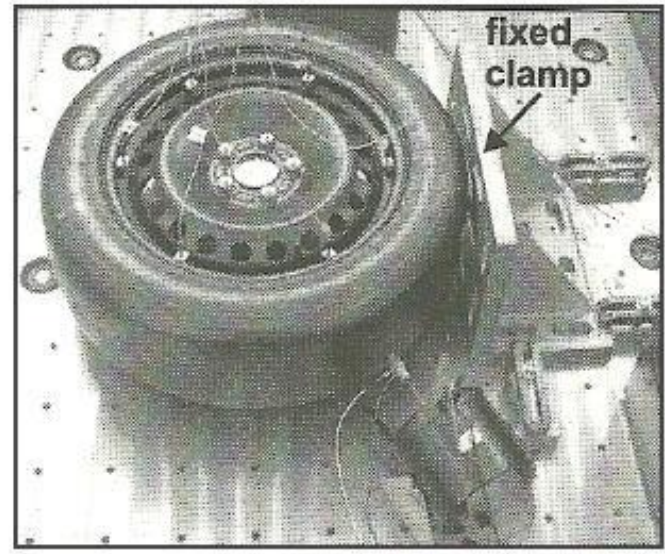

(b) loaded tyre

Figura 2.16: Exemplo de medição de resposta vibracional

Estes exemplos são metodologias experimentais que visam conhecer o comportamento acústico e vibracional do pneu. Ainda que as respostas acústicas e vibracionais sejam 
conhecidas, é importante entender como estas características podem resultar em respostas distintas de ruído de rodagem no interior de diferentes modelos de veículos.

\subsubsection{Conhecendo o ruído interno}

A figura 2.18 a seguir é um exemplo de uma análise convencional em 1/3 de oitava em $\mathrm{dB}(\mathrm{A})$, para o ruído de rodagem em um protótipo, medido a $50 \mathrm{~km} / \mathrm{h}$ em uma condição de pista áspera. Veem-se os microfones nas posições do ouvido externo do motorista (driver outer ear - DOE) e ouvido externo do passageiro, banco traseiro (rear side passenger outer ear - RSPOE) do protótipo. Este tipo de análise descreve a distribuição geral da energia sonora dentro veículo. A duas barras a direita mostram os níveis globais de cada microfone. Neste exemplo, é interessante observar que o domínio do ruído abaixo de $400 \mathrm{~Hz}$ é o maior responsável pelo nível global, comparado as frequências mais altas.

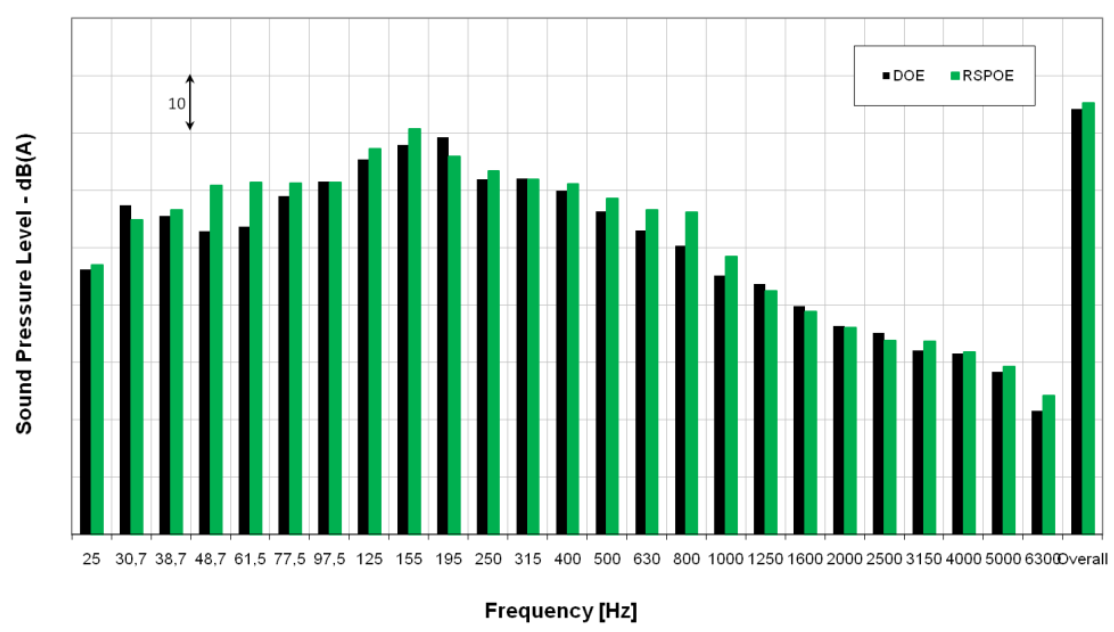

Figura 2.17: Nível de pressão sonora $\mathrm{dB}(\mathrm{A})$ por frequência em terço de oitava

O compromisso para o baixo ruído interno, para cada modelo de veículo, deve ser assumido considerando também as relações específicas entre a resistência ao rolamento, frenagem no molhado, conforto vibracional (ride), dirigibilidade, estabilidade e 
manobrabilidade. Assim, faz-se necessário interpretar as respostas do ruído de rodagem com maior profundidade.

No caso do exemplo na figura 2.18 , do protótipo a ser analisado neste trabalho, é possível questionar o porquê a maior parte do ruído está abaixo de $400 \mathrm{~Hz}$, qual o motivo da diferencia nos níveis de ruído medidos entre os microfones, como cada eixo contribui para o ruído, ou mesmo, o porquê a maior resposta está entre 125 e $195 \mathrm{~Hz}$.

Esta medição, relativamente rápida, permite conhecer qual o nível de ruído presente internamente. Para maiores conclusões de como é a sua formação ou o que deve ser melhorado, mais teste são necessários para compreender as fontes e as funções transferências do ruído, originando assim o racional para a utilização dos métodos de TPA.

\subsubsection{Os caminhos das fontes para o ruído interno, TPA}

Os métodos de Análises dos Caminhos de Transferência de energia (TPA), também referenciados nas literaturas como Análises das Fontes dos Caminhos das Contribuições (Source Path Contribution Analysis) ou simplesmente Análises dos Caminhos de Ruído (Noise Path Anaysis - NPA) têm se tornado umas das ferramentas mais importantes para $N V H$, surgido entre os anos 80 e 90, com os trabalhos de (J.S. Bendat; A.G. Piersol, 1980), (D., Otte, 1994), (Katrien Wyckaert, Herman Van der Auweraer, 1995) e embalado nos moldes para aplicação de análises veicular na última década (K. H. Ko; S. J. Heo; H. Kook, 2003).

O TPA permite o maior entendimento das funções das fontes e como se propagam por caminhos diferentes (H. Van der Auweraer, 2007). No desenvolvimento automobilístico, diversos conceitos evoluíram para combinar as técnicas experimentais de testes em laboratórios e testes em condições de operação em pista, sendo possível 
atualmente encontrar artigos que já trabalhos com modelos matemáticos para simulação (Sung-Jong Kim; Hae-In Yang; Sang-Kwon Lee, 2009).

O principio do processo de TPA é quantificar as respostas totais da energia em termos das respostas individuais dos caminhos de transmissão e fontes de contribuições (estruturais e aéreas) e pode ser aplicado para estudos de casos em $N V H$ de motorização e rodagem (W. Hendricx; D. Vandenbroeck, 1993), (H. Van der Auweraer, 2007). Esta abordagem permite dividir cada uma das contribuições de carregamento (força e velocidade do volume) e as funções de resposta em frequência (FRF) vibracional e acústica, relacionados a respostas em referências específicas, em termos de velocidades (ou acelerações) e ruído, respectivamente.

Ao contrário do exemplo anterior, a figura 2.19 a seguir mostra um caso distinto que exemplifica a análise dos caminhos de transferência de energia em termos de ruído, onde é possível agora visualizar quais são os caminhos mais críticos entre a soma dos ruídos (Sum), comparado com o ruído de referência desejado, chamado de target. Os caminhos mais críticos são as contribuições aéreas dos microfones MIC1 e 3. (H. Van der Auweraer, 2007).

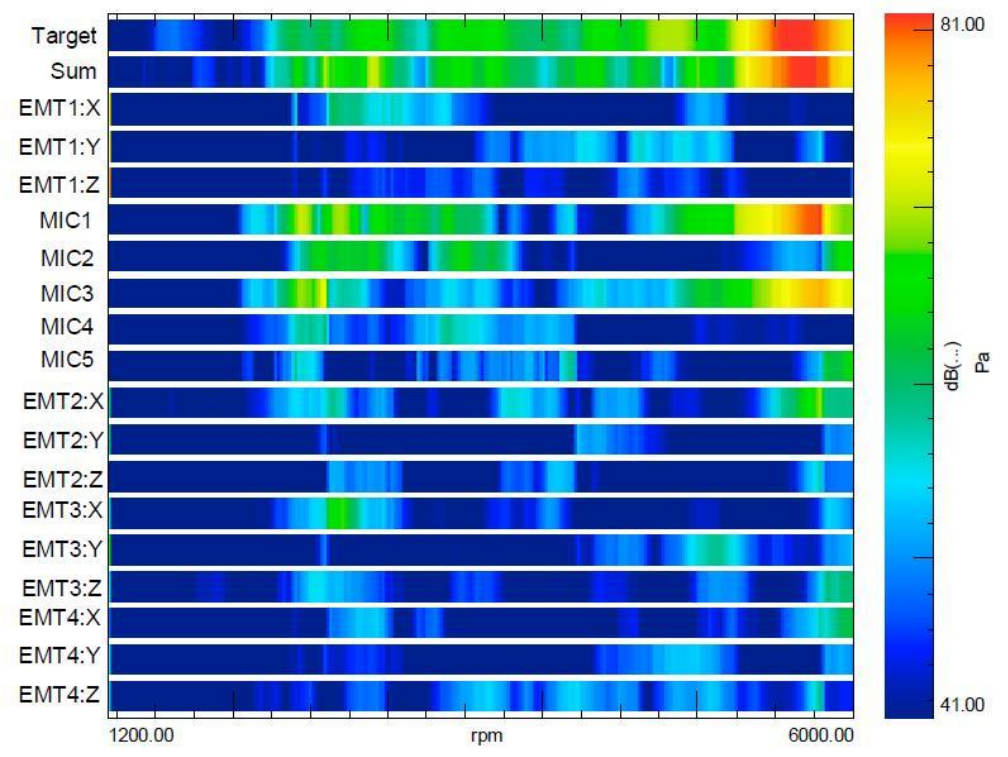

Figura 2.18: Exemplo de analise de TPA com os caminhos críticos em MIC1 e MIC3

Apesar de esta metodologia exigir maior tempo de testes em pista e agora também em laboratório, e mais canais, a experiência de se conhecer os mecanismos de geração e transferência de vibrações e ruído para conceitos de suspensões e carrocerias fornecem informações valiosas para decisões de projetos e novos designs de chassi e carroceria. 


\section{Capítulo 3}

\section{Revisão Teórica}

A Análise dos Caminhos de transferência de energia, também referida na literatura como Análise da Contribuição das Fontes e Caminhos ou simplesmente como Análise dos Caminhos de Ruído, é uma das metodologias mais importantes na área de $N V H$, criada há aproximadamente duas décadas. Mais recentemente, nos últimos dez anos, o TPA tem evoluído usando métodos diretos e indiretos de medições, aplicado na engenharia automobilística (H. Van der Auweraer, 2007). Estas metodologias, nos moldes atuais, são ferramentas imprescindíveis para quantificar individualmente as fontes e caminhos dos ruídos e vibrações, que quando somados, permitem caracterizar o conforto táctil e psicoacústico dos veículos, conforme apresentado na figura 3.1 (LMS, 2010).

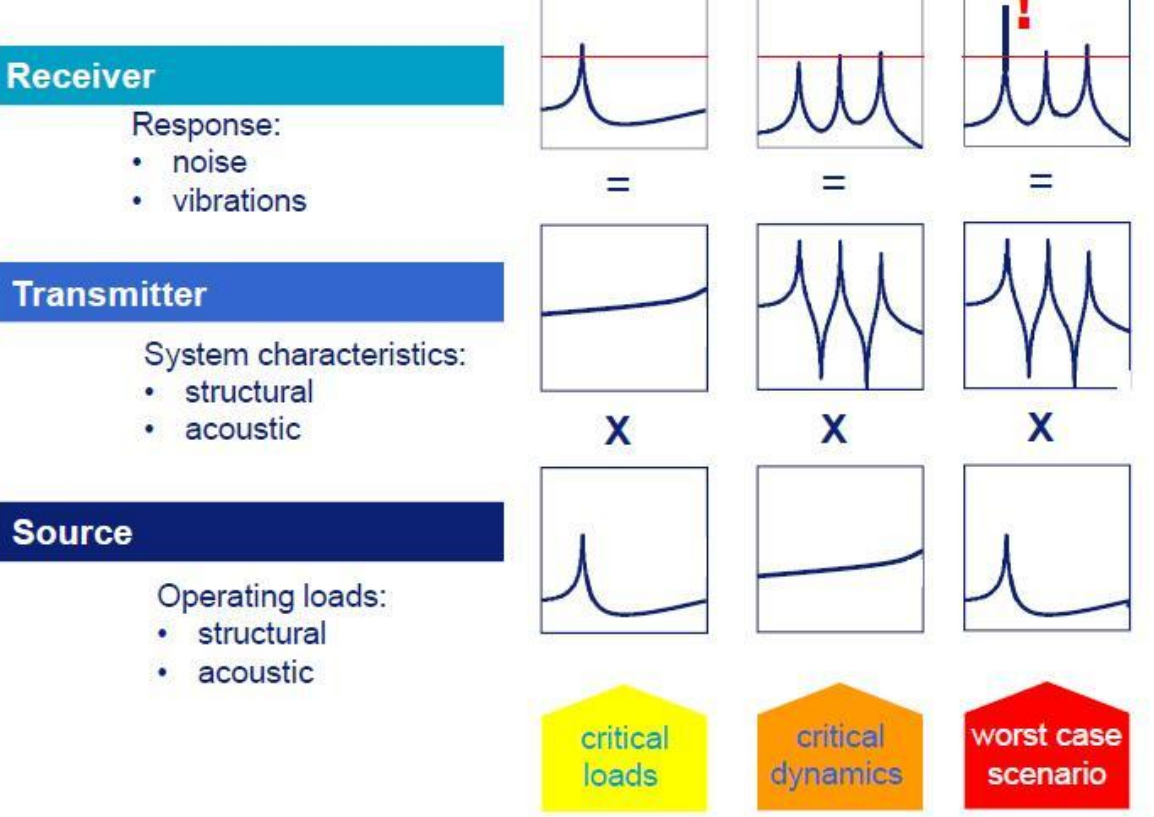

Figura 3.1: Respostas em função das características do meio transmissor e da fonte (LMS) 
As bases que fundamentam o TPA fazem o uso de teorias de vibrações, análises de sinais, equipamentos para medições de ruído e vibrações combinados entre pistas e laboratórios e a abordagem sistemática na medição das fontes, transmissores e referências. A demonstração dos fundamentos e os diferentes métodos para acessar $T P A$, são revisados a seguir, neste capítulo.

\subsection{Fundamentação para o TPA}

O TPA é um método de análise dos resultados de medições, baseado em testes experimentais, no qual permite rastrear o fluxo de energia vibroacústica de uma ou diversas fontes, através dos possíveis caminhos estruturais e aéreos de um meio físico, até um determinado receptor. O objetivo é avaliar os vetores de cada caminho da propagação de energia, de modo que seja possível identificar quais são os componentes mais críticos em um dado sistema, ou mesmo refinar as especificações dos componentes, alterando lhe suas características físicas.

$$
X_{i}(\omega)=\sum_{\mathrm{j}}^{\mathrm{n} \text { caminhos }} \mathrm{H}_{\mathrm{ij}} \cdot \mathrm{F}_{\mathrm{j}}
$$

\footnotetext{
Onde $X_{i}(\omega)$ : resposta total para uma referência, em função da frequência;

$\mathrm{H}_{i j}(\omega)$ : FRFs vibroacústicas dos caminhos;

$F_{j}(\omega)$ : entrada de força da fonte, devido a condição do teste.
}

Apesar do conceito do TPA parecer simples, é necessário muito tempo de medições em laboratório para acessar as todas ou, mesmo as mais relevantes FRFs (Funções Resposta em Frequência) estruturais e acústicas, sumarizado equação (1) como $\mathrm{H}_{\mathrm{ij}}(\omega)$. Além da etapa de laboratório, há também as medições de pistas que por sua vez demandam um maior tempo de instrumentação, disponibilidades de canais no analisador e maior 
número de acelerômetros e microfones, para aquisição dos pontos de entrada de força relevantes, $F_{j}(\omega)$.

Mesmo consumindo mais recursos que apenas as medições de convencionais em pista, conforme descrito no capitulo 2, o exercício de analisar as contribuições dos caminhos vibroacústicos permite visualizar direto e sistematicamente a origem do problema, refinar o veículo atual, e em avançado, trabalhar com o modelo virtual de protótipos, antecipando futuras especificações e targets de componentes.

Consequentemente, o TPA também facilita a diferenciação entre os caminhos estruturais do ruído dos aéreos. Como exemplo, a equação (2) mostra os carregamentos parciais de forças e acústicas do modelo e suas respectivas FRFs para formação do ruído no ouvido externo do motorista:

$$
P(\omega)=\sum^{\text {Vias estruturais }} F(\omega)_{j} \cdot\left[\frac{P}{F}(\omega)\right]_{j}+\sum^{\text {Vias aéreas }} Q(\omega)_{k} \cdot\left[\frac{P}{Q}(\omega)\right]_{k}
$$

Onde: P $(\omega)$ : pressão sonora total de referência, ex., ouvido externo do motorista (DOE);

F ( $\omega)$ : forças operacionais, no lado passivo das vias estruturais de transmissão;

Q ( $\omega)$ : cargas operacionais acústicas das fontes de transmissões aéreas;

$\mathrm{P} / \mathrm{F}(\omega)$ : FRFs das sensibilidades vibroacústicas da carroceria;

$\mathrm{P} / \mathrm{Q}(\omega)$ : FRFs das sensibilidades acústicas da carroceria.

As respostas obtidas da soma de todos os caminhos de propagação de energia podem ser analisadas tanto para ruído quanto vibrações, desde que utilizando as funções de transferências e carregamentos corretos. Com os dados em mãos, para qualquer condição do veículo, é possível modelar investigações de motorizações e rodagem $(H$. Van der Auweraer, 2007).

Em sistemas complexos que possuam subconjuntos, como por exemplo, um automóvel como na figura 3.2 (LMS, 2010), as sensações vibroacústicas que são vivenciadas por um observador em qualquer local pode facilmente ter sido causado por uma fonte de vibração distante. Por exemplo, a energia de um motor é transmitida para a cabine de passageiros por uma série de rotas diferentes. Estruturalmente, a partir dos coxins, fixação do sistema de escapamento, ainda que indiretamente, através dos eixos de tração das rodas e subframe. As contribuições aéreas das fontes como, por exemplo, filtro de 
ar, ruído irradiado e de ponteira do sistema de escapamento, podem ser relevantes também. Mas, em se tratando de caminhos, alguns dessas vias são importantes, outros não. Esta análise dependerá das FRFs e das amplitudes e a fases do ruído nestes caminhos, a ser explicado a seguir.

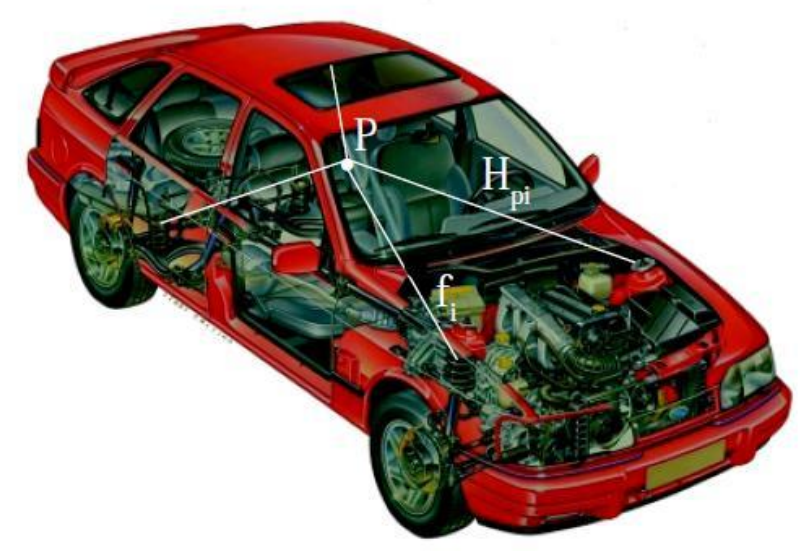

Figura 3.2: Exemplos de caminhos de transferências estruturais em um veículo

\subsubsection{Lei da Reciprocidade - sistemas SISO e MIMO em múltiplos GDF}

Para entendermos as respostas do TPA, deve ser revisado o princípio base que permite o cálculo do ruído ou vibração no automóvel. Para fins didáticos, vamos considerar um sistema com $n$ graus de liberdade, nosso ponto de partida para analisar as respostas vibracionais, conforme a figura 3.3. 


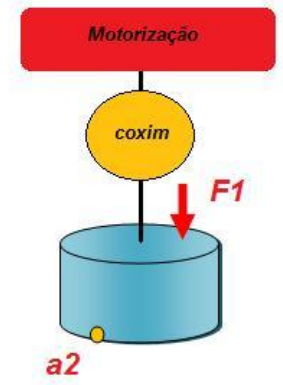

Em operação (pista)

[OP]

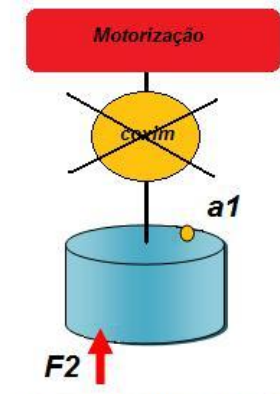

Teste de Impactação (laboratório)

[FRF]

Figura 3.3: Sistema SISO em condição de operação e medição de FRF

Para construir o TPA é necessário unir os dados das funções de carregamentos operacionais, em pista, e as funções de transferência do laboratório (FRFs). Estes distintos procedimentos de testes podem ser relacionados através da lei da reciprocidade. Esta lei é descrita utilizando o sistema SISO.

Do acrônimo em inglês para Single Input Single Output - SISO, termo normalmente usado pela engenharia de controle (William S. Levine, 1996), define um sistema simples com uma única entrada e única saída. Tendo $F_{1}$ e $F_{2}$ como entradas de força nos pontos 1 e 2, e as saídas das acelerações respectivamente, pode se demonstrar que:

$$
\left(\frac{a_{2}}{F_{1}}\right)^{[O P]}=\left(\frac{a_{1}}{F_{2}}\right)^{[F R F]}
$$

No qual pode ser escrito como:

$$
a_{2}^{[O P]} \cdot F_{2}^{[F R F]}=a_{1}^{[F R F]} \cdot F_{1}^{[O P]}
$$

Desta maneira, mostra-se que é possível calcular uma força desconhecida $F_{1}$ fazendo:

$$
F_{1}^{[O P]}=\left(\frac{a_{1}^{F R F}}{F_{2}^{F R F}}\right)^{[-1]} \cdot a_{2}^{[O P]}=\left(\frac{F_{2}}{a_{1}}\right)^{[F R F]} \bullet a_{2}^{[O P]}
$$

Caso ponto 1 seja igual ao 2, faz-se o calculo da força usando seu point mobility (a ser explicado nos métodos de TPA) conhecido como "quick NPA" ou "Fast TPA", utilizado neste estudo de caso. 


$$
F_{1}^{[O P]}=\left(\frac{F_{1}}{a_{1}}\right)^{[F R F]} \bullet a_{1}^{[O P]}
$$

Na prática, a equação (4) pode ser generalizada para sistemas MIMO (Multiple Input Multiple Output), ou seja, sistemas de múltiplas entradas e saídas, sendo os índices "i”" as referências para as direções $\mathrm{x}, \mathrm{y}$ e $\mathrm{z}$.

$$
\sum_{i=1}^{N} F_{i}^{[O P]} \bullet a_{i}^{[F R F]}=\sum_{i=1}^{N} F_{i}^{[F R F]} \bullet a_{i}^{[O P]}
$$

\subsubsection{Análises de sinais: relações entrada/saída de sistemas lineares}

Matematicamente falando, um sistema é uma regra para atribuir a uma função $x(t)$ outra função $y(t)$. Chamemos a $x(t)$ entrada e a $y(t)$ saída e o sistema faz a transformação L $[x(t)]$ (Arruda \& Huallpa, 2005):

$$
y(t)=\mathrm{L}[x(t)]
$$

Fisicamente falando, um sistema produz um objetivo, uma resposta, quando estimulado por uma excitação. Resposta e excitação são os termos correspondentes a saída e entrada, respectivamente. Exemplos de sistemas físicos são sistemas de potência, máquinas, sistemas de rádio - comunicação, etc. Restringiremos o estudo aos sistemas mecânicos lineares, fisicamente realizáveis e invariantes no tempo, que podem ser representados por uma equação diferencial linear a parâmetros constantes. 


\section{Integral de Duhamel - Teorema da convolução}

Se a resposta de um sistema linear à distribuição $\delta(t)$ é uma função $h(t)$, podemos obter a resposta a uma entrada qualquer $x(t)$ em função de $h(t)$. Para tanto, a entrada $x(t)$ pode ser escrita como a soma de entradas elementares, figura 3.4.

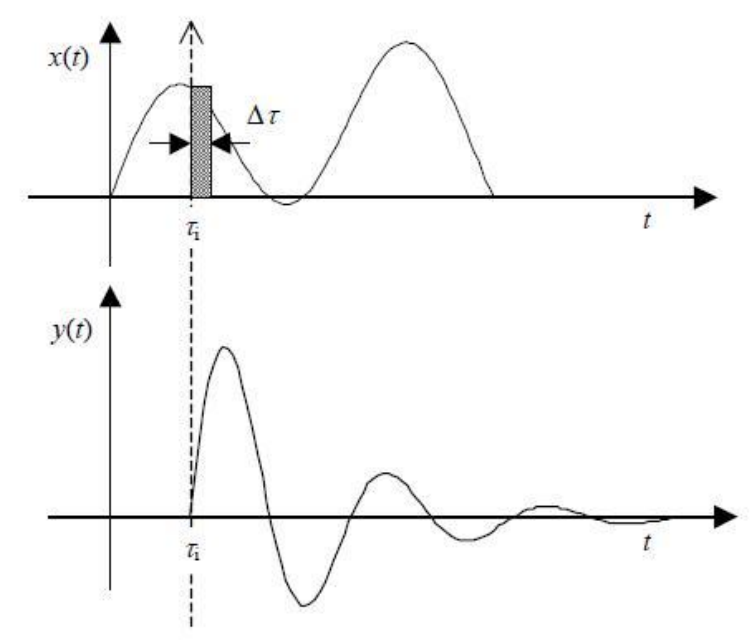

Figura 3.4: Sinal de entrada indicando uma das entradas e respectiva resposta

Com $\Delta \tau$ suficientemente pequeno podemos escrever:

$$
x(t)=\sum_{i=1}^{N} x_{i}(t)=\sum_{i=1}^{N} x_{i}\left(\tau_{i}\right) \Delta \tau . \delta\left(t-\tau_{i}\right)
$$

Como o sistema é linear, pelo princípio da superposição, temos que a resposta será:

$$
y(t)=\sum_{i=1}^{N} y_{i}(t)=\sum_{i=1}^{N} x_{i}\left(\tau_{i}\right) h\left(t-\tau_{i}\right) . \Delta \tau
$$

fazendo $\Delta \tau \rightarrow d \tau:$

$$
y(t)=\int_{0}^{t} x_{i}\left(\tau_{i}\right) h\left(t-\tau_{i}\right) \cdot \mathrm{d} \tau
$$

Geralmente, tomamos, por conveniência, a entrada $x(t)$ só para tempos positivos (função causal), ou seja:

$$
x(t)=0 \text { para } t<0
$$

Como o sistema é causal, a saída $y(t)$ não pode depender de entradas futuras $x(\tau>t)$, ou seja:

$$
h(t)=0 \text { para } t<0
$$


Donde a integral (11) fica:

$$
y(t)=\int_{-\infty}^{\infty} \mathrm{x}(\tau) h(t-\tau) \cdot \mathrm{d} \tau
$$

A equação (11), que expressa a resposta de um sistema linear causal a uma entrada qualquer, é conhecida por integral de Duhamel. Devido às equações (12) e (13), as expressões (11 e (14) expressam o mesmo resultado.

Da definição da transformada de Fourier para o teorema da energia em (15):

$$
\int_{-\infty}^{\infty} \mathrm{x}(\tau) \cdot g(-\tau) \cdot \mathrm{d} \tau=\int_{-\infty}^{\infty} \mathrm{X}(\mathrm{f}) \cdot G(\mathrm{f}) \cdot \mathrm{d} f
$$

Temos que a expressão (14) expressa a convolução de $x(t)$ com $h(t)$, ou seja:

A resposta de um sistema linear a uma excitação qualquer é a convolução do sinal de entrada com a função resposta ao impulso unitário. Do teorema da convolução (16):

$$
H^{*}(f)=\int_{-\infty}^{\infty} \mathrm{h}^{*}(\mathrm{t}) \cdot e^{i 2 \pi f t} \cdot \mathrm{dt}=\int_{-\infty}^{\infty} \mathrm{g}(-\mathrm{t}) \cdot e^{i 2 \pi f t} \cdot d t
$$

Temos que, fazendo a transformada de Fourier da expressão (14) a:

$$
Y(f)=X(f) \cdot H(f)
$$

Onde

$$
\begin{aligned}
& X(f) \leftarrow \tilde{f} \rightarrow x(t) \\
& Y(f) \leftarrow \tilde{f} \rightarrow y(t) \\
& H(f) \leftarrow \tilde{f} \rightarrow h(t)
\end{aligned}
$$

Mas este resultado pode ser obtido por outro caminho mais rigoroso.

A resposta de um sistema linear à entrada $e^{i 2 \pi f t}$ é uma função de $f$ e $t$.

$$
y(t, f)=L\left[e^{i 2 \pi f t}\right]
$$

Pela invariância com o tempo:

$$
y(t+\mathrm{T}, f)=L\left[e^{i 2 \pi f(t+r)}\right]
$$


Para qualquer $\tau$. Devido à linearidade:

$$
L\left[e^{i 2 \pi f t} \cdot e^{i 2 \pi f \tau}\right]=e^{i 2 \pi f \tau} L\left[e^{i 2 \pi f t}\right]=e^{i 2 \pi f \tau} \cdot y(t, f)
$$

Donde:

$$
y(t+\tau, f)=e^{i 2 \pi f \tau} \cdot y(t, f)
$$

Fazendo $t=0$ :

$$
y(\tau, f)=e^{i 2 \pi f \tau} \cdot y(0, f)
$$

Como (21) é válida para qualquer $\tau$ e $y(0, f)$ é uma função apenas de $f$ e chamaremos $H(f)=y(0, f)$ :

$$
y(t, f)=H(f) \cdot e^{i 2 \pi f t}
$$

Ou seja, a resposta a uma exponencial complexa é também uma exponencial complexa.

Da expressão da transformada de Fourier inversa podemos escrever:

$$
x(t)=\int_{-\infty}^{\infty} X(f) \cdot e^{i 2 \pi f t} d f
$$

E como resposta a $e^{i 2 \pi f t}$ é $H(f) e^{i 2 \pi f t}$ temos, pelo princípio da superposição:

$$
y(t)=\int_{-\infty}^{\infty} X(f) \cdot H(f) \cdot e^{i 2 \pi f t} d f
$$

Fazendo a transformada de (24) temos:

$$
Y(f)=\int_{-\infty}^{\infty}\left[\int_{-\infty}^{\infty} X(\xi) \cdot H(\xi) \cdot e^{i 2 \pi \xi t} d \xi\right] e^{-i 2 \pi f t} d t
$$

ou seja:

$$
Y(f)=\int_{-\infty}^{\infty} X(\xi) \cdot H(\xi)\left[\int_{-\infty}^{\infty} e^{i 2 \pi \xi t} \cdot e^{-i 2 \pi f t} d t\right] d \xi
$$

Mas, das propriedades associadas á transformada de Fourier descritas em (26),

$$
x(t) * h(t) \rightarrow \tilde{f} \rightarrow X(f) . H(f)
$$




$$
x(t) . h(t) \rightarrow \tilde{f} \rightarrow X(f) * H(f)
$$

Temos que o termo no colchete vale $\delta(f-\xi)$ donde:

$$
\begin{gathered}
Y(f)=\int_{-\infty}^{\infty} X(\xi) \cdot H(\xi) \cdot \delta(f-\xi) d \xi \\
Y(f)=X(f)=H(f)
\end{gathered}
$$

Ou seja, o mesmo resultado de (17). Pelo teorema da convolução (16), chegamos a (14) e, para mostrar que $h(t)$ é a resposta ao impulso $\delta(t)$ basta substituir $x(t)=\delta(t)$ em (14).

\section{Análises entre dois canais - FRF}

As análises de frequências de um único canal remetem diretamente á investigação de um problema, interpretando a resposta vibracional no espectro da frequência. Tão importante quanto estas respostas, é também a necessidade de medir as funções de respostas em frequência, FRF, de uma determinada estrutura (Kenneth McConnell, Paulo S. Varoto, 2008). Estas funções permitem visualizar o comportamento de uma estrutura, conforme resumido na figura 3.5 abaixo (LMS, 2010)

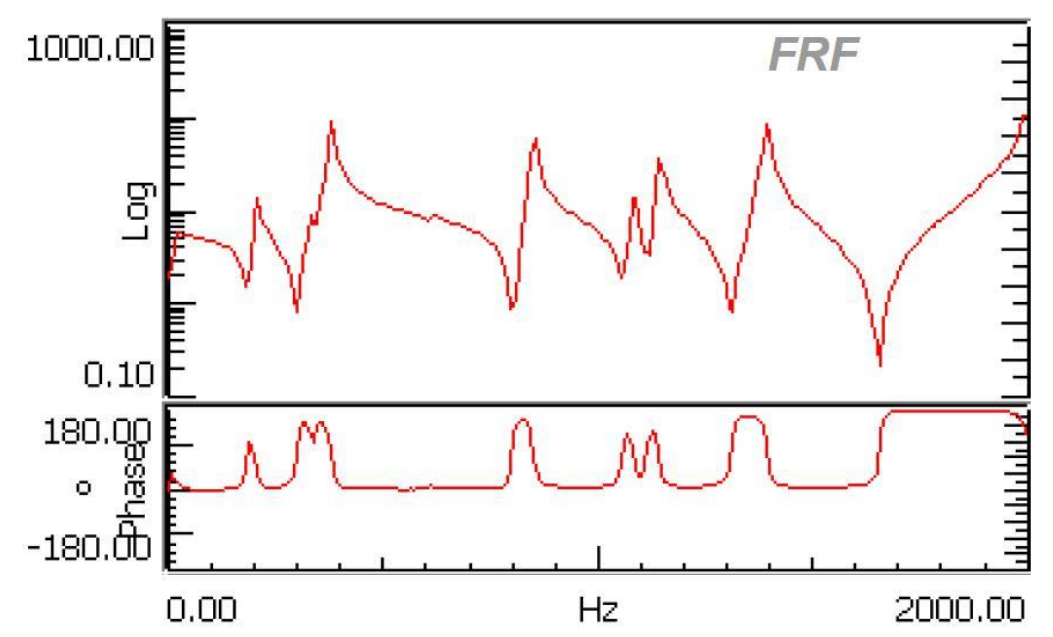

Figura 3.5: Exemplo de uma FRF com fase 
A aquisição de uma FRF necessita de no mínimo um analisador de dois canais. Um para medir a excitação de entrada e o outro para medir a resposta de saída. Logicamente, com mais canais, pode ser realizado a aquisição direta de um sistema MIMO. A figura 3.6 apresenta o SISO para analise entre dois canais, a base para o entendimento do processo para FRF. Os autores (Bendat e Piersol, 1986) fazem esta discussão para múltiplos canais em detalhes.

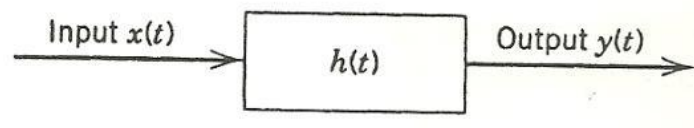

(a)

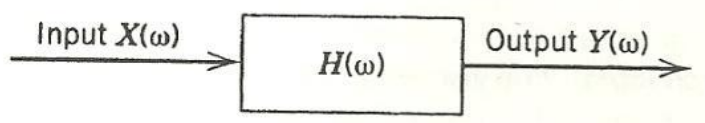

(b)

Figura 3.6: Modelos de sistemas lineares input-output. (a) Convolução no domínio do tempo. (b) Multiplicação no domínio da frequência.

A partir das relações entrada/saída de sistemas lineares, pode-se facilmente estabelecer estas relações em termos de auto espectros e espectros cruzados para sinais aleatórios. Partindo da integral da convolução para sistemas causais $(h(t)=0, t<0)$, pode-se usar integral de Duhamel (14). Substituindo $t$ por $t+\tau$ na equação e substituindo o resultado na expressão da auto correlação, tem-se:

$$
\begin{gathered}
R_{y y}(\tau)=\lim _{T \rightarrow \infty} \frac{1}{T} \int_{0}^{T} y(t) \cdot y(t+\tau) d t \\
=\int_{0}^{\infty} \int_{0}^{\infty} \mathrm{h}(\xi) \mathrm{h}(\eta) \lim _{T \rightarrow \infty} \frac{1}{T} \int_{0}^{T} x(t-\xi) \cdot x(t+\tau-\eta) d t d \xi d \eta \\
=\int_{0}^{\infty} \int_{0}^{\infty} \mathrm{h}(\xi) \mathrm{h}(\eta) \mathrm{R}_{\mathrm{xx}}(\tau-\eta+\xi) d t d \xi d \eta
\end{gathered}
$$

Já que:

$$
\int_{0}^{\infty} x(t-\xi) \cdot x(t+\tau-\eta) d t=\int_{-\xi}^{T-\xi} x(\theta+\tau-\eta+\xi) d \theta, \text { com } t-\xi=\theta
$$

Mas, aplicando a transformada de Fourier em (28) vem, 


$$
\begin{gathered}
S_{y y}(f)=\int_{-\infty}^{\infty} R_{y y}(\tau) e^{-i e \pi f \tau} d t \\
=\int_{0}^{\infty} \int_{0}^{\infty} \mathrm{h}(\xi) \mathrm{h}(\eta) \int_{-\infty}^{\infty} R_{x x}(t-\eta+\xi) \cdot e^{-i 2 \pi f \tau} d \tau
\end{gathered}
$$

Fazendo a substituição $\gamma=\tau+\xi-\eta ; d \gamma=d \tau$ em (29):

$$
S_{y y}(f)=\int_{0}^{\infty} h(\xi) \int_{0}^{\infty} h(\eta)\left\{\int_{-\infty}^{\infty} R_{x x}(\gamma) e^{-i 2 \pi f \gamma}\right\} \cdot e^{-i 2 \pi f \eta} d \eta \cdot e^{-i 2 \pi f \xi} d \xi
$$

Reconhecendo a expressão de $S_{x x}(f)$ em (30), tem-se:

$$
S_{y y}(f)=S_{x x}(f) \int_{0}^{\infty} \mathrm{h}(\xi) \mathrm{e}^{-\mathrm{i} 2 \pi \mathrm{f} \xi} \mathrm{d} \xi \int_{0}^{\infty} h(\eta) e^{i 2 \pi f \eta} d \eta
$$

E reconhecendo a transformada de Fourier de $h(t)$ e seu conjugado em (6.37) tem-se finalmente:

$$
S_{y y}(f)=H(f) \cdot H^{*}(f) S_{x x}(f)
$$

Ou seja:

$$
S_{y y}(f)=|H(f)|^{2} \cdot S_{x x}(f)
$$

A equação (33) expressa a relação entre o autoespectro da saída e o autoespectro da entrada com sinais aleatórios. A partir desta relação, em deduções análogas, pode-se chegar a outros resultados.

Por exemplo, fazendo $x(t) y(t+\tau)$ em (28), é fácil chegar a:

$$
S_{x y}(f)=H(f) S_{x x}(f)
$$

E fazendo $y(t) y(t+\tau)$, porém sem substituir $y(t)$ de (6.33), é imediato chegar a:

$$
S_{y y}(f)=H(f) S_{y x}(f)
$$

Relações intermediárias das demonstrações anteriores expressam a relação entrada/saída no domínio do tempo para sinais aleatórios:

$$
R_{x y}=\int_{0}^{\infty} h(\xi) R_{x x}(\tau-\xi) d \xi=h(t) * R_{x x}(t)
$$




$$
R_{y y}=\int_{0}^{\infty} h(\xi) R_{y x}(\tau-\xi) d \xi=h(t) * R_{y x}(t)
$$

As mesmas relações entre espectros de entrada e saída podem ser obtidas partindo-se da transformada de Fourier finita dos sinais de entrada e saída.

Sabemos que para sistemas lineares,

$$
Y(f)=H(f) \cdot X(f)
$$

Assumindo que esta relação é válida para a transformada de Fourier finita:

$$
Y(f, T)=H(f, T) \cdot X(f, T)
$$

Omitindo a dependência de $f$ e $T$ para facilitar a notação tem-se:

$$
Y=H X
$$

E, multiplicando por $X^{*}$

$$
X^{*} Y=H X^{*} \mathrm{X}
$$

Fazendo o valor esperado da equação anterior, tem-se:

$$
S_{x y}=H(f) \cdot S_{x x}
$$

onde $S_{x x}=T E\left[X^{*} X\right]$ e $S_{x y}=T E\left[X^{*} Y\right]$, onde $E[$ ] denota a média de conjunto.

Alternativamente, multiplicando a expressão (6.44) por $Y^{*}$ tem-se

$$
Y^{*} X=H Y^{*} \mathrm{X}
$$

Aplicando a média:

$$
S_{y y}=H(f) \cdot S_{y x}
$$

Cabe notar que, quando resolvendo o problema inverso, onde se procura determinar a FRF a partir dos sinais $x(t)$ e $y(t)$ aleatórios medidos, denominam-se de $\widehat{H}_{1}$ e $\widehat{H}_{2}$ os estimadores das equações (34) e (35). 


$$
\begin{aligned}
& \widehat{H}_{1}(f)=\frac{s_{x y}(f)}{s_{x x}(f)} \\
& \widehat{H}_{2}(f)=\frac{s_{y y}(f)}{s_{y x}(f)}
\end{aligned}
$$

\subsubsection{Função de coerência da FRF}

Dados dois sinais aleatórios, $x(t)$ e $y(t)$, já foi mostrado que (Arruda \& Huallpa, 2005):

$$
\left|R_{x y}(\tau)\right|^{2} \leq R_{x x}(0) \cdot R_{y y}(0)
$$

Esta equação vale para qualquer $\tau$, inclusive para $\tau=0$.

$$
\left|R_{x y}(0)\right|^{2} \leq R_{x x}(0) \cdot R_{y y}(0)
$$

Filtrando os sinais em torno de uma frequência $f_{0}$ com filtro passa-banda ideal de largura $\Delta f$, tem-se:

$$
R_{x x}=\int_{0}^{\infty} G_{x x}(f) d f=\int_{f_{0}-\Delta f / 2}^{f_{0}+\Delta f / 2} G_{x x}(f) d f \cong G_{x x}\left(f_{0}\right) \Delta f
$$

Já que $\Delta f$ pode ser feito tão pequeno quanto se queira. Da mesma forma:

$$
\begin{aligned}
& R_{y y}(0)=\mathrm{G}_{\mathrm{yy}}\left(f_{0}\right) \cdot \Delta \mathrm{f} \\
& R_{x y}(0)=\mathrm{G}_{\mathrm{xy}}\left(f_{0}\right) \cdot \Delta \mathrm{f}
\end{aligned}
$$

A última expressão merece um comentário:

$$
R_{y x}(0)=\int_{-\infty}^{\infty} G_{x y}(f) d f \cong G_{x y}\left(f_{0}\right) \Delta f
$$

Substituindo (6.54) - (6.56) em (6.53) vem: 


$$
\left|G_{x y}\left(f_{0}\right)\right|^{2} \leq G_{x x}\left(f_{0}\right) G_{y y}\left(f_{0}\right)
$$

Que é válida para qualquer $f 0$. A desigualdade é obviamente válida também para as DEP's “double sided”, i.e.;

$$
\left|S_{x y}(f)\right|^{2} \leq S_{x x}(f) S_{y y}(f)
$$

A partir da relação (6.58) podemos definir uma função da frequência que chamaremos função de coerência ordinária:

$$
\gamma_{x y}^{2}(f)=\frac{\left|s_{x y}(f)\right|^{2}}{s_{x x}(f) \cdot s_{y y}(f)}
$$

E, devido a (52), tem-se:

$$
0 \leq \gamma_{x y}^{2} \leq 1
$$

No caso de $y(t)$ e $x(t)$ serem ligados por uma relação linear, que pode ser representada por uma FRF, $H(f)$, tem-se:

$$
S_{x y}(f)=H(f) S_{x x}(f)
$$

Donde,

$$
\gamma_{x y}^{2}(f)=\frac{|H(f)|^{2} S_{x x}{ }^{2}(f)}{S_{x x}(f) \cdot S_{y y}(f)}
$$

E substituindo (53):

$$
\gamma_{x y}^{2}(f)=\frac{|H(f)|^{2} \cdot S_{x x}{ }^{2}(f)}{S_{x x}(f) \cdot|H(f)|^{2} \cdot S_{x x}(f)}=1
$$

Ou seja, se $x(t)$ e $y(t)$ têm uma relação linear, a coerência é unitária. Portanto, pode-se interpretar a coerência como um coeficiente de correlação no domínio da frequência.

Seguindo a modelagem de ruído proposta por Bendat e Piersol ( J.S., Bendat; A.G., Piersol, 1980), (J.R.F., Arruda; E., Godoy, 1989), imagine-se que ruídos de medição 
Gaussianos aditivos independentes contaminem a entrada e a saída de um sistema linear, como mostrado na figura 3.7.

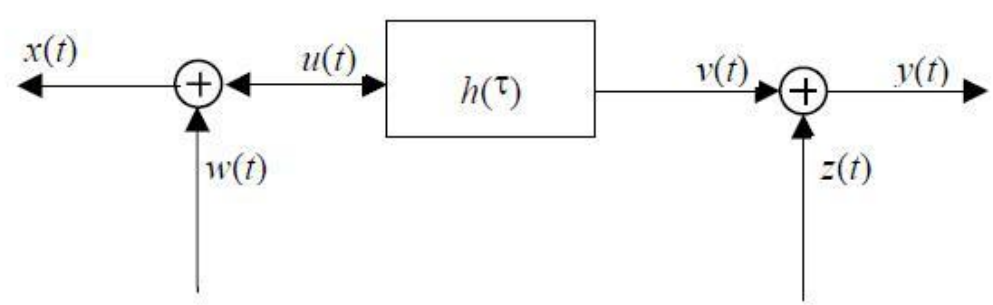

Figura 3.7: Modelo de ruído de medição em um sistema linear

Da figura 3.7, tem-se:

$$
\begin{aligned}
& x(t)=u(t)+w(t) \\
& y(t)=\mathrm{v}(t)+\mathrm{z}(t)
\end{aligned}
$$

Ou, aplicando a transformada de Fourier finita:

$$
\begin{gathered}
X(f, T)=U(f, T)+W(f, T) \\
Y(f, T)=V(f, T)+Z(f, T)
\end{gathered}
$$

Os espectros são dados por:

$$
G_{x x}(f)=2 E\left[X^{*} X\right]=\frac{2}{\Delta f} E\left[U^{*} U+U^{*} W+W^{*} U\right]
$$

Mas, como o ruído é suposto estatisticamente independente, tem-se que,

$$
E\left[U^{*} \mathrm{~W}\right]=E\left[W^{*} U\right]=0
$$

Donde

$$
G_{x x}(f)=G_{u u}(f) G_{w w}(f)
$$

Note que a dependência de $f$ e $T$ foi omitida para simplificar a notação. Analogamente: 


$$
\begin{gathered}
G_{y y}(f)=G_{v v}(f) G_{z z}(f) \\
G_{x y}(f)=G_{u v}(f)
\end{gathered}
$$

Note-se que o espectro cruzado não é afetado pelo ruído Gaussiano aditivo. Observe-se, agora, a influência do ruído nos estimadores $\widehat{H}_{1}$ e $\widehat{H}_{2}$ dados pelas equações (45) e (46):

$$
\begin{aligned}
& \left|\widehat{H}_{1}(f)\right|=\frac{\left|G_{x y}(f)\right|}{\left|G_{x x}(f)\right|}=\frac{\left|G_{u v}\right|}{G_{u u}+G_{w w}} \leq|H(f)| \\
& \left|\widehat{H}_{2}(f)\right|=\frac{\left|G_{y y}(f)\right|}{\left|G_{x y}(f)\right|}=\frac{G_{v v}+G_{z z}}{\left|G_{v u}\right|} \geq|H(f)|
\end{aligned}
$$

já que $G_{w w} \geq 0$ e $G_{z z} \geq 0$, tem-se que:

$$
\left|\widehat{H}_{1}(f)\right| \leq|H(f)| \leq\left|\widehat{H}_{2}(f)\right|
$$

Onde os estimadores $\widehat{H}_{1} e \widehat{H}_{2}$ são limite inferior e superior ao valor de H(f) quanto ao ruído de medição. Cabe notar que a equação anterior não é geralmente verificada devido aos erros de leakage, janelamento triangular dos espectros, erro estatístico de estimação dos espectros e ruídos não independentes ou não Gaussianos.

Existem outros estimadores da FRF, porém $\widehat{H}_{1}$ e $\widehat{H}_{2}$ são os mais comumente utilizados. O estimador $\widehat{H}_{1}$ deve ser utilizado quando o ruído contamina principalmente o sinal de resposta, enquanto $\widehat{H}_{2}$ deve ser utilizado quando o ruído contamina o sinal de entrada. $\mathrm{O}$ ruído no sinal de entrada é típico de situações onde excitadores eletrodinâmicos são pilotados com sinais de banda larga sem realimentação para manter a amplitude da força constante. Como o sistema apresenta uma reação menor nas ressonâncias, a amplitude da força (entrada) tende a diminuir muito nas ressonâncias, tornando a relação sinal/ruído muito baixa.

A figura 3.8 demonstra uma FRF e sua função de coerência (LMS, Fundamentals of Vibration and Modal Analysis). 


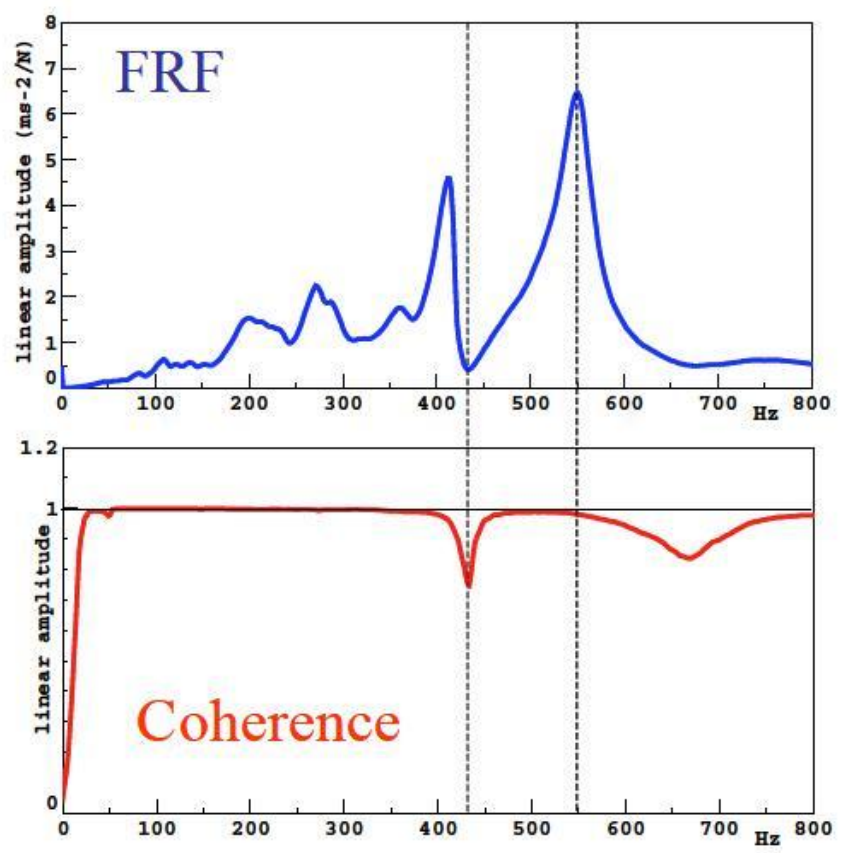

Figura 3.8: ilustração de uma FRF e sua função de coerência (LMS)

A função de coerência na prática é um indicador útil para quantificar a relação linear entre dois sinais variáveis, representado com número real com faixa entre zero e um. Uma coerência pobre $(<<1)$ pode ser causada por ruídos na medição, vazamentos (leakages) ou mesmo não linearidades que podem existir no sistema. Portanto, um baixo valor de coerência em determinada frequência não significa, necessariamente, que exista um problema na medição da FRF. Ou mesmo o oposto pode ocorrer, a melhor curva de coerência pode não significar a FRF mais representativa ao dado ponto analisado.

\subsubsection{Vibração - Fase \& Coerência de fase}

\section{Fase}

Fase é a fração de um ciclo de onda que tem decorrido em relação a um ponto arbitrário (Ballou, Glen, 2005). A fase de oscilação ou onda pode ser demonstrada com uma função senoidal, como o seguinte: 


$$
\begin{gathered}
x(t)=A \cdot \cos (2 \pi f t+\theta) \\
y(t)=A \cdot \sin (2 \pi f t+\theta)=A \cdot \cos (2 \pi f t+\theta-\pi / 2)
\end{gathered}
$$

Sendo A, F e $\theta$ parâmetros constantes, essas funções são periódicas com período $\mathrm{T}=$ 1/f, com magnitudes idênticas, com uma defasagem de T/4 ao longo do tempo.

O termo fase pode ser usado para se referir a mudança de um sinal a um "ponto zero" ou outro sinal qualquer, ou também expressar em graus ou tempo, a diferença entre duas ondas com a mesma frequência e referenciadas ao mesmo ponto no tempo (Ballou, Glen, 2005), como na figura 3.9.

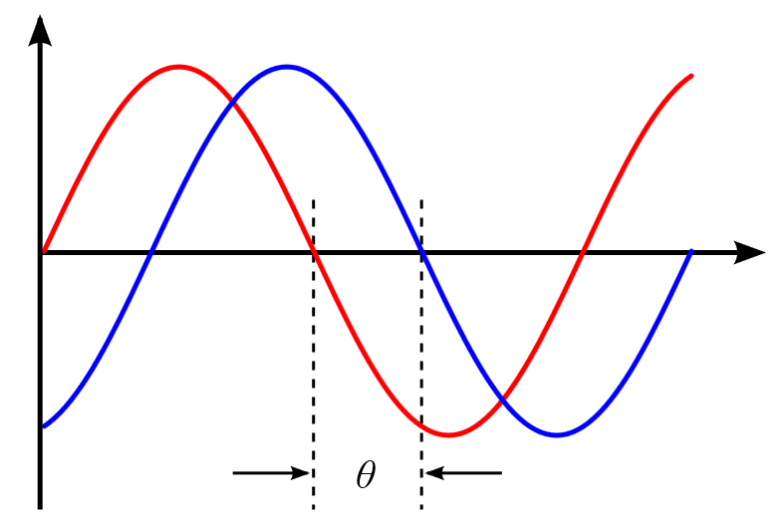

Figura 3.9: Duas ondas senoidais com diferença de tempo entre elas, medido pela fase $\theta$

\section{Coerência de Fase}

Coerência de fase, proposta semelhante á coerência usada na análise de FRF, descreve a qualidade de entre as fases de dois sinais em seu domínio de frequência ou tempo. Fisicamente, a função de uma onda é complexa, uma vez que seu módulo quadrado é associado com a probabilidade de observar o objeto, energia, e o caráter complexo da função de onda está associada à fase.

A coerência de duas ondas resulta da forma como as ondas são corretamente correlacionadas, quantificada pela função de correlação cruzada (Winter \& Steinberg, 2011). A correlação cruzada quantifica a habilidade de prever o valor da segunda onda, 
sabendo o valor da primeira. Como exemplo, considere duas ondas perfeitamente correlacionadas para todos os tempos. A qualquer momento, se as mudanças primeira onda, o segundo vai mudar da mesma maneira. Se combinados podem exibir uma interferência construtiva completa / sobreposição em todos os momentos. Daqui resulta que elas são perfeitamente coerentes. A segunda onda não precisa ser uma entidade separada. Poderia ser a primeira em um horário diferente ou posição. Neste caso, a medida de correlação é a função de autocorrelação (às vezes chamado de autocoerência). Grau de correlação envolve funções de correlação (autocorrelação e correlação cruzada).

Em termos práticos para o TPA, a informação da fase para um ruído calculado comparado com o ruído real medido, por exemplo, para um mesmo fenômeno observado, mostrará se a correlação dos dados de carregamentos de pista e FRFs estão contribuindo corretamente, com a mesma natureza de resposta. Ou seja, o fenômeno calculado ocorre pelo mesmo motivo real.

\subsection{Medindo os caminhos de transferência de energia}

No TPA, a fonte e o receptor são considerados dois subsistemas diferentes, sistematicamente representados entre parte ativa e passiva respectivamente, conforme a figura 3.10 abaixo (Gajdatsy, Gielen, Janssens, Auweraer, Mas, \& Desmet, 2009). 


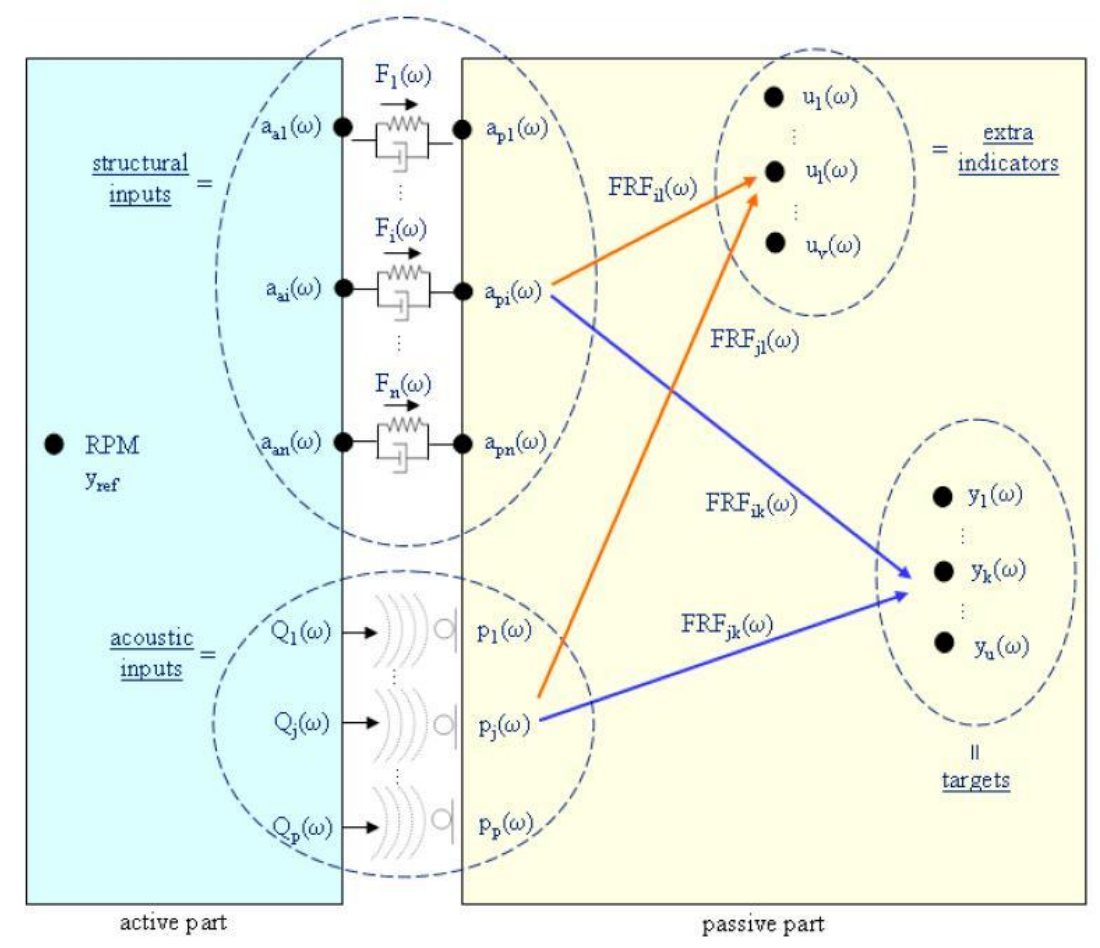

Figura 3.10: Representação de um sistema com parte ativa e passiva

Para uma análise dos caminhos estruturais, os dois subsistemas estão conectados através de um determinado número de conexões rígidas, chamado de caminhos de transferência. Independente do tipo de tração do veículo, é possível incluir na análise dos caminhos os suportes de motores, suportes de semieixos e cardãs, da transmissão, sub-quadro e sistema de escapamento. Caminhos secundários como batentes e coxim da alavanca de cambio também podem ser considerados (LMS, 1995).

Nos caminhos aéreos, a análise dos caminhos de transferência é, por exemplo, bocais dos sistemas de admissão e exaustão do motor, painéis em vibração no interior do veículo, ruídos irradiados no geral.

O TPA utiliza as funções de resposta de frequência entre o receptor e as entradas de carregamentos, forças ou velocidades de volume, aplicada nos diferentes locais de possível fonte de energia, e combina-os com os respectivos carregamentos locais, atuando sob condições operacionais. O receptor, nível de pressão sonora (ou nível de aceleração, se for o caso) durante as condições de operação é então explicado como uma superposição de resultados parciais, descrito pela contribuição dos caminhos de transferência individuais, conforme a equação (2) mencionada. 


$$
P(\omega)=\sum^{\text {Vias estruturais }} F(\omega)_{j} \cdot\left[\frac{P}{F}(\omega)\right]_{j}+\sum^{\text {Vias aéreas }} Q(\omega)_{k} \cdot\left[\frac{P}{Q}(\omega)\right]_{k}
$$

As funções de transferência vibroacústica podem ser medidos utilizando os procedimentos mais comuns como o uso de martelo ou um shaker. As funções de transferência acústica (de velocidade de volume à pressão) são medidas verificando a redução do ruído entre os subsistemas. As entradas operacionais (forças ou velocidades de volume) podem ser disponibilizadas por dados de medições ou simulações, comumente determinados por métodos indiretos. Portanto, os dados necessários são:

- Carregamentos operacionais, como por exemplo: forças, velocidade de volume, acelerações, pressões;

- FRF acústicos ou vibracionais, como por exemplo, mobilidade mecânica, inertância;

- Rigidez dinâmica de coxins, batentes, suportes e buchas, quando disponíveis.

Os dados operacionais abrangem muitos canais, normalmente mais do que uma medição convencional, por exemplo, de ruído. Como normalmente não se usa um trigger para sincronizar as corridas, é importante fazer as medições tendo em um dos canais, um sinal para referencia. Para aplicações em condições estacionárias, como velocidade constante, medições devem ser feitas usando espectro cruzado com um único canal de referência. Para aplicações não estacionárias, as medidas mencionadas podem ser processadas de forma a extrair um conjunto de ordem em função, por exemplo, o rpm do sinal do tacômetro.

As FRFs vibroacústicas são necessárias para que os caminhos de transferência destes carregamentos sejam conhecidos nas referências necessárias, e podem medidos de forma direta com uso de martelo ou pela excitação de um shaker, ou de forma recíproca usando uma fonte de velocidade de volume. Estas medições são normalmente realizadas desconectando as fontes (lado ativo) das referências (lado passivo). Uma direção de uma conexão é considerada um caminho de transmissão.

Medições de ruído e vibração, durante o levantamento dos carregamentos operacionais, não são mandatórios, mas importantes caso ainda não exista uma correlação entre os dados reais medidos e o calculado pelo TPA. Nesta correlação, devem ser verificados se 
os modelos de FRFs e dados operacionais são representativos, assim como se instrumentação realizada e os pontos considerados, são suficientes ao estudo (Silva, César Helou, 2010). Tempo de testes/análises e volume de dados são fatores relevantes no TPA e conforme já dito, nem todos os caminhos são importantes.

\subsubsection{Laboratório de Vibroacústica}

Em um laboratório de Vibroacústica, são realizados os testes de FRF de ponto (point mobility) e funções de transferência acústica para levantar as características estruturais dos pontos de ancoragem e sensitividade acústica da carroceria. Os dados obtidos podem ser usados para verificação da competição (benchmarking), levantamento de targets, comportamentos modais, identificação em avançado de possíveis deficiências na carroceria de protótipos e o próprio $T P A$.

Como exemplos, seguem algumas relações de respostas que podem ser obtidas em laboratório:

- Compliance dinâmico: deformação/excitação;

- Mobilidade mecânica: velocidade/excitação;

- Inertancia: aceleração/excitação

- Rigidez dinâmica: excitação/deformação

- Impedância mecânica: excitação/velocidade

Medir a FRF lado do passivo do subsistema é um elemento crítico na análise do caminho de transferência, pois na prática é a tarefa mais difícil de realizar. Entre os motivos, há uma grave falta de espaço físico entre o motor e a sua montagem, para colocar os transdutores de força. Teoricamente, o motor deve ser removido ao analisar o outro lado do sistema que recebe a energia. Uma abordagem pragmática é retirar o motor para ter acesso ao lado de montagem, diretamente na carroceria, para usar um excitador. Da mesma forma, a suspensão deve ser removida quando a medição de FRFs 
de carroceria relacionadas com o ruído de rodagem. Como exemplificação, as figuras 3.11 (a) e (b) são fotos tirados no laboratório de vibroacústica, onde se mostram as preparações que antecedem medições de FRFs em um veiculo.

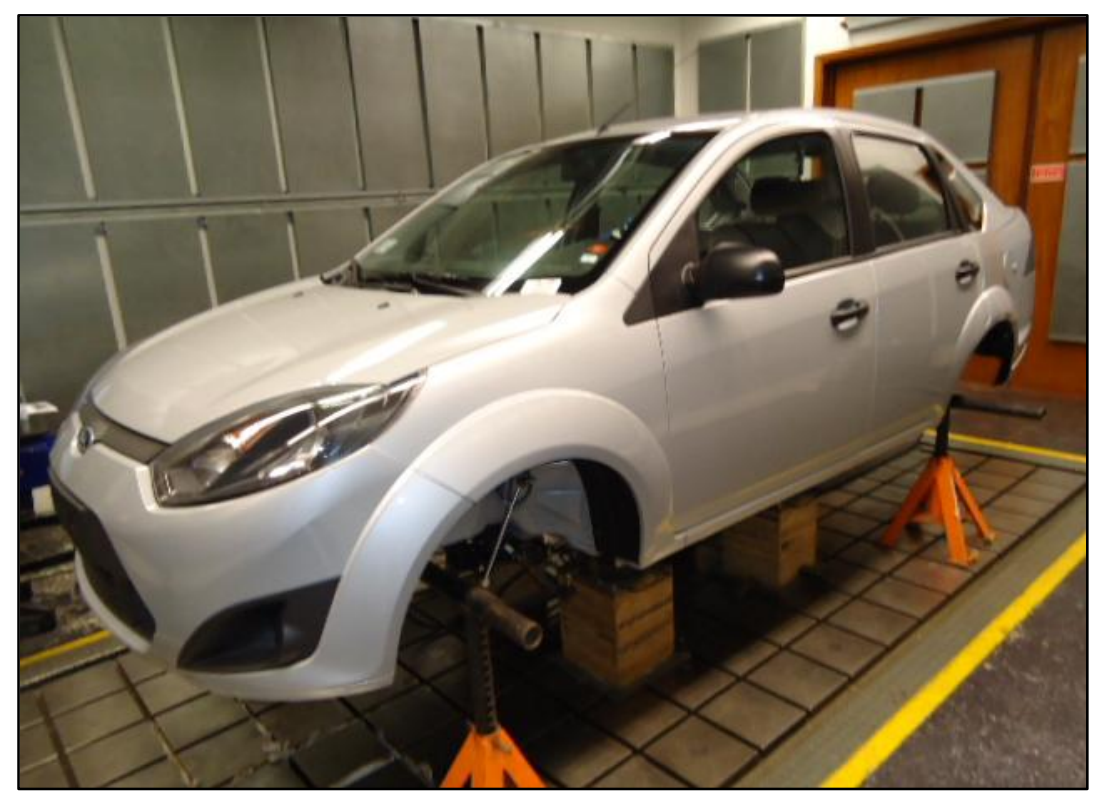

Figura 3.11 (a)

Para que não haja interferência de carregamentos na estrutura da carroceria, o teste deve ser realizado com os componentes do chassi removidos (roda, pneu e suspensão) e na condição livre-livre, utilizando colchões de ar ou qualquer outro artifício de suspensão, fazendo com que as frequências de corpo rígido sejam as mais baixas possíveis e não interfiram nos modos flexíveis da estrutura (McConnell, 1995).

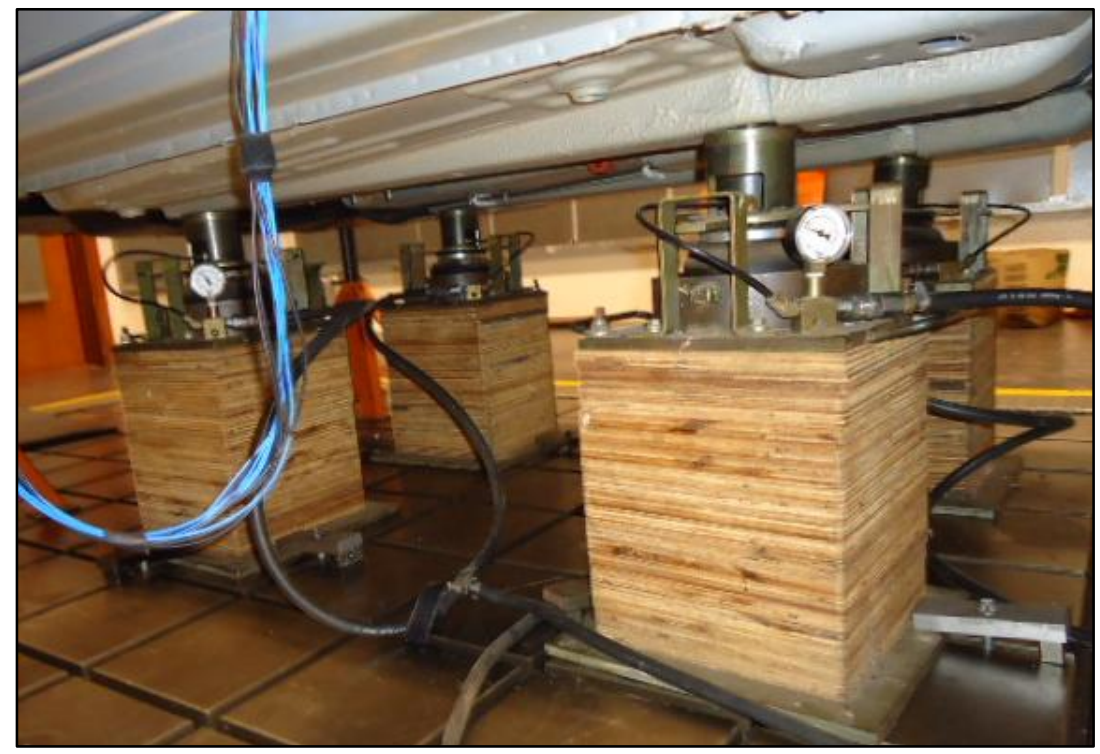

Figura 3.11 (b)

Figuras 3.11 (a) e (b): Ford Fiesta apoiado em colchões de ar - condição livre-livre de carregamento 
Conforme já mencionado, os testes que envolvem excitação no sinal de entrada podem ser realizados utilizando, por exemplo, um martelo, shaker, ou fontes acústicas. Especificamente para o martelo, podem ser utilizadas ponteiras de impactos de massa e rigidez variados, indicado na figura 3.12 como $\mathrm{m}_{1}$ (Mechanics, Society for Experimental), de acordo com a necessidade do espectro de frequência em investigação. Detalhes sobre as configurações e análises do estudo de caso deste trabalho serão apresentados no capitulo 4, a seguir.

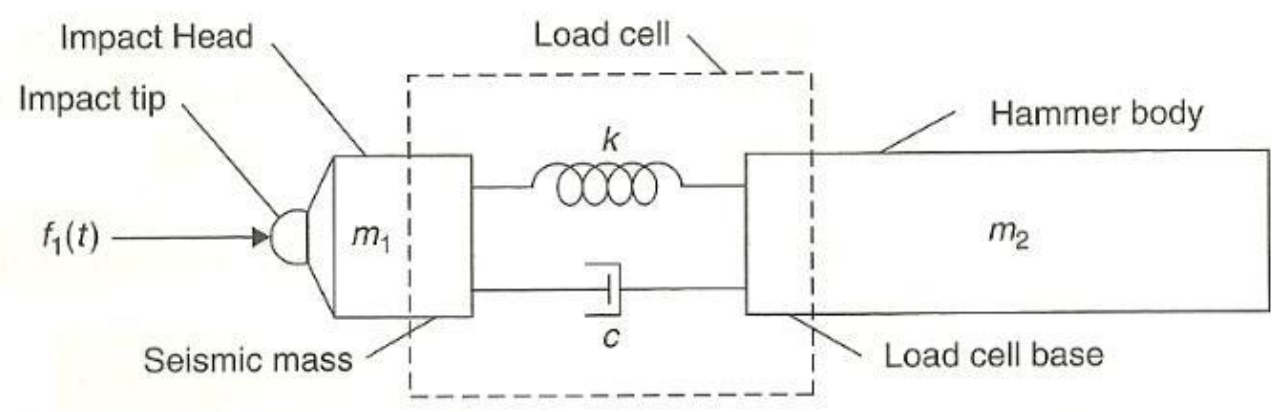

Figura 3.12: Esquema do martelo utilizado em testes de impacto

Por fim, nas figuras 3.13 (a) e (b), segue respectivamente um exemplo de FRF de ponto e sensibilidade acústica da carroceria, por em uma das entradas de força do sistema de escapamento na direção z, com o impacto do martelo também em z.

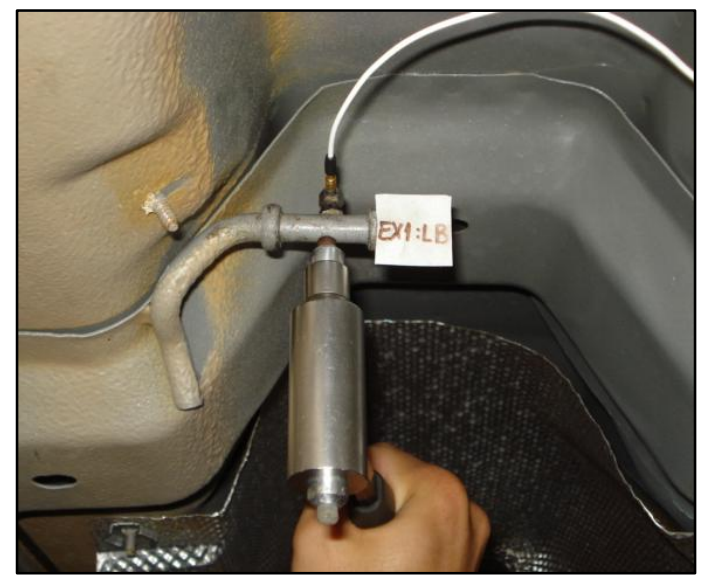

Figura 3.13 (a)

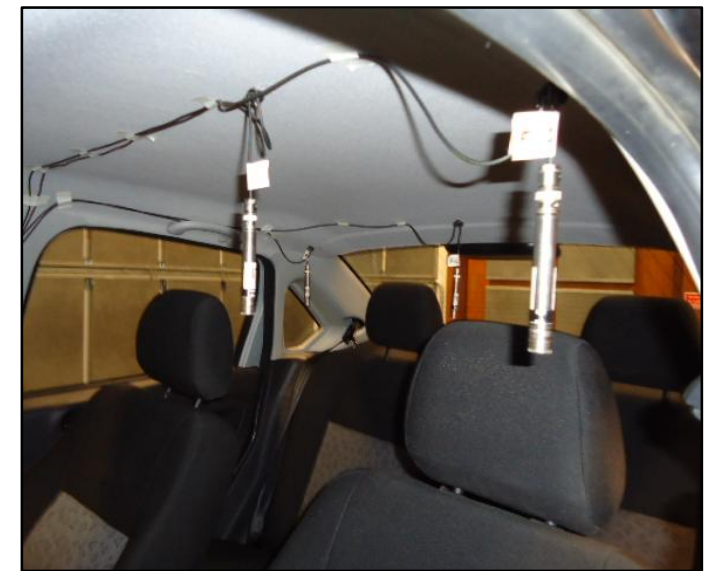

Figura 3.13 (b)

Figura 3.13 (a) e (b): Medições de FRFs 


\subsubsection{Testes em pistas, dinamômetros e bancadas}

Para os testes em pista, entram os carregamentos operacionais a serem usados com as respectivas FRFs. Neste momento, devem ser determinadas as condições de velocidade do veículo e quais texturas e severidades de pistas relevantes ao estudo.

Como exemplo de condições operacionais, as figuras 3.14 (a) e (b), fotos tiradas pelo autor em abril de 2011, são exemplos de níveis de macrotextura diferenciados, presentes na Rodovia Pres. Castelo Branco. Estas pistas produzem efeitos distintos de ruído de rodagem, sendo a primeira, menos rugosa, com predomínio do ruído de rodagem aéreo e a segunda, com predominância do ruído de rodagem estrutural. A mudança entre as superfícies, predomínio estrutural para o aéreo e vice versa, pode ser avaliada em ambos os sentidos da Rodovia Castelo Branco, próximo do km 79, conforme figura 3.15.

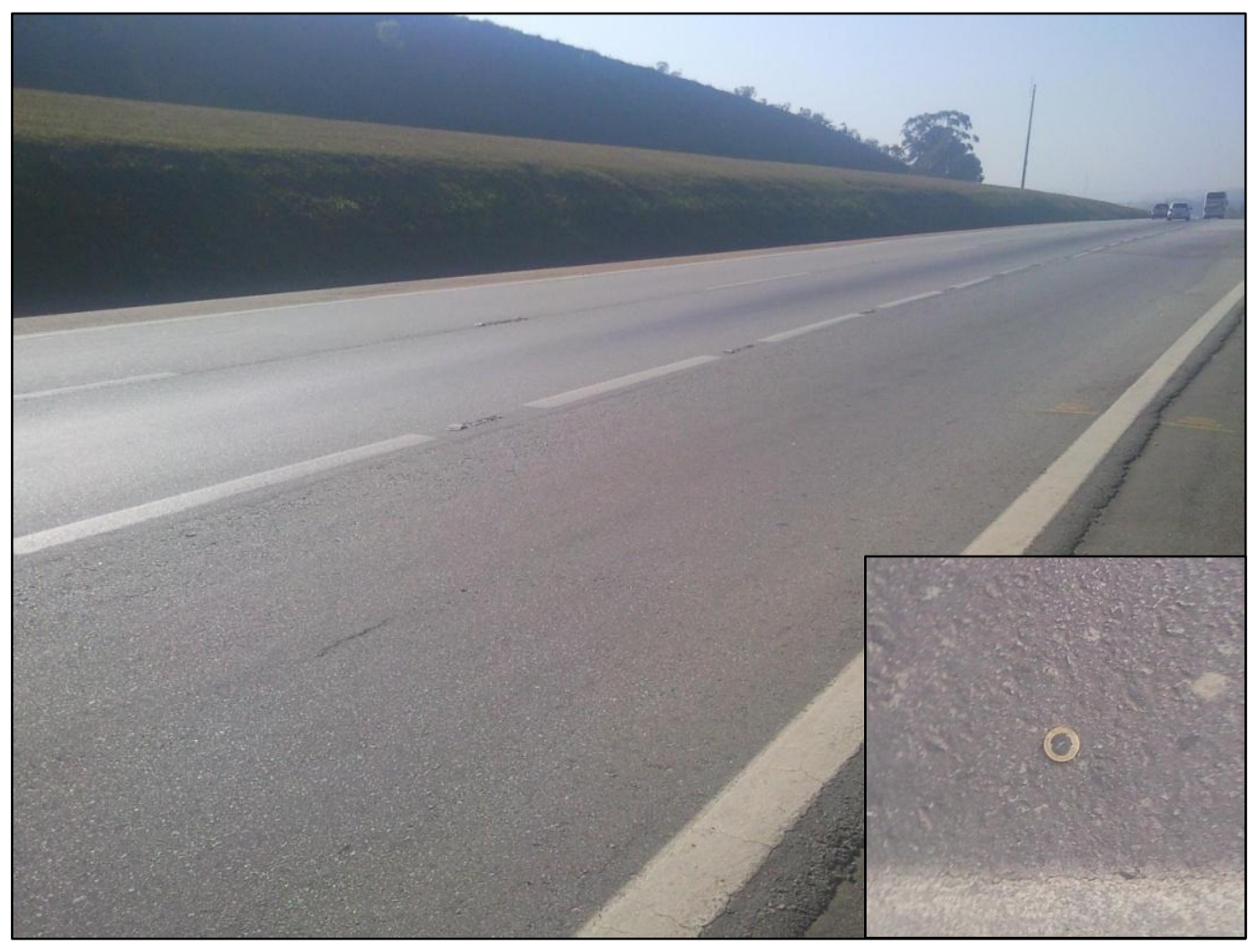

Figura 3.14 (a) 


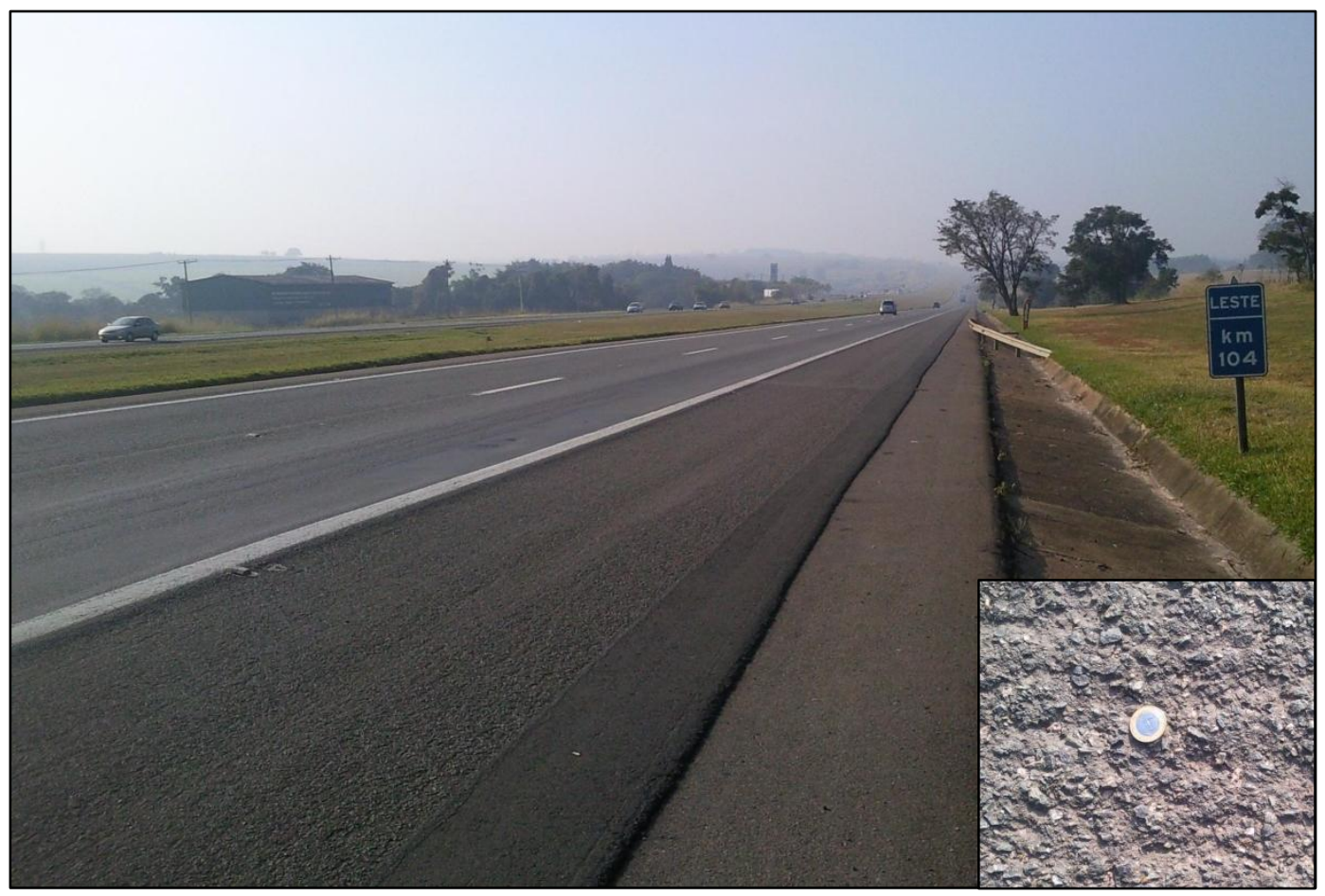

Figura 3.14 (b)

Figura 3.14 (a) e (b): Exemplos de superfícies com rugosidades e respostas de ruídos distintos, SP-280

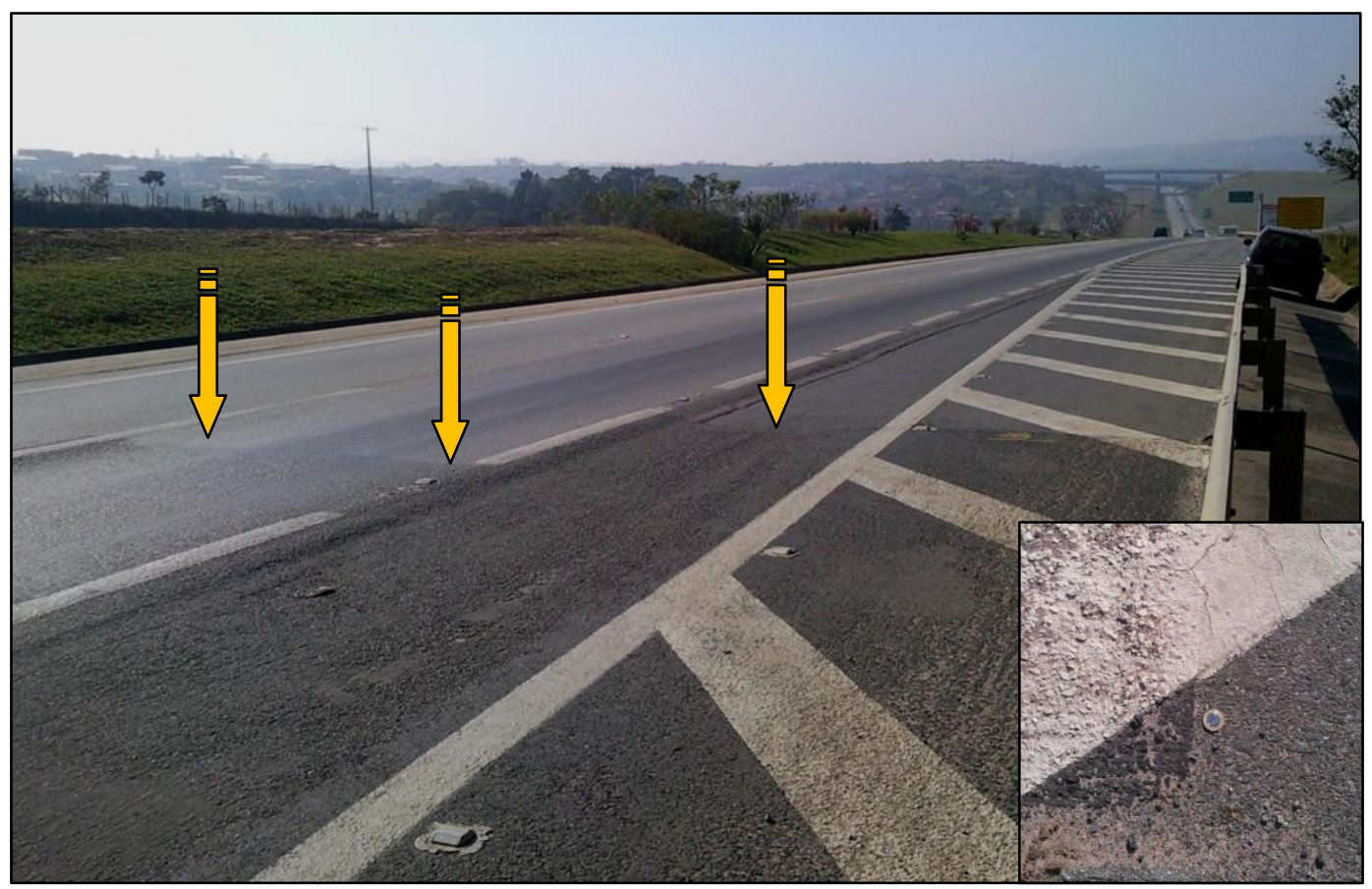

Figura 3.15: Mudança para superfície menos rugosa, SP-280, km 80, sentido São Paulo

Os carregamentos (força e velocidade de volume) podem ser obtidos de três maneiras básicas as quais definiram o método de TPA que será aplicado, além de determinar também o número de medições que devem ser feitas em laboratório. 
- Método direto - medição dos transdutores de força (nos pontos de interesse do veículo).

- Métodos indiretos, que se dividem basicamente em dois modelos:

- Método da Rigidez Complexa;

○ Método da Matriz Inversa.

Testes em dinamômetros são usados quando é necessário realizar uma medição com maior controle de condições de pista ou ambiente. No mesmo caminho, os testes de bancadas são normalmente usados para determinação individual das fontes acústicas e vibracionais, medidos, fora do veículo, sob condições especiais de controle de condição veicular e ambiente.

Nos exemplos ilustrados nas figuras 3.16 são apresentados alguns dos possíveis pontos de entrada de força em um veiculo de passeio, para medição das condições operacionais. Nas imagens, mostra-se a instalação de acelerômetros triaxiais nos lados ativo e passivo dos componentes da suspensão, para o calculo de entrada de força na bucha traseira da suspensão dianteira (a) e no batente da torre do amortecedor dianteiro (b).

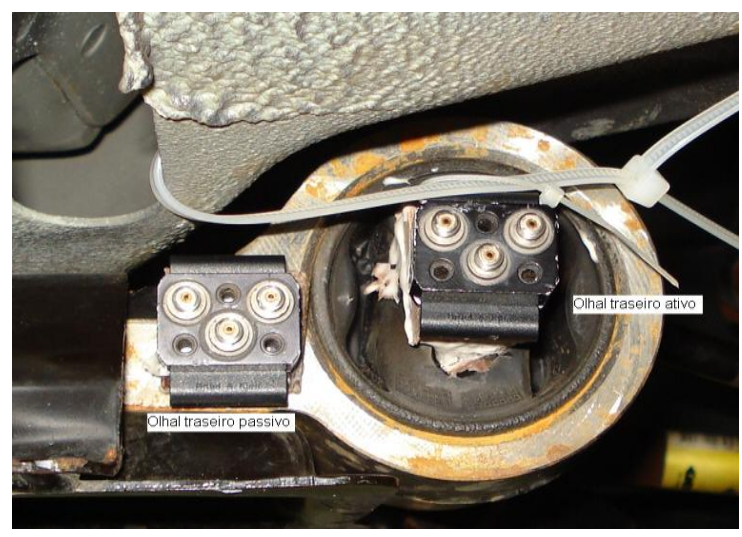

Figura 3.16 (a)

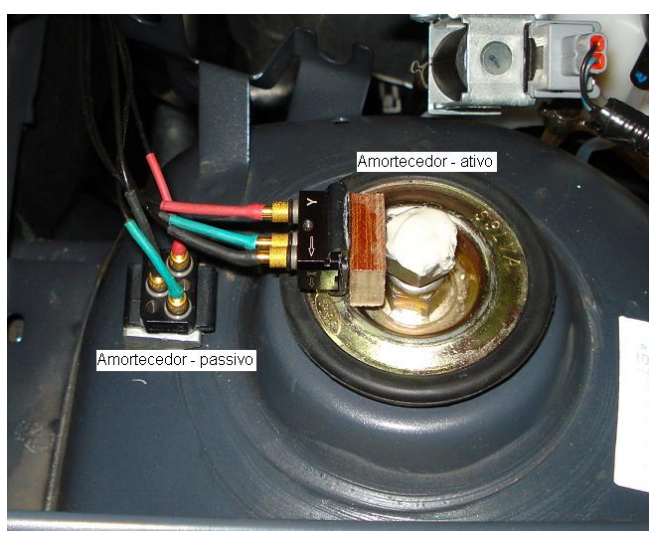

Figura 3.16 (b)

Figura 3.16 (a) e (b): Acelerômetros nos lados ativos e passivos das entradas de forças 


\subsection{Métodos para determinação das forças operacionais}

Existem diferentes métodos disponíveis hoje para o calculo das forças para as análises de TPA. As medições operacionais deverão quantificar o carregamento que as fontes deverão causar nos chassis e carrocerias. Basicamente, se dividem entre métodos diretos e indiretos, revisados a seguir:

\subsubsection{Método direto}

As medições diretas de força operacional por meio de transdutores de força são muito difíceis, devido à necessidade de desmontagem do veículo para acomodação de todo os suportes e sensores. Após a instalação, o comportamento dinâmico e as FRFs podem facilmente ser afetados, sem mencionar o investimento necessário para a compra e manutenção das células de carga exclusivas para a arquitetura de cada chassi.

Entretanto, este método ainda é usado nos testes de bancada e tem ganhado atenção nos ambientes de simulações, $C A E$, fornecendo dados de carregamentos operacionais e também de FRF. Trabalhos como o de Kim, Yang, Lee e Auweraer (Sung-Jong Kim, Hae-In Yang, Sang-Kwon Lee, 2009), (H. Van der Auweraer, 2007) já citam formulações hibridas de TPA, entre dados experimentais e virtuais. 


\subsubsection{Métodos Indiretos}

De maneira semelhante às dificuldades encontradas para acessar as FRFs na carroceria, as forças que operam normalmente devem ser estimadas a partir de técnicas indiretas, ao invés de ser medido diretamente. Duas abordagens alternativas, ambas muitas vezes usadas simultaneamente, podem ajudar: Método da Rigidez Complexa e o Método da Matriz inversa. Para alguns caminhos de transferência, o método da rigidez dinâmica complexa é recomendado, porém, para outros caminhos, nem sempre pode ser usado. Isto normalmente pode ocorrer porque a rigidez dinâmica do local analisado pode não estar disponível, ou o deslocamento operacional através da conexão é relativamente muito pequeno, ou mesmo porque simplesmente a conexão é rígida.

\section{Método da Rigidez Complexa}

Para os caminhos de transferência, onde o lado da fonte é conectado ao receptor através de coxins, as forças operacionais podem ser determinadas a partir do conhecimento da rigidez dinâmica complexa destes coxins $K(\omega)$ e pela deformação sofrida por este coxim durante a operação, usando a lei de Hooke (67). Os deslocamentos são geralmente obtidos integrando duas vezes as medidas de aceleração.

$$
\begin{gathered}
f_{i}=K(\omega) \cdot\left(X_{f}(\omega)-X_{r}(\omega)\right. \\
f_{i}=K(\omega) \cdot\left[\int \int \left(\ddot{X}_{f}(\omega) \cdot \mathrm{dtd} t-\iint\left(\ddot{X}_{r}(\omega) \cdot \mathrm{dtdt}\right]\right.\right.
\end{gathered}
$$

Onde: $f i(\omega)$ é a força operacional no caminho da transferência i;

$K(\omega)$ é a rigidez dinâmica complexa em função da frequência;

$\mathrm{X}_{\mathrm{r}}(\omega)$ é o desloc. operacional no ponto de conexão do lado receptor;

$\mathrm{X}_{\mathrm{f}}(\omega)$ é o desloc. operacional no ponto de conexão do lado da fonte.

No domínio da frequência, a equação 68 é expressa como: 


$$
f_{i}=K(\omega) \cdot\left[\frac{1}{\omega^{2}} \ddot{X}_{f}(\omega)-\frac{1}{\omega^{2}} \ddot{X}_{\mathrm{r}}(\omega)\right]
$$

No método da rigidez dinâmica complexa, é importante medir o deslocamento operacional colocando os acelerômetros tão perto quanto possível os pontos de dos coxins, centro elástico. Se a medição ocorrer a certa distancia deste centro, os sinais de aceleração farão leituras com adição de Momentos, em frequências mais altas.

Os dados de rigidez dinâmica complexa deverão estar disponíveis como dados complexos em função da frequência, ou seja, magnitude e fase de vibração. Ao avaliar a rigidez dinâmica do coxim é importante considerar a pré-carga o mais próximo possível das condições operacionais reais. Além disso, também é importante considerar a temperatura mais próximo possível de temperatura de trabalho.

\section{Método da Matriz Inversa}

O método de inversão da matriz, também conhecido como Matriz de Inertância ou Acelerância, é usado para os caminhos de transferência que possuam conexões rígidas, ou onde a rigidez dos coxins é consideravelmente maior em relação à impedância do ponto de fixação na carroceria ou chassi. Neste caso, a técnica é baseada na obtenção de um conjunto de FRFs, acelerações ou velocidades, medidos entre a resposta estrutural no lado passivo e a força de excitação do martelo. Estas acelerações ou Matriz de impedância devem ser previamente medidas com as fontes desconectadas, no laboratório. Este conjunto de dados forma uma matriz que ao ser invertida e multiplicada pela vibração operacional das pistas, no lado passivo das conexões, resultam nas forças de entrada. Essa matriz é então combinada com medidas operacionais de vibração das estruturas no lado passivo, receptor, a fim de estimar os dados de forças. O uso do método de decomposição em valores singulares ajuda a minimizar problemas numéricos causados pela inversão de matriz (Katrien Wyckaert, Herman Van der Auweraer, 1995). É aconselhável medir uma matriz de acelerações completa (70), mas em alguns casos como mesmo será visto neste estudo de caso, é aceitável desconsiderar alguns efeitos de acoplamento cruzado. Para os dados de 
acelerância cruzada descartados, assume-se o valor zero no acoplamento transversal conforme visto na equação (71):

$$
\begin{aligned}
& \left\{\begin{array}{l}
f_{1} \\
\ldots \\
f_{\mathrm{n}}
\end{array}\right\}=\left[\begin{array}{cccc}
\frac{\ddot{X}_{11}}{F_{1}} & \frac{\ddot{X}_{12}}{F_{2}} & \ldots \frac{\ddot{X}_{1 n}}{F_{n}} \\
\frac{\ddot{X}_{21}}{F_{1}} & \frac{\ddot{X}_{22}}{F_{2}} & \ldots & \frac{\ddot{X}_{2 n}}{F_{n}} \\
\frac{\ddot{X}_{m 1}}{F_{1}} & \ldots & \ldots \frac{\ddot{X}_{m n}}{F_{n}}
\end{array}\right]^{-1}\left\{\begin{array}{l}
\ddot{X}_{1} \\
\ddot{X}_{2} \\
\ddot{X}_{\mathrm{m}}
\end{array}\right\} \\
& \left\{\begin{array}{l}
f_{1} \\
\ldots \\
f_{\mathrm{n}}
\end{array}\right\}=\left[\begin{array}{cccc}
\frac{\ddot{X}_{11}}{F_{1}} & 0 & \ldots & 0 \\
0 & \frac{\ddot{X}_{22}}{F_{2}} & \ldots 0 \\
0 & \ldots & \ldots & 0 \\
\ddot{X}_{m n}
\end{array}\right]^{-1}\left\{\begin{array}{l}
\ddot{X}_{1} \\
\ddot{X}_{2} \\
\ddot{X}_{\mathrm{m}}
\end{array}\right\}
\end{aligned}
$$

Onde: $\left\{\begin{array}{l}\ddot{X}_{1} \\ \ddot{X}_{2} \\ \ddot{X}_{\mathrm{m}}\end{array}\right\}$ é o vetor das acelerações operacionais no lado passivo;

$\frac{\ddot{X}_{\mathrm{ij}}}{F_{\mathrm{j}}}$ é a medição do FRF de aceleração/força entre a aceleração do ponto i e a aceleração do martelo aplicada no caminho j.

\subsection{Métodos para determinação das velocidades de volume operacionais}

Caminhos aéreos de transferência são quantificados por suas velocidades do volume operacionais. Essas velocidades de volume são estimadas a partir de técnicas indiretas, de forma similar às forças operacionais.

Três técnicas estão disponíveis: Amostragem de superfície ponto a ponto, Medições de intensidade sonora e Inversão de matriz. O primeiro método é usado para determinar as 
contribuições de vibração dos painéis. O segundo método pode ser usado para determinar as contribuições aéreas como, por exemplo, ruído irradiado do motor. Uma aplicação típica de inversão de matriz seria a quantificação do ruído de admissão e escapamento.

\section{Amostragem de Superfície Ponto-a-ponto}

Esta técnica permite que a velocidade do volume seja varrida de uma amostra de superfícies radiantes. A ideia é que a aceleração medida em um determinado ponto normal à superfície $\mathrm{S}$ represente um perfil de aceleração (constante) que pode ser usado em uma área determinada, para desta maneira, quantificar o volume de aceleração dessa superfície. Isto requer a divisão da superfície irradiada total em superfícies individuais. A aceleração do volume de cada uma dessas amostras de superfícies $S_{j}$ é calculada como:

$$
\dot{q}_{j}=S_{j} \cdot \ddot{X}_{j n}
$$

A velocidade de volume pode ser calculada fazendo a integral da aceleração do volume. Nos cálculos, o contínuo ruído irradiado da fonte deve ser dividido em caminhos. Uma recomendação que se faz é que a dimensão das partes deve ser menor do que o menor comprimento de onda acústica de interesse, dividido por 2. O tamanho das partes manchas depende, assim, a gama de frequências.

Esta técnica é frequentemente chamada de Painel de Análise de Contribuição porque é principalmente utilizado para identificar as contribuições de vibrar painéis em uma cavidade de carro (P.J.G. van der Linden, Ph. Varet, 1996).

\section{Medições de intensidade sonora}

Sob condições estacionárias, medições de intensidade de campo-próximo nas podem ser realizados na fonte em uma sala anecóica. O que se obtêm é uma estimativa de potência sonora da fonte, colocados em condições de ambiente sem reflexões de som. A partir desta potência sonora, estima-se, de sua derivada, a velocidade de volume (sem fase) da 
fonte. Assume-se que a velocidade de volume da fonte é invariável com a mudança de condições de contorno acústico no ambiente. A partir de medições da intensidade, podese obter a intensidade média de uma superfície de medição $\mathrm{S}$ em torno da fonte. $\mathrm{A}$ intensidade média é dada pelo tempo médio do produto de pressão sonora e velocidade da partícula:

$$
\vec{I}=\frac{1}{T} \int_{0}^{T} p(t) \cdot \vec{v}(t) d t
$$

A superfície $S$ também é dividida em m subáreas $S_{j}$ que são considerados como fontes parciais. Integrando o produto escalar do vetor de intensidade média e do vetor normal ao longo de uma subárea $S_{\mathrm{j}}$, leva à potência sonora daquela sub-área $S_{\mathrm{j}}$ :

$$
\text { Pow }_{\mathrm{J}}=\int_{\mathrm{Sj}} \vec{I} \cdot \overrightarrow{\mathrm{n}} \mathrm{dS}
$$

Esta potência sonora Pow $_{\mathrm{j}}$ é obtida como resultado do módulo de intensidade.

Com esta proposta de que a fonte de radiação pode ser substituída por uma fonte monopolo irradiante no espaço livre, segue relação pode ser utilizada:

$$
Q_{\mathrm{J}}^{2}=\operatorname{Pow}_{j} \frac{4 \pi c}{\rho \omega^{2}} \frac{1}{C}
$$

Neste método, não há informações fase associada com a intensidade da fonte $\left(Q^{2}\right.$ é calculado). Para baixas frequências, este método tem suas limitações.

Quando a proposta de se usar fontes monopolos de irradiação no espaço livre não funciona mais, um fator $\mathrm{C}$ é introduzido e é determinado pelo engenheiro: o padrão é 2 (monopolo radiante na metade do espaço, a situação mais comum).

\section{Inversão da matriz}

Inversão de matriz pode ser usada para estimar indiretamente a velocidade do volume de um caminho de superfície de radiação. Certo número de respostas de indicadores de pressão sonora é medido próximo á superfície de radiação, em condições de operação. Funções de transferência de campo-próximo, entre as pressões no indicador nestas 
posições e as velocidades de volume na superfície de radiação, são processadas para calcular a velocidade do volume operacional dos caminhos da superfície radiante. Este é representado visualmente na figura 3.17. A matriz função transferência é medido reciprocamente, colocando auto - falantes no lugar dos microfones indicadores, e os microfones colocados no lugar das superfícies em estudo.
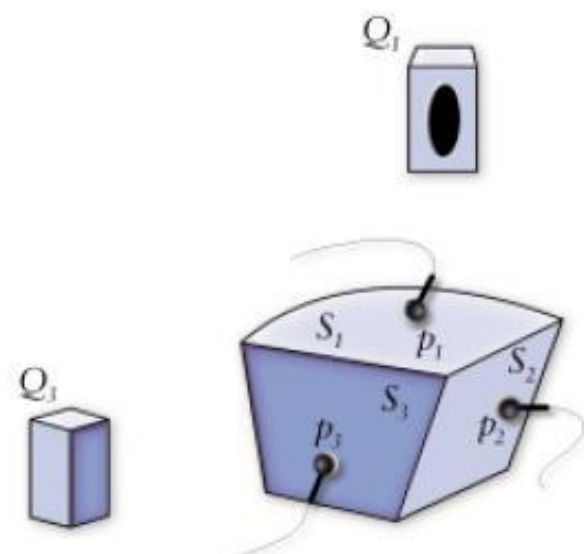

$\left|H_{i j}\right|=\frac{p_{i}}{Q}$

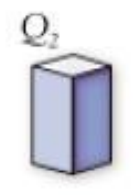

Figura 3.17: Medição da Função transferência Inversa

Nas equações (76) (77) a anotação “oper” representa quantidades em condições de operação. A função $P_{\mathrm{j}} / Q_{\mathrm{I}}$ é a função transferência entre a velocidade do volume medido no caminho i e a pressão no microfone j. Estas funções de transferência são normalmente medidas de forma recíproca, colocando o alto - falante no local j, o microfone na posição i. Colocando o alto-falante na localidade i, próximo à superfície, normalmente é impossível.

$$
\begin{gathered}
{\left[\begin{array}{c}
Q_{1}^{\text {oper }} \\
\ldots \\
Q_{n}^{\text {oper }}
\end{array}\right]=\left[\begin{array}{ccc}
\frac{P_{1}}{Q_{1}} & \cdots & \frac{P_{1}}{Q_{n}} \\
\ldots & \cdots & \ldots \\
\frac{P_{m}}{Q_{1}} & \cdots & \frac{P_{m}}{Q_{n}}
\end{array}\right]^{-1}\left[\begin{array}{c}
P_{1}^{\text {oper }} \\
\ldots \\
P_{m}^{\text {oper }}
\end{array}\right]} \\
P_{r}^{\text {oper }}=\sum_{i=1}^{n} \frac{P_{r}}{Q_{i}} Q_{i}^{\text {oper }}
\end{gathered}
$$

A inversão da matriz é melhorada pela sobre - determinação, isto é, tendo o número de pressões indicador $(\mathrm{m})$ maior que o número equivalente de fontes de velocidade de volume (n). Esta técnica é exatamente a mesma que a inversão de matriz utilizada para determinar as forças operacionais. 


\subsection{Validação do modelo}

Como em todos os modelos experimentais, a precisão dos resultados do TPA depende da precisão dos dados obtidos. Isto significa ter cuidados com as aquisições dos dados operacionais, a qualidade das medições de função de transferência, e caso também seja usado, a qualidade nos dados para o método da rigidez complexa dinâmica dos elementos de coxinização.

A verificação final do TPA é feita por uma análise de contribuições para o receptor. Os resultados são confiáveis quando as somas de contribuições de todos os caminhos correspondem em grande parte aos níveis reais medidos no mesmo receptor.

Certamente, quando o receptor foi medido várias vezes (por exemplo, em um número de corridas de medição consequênciais) uma ideia pode ser formada sobre a coerência entre os conjuntos de dados e uma estimativa de variabilidade do nível do receptor. Se o cálculo e as contribuições medidas não corresponderem bem, isso pode ser ocasionado devido à qualidade dos dados. Mas isso também pode ocorrer porque o receptor é afetado por fontes (ou os caminhos mais prováveis, transferência), que não foram considerados na análise inicial. Normalmente, esses caminhos poderiam ser aéreos, ou, por exemplo, em teste em rodovias, o ruído de rolagem ou aerodinâmicos que afeta o nível de ruído total no receptor. Portanto as condições de contorno dos testes operacionais devem ser consideradas com cuidado. 


\subsection{TPA de Múltiplas referências - Road TPA}

As técnicas de TPA não são apenas aplicáveis para uma única fonte coerente (como, por exemplo, o ruído do motor), mas também para várias fontes parcialmente correlacionadas (como, ruído de rodagem induzido em um carro) (Katrien Wyckaert, Herman Van der Auweraer, 1995).

Assim para resolver problemas de ruído de rodagem estrutural, é importante entender como os carregamentos da rodagem, pelas quatro rodas, são transmitidos pelos componentes da suspensão e através das buchas e batentes do veículo. As entradas de cada roda são filtradas de formas diferentes, dependendo da dinâmica das funções transferências, o que influencia os caminhos de transmissões e estimula a problemas de ressonância.

Quando múltiplas fontes parcialmente correlacionadas estão ativas em um sistema, um processamento em espectro cruzado de múltiplas referências das medidas operacionais é necessária. Uma fonte totalmente não correlacionada pode ser separada das outras fontes, por meio de medições de espectro cruzado á uma única referência - fazendo a medição de referência a um ponto que é descritivo para o comportamento de origem. Em muitos casos, no entanto, é muito difícil encontrar uma localização adequada do sensor de referência e, certamente, onde as fontes não são totalmente não correlacionadas, mas parcialmente correlacionadas, ou fisicamente não muito bem separados.

As entradas de força das rodas estão sempre parcialmente correlacionadas, com um grau de correlação em função das características da superfície da pista. Portanto as medições de múltiplas referências, em espectro cruzado, são necessárias para descrever um problema de ruído de rodagem corretamente. O número de referências deve ser maior que o número de fontes ativas a ser quantificado. 
As técnicas clássicas de TPA podem ser usadas para uma análise da contribuição do problema do ruído interior, quando o caso a ser investigado de múltiplas fontes puder ser descrito adequadamente. No entanto, as medições de múltiplas referências de espectro cruzado não podem ser usadas diretamente em uma análise do caminho de transferência. - são necessários técnicas de decomposição da referência multi-espectro cruzado. Não é só o ruído induzido de rodagem induzida que possui um caráter de múltiplas referências. Outros problemas também podem ser enfrentados através de uma abordagem de múltiplas referências, por exemplo, no estudo do efeito combinado de compressores de ar condicionado e barulho do motor.

\subsubsection{Técnicas de coerência parcial}

No passado, as técnicas de coerência parcial têm sido utilizadas para quantificar as contribuições de cada fonte de entrada ou de rodas para a pressão interior do carro. No entanto, devido ao caráter parcialmente correlacionado dos carregamentos entre as rodas, as técnicas de coerência parcial dão origem a uma superestimação da importância da primeira roda de entrada na análise e, consequentemente, a subestimação das entradas de outra roda. Além disso, o resultado das técnicas de coerência parcial, fortemente depende da sequência em que as referências são eliminadas. Esta não é a forma mais adequada de decompor o conjunto de múltiplas referências em espetro cruzado. 


\subsubsection{Análise virtual de coerência}

A análise de coerência virtual é uma técnica baseada na "decomposição de valores singulares", usada para decompor um conjunto de dados parcialmente correlacionados nos seus componentes constitutivos ortogonais ("os componentes principais"), conforme visto na figura 3.17 (LMS, 2010). Os sinais de espectro cruzado entre outros pontos medidos podem ser processados hora uma única referencia de espectro cruzado com relação a estes componentes principais. Esta referencia de espectro cruzado é chamado de "espectro cruzado virtual". Quando é dimensionado cada um dos espectros cruzados com seu correspondente autoespectro, isso resulta em um espectro de referencia chamado de Espectro virtual de referencia.

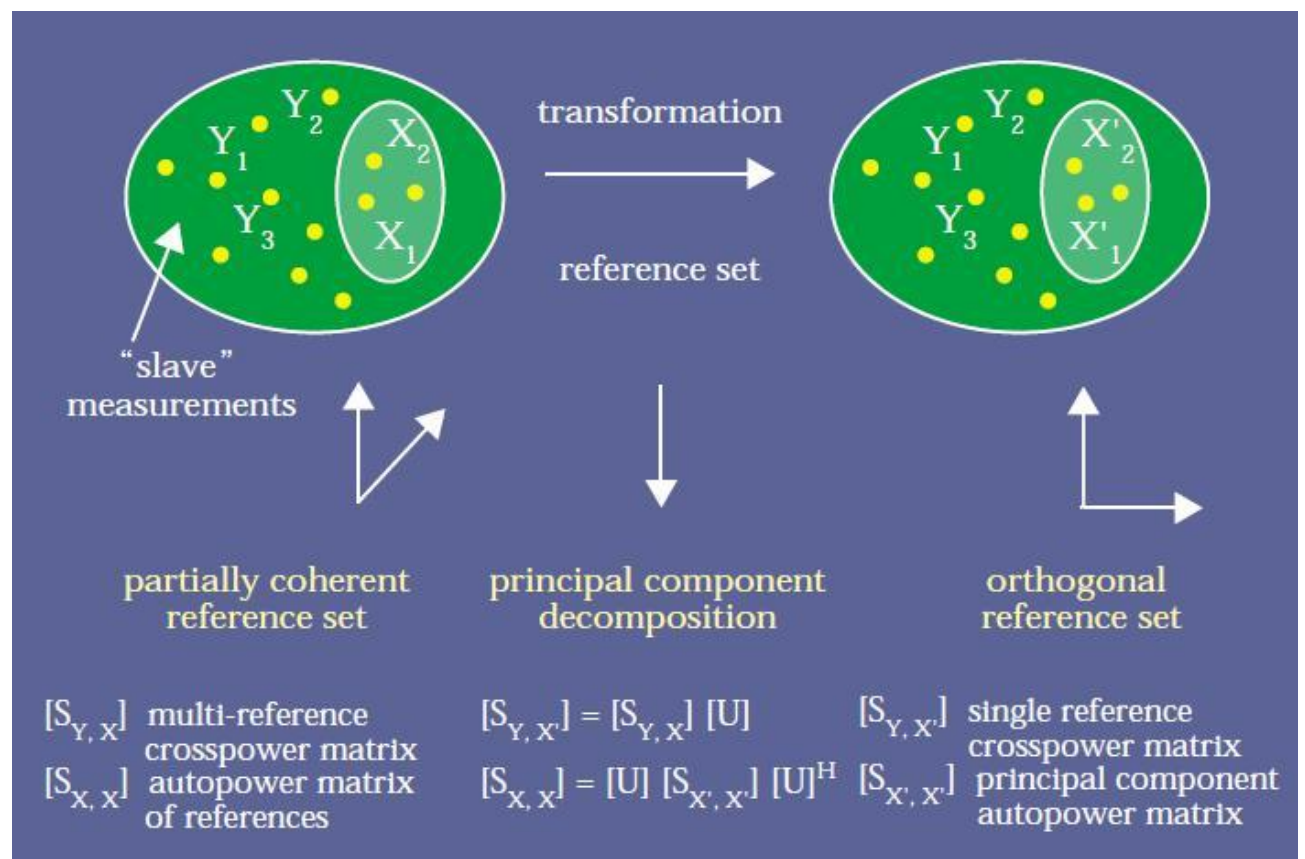

Figura 3.18: Transformação em referencia ortogonal parcialmente coerente

Essencialmente, o processo decompõe o problema de múltiplas referências em um número de casos mutuamente independentes e de referência única, sendo que cada referencia descreve uma parte do problema total. Estes dados de única referência podem ser usados como dados de entrada para a análise do caminho de transferência. As contribuições destes caminhos podem ser determinadas para cada um dos componentes 
principais, porque as fases entre os caminhos de transferência ainda existem. Assim, para avaliar o efeito global de um caminho, devem-se somar os valores em rms para combinar a contribuição de cada componente principal e independente, como apresentado na figura 3.19 (LMS, 2010).

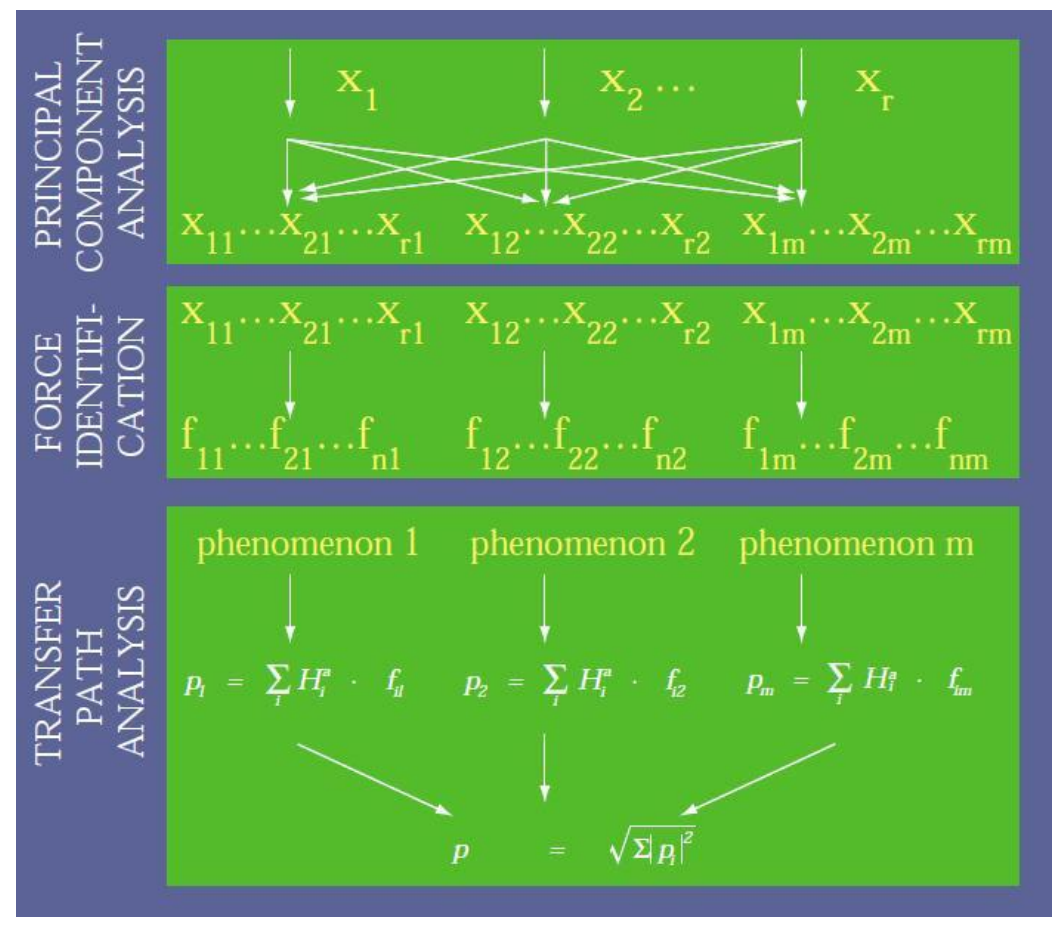

Figura 3.19: Formação do TPA

\subsubsection{Análise de Componentes Principais:}

Para demonstrar a terminologia de um espectro cruzado virtual com multiplas referências de medições cruzadas, os dados são condensados em duas matrizes: A matriz de auto espectro das referências e matriz de espectro cruzado das respostas, em relação a uma referencia. A matriz de auto espectro de referencia é decomposta pela decomposição dos valores singulares em suas ortogonais independentes, ou componentes principais da matriz de autoespectro:

$$
\left[S_{X, X}\right]=[U] \cdot\left[S_{X^{\prime}, X}\right] \cdot[U]^{H}
$$


A matriz de autoespectro do componente principal é uma matriz diagonal. Os componentes principais são ortogonais com relação ao outro. Ele representa o conjunto de novas referências ortogonais, ou o conjunto de referências virtuais independentes. A matriz cruzada pode ser transformada em um conjunto de (referência única) espectro cruzado, com relação a este conjunto de novas referências ortogonais virtual. Isso dá: por:

$$
\left[S_{y, x^{\prime}}\right]=[U] \cdot\left[S_{y, x}\right] \cdot[U]
$$

\section{Coerência virtual}

A coerência virtual reflete a coerência de cada uma das referências e respostas com relação as referências ortogonais virtuais. Para uma resposta j e um componente principal i, a coerência virtual é definido como:

$$
\gamma_{j i^{\prime}}^{2}=\frac{S_{j i \prime}^{2}}{S_{j j} S_{j^{\prime} j^{\prime}}}
$$

\section{Coerência de autopower}

O AutoPower coerente é o AutoPower das referências e as respostas como originalmente medido, multiplicado pela coerência correspondentes virtual: é a parte do AutoPower de uma referência ou uma resposta que seja coerente com um componente principal dado.

$$
\gamma_{j i}^{2} \cdot S_{j j}
$$




\section{Capítulo 4}

\section{Modelo experimental e resultados}

Neste capitulo será apresentado os dados do modelo experimental do protótipo, o cenário do estudo de caso em que se originam as investigações e a aplicação do TPA. $\mathrm{Na}$ sequência, são apresentados os equipamentos e instrumentações utilizados, procedimentos de testes e resultados obtidos. Por fim, são apresentados propostas para atenuação do ruído de rodagem na faixa de rumble.

\subsection{0 estudo de caso}

Entre diversos modelos de pneus avaliados em um protótipo, um modelo em especifico é identificado como responsável pelo aumento considerável no ruído de rodagem interno do veículo. Este modelo de pneu é batizado de "Pneu A" e servirá como ponto de partida do estudo de caso deste trabalho.

Através das avaliações subjetivas preliminares, o ruído de rodagem, causado pelo jogo de "Pneus A", é classificado como um rumble, termo em inglês para caracterizar um ronco ou rumor de rodagem. Como analogia a este ruído, pode-se dar o exemplo de ruído de rolamento de cubo de roda com defeito, em um veículo de passeio qualquer. No caso deste estudo, o rumble provoca um desbalanceamento do ruído de rodagem em relação às demais fontes sonoras do protótipo (motorização e vento). 
Assim, a motivação para o estudo está em entender e evitar a ocorrência do ruído, rumble, garantindo o mesmo balanço entre fontes sonoras, independente do modelo de pneu montado.

Este cenário propicia um estudo real para aplicação do TPA, em uma condição hipotética de configuração de pneu e veículo. Os resultados obtidos não representam dados de veículos de produção ou modelos futuros.

\subsubsection{Condições críticas para o rumble}

Inicialmente, compara-se o pneu "A" com outros dois pneus, aleatoriamente batizados de "B" e "C", em uma pista de baixa rugosidade (lisa), em um ambiente controlado pistas padronizadas de um Campo de Provas Veicular. Outras classificações de superfícies serão apresentadas na sequência para demonstração do rumble do pneu sob maior condição de forças. Estes nomes serão mantidos como referencia para os mesmos modelos de pneus e pavimentos ao longo deste trabalho. Os detalhes técnicos que qualificam as superfícies não serão abordados nesta dissertação, porém para fins didáticos, será usado as referências de textura, supracitadas no capitulo 2.

A figura 4.1 apresenta o nível de pressão sonora medido no interior do protótipo, na posição do ouvido externo do motorista. A pista Lisa é a primeira e também a mais critica ao rumble. A velocidade é de $20 \mathrm{~km} / \mathrm{h}$ e constante para os três diferentes modelos de pneus ilustrados a seguir. Em evidencia na cor vermelha, a versão batizada de "Tire A", mostra um acréscimo de aproximadamente $10 \mathrm{~dB}(\mathrm{~A})$ em torno da frequência de $170 \mathrm{~Hz}$ á $180 \mathrm{HZ}$, em relação aos demais modelos de pneus. Na sequência de pistas avaliadas a seguir, serão demonstradas as respostas dos ruídos de rodagem com o aumento das forças de entrada nos pneus, causados pelos pavimentos com diferentes texturas. 


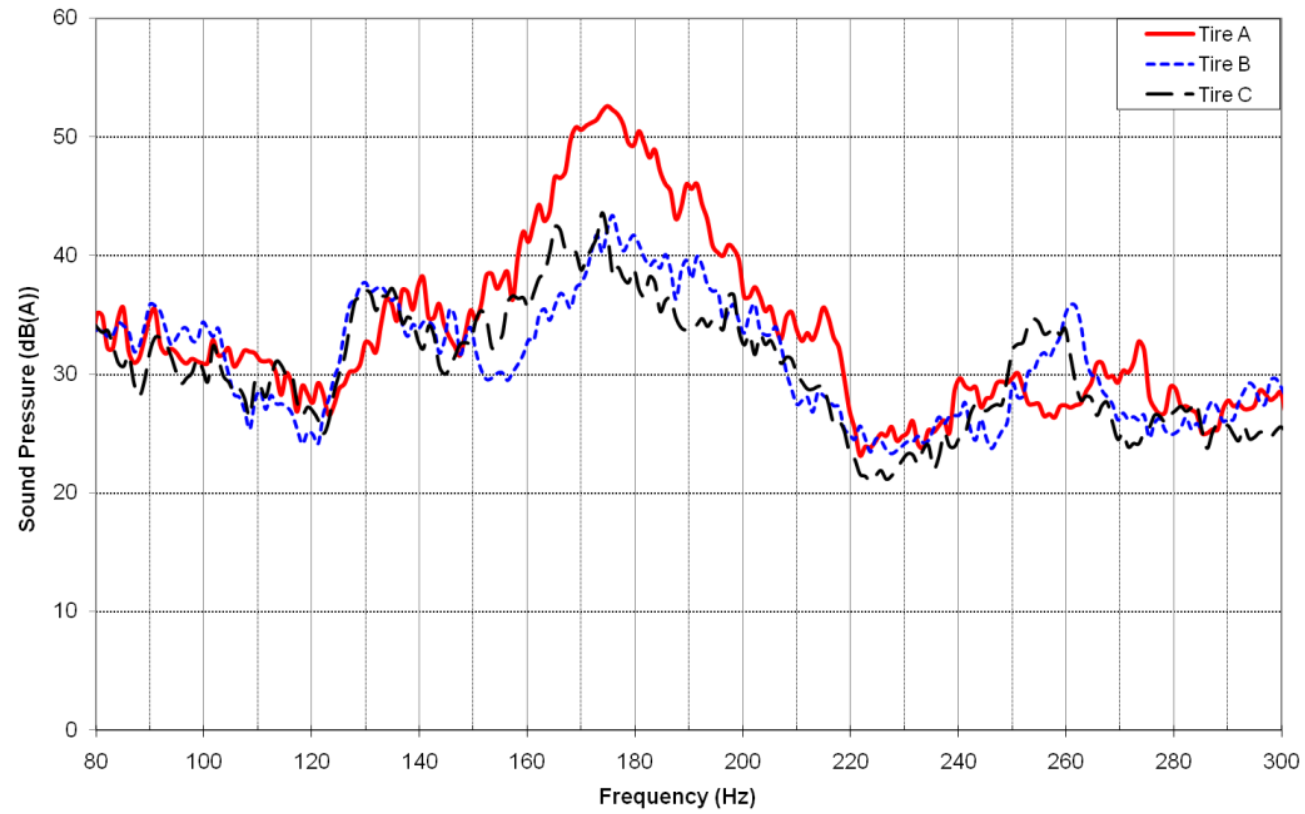

Figura 4.1: Pressão sonora no interior do veiculo para três modelos de pneus, pista Lisa á $20 \mathrm{~km} / \mathrm{h}$

Conforme a definição revisada no capitulo 2, partes dos ruídos estão relacionados ás características construtivas do veículo e permanecem fixas a uma determinada frequência. Outros são dependentes da velocidade do veículo e, em geral, estão relacionados às características dos pneus. A figura 4.2 a seguir, demonstra as mesmas condições de medições de ruído para o pneu "A" em pista Lisa, porem em diversas velocidades do protótipo.

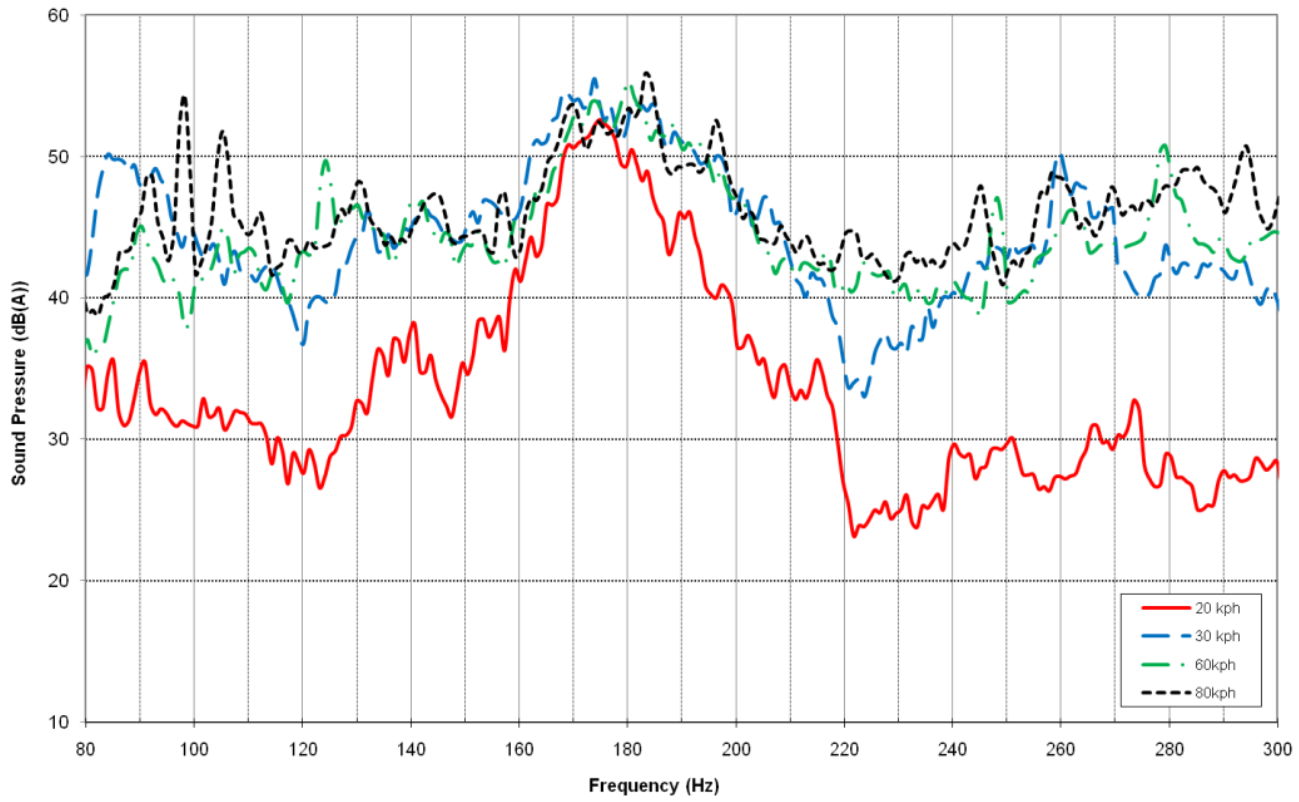

Figura 4.2: Ruído interno com o pneu "A" em diversas velocidades, pista Lisa 
Como primeiro direcional do caso e motivação, este ruído de banda estreita não é dependente da velocidade. Porém, mesmo que esta característica seja do protótipo, este efeito só ocorre quando pneu modelo "A" é utilizado. O rumble é perceptível em pista Lisa e baixa velocidade. Deve-se agora entender se esta diferença entre os pneus é a mais critica ao variar o tipo de pavimento, ou seja, o nível de textura e consequentemente, a força de reação nos pneumáticos.

Realizando a investigação em uma pista um pouco mais áspera, porém sem ondulações ou descontinuidades, novamente o pneu "A" é testado e comparado apenas com o pneu "B", para referencia, a $50 \mathrm{~km} / \mathrm{h}$. Na figura 4.3 ambos os modelos resultam em nível de ruído próximos, porém o pneu "A" ainda apresenta maior rumble em relação ao "B". No geral, para pista Áspera, ambos o modelos causaram maior ruído do que o medido na pista Lisa, na faixa de frequência analisada, conforme esperado com o aumento da textura do pavimento. Contudo, a diferença do ruído em torno de $180 \mathrm{~Hz}$ é menor.

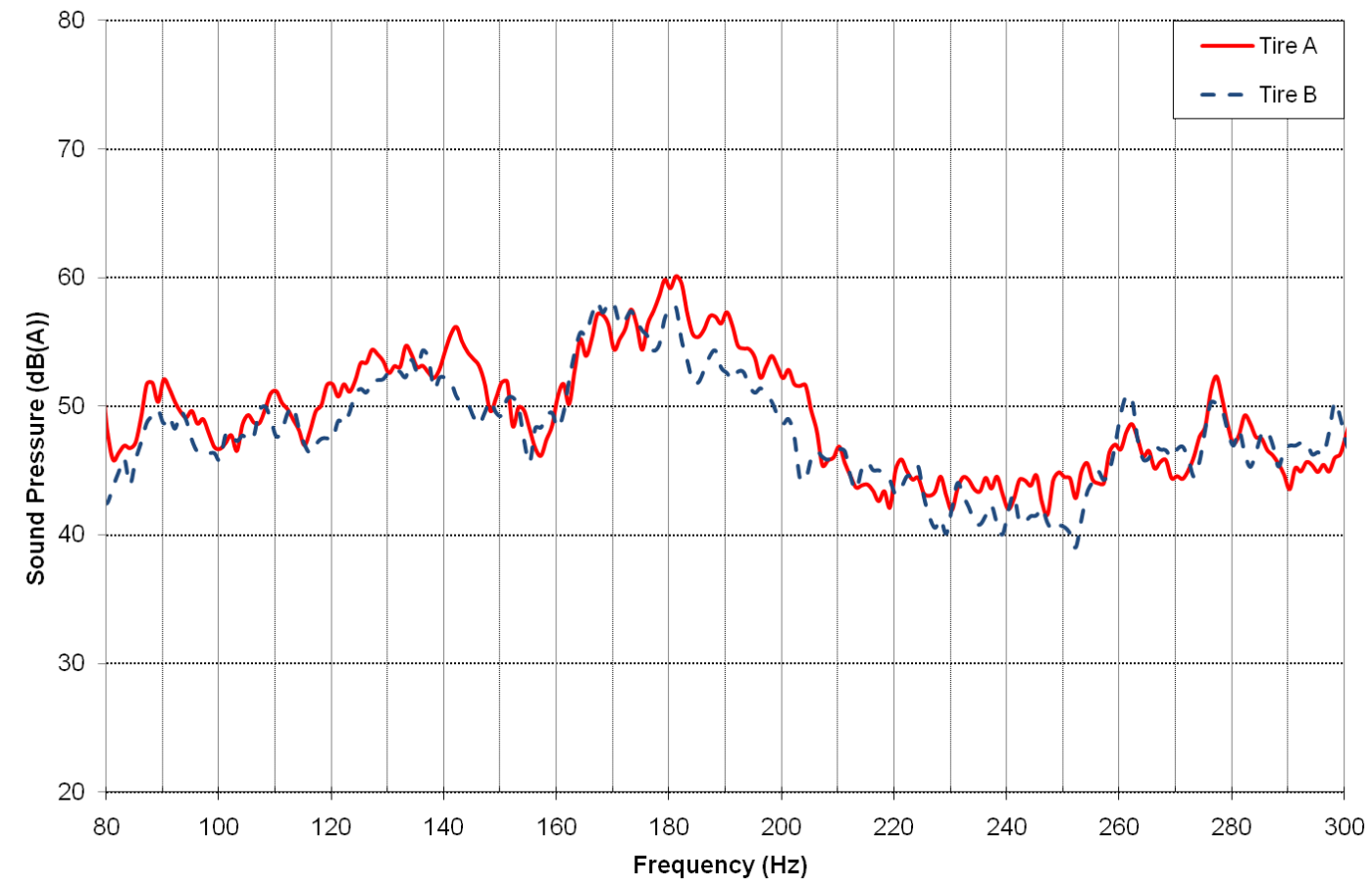

Figura 4.3: Ruído interno em pista Áspera, 50 km/h

A próxima figura 4.4 a seguir mostra a mesma medição de ruído interno em uma pista de rugosidade média de megatextura, porém irregular, classificada como pista de paralelepípedos alinhados, a $60 \mathrm{~km} / \mathrm{h}$. A entrada de força nos pneus é ainda maior que nas pistas Ásperas e Lisas e há maior excitação das contribuições estruturais do ruído. Nesta condição, ambos os pneus resultam em um maior ruído de rodagem, com uma 
diferencia rumble maior para pneu "A". Porém, com o aumento das forças de entrada, percebe-se que esta diferença da resposta em ruído entre os pneus tende a diminuir.

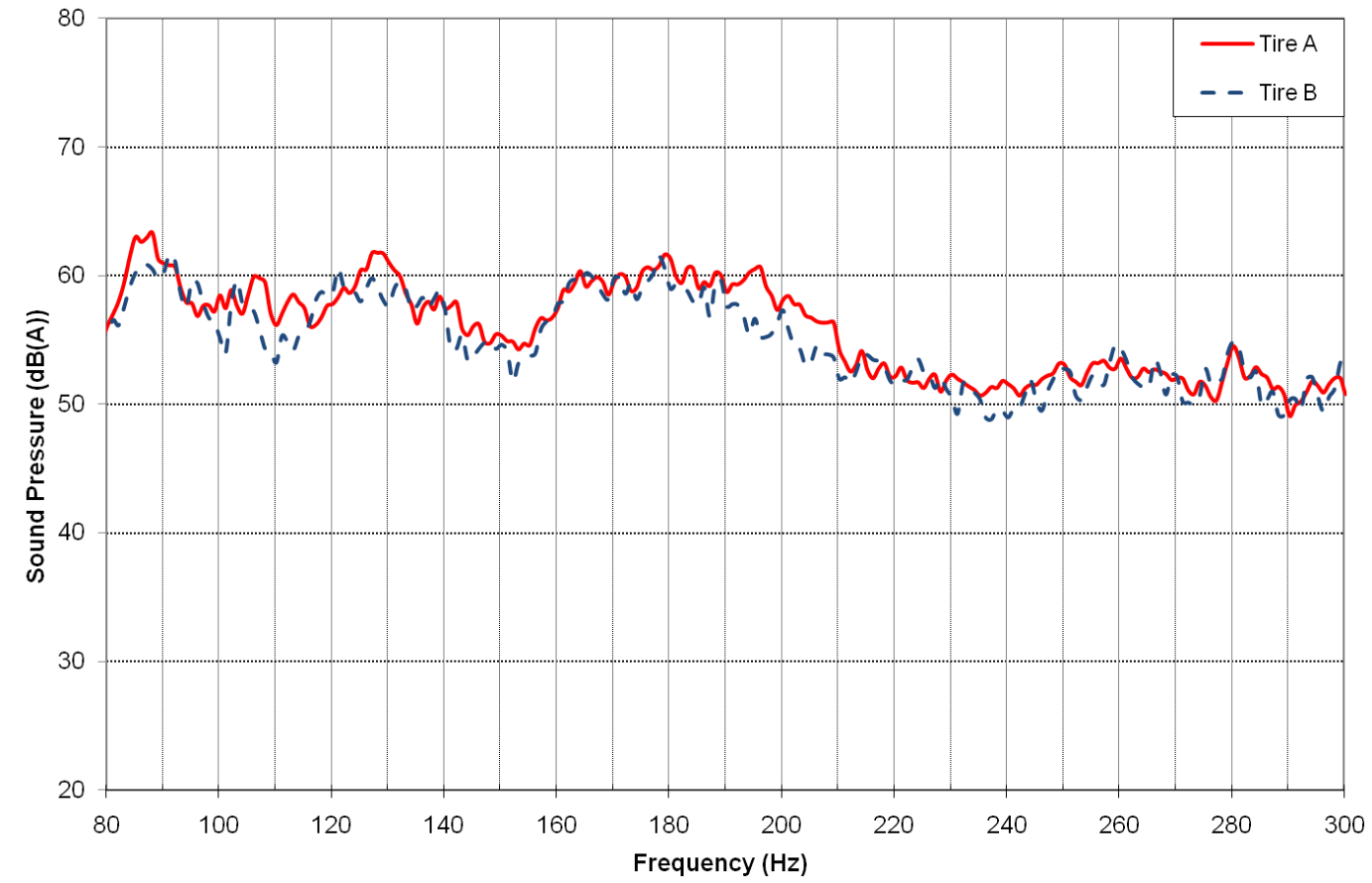

Figura 4.4: Ruído interno, pista Paralelepípedo Alinhado, 60 km/h

Finalmente, testa-se o pneu "A" vs. "B", figura 4.5, em pista de rugosidade alta e irregular, não asfaltada, de terra batida.

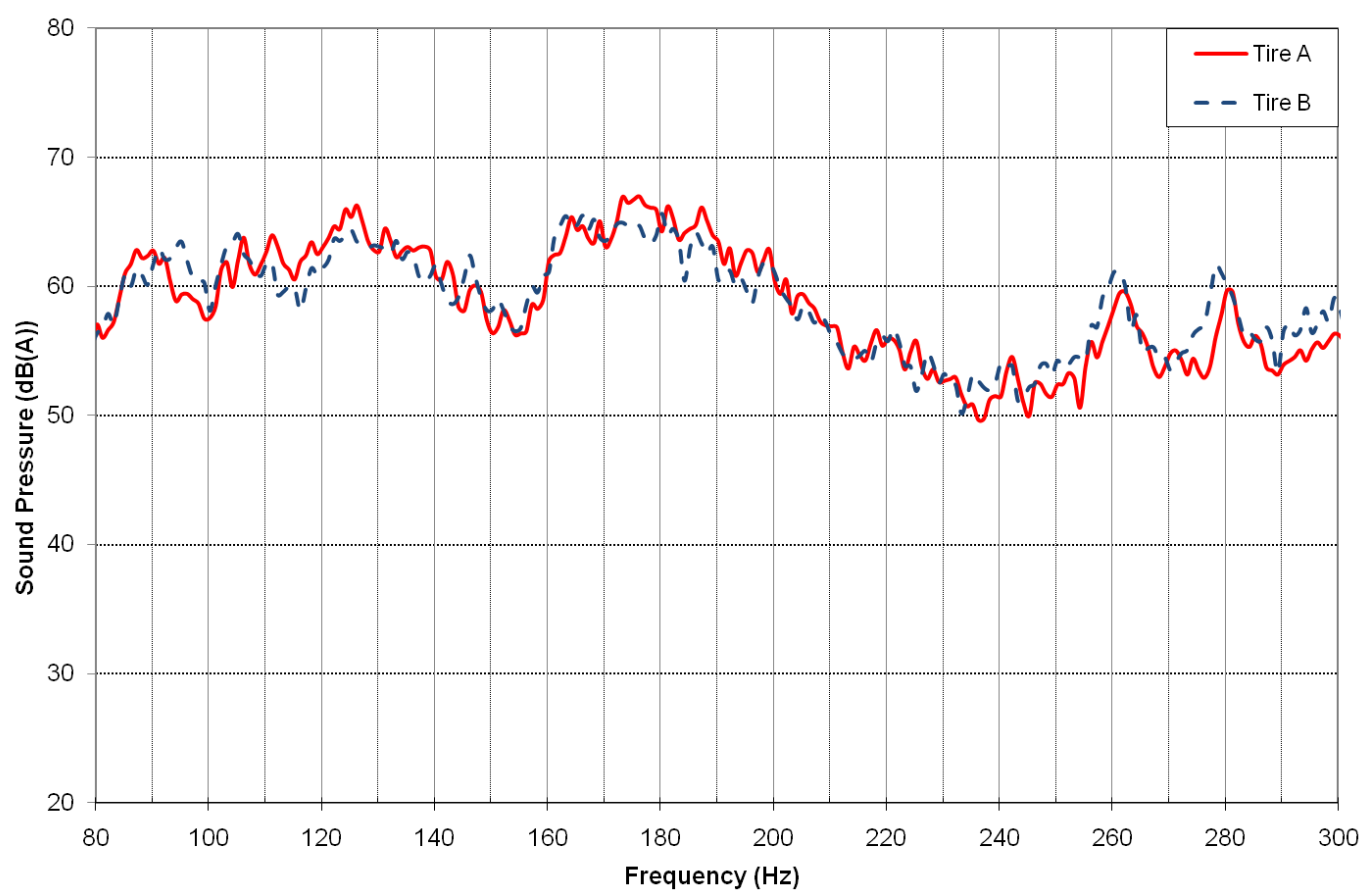

Figura 4.5: Ruído interno, pista de terra, $60 \mathrm{~km} / \mathrm{h}$ 
Esta pista assemelha-se ao efeito de uma superfície de Paralelepípedos Alinhados, o que permite uma maior força de reação nos pneus e consequentemente maior nível de ruído de rodagem. Nesta condição a diferença entre os dois modelos diminui em torno do rumble.

Os resultados parciais demonstram em avançado que o rumble deste caso é mais crítico para pistas mais lisas e contínuas, somente ocorrendo com pneu modelo "A". Nestas condições, o protótipo possui alta sensibilidade acústica devido à resposta estrutural de vibrações da suspensão, causado pelas características dinâmicas de forcas do "Tire A". Na prática, quanto mais lisa e menor a velocidade do veículo, maior será a percepção do rumble, provocando assim um maior o desbalanceamento entre as fontes de ruído. Para desenvolvimento desta dissertação, as condições apresentadas nas figuras 4.1 e 4.2 (pista Lisa á $20 \mathrm{~km} / \mathrm{h}$ ) serão o foco para a demonstração do TPA.

As soluções que serão apresentadas se dividem em dois focos distintos. Mudar as características construtivas do pneu "A" ou modificar o protótipo. Nesta segunda opção, as possibilidades também podem ser subdivididas em alterações nos componentes da suspensão ou nas características de sensibilidade acústica da carroceria. Sendo esta dissertação focada na atenuação do ruído estrutural antes da carroceria, define-se como objetivo, buscar a solução mais efetiva entre mudanças no pneu e na suspensão que possam absorver o comportamento vibracional do modelo "A". São citados cuidados que devem ser tomados nestas mudanças para que não alterem o comportamento dinâmico, durabilidade ou o peso do veículo. Neste escopo, as possíveis soluções são demonstradas utilizando a análise dos caminhos de transferência de energia, TPA, ao ruído de rodagem.

\subsubsection{Avaliações subjetivas e otimizações do TPA}

As avaliações subjetivas e sessões de áudio (listening) confirmaram o rumble em torno de $180 \mathrm{~Hz}$ e também possibilitaram as seguintes otimizações para o TPA experimental. 
Primeiramente, o rumble é ouvido em qualquer posição da cabine, entre os bancos dianteiros ou traseiros. Curiosamente, o ruído permanece no mesmo nível quando as janelas são abertas, o que mostra que o rumble não dependente de vazamentos de ruído da carroceria, e, portanto, de caminhos e contribuições aéreas do ruído.

Em segundo, os diferentes modelos de pneus também foram misturados entre os eixos do protótipo. Um par do modelo "A" foi usado apenas para suspensão dianteira e outros modelos foram usados na traseira. Nesta condição, o rumble era igualmente presente. Contudo, ao se inverter esta configuração, ou seja, modelo "A" na suspensão traseira e outros modelos na dianteira, o efeito em torno de $180 \mathrm{~Hz}$ o efeito não mais ocorria.

\section{ROAD TPA para contribuição estrutural}

Fundamentalmente, na acústica, quanto mais baixo for a frequência do som, maior será o seu comprimento de onda para a propagação da energia, como visto na equação (82). Sendo assim, é difícil e na verdade impossível localizar a propagação de um ruído estrutural, dentro da cabine do veículo, apenas por impressões sensos-direcionais.

$$
f=c \cdot \lambda
$$

Isto seria o mesmo em termos práticos em se tentar descobrir apenas com os ouvidos, por exemplo, qual chapa da carroceria é o causador do ruído estrutural do veículo como consequência das vibrações causadas pelo pneu "A". Entretanto é importante conhecer quais são os caminhos mais críticos do ruído e focar na real causa do problema.

Sendo este ruído presente em baixas frequências, entre $100 \mathrm{~Hz}$ e $200 \mathrm{~Hz}$, estima-se que sua natureza de propagação seja em maior parte por contribuições estruturais (Vandenbroeck, 1993). Como visto no capitulo três, um ponto negativo ao uso do TPA é a quantidade de canais envolvidos em uma investigação geral. Portanto, assim como prega a metodologia do TPA, a instrumentação é feita para contabilizar os caminhos estruturais da contribuição para o rumble. Os caminhos das contribuições aéreas do ruído de rodagem, neste momento são desconsiderados. 


\section{ROAD TPA estrutural para suspensão dianteira}

Especificamente para este caso estrutural, em baixa frequência, causado pelo "tire A", o exercício de usar diferentes modelos de pneus entre os eixos permitiu entender que o rumble do caso possui os caminhos críticos do ruído somente no eixo dianteiro. O foco nos componentes da suspensão dianteira permite neste estudo a redução aproximada de $50 \%$ os sensores a serem utilizados para as medições de TPA e o tempo de instrumentação, medição em laboratório e análises.

\section{Pontos para o Road TPA}

Sendo as medições do TPA divididos em duas etapas (laboratório e pista), o número de pontos e o método para o calculo de força devem ser previamente definidos para a escolha dos sensores e setup de teste. Deve-se ter a consciência de que quanto maior o número de pontos, maior será a quantidade de sensores para medição em pista, maior o tempo em laboratório e consequentemente, maior o tempo para a conclusão das análises. Desta maneira, para estudos de casos específicos, a medição de fontes que não contribuem para o rumble ou os caminhos de transferência previamente avaliados e que não afetam o fenômeno, deve ser desconsiderados.

O sistema de suspensão dianteira do protótipo é do tipo Mc. Pherson. Os caminhos de propagação do ruído estrutural definidos são: buchas anteriores e posteriores do braço de controle, identificados nos testes como ponto \#3 e \#4 e as buchas entre a torre do amortecedor e carroceria, chamados de Top Mount. Nestes pontos de atenuação de vibrações, são aquisitados as FRFs de ponto ou point mobility e de sensibilidade acústica da carroceria no lado passivo e acelerações nos lados ativos e passivos destas conexões. A figura 4.6 mostra a suspensão dianteira do lado direito para ilustrar os pontos. 


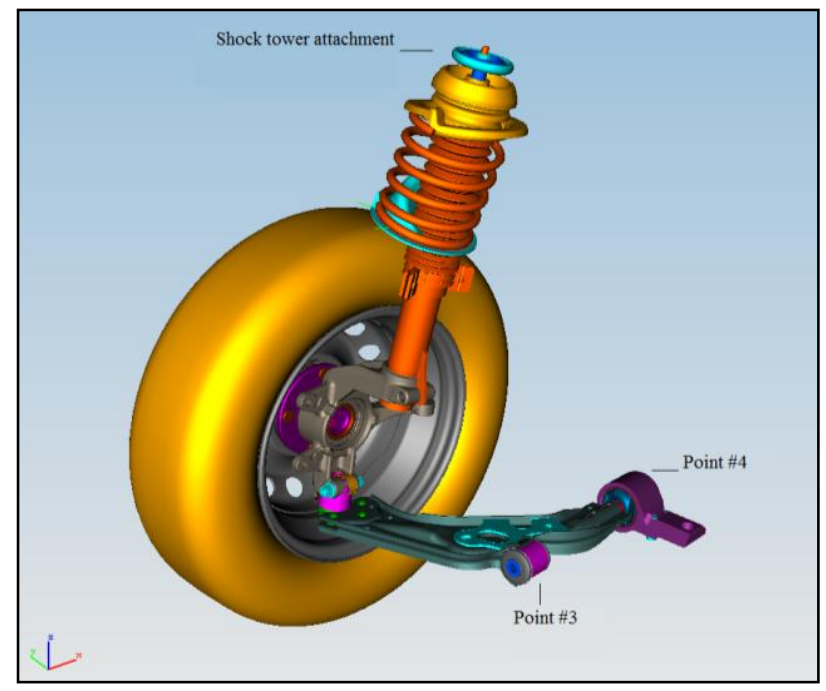

Figura 4.6:- Pontos de entrada de força considerados para o TPA

\section{Simetria de FRFs}

Em tese, considerando a simetria de geometria da suspensão e sua ancoragem no chassi, as FRFs podem ser comparadas entre os lados direito e esquerdo durante as medições do laboratório. Neste estudo de resposta de carroceria, assume-se que para a sensitividade acústica (p/f) e FRF de ponto (a/f), ambos os lados são iguais. Nesta consideração, a número de sensores instalados para a etapa de medições em pista, e o tempo de análise dos resultados, reduzem em cerca de $50 \%$.

Para contabilizar ambos os lados para o calculo do ruído de rodagem, os caminhos da propagação acústica do ruído calculado deve ser dobrado, baseado na soma de fontes não coerentes, conforme revisado na revisão teórica.

\section{Análises de Energia}

Neste estudo as análises são apresentas em forma de energia, ou seja, em sua magnitude apenas. O refinamento das respostas dos caminhos de vibrações, ativas e reativas, pelas suspensões faz-se recomendável para os próximos trabalhos. 


\section{FRFs de ponto vs. Espectro cruzado.}

Segundo visto na revisão teórica, a complexidade da rotina experimental para o calculo do ruído de rodagem, precisamente correlacionado com toda a banda larga do ruído medido, é grande. Contando com todas as contribuições estruturais e aéreas, a quantidade de sensores necessários, o processo de montagem dos equipamentos e o tempo despendido durante as medições no laboratório, são os únicos pontos fracos na aplicação clássica do TPA.

Para este estudo, a redução da complexidade e rotina de medições do Road TPA é possível, primeiramente pelas instrumentações focarem nas contribuições estruturais em um dos lados na suspensão dianteira. Por fim, também é assumido que os efeitos de acoplamento de vibrações devido aos pontos de entradas e saídas de energia cruzadas serão desconsiderados, adotando-se o método da matriz inversa reduzida. Esta simplificação deve ser feito com cautela, principalmente quando os modos de vibrar de componentes também estão sob investigação, como por ex. os pontos do subquadro. $\mathrm{Na}$ pratica, o método da matriz inversa para o calculo de força de entrada, não necessita de inversão. Conforme a equação (71) já mencionada no capitulo 3, esta matriz se torna agora uma matriz $3 \times 3$ com valores apenas na diagonal principal.

$$
\left\{\begin{array}{l}
f_{1} \\
\cdots \\
f_{3}
\end{array}\right\}=\left[\begin{array}{ccc}
\frac{\ddot{X}_{11}}{F_{1}} & 0 & 0 \\
0 & \frac{\ddot{X}_{22}}{F_{2}} & 0 \\
0 & 0 & \frac{\ddot{X}_{33}}{F_{2}}
\end{array}\right]^{-1}\left\{\begin{array}{l}
\ddot{X}_{1} \\
\ddot{X}_{2} \\
\ddot{X}_{3}
\end{array}\right\}
$$

Por fim, todas as considerações acima contribuem para a otimização e redução dos procedimentos de instrumentação, medições e análises de dados para o TPA. As informações de laboratório e pista são unidas e tratadas para correlação com o ruído real medido. A adição das fontes não coerentes do lado oposto da suspensão é feito durante estas análises. Analiticamente, conforme equação (83), para a formulação do método da matriz inversa reduzido, tem-se o calculo do nível de pressão sonora, para cada frequência aquisitada:

$$
p_{i i}=(\ddot{x} / F)_{i i}^{-1} \cdot[\ddot{x}]_{\text {passivo }} \cdot(p / F)_{i i} \cdot[F]_{i i}+\text { Fator } d B(A)+3 d B(A)
$$




\subsubsection{Instrumentação e Setup}

Os procedimentos a seguir são realizados para a execução do TPA pelo método da matriz inversa para o cálculo indireto das forças. Os testes foram realizados no laboratório de Vibroacústica (Quiet Room) e em diversos tipos de superfícies.

\section{Laboratório}

Para as medições sensitividade acústica e FRF de ponto usa-se o SCADAS III 316 com o software CADA-X, ambos da LMS. É utilizado o martelo de impacto com duas ponteiras (borracha e nylon), nas direções x, y e z. O emprego de diferentes ponteiras para a impactação serve para alterar a faixa de frequência de maior relevância na FRF, sob as seguintes condições:

- Setup \#1: Ponteira p/ baixa frequência (borracha):

○ Freq. mínima: $0 \mathrm{~Hz}$

○ Freq. máxima: $128 \mathrm{~Hz}$

○ Resolução em freq.: $1 \mathrm{~Hz}$

- Setup \#2: Ponteira p/ médio - altas frequências (nylon) $\leq 600 \mathrm{~Hz}$

○ Freq. mínima: $0 \mathrm{~Hz}$

○ Freq. máxima: $1024 \mathrm{~Hz}$

○ Resolução em freq.: $1 \mathrm{~Hz}$

Taxa de aquisição é automática a partir da definição da freq. Máxima.

As figuras 4.7, 4.8 e 4.9 demonstram respectivamente exemplos de medições usando martelo de impacto com uma ponteira de nylon, na direção e sentido - z para o impacto no lado passivo da bucha anterior do braço de controle, e em $+\mathrm{z}$ nos lados passivos da bucha posterior batente de suspensão. As FRFs obtidos do protótipo são apresentadas a seguir corrigindo-se o sentido da medição -z. Assim, o valor negativo é invertido para o calculo das FRFs e fases. Deseja-se sempre aquisitar estas funções o mais próximo possível do centro elástico de atuação das buchas. 


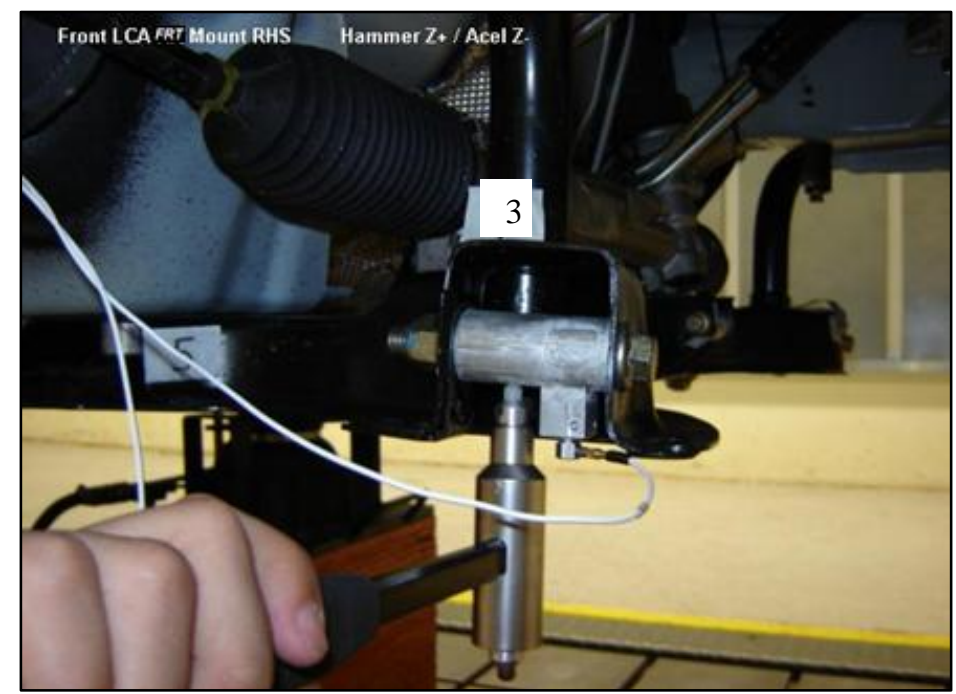

Figura 4.7: Impacto em +z no lado passivo do Ponto 3 em -z

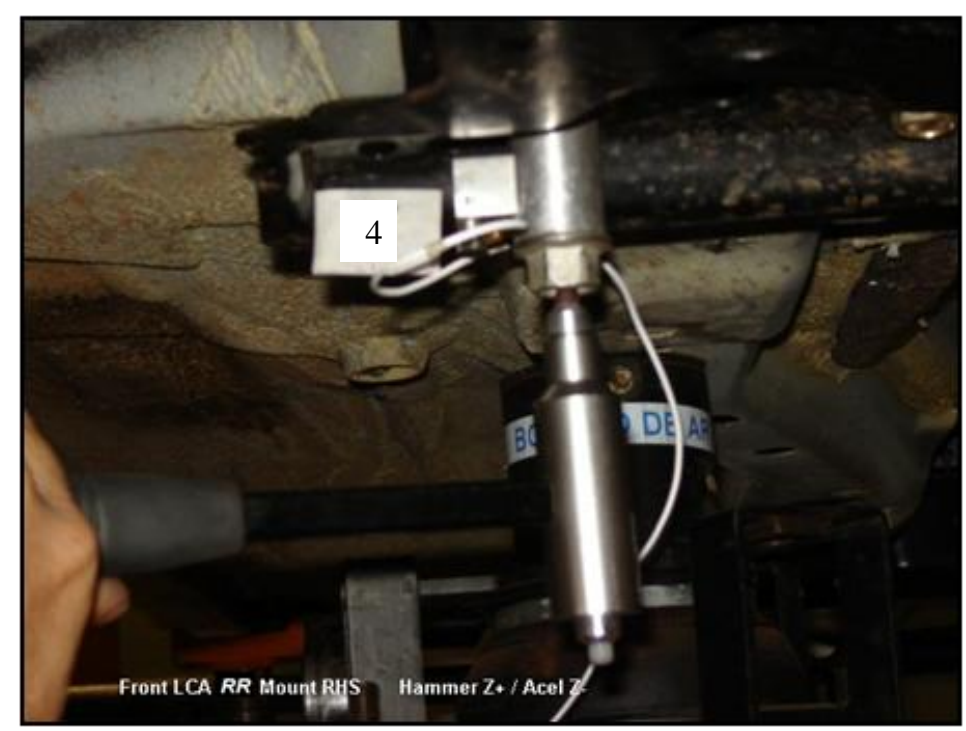

Figura 4.8: Impacto em +z no lado passivo do Ponto 4 em $-\mathrm{z}$

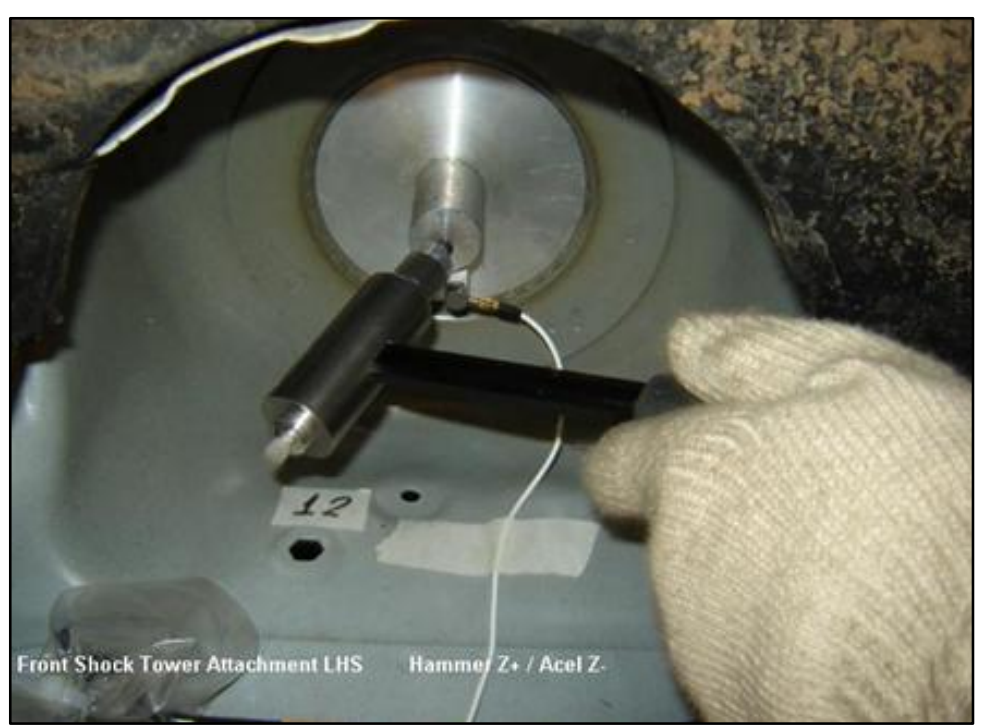

Figura 4.9: Impacto em +z no lado passivo da torre da suspensão em $-z$ 
As medições mobilidade dos pontos e sensibilidade acústica são realizadas simultaneamente. A figura 4.10 mostra um exemplo de teste com o posicionamento do microfone no lado externo do motorista (DOE) em evidencia.

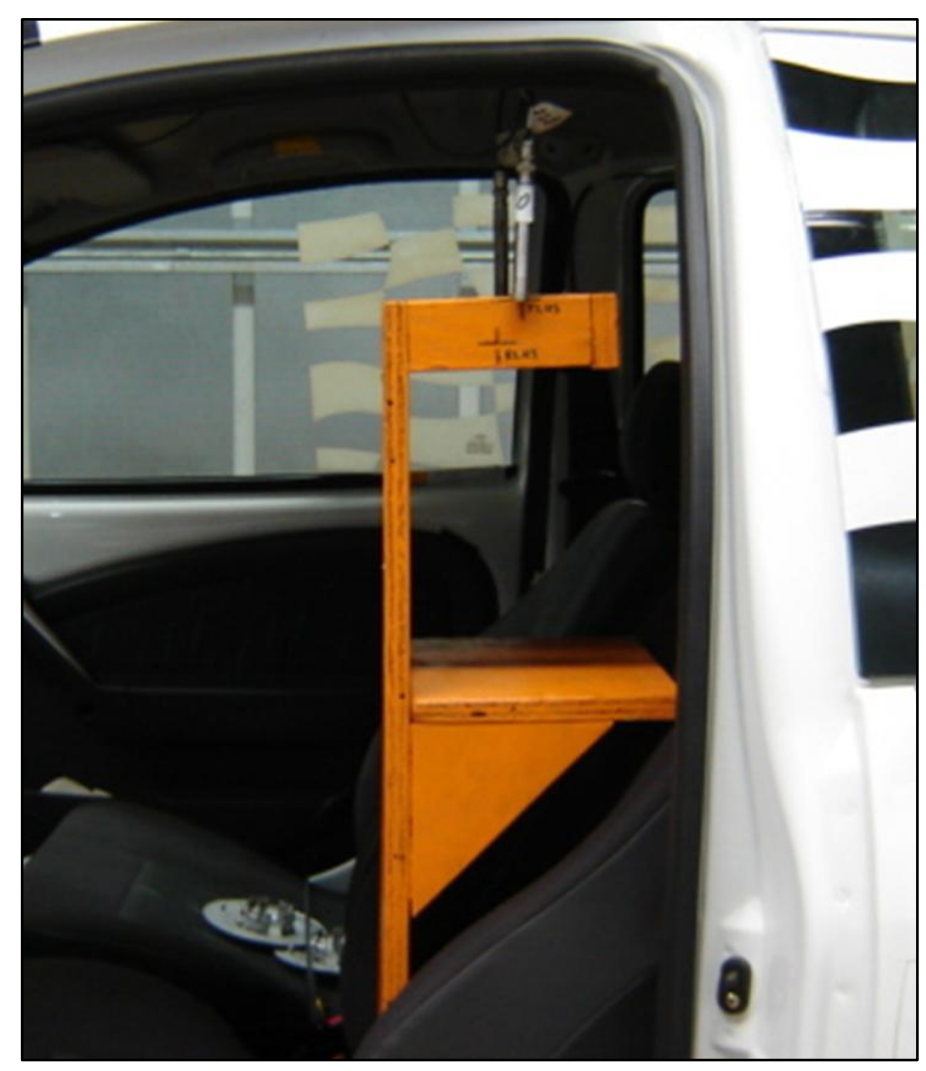

Figura 4.10: Microfone lado externo do motorista

Durante impulso (f) do martelo, o sinal de entrada é monitorado e analisado com janela de força para isolar o impulso, atenuando o ruído após impacto. O autoespectro é avaliado buscando uma curva com melhor distribuição de energia ao longo da faixa de frequência de interesse.

Para o sinal de saída, o driving point ou point mobility, se aplica o janelamento exponencial também para garantir que o sinal tende a zero antes do final da janela. A figura 4.11 ilustra estas análises de sinais. 


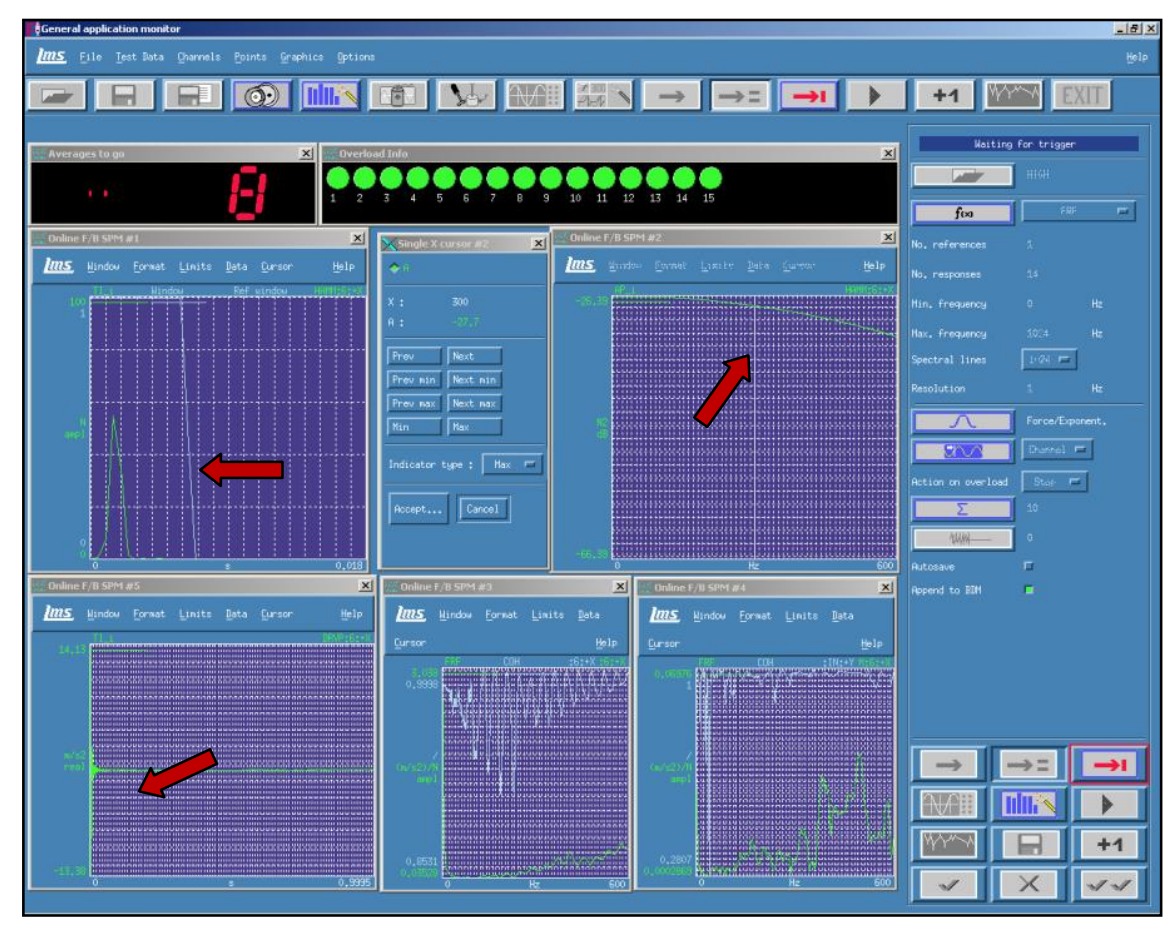

Figura 4.11: Análises de sinais para obtenção das FRFs

\section{Pista}

Para as medições das vibrações operacionais nas buchas, com os acelerômetros, e ruído interno (microfone na mesma posição DOE usado no laboratório), utiliza-se o equipamento Prosig com o seguinte setup: $16384 \mathrm{~Hz}$ de taxa de aquisição e filtro passa baixo em 6554 Hz. Filtro passa banda Butterworth entre $5 \mathrm{~Hz}$ e $800 \mathrm{~Hz}$. Nesta condição, apenas uma fonte entre as 4 faz-se necessário medir, o que simplifica o problema de múltiplas referências parcialmente correlacionadas. Os espectros obtidos são tratados sem a adoção de um sinal de referencia e, portanto sem considerar os efeitos de fases no refino do calculo do ruído.

As correlações entre o ruído calculado e o medido são apresentadas para a pista Lisa nas velocidades de 20 e $60 \mathrm{Km} / \mathrm{h}$, e na pista Áspera, a $50 \mathrm{Km} / \mathrm{h}$. Com o modelo experimental correlacionado, as investigações quanto o caminho mais crítico para o rumble serão apresentados para a condição mais critica, pista Lisa a $20 \mathrm{~km} / \mathrm{h}$. O ruído medido é analisado em $\mathrm{dB}(\mathrm{A})$ por frequência, e os acelerômetro, aceleração [m/s2] x frequência. Para o TPA, os resultados são apresentados entre 80 e $300 \mathrm{~Hz}$. As figuras 4.12, 4.13 e 4.14 mostram respectivamente a instalação de acelerômetros triaxiais no lado ativo e passivo das buchas da suspensão dianteira direita. 


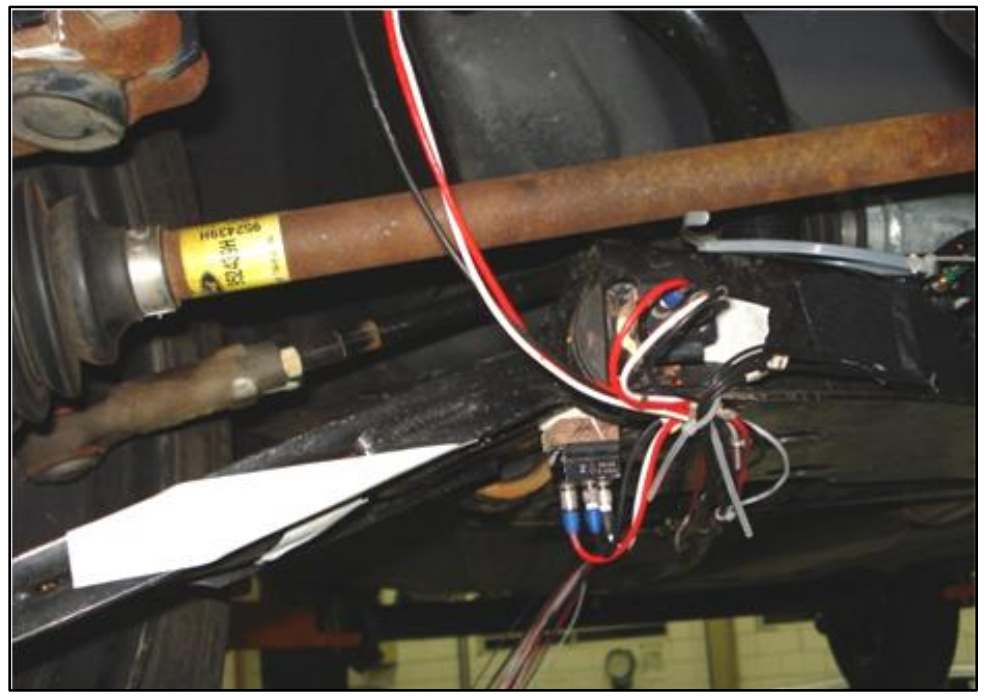

Figura 4.12: Acelerômetros instalados no Ponto 3

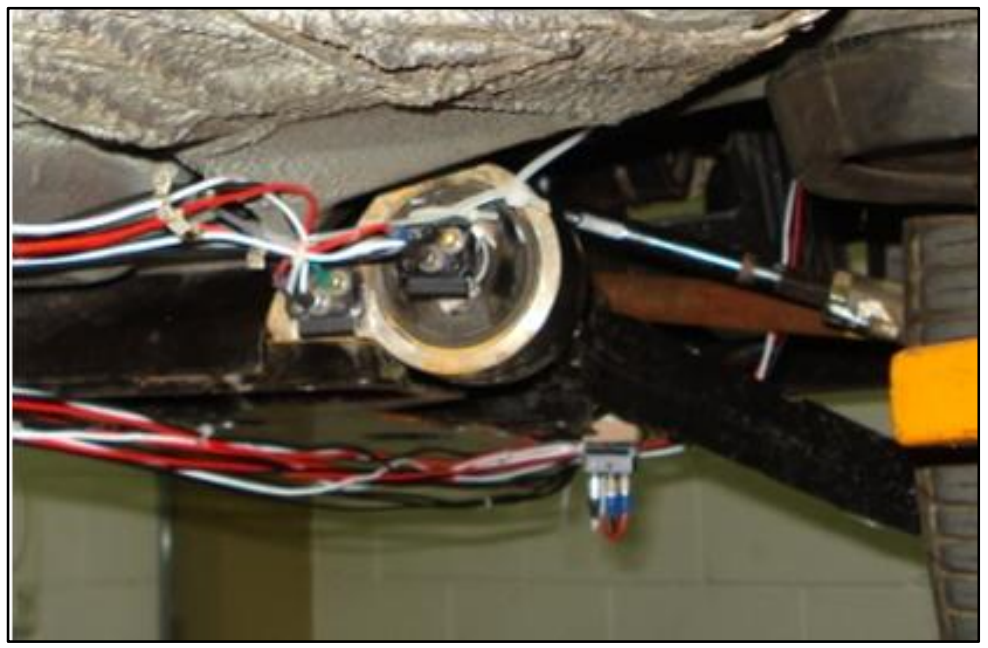

Figura 4.13: Acelerômetros instalados no ponto 4

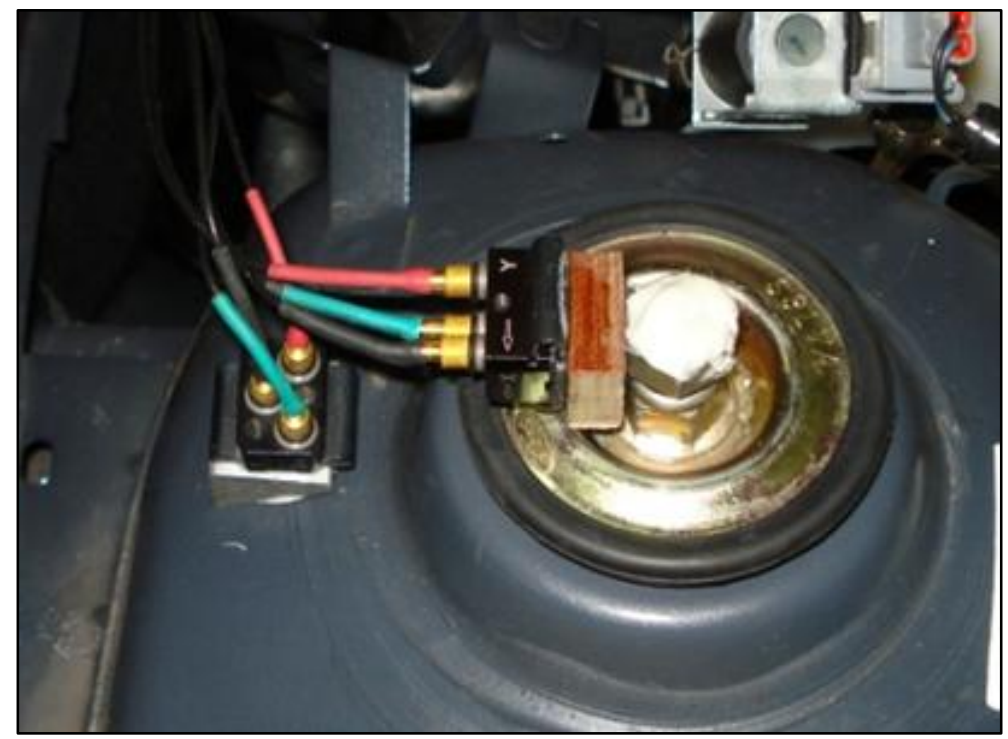

Figura 4.14: Acelerômetros instalados no Top Mount 


\subsubsection{Dados do protótipo}

As características gerais do protótipo usado como modelo experimental é apresentado abaixo e é baseado em um veículo de passeio.

\begin{tabular}{|c|c|c|}
\hline Parâmetros do protótipo & Unidade & \\
\hline \hline Peso Total & $\mathrm{kg}$ & 912,16 \\
\hline Peso Eixo Dianteiro & $\mathrm{kg}$ & 577,87 \\
\hline Massa Não-suspensa Dianteira & $\mathrm{kg}$ & 77,89 \\
\hline Peso Eixo Traseiro & $\mathrm{kg}$ & 334,29 \\
\hline Massa Não-suspensa Traseira & $\mathrm{kg}$ & 69,99 \\
\hline Distância Entre eixos & $\mathrm{mm}$ & 2452,93 \\
\hline Bitola Dianteira & $\mathrm{mm}$ & 1812 \\
\hline Bitola Traseira & $\mathrm{mm}$ & 1812 \\
\hline Frequência natural Dianteira & $\mathrm{Hz}$ & 11,76 \\
\hline Frequência Traseira & $\mathrm{Hz}$ & 12,15 \\
\hline Altura do CG & $\mathrm{mm}$ & 542,52 \\
\hline
\end{tabular}

Tabela 4.1: Características gerais do protótipo

\section{Motorização}

O sistema de motorização, abrangendo o motor, transmissão, sistemas de exaustão e entrada de ar, coxinização, compressor de ar condicionado, alternador, bomba de óleo, correias ou correntes, etc., também são fontes importantes de ruído e vibração devidos suas contribuições estruturais e aéreas para o conforto interno no veículo.

Contudo, as avaliações de rumble em baixas velocidades, o efeito se mostrou independente do funcionamento da motorização. Como o ruído de rodagem deste caso não é afetado pelo tipo ou condição de uso da motorização, as características técnicas foram dispensadas. As características de maior relevância ao estudo de caso são os dados de rigidez de buchas da suspensão dianteira e sensibilidade acústica da carroceria. 


\section{Pneus}

Os modelos de pneus batizados de $\mathrm{A}, \mathrm{B}$ e $\mathrm{C}$, permaneceram com as marcas e características físicas omitidas para preservação dos modelos, uma vez que o foco está em entender qual o caminho no veículo mais crítico ao rumble. As forças de reação do pneu A serão apresentadas usando as análises feitas com o TPA.

\section{Suspensão Dianteira}

A suspensão dianteira é do tipo McPherson, com um braço de controle com buchas convencionais e com eixo de orientação horizontal e direção longitudinal. A suspensão não possui barra estabilizadora montada entre o amortecedor dianteiro e o sub-quadro dianteiro, no qual é fixado diretamente, sem buchas, na carroceria.

A figura 4.15 mostra o modelo de suspensão dianteira com seus vínculos e elementos elásticos. No conjunto mola/amortecedor dianteiro inclui-se também o batente de compressão e uma bucha de ligação entre a carroceria e a suspensão em sua porção superior, chamada de Top mount.

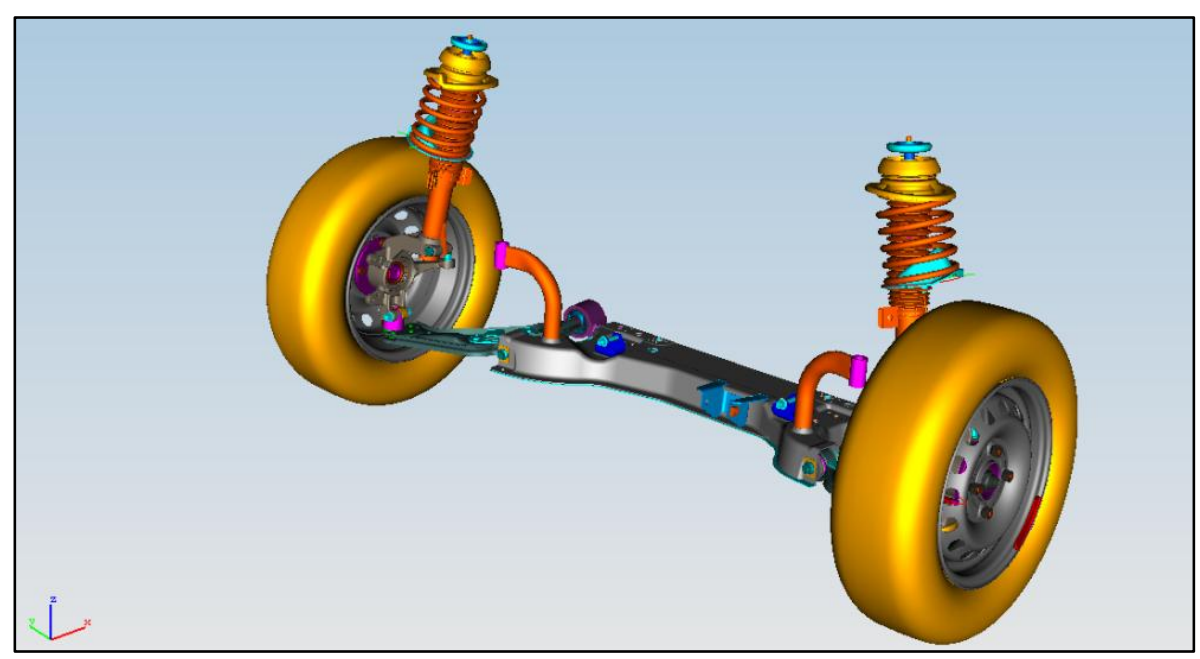

Figura 4.15: Suspensão e sub-quadro dianteiros

A mola usada possui rigidez constante em $20 \mathrm{~N} / \mathrm{mm}$, e a rigidez do batente de compressão é representado por uma curva de deflexão estática não-linear. A iteração 
entre os dois componentes cria um comportamento de mola não-linear, importante no gerenciamento de cargas da suspensão dianteira e no controle de movimentação vertical do eixo dianteiro em pistas de deflexão estática de grande amplitude. A figura 4.16 mostra a curva de rigidez estática do batente de compressão.

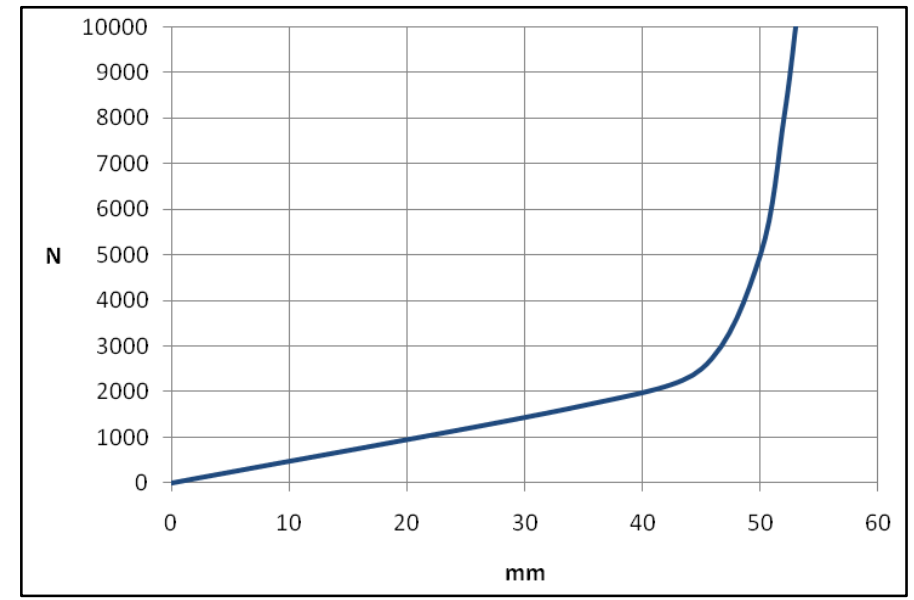

Figura 4.16: Curva de rigidez do batente de compressão dianteiro

Os amortecedores possuem grandes influencias no ride de um veículo, ao permitir a eficiente dissipação de movimentos verticais. Em geral são caracterizados para velocidades de haste de até $1500 \mathrm{~mm} / \mathrm{s}$, o que assegura seu correto funcionamento nas condições normais de uso do veículo.

Com a finalidade de isolar a carroceria do veículo e atenuar a transmissão de vibrações, os sistemas de suspensão em carros de passeio possuem buchas elásticas em seus pontos de conexão entre chassi e carroceria. No caso de uma suspensão do tipo McPherson, usualmente são três as buchas: bucha anterior do braço de controle, bucha posterior do braço de controle e o Top mount. As especificações destas buchas são de fundamental importância para a relação entre dinâmica e $N V H$ veicular. Além de garantirem as melhores relações de compliance (em geral conflitantes entre steering, handling e ride), também precisam cada vez mais assegurar a melhor atenuação das forças que causam o ruído estrutural de rodagem.

As informações a seguir de curvas de deflexão estáticas e rigidez dos eixos principais das buchas do braço de controle e do Top mount são as mais relevantes para absorção de respostas vibracionais do pneu "A". A tabela 4.2 refere-se á rigidez da bucha do Top mount. As curvas de deflexão estática das buchas do braço de controle dianteiro, do tipo A-Arm, são apresentadas na sequencia com as figuras 4.17 e 4.18 . 


\begin{tabular}{|c|c|}
\hline Top mount & Rigidez N/mm \\
\hline Radial & 1600 \\
\hline Axial 1 & 1600 \\
\hline Axial 2 & 320 \\
\hline
\end{tabular}

Tabela 4.2: Rigidez Top mount dianteiro

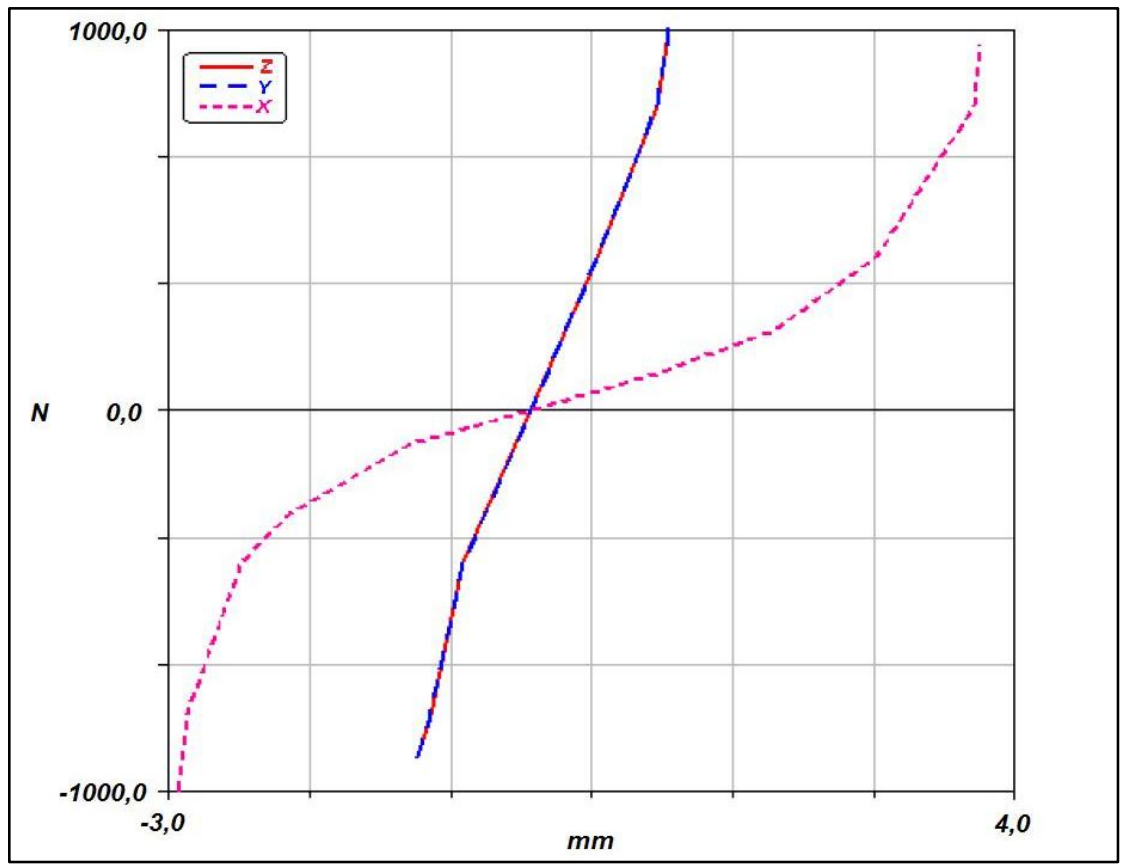

Figura 4.17: Rigidez da bucha anterior do braço de controle dianteiro

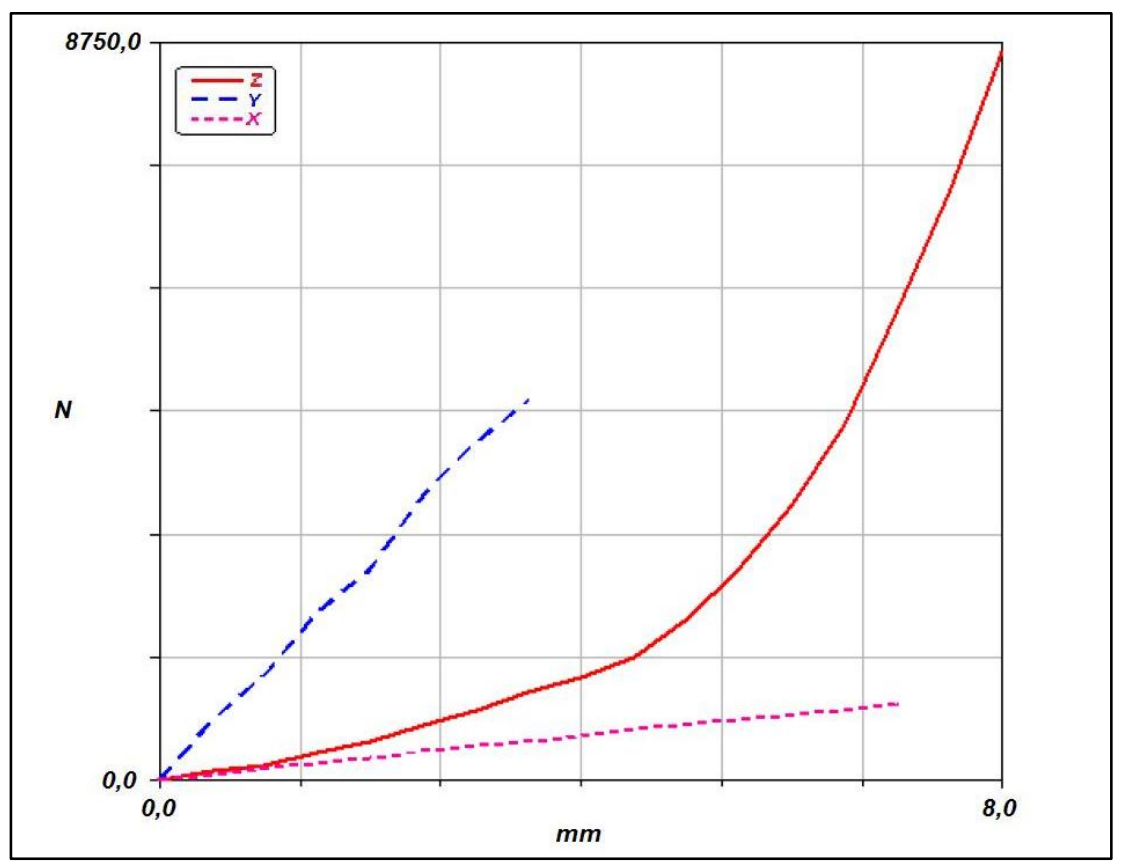

Figura 4.18: Rigidez da bucha posterior do braço de controle dianteiro 


\section{Suspensão Traseira}

O protótipo possui suspensão traseira do tipo Twistbeam (eixo de torção). Este tipo de suspensão popularizou-se entre carros compactos e médios de tração dianteira a partir dos anos 70. O sistema consiste de dois braços de controle longitudinais em geral soldados a uma viga de torção. Esta viga tem como função prover rigidez a rolagem e lidar com os carregamentos vertical e lateral a que a suspensão é submetida. Em geral tal viga faz também o papel de barra anti-rolagem nessa arquitetura. Dentre os motivos que viabilizaram a popularização deste tipo de suspensão pode-se citar a facilidade de construção e montagem do sistema, o fato de ser um design bastante compacto e suas boas características cinemáticas quanto a variação de ângulos de convergência e cambagem (Reimpell, J. and Stoll, H., 1996).

A mola usada possui rigidez constante de $15 \mathrm{~N} / \mathrm{mm}$, e o batente de compressão é representado por uma curva de deflexão estática não linear, tais como no modelo da suspensão dianteira. A iteração entre os dois componentes cria um comportamento de mola não-linear, importante no gerenciamento de cargas da suspensão traseira e no controle de movimentação vertical do eixo traseiro em pistas de grande amplitude. A figura 4.19 mostra a curva de rigidez estática do batente de compressão.

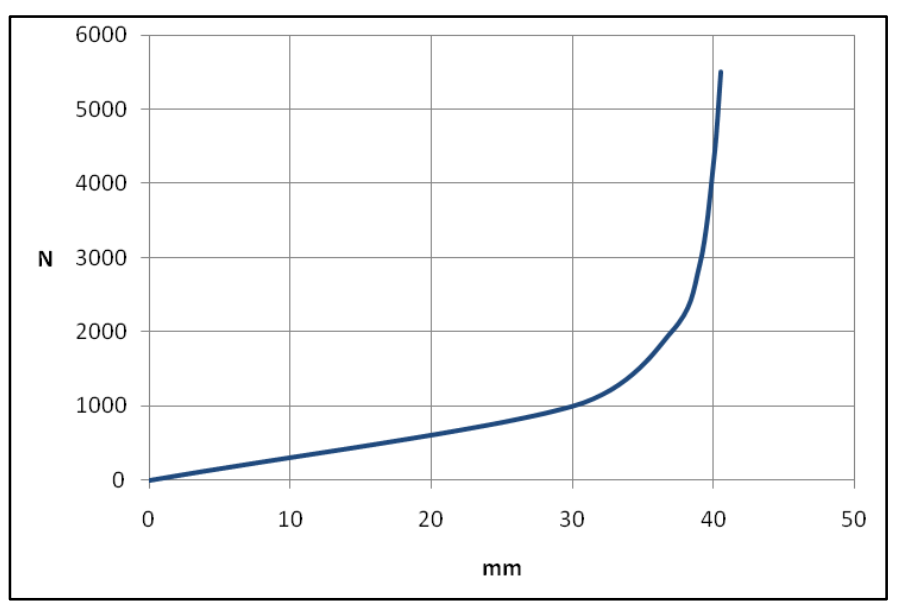

Figura 4.19: Curva de rigidez do batente de compressão traseiro

No caso de uma suspensão do tipo Twistbeam, usualmente são duas as buchas: bucha do braço de controle e Top mount. A tabela 4.3 e a figura 4.20 mostram as curvas de deflexão estática e a rigidez dos eixos principais de cada uma das buchas. 


\begin{tabular}{|c|c|}
\hline Top mount & Rigidez N/mm \\
\hline \hline Radial & 1600 \\
\hline Axial 1 & 1600 \\
\hline Axial 2 & 220 \\
\hline
\end{tabular}

Tabela 4.3: Rigidez da bucha do Top mount traseiro

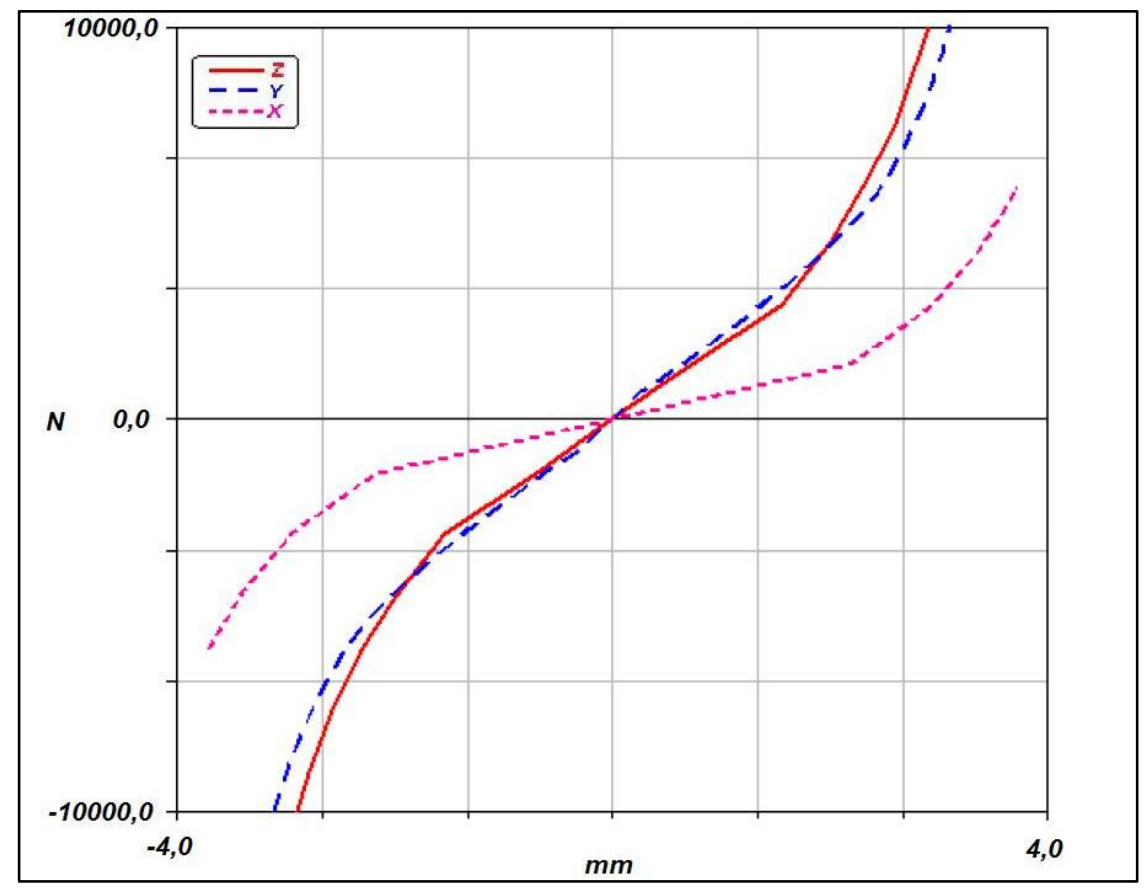

Figura 4.20: Rigidez da bucha do braço de controle traseiro

\section{Carroceria}

O protótipo teve 34 pontos medidos entre suas curvas de mobilidade de ponto e sensibilidade acústica de carroceria, nas três direções x, y e z. Para o estudo dos caminhos críticos do rumble, são selecionados 3 pontos da suspensão dianteira: Buchas do braço de controle e Top mount, o que reduz a manipulação de um total de 204 FRFs 204 para 18.

Os testes são conduzidos no laboratório de vibro-acústica da Ford Motor Company, no Campo de Provas de Tatuí. As FRFs são obtidas utilizando o método do martelo de impacto com as ponteiras de borracha e nylon. Para a ponteira de borracha, o objetivo é olhar as respostas em baixa frequência, de aproximadamente até $128 \mathrm{~Hz}$. Com a ponteira de nylon, a precisão da faixa de resposta está em torno de até $600 \mathrm{~Hz}$. As curvas dos três pontos apresentadas a seguir (figuras 4.21 á 4.26) referem-se á FRF vibracional de ponto (aceleração/força) e a FRF de sensibilidade acústica (Pascal/força), usando a ponteira de nylon. Os gráficos são apresentados para toda faixa de frequência aquisitada, de $0 \mathrm{~Hz}$ á $1024 \mathrm{~Hz}$. 
1.a Bucha anterior do braço - Acelerômetro Pto. 3/Martelo Pto. 3 (aceleração / força)

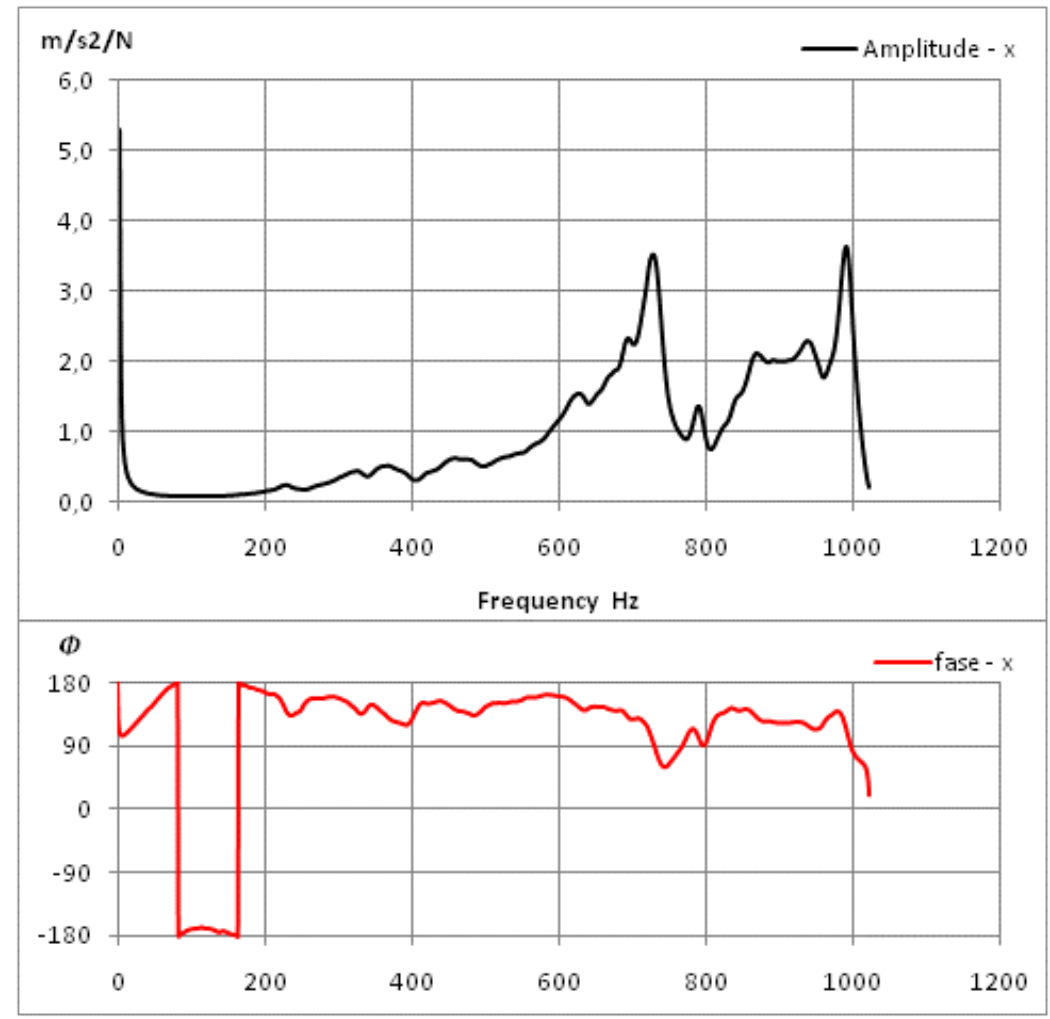

Figura 4.21 (a)

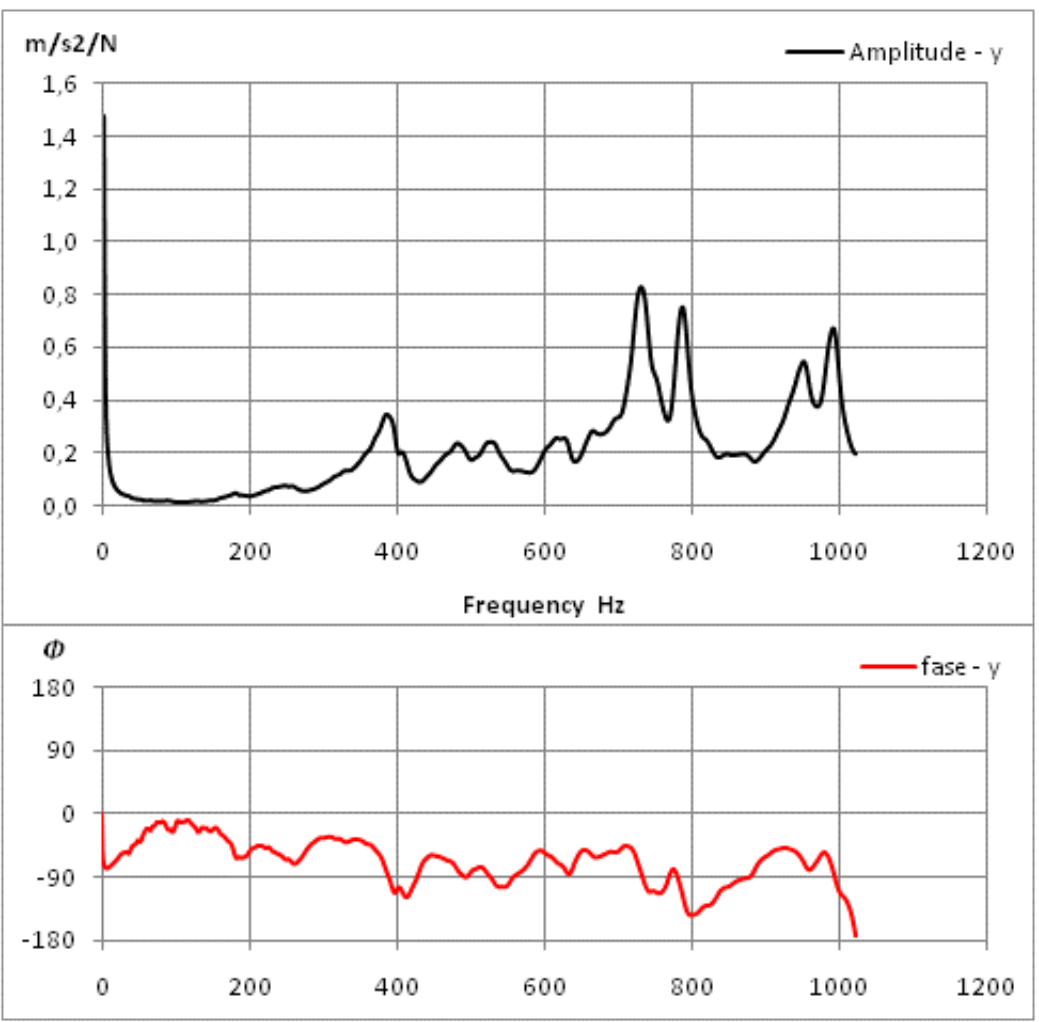

Figura 4.21 (b) 


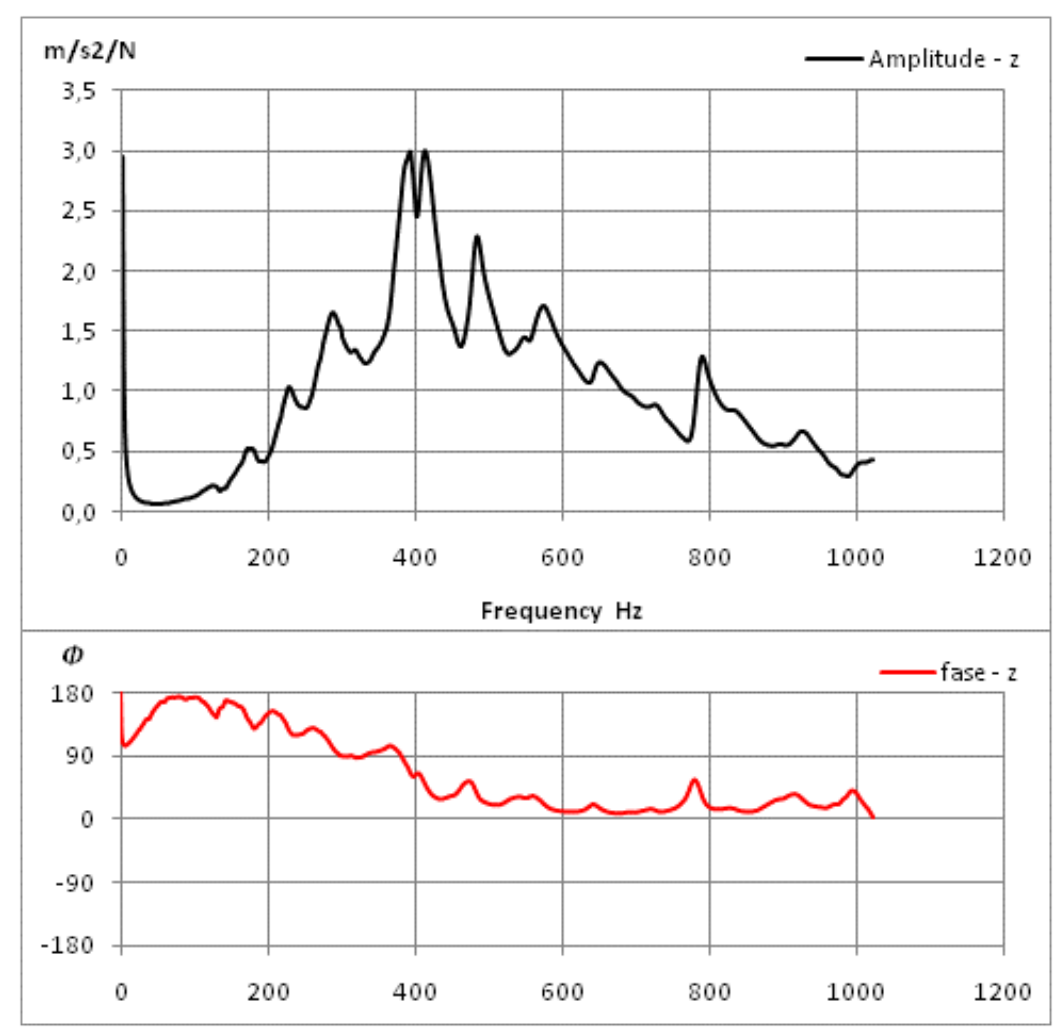

Figura 4.21 (c)

Figuras 4.21 (a), (b) e (c): FRF de ponto em x, y e z, bucha anterior - Ponto 3

1.b Bucha anterior do braço - Microfone DOE/Martelo Pto. 3 (Pascal / força)

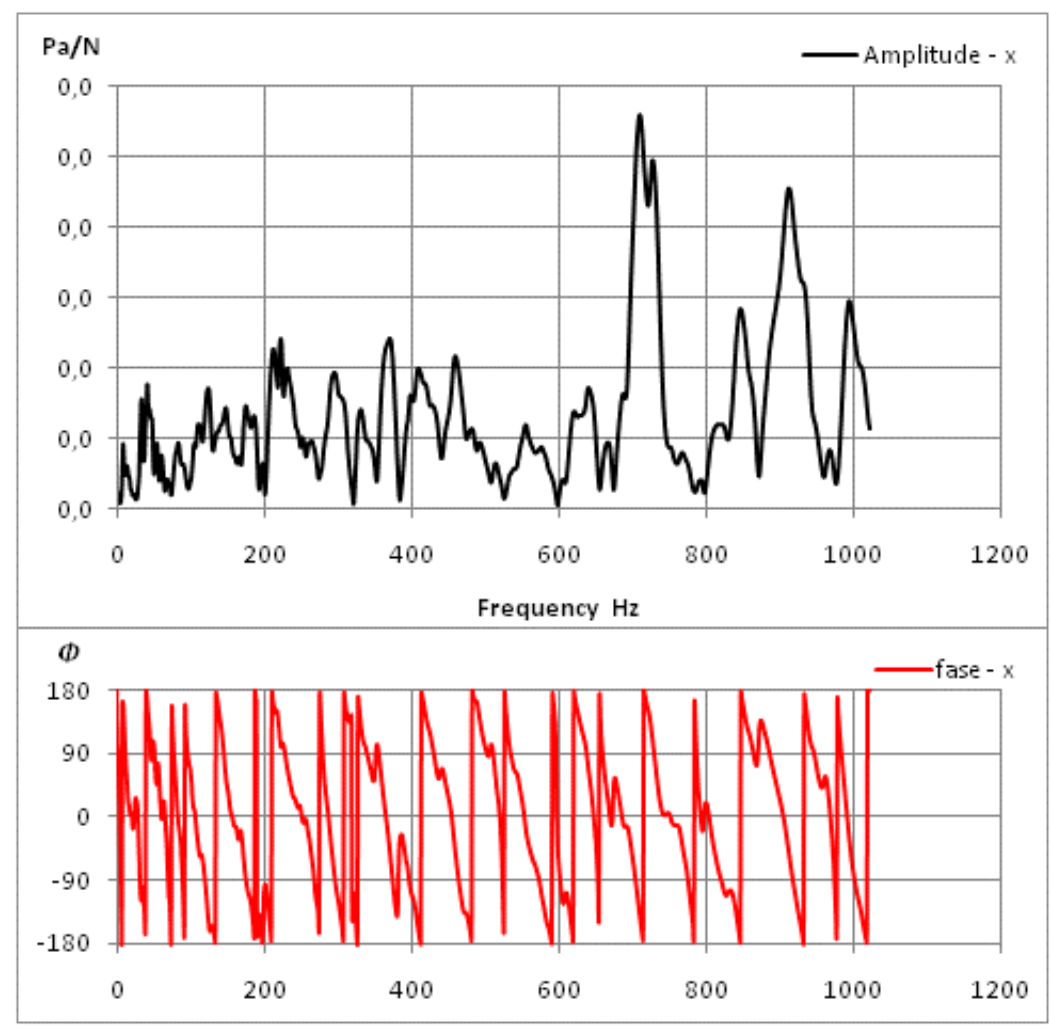

Figura 4.22 (a) 


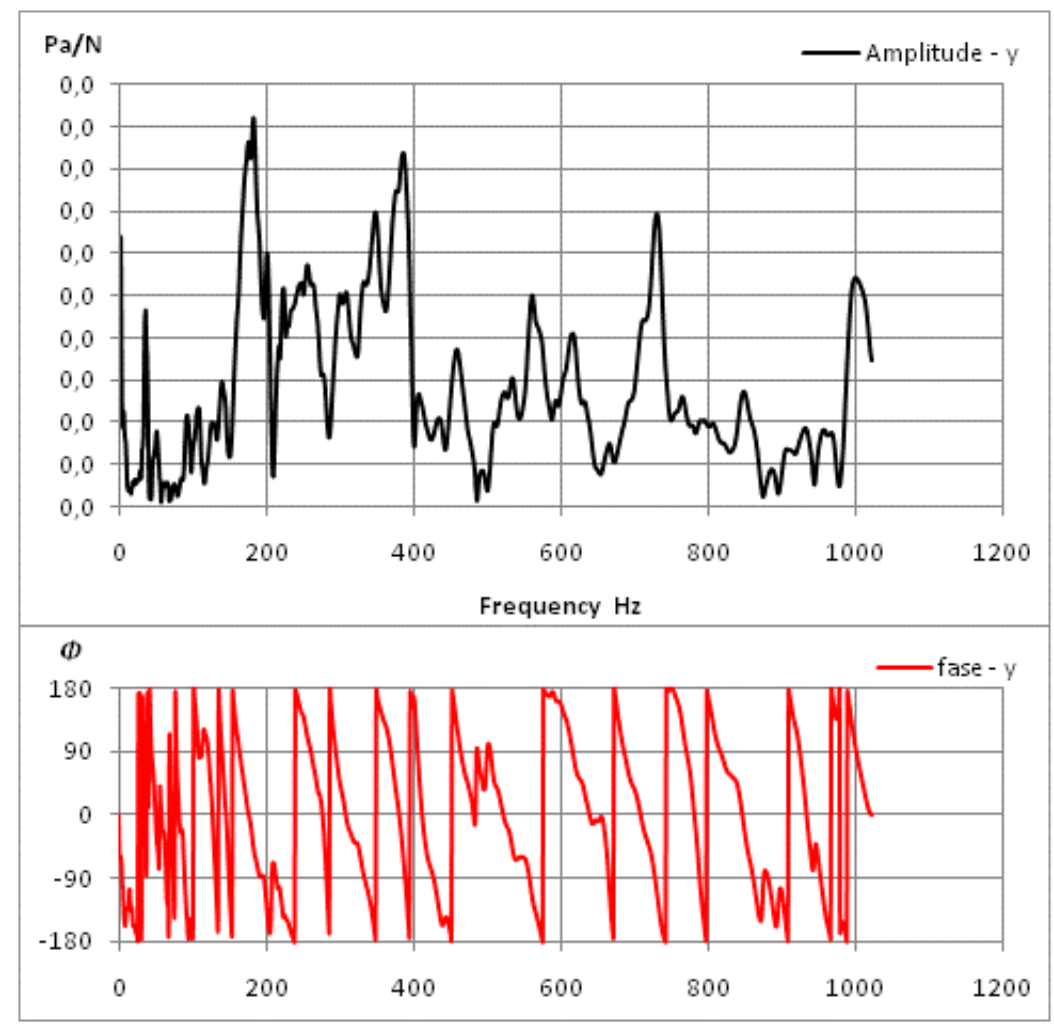

Figura 4.22 (b)

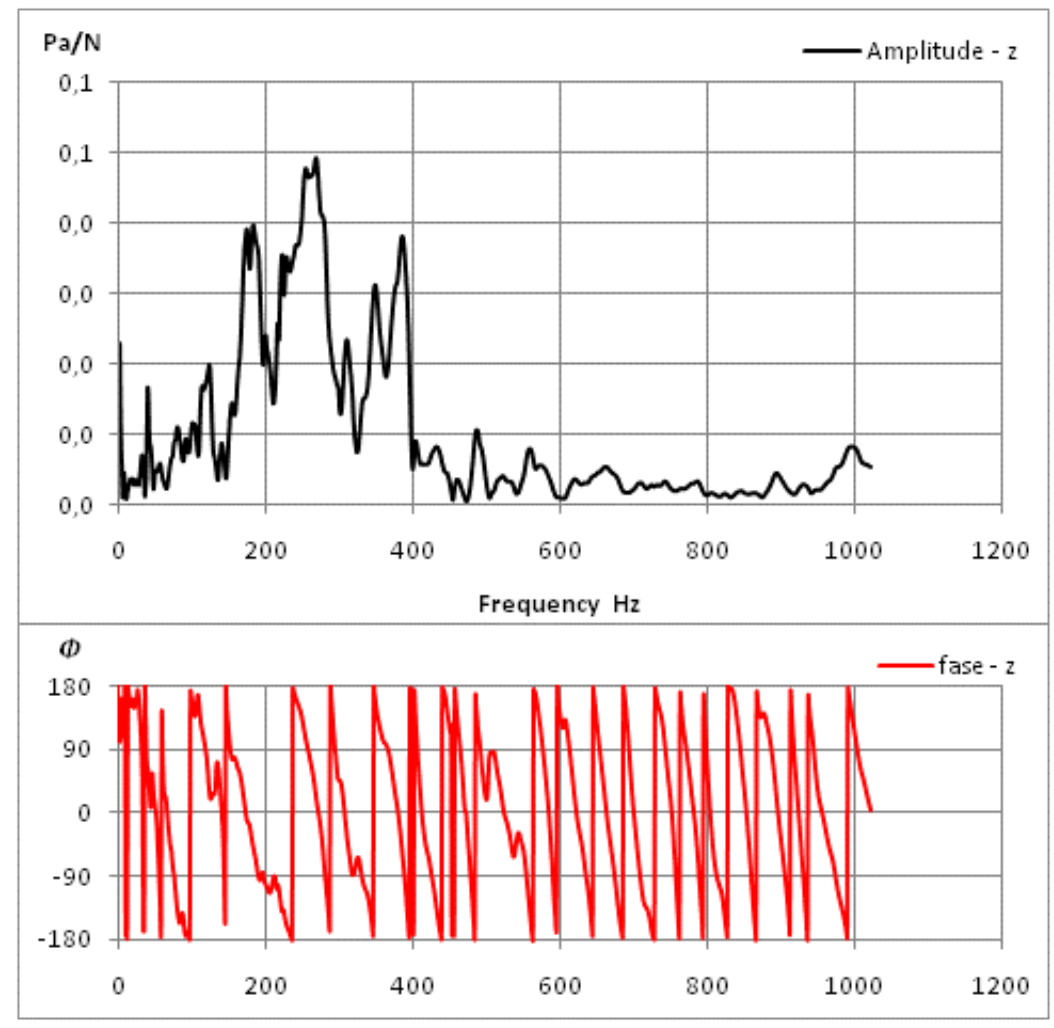

Figura 4.22 (c)

Figuras 4.22 (a), (b) e (c): FRF para sensibilidade acústica em x, y e z, bucha anterior - Ponto 3 
2.a Bucha posterior do braço - Acelerômetro Pto. 4/Martelo Pto. 4 (Aceleração /força)

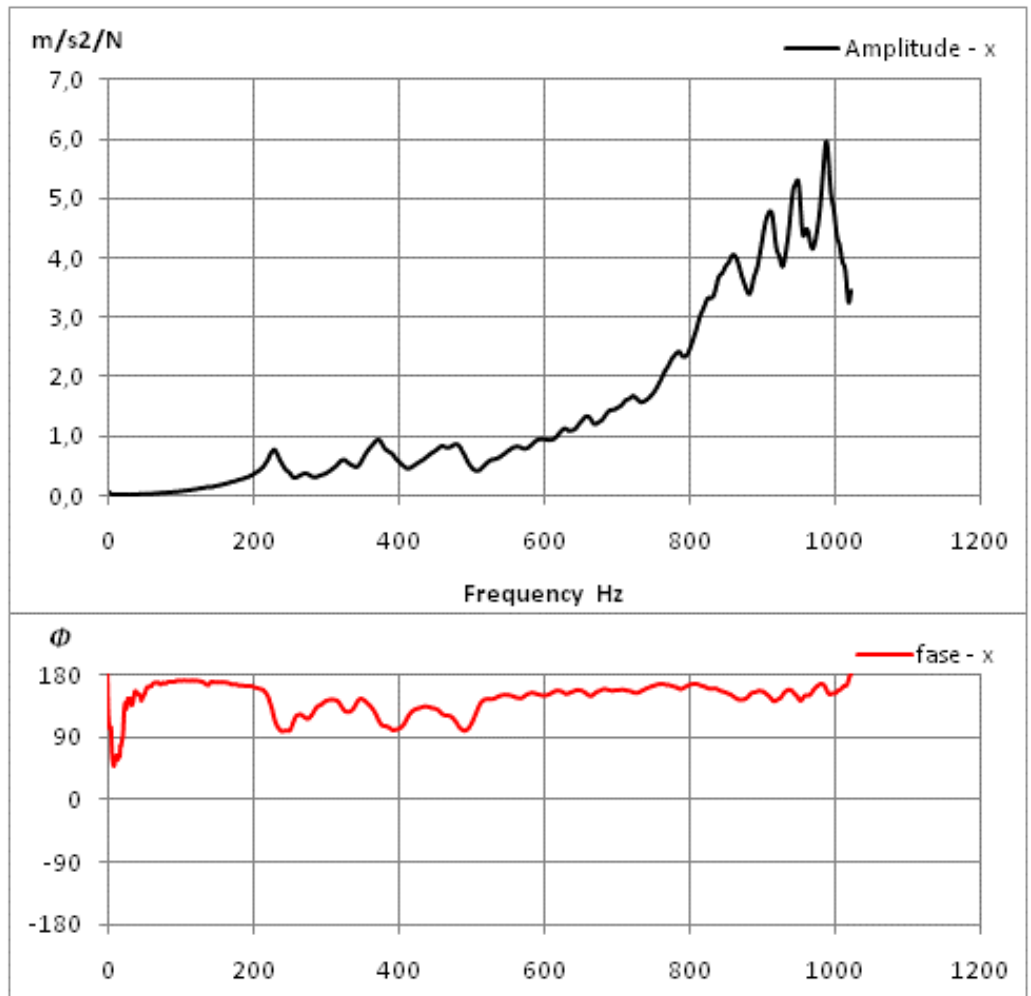

Figura 4.23 (a)

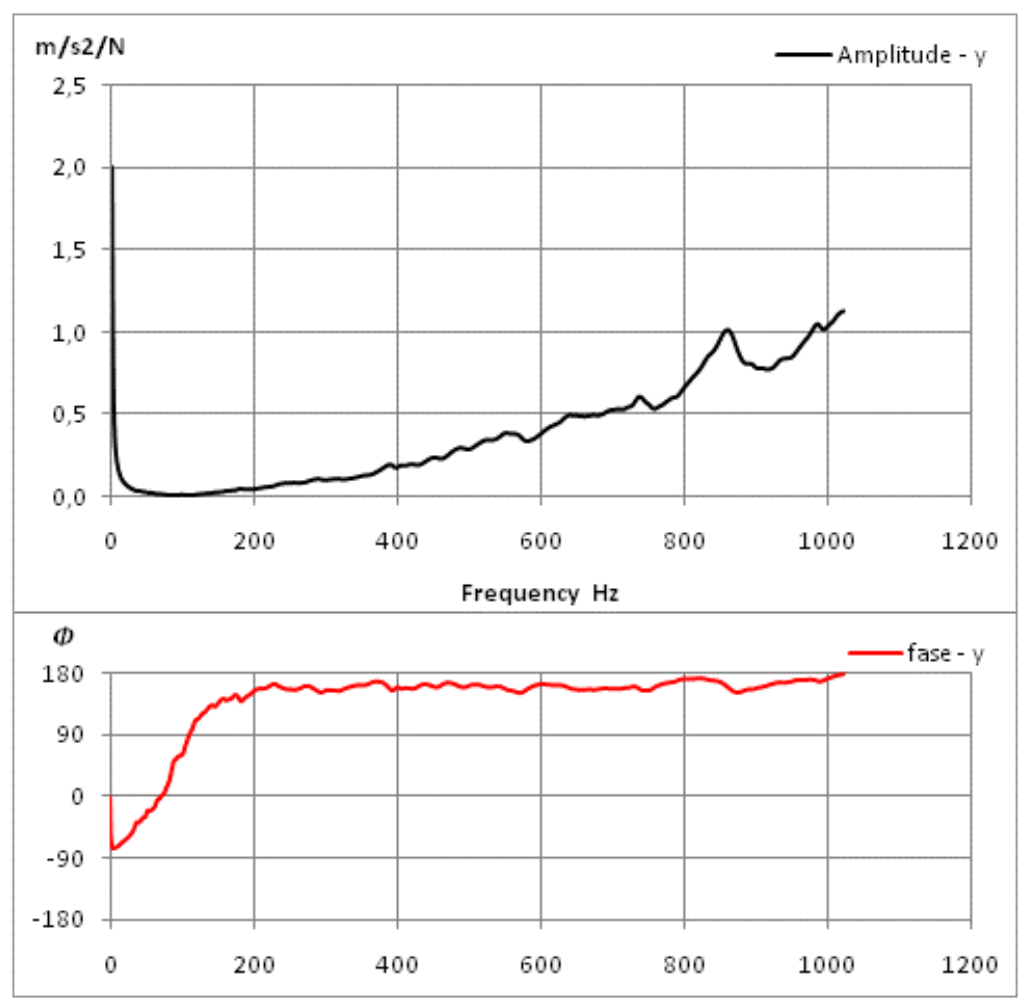

Figura 4.23 (b) 


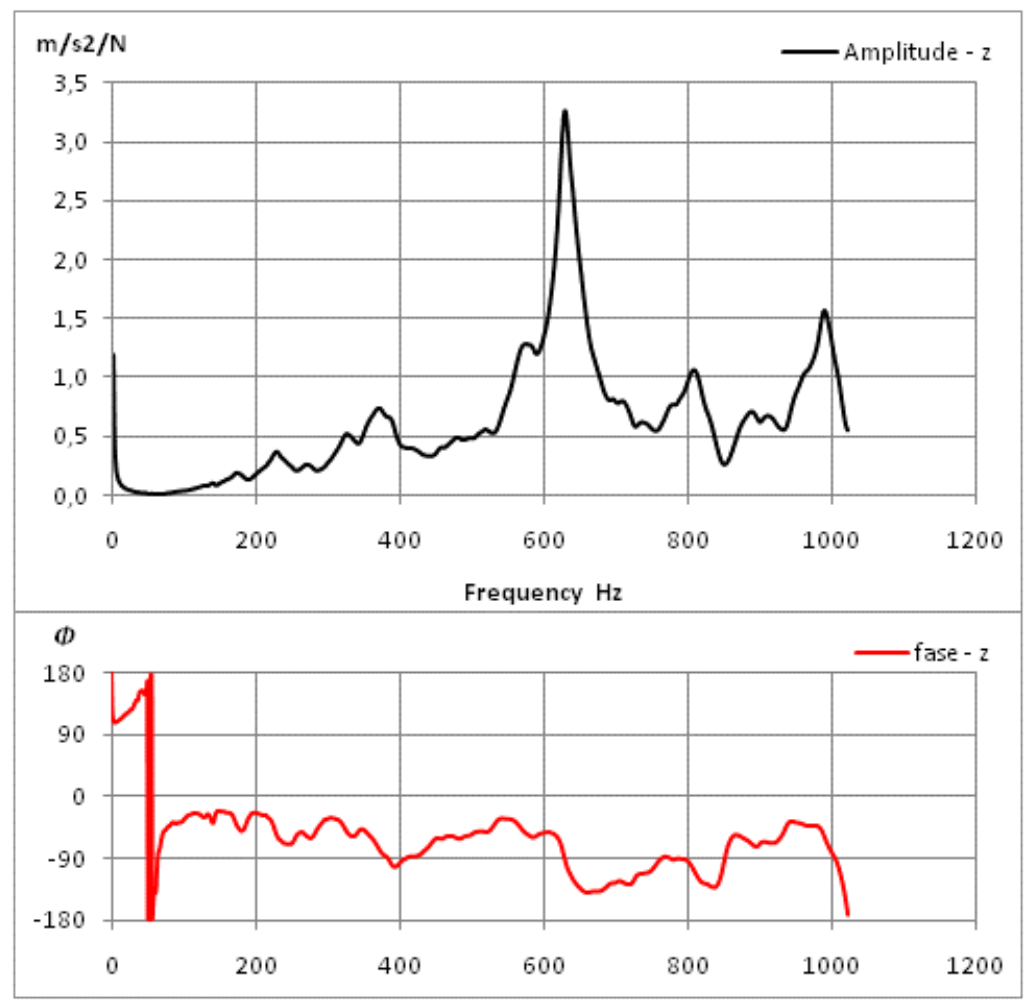

Figura 4.23 (c)

Figuras 4.23 (a), (b) e (c): FRF de ponto em x, y e z, bucha posterior - Ponto 4

\section{2.b Bucha posterior do braço - Microfone DOE/Martelo Pto. 4 (Pascal / força)}

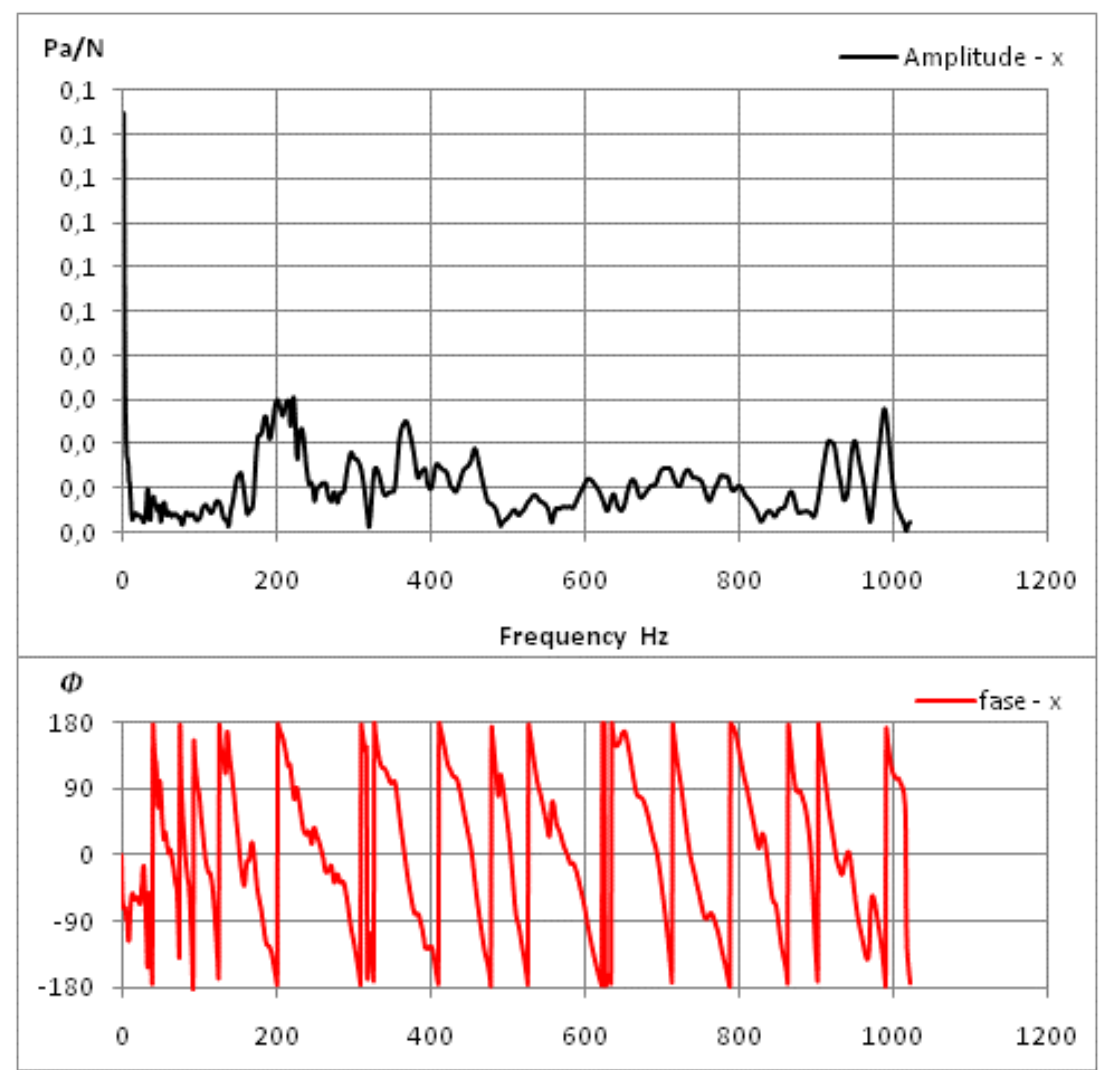

Figura 4.24 (a) 


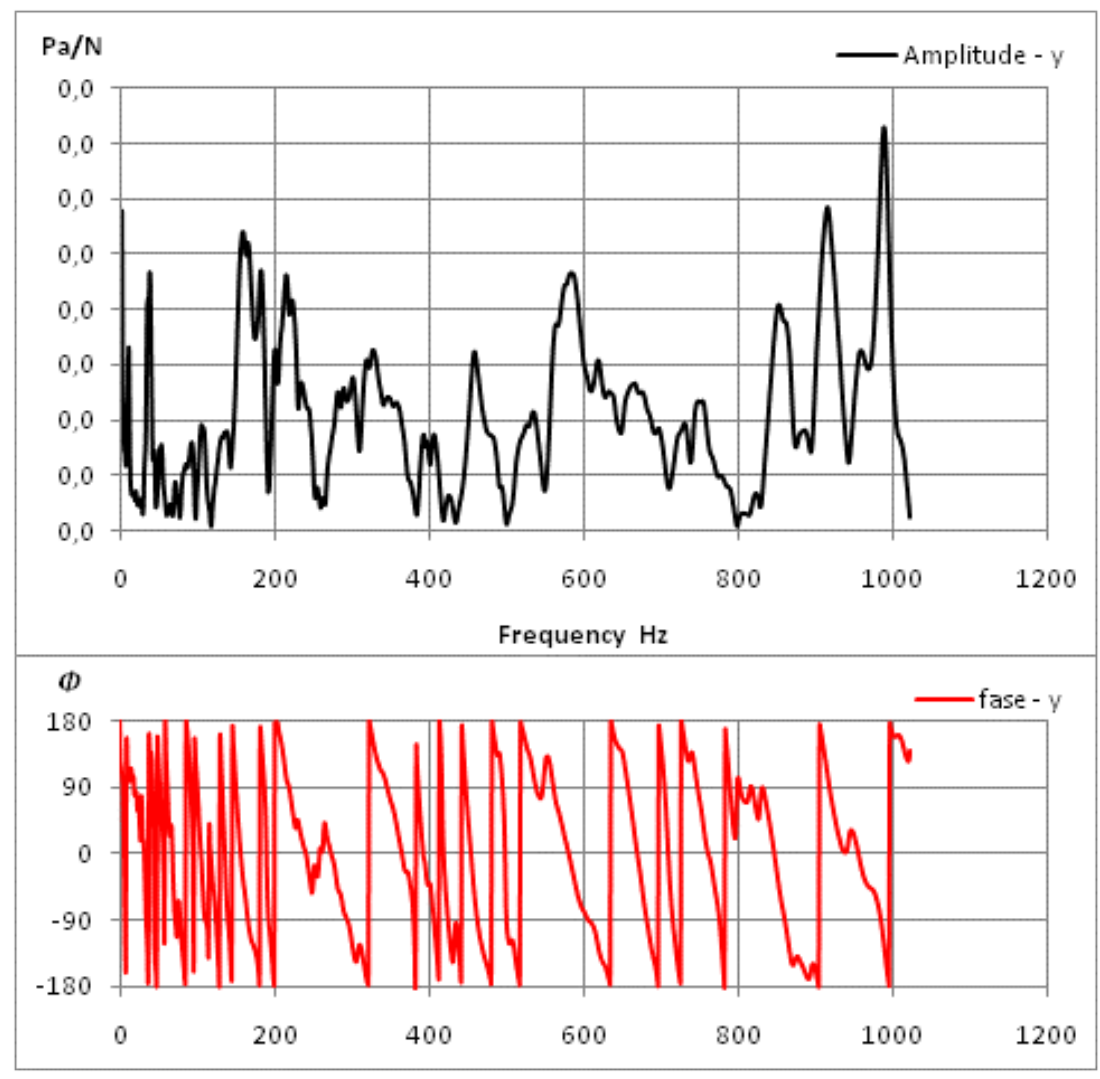

Figura 4.24 (b)

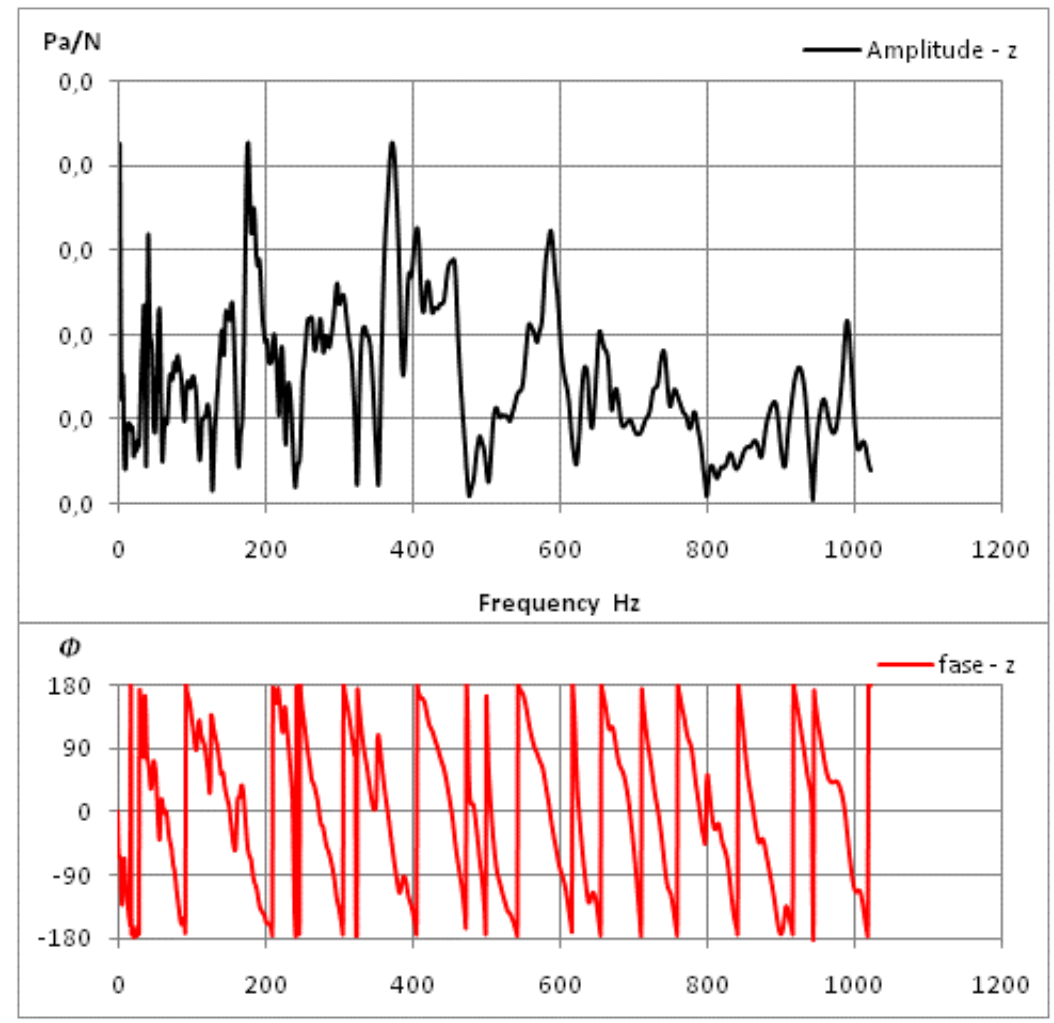

Figura 4.24 (c)

Figuras 4.24 (a), (b) e (c): FRF para sensibilidade acústica em x, y e z, bucha posterior - Ponto 4 
3.a Top Mount - Acelerômetro Topmount/Martelo Topmount (Aceleração / força)

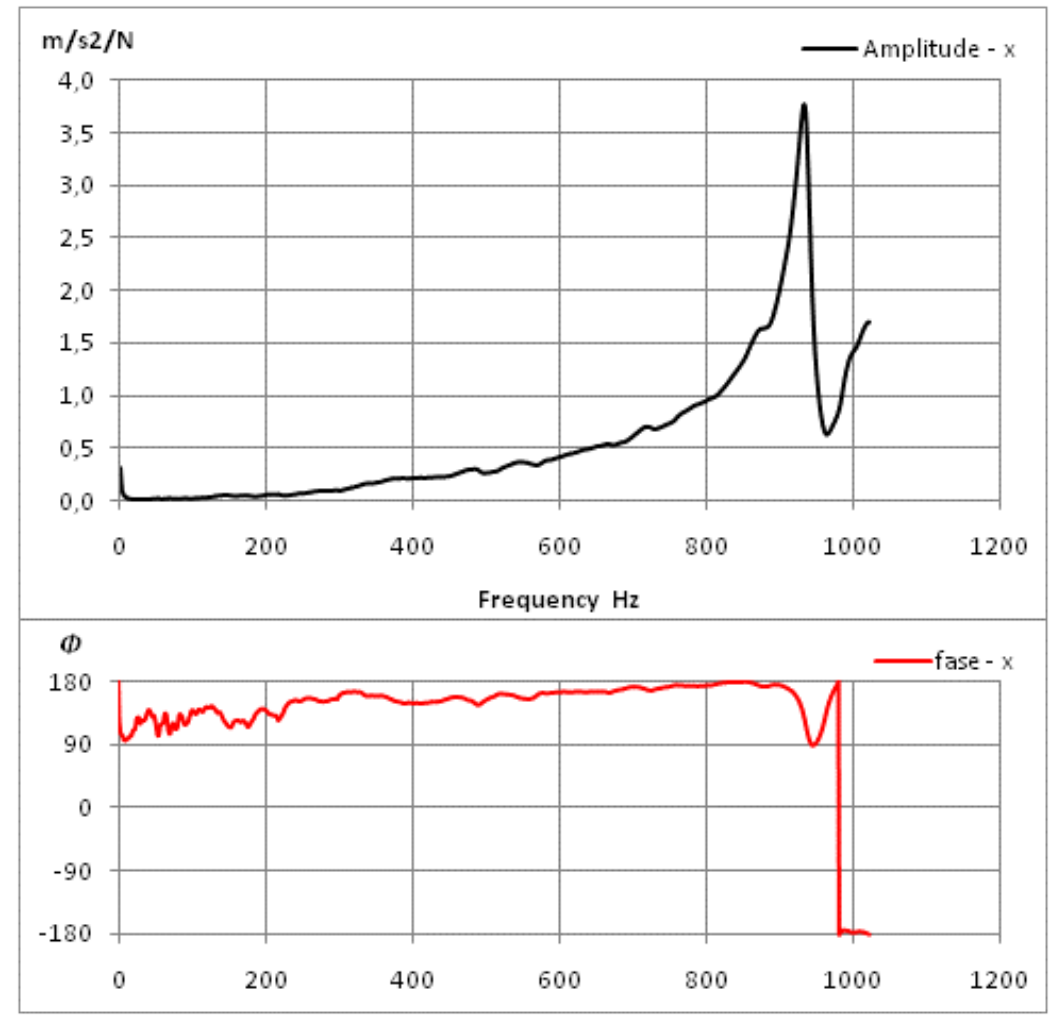

Figura 4.25 (a)

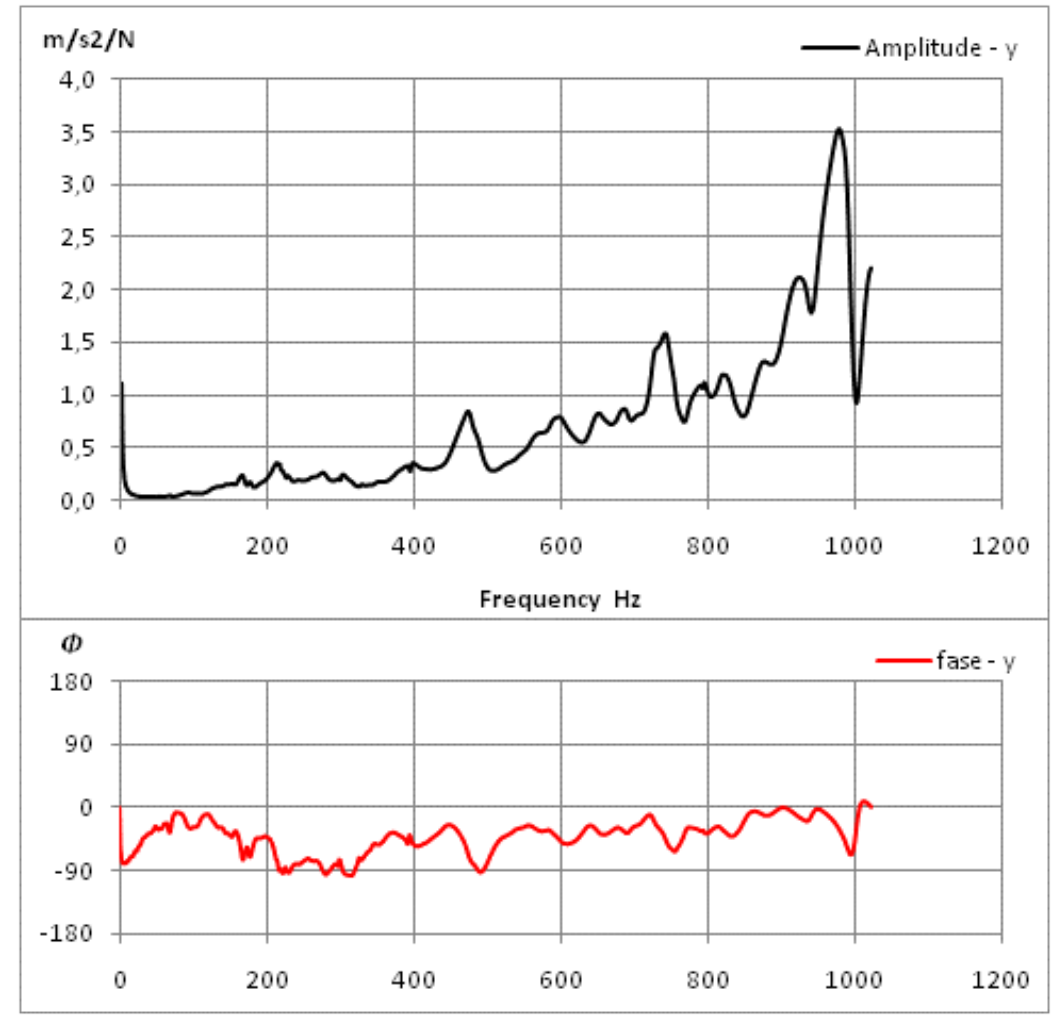

Figura 4.25 (b) 


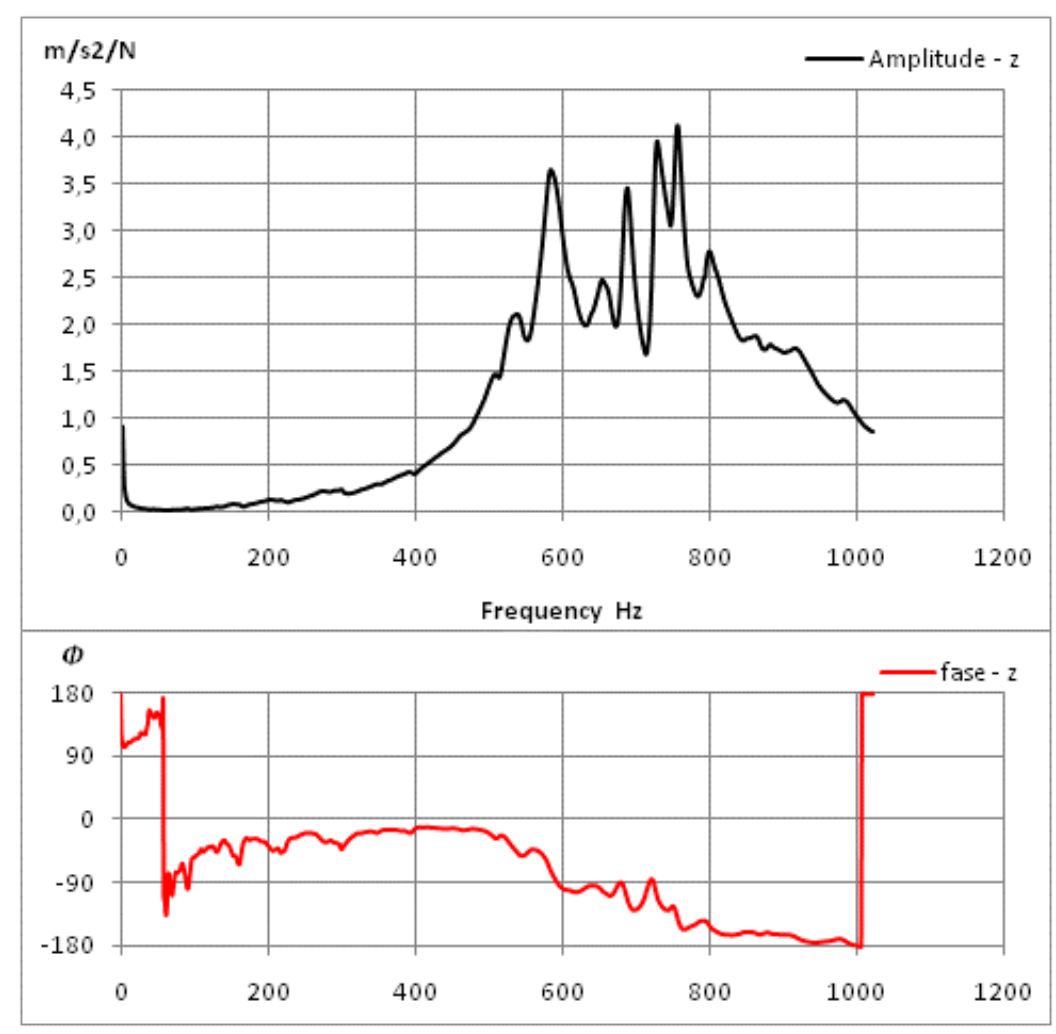

Figura 4.25 (c)

Figuras 4.25 (a), (b) e (c): ): FRF de ponto em x, y e z, Top Mount

3.b Top Mount - Microfone DOE /Martelo TopMount (Pascal / força)

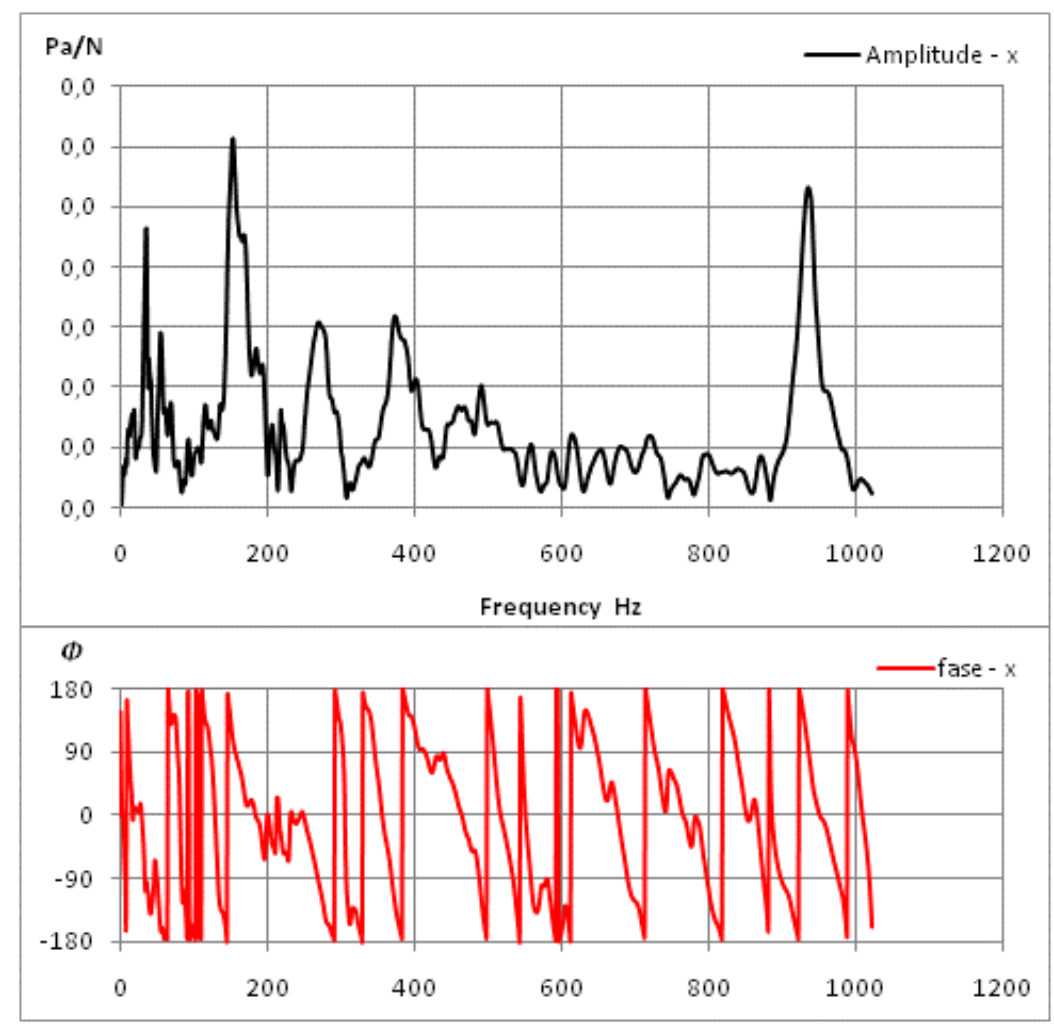

Figura 4.26 (a) 


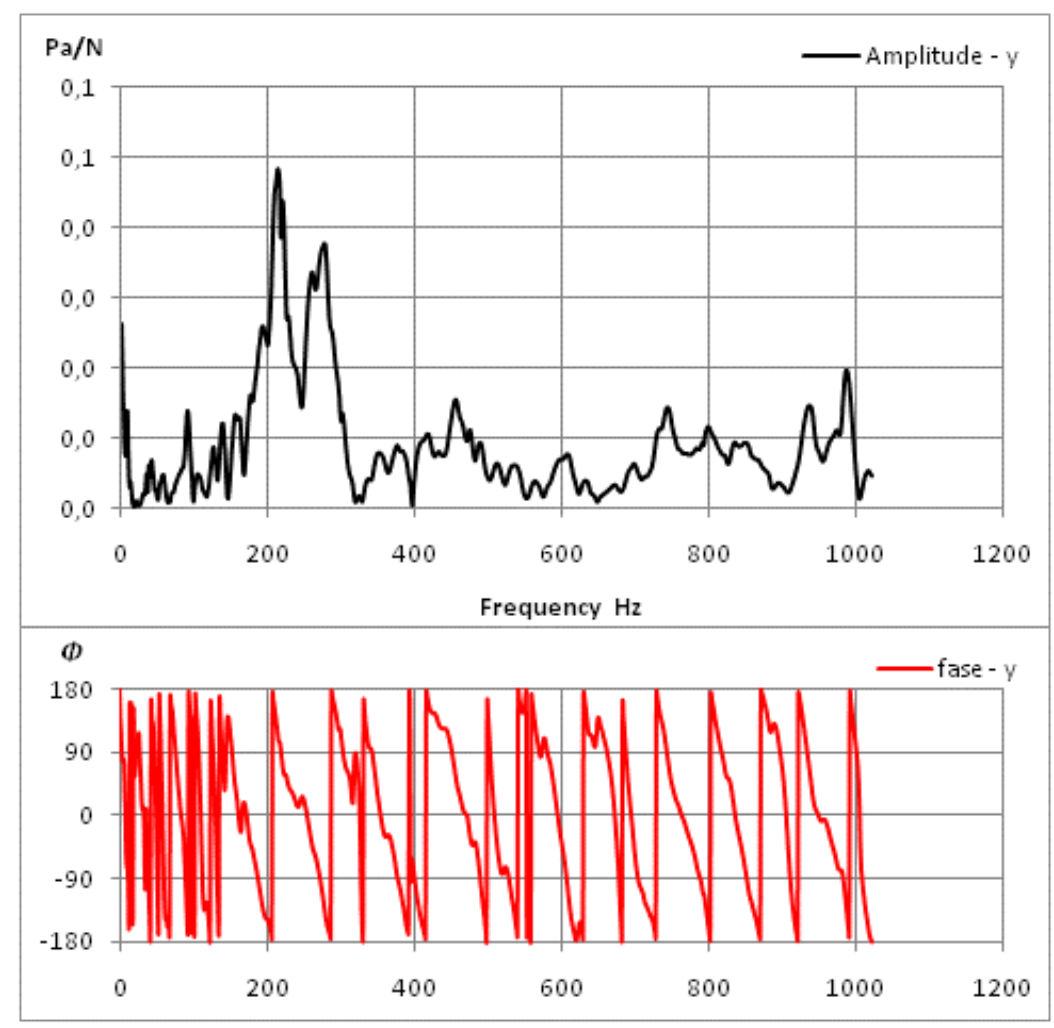

Figura 4.26 (b)

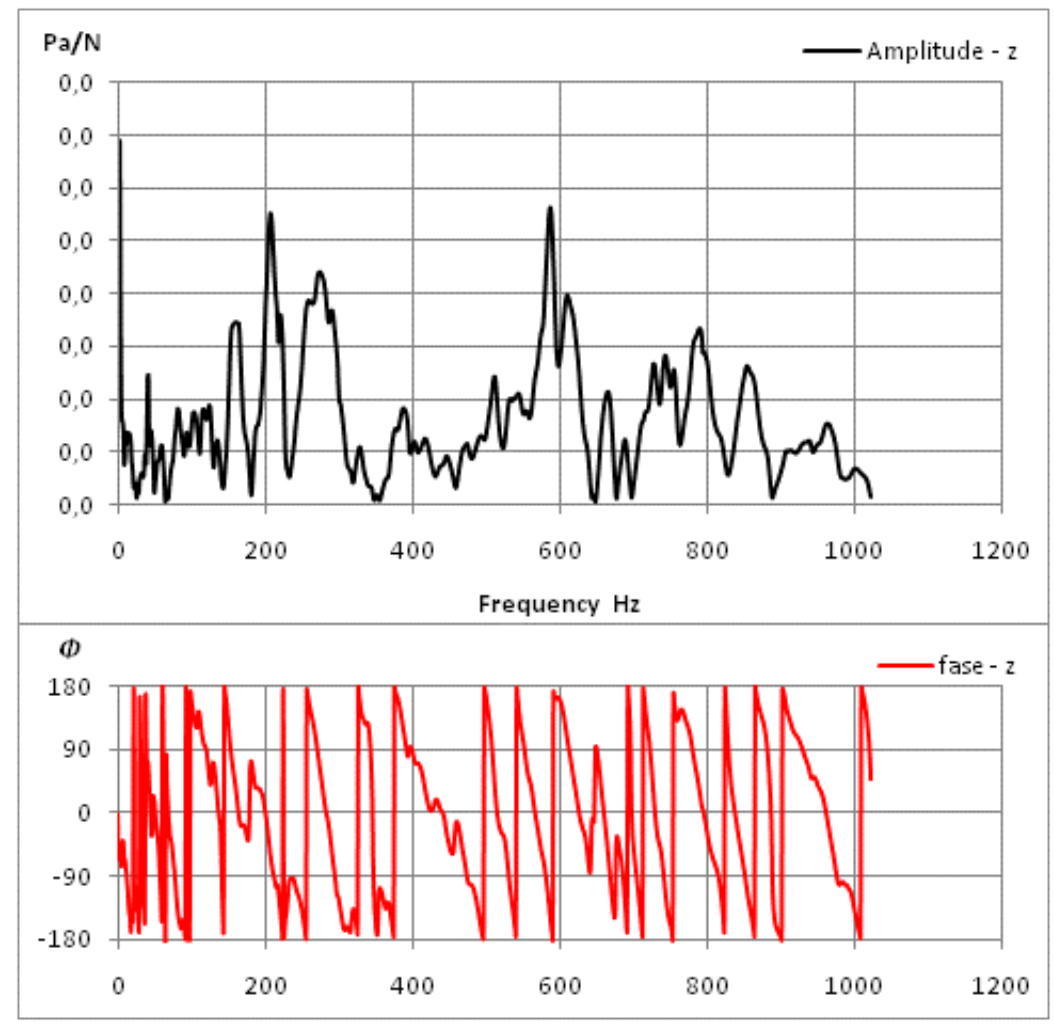

Figura $4.26($ c)

Figuras 4.26 (a), (b) e (c): FRF para sensibilidade acústica em x, y e z, Top Mount 


\subsection{Análises dos resultados}

Após as medições em laboratório, o protótipo foi instrumentado para medições das vibrações operacionais no qual são necessários para calculo indireto das forças atuantes nos caminhos do ruído.

Simultaneamente, é realizada a aquisição do nível de pressão sonora em pista, com o microfone posicionado próximo ao ouvido externo do motorista. As medições em pistas foram realizadas com o motor desligado, em declive, para contribuir com uma melhor correlação com o ruído interno medido diretamente.

Calculam-se as entradas de forças e as respostas acústicas no veículo. Conforme teoria, a adição da fonte parcialmente correlacionada, mas não coerente de ruído, usa-se a equação (83), para contabilizar o lado esquerdo da suspensão que não foi instrumentada. Assim, chega-se ao valor final de pressão sonora interna no protótipo, para correlação com o ruído interno medido.

\subsubsection{Correlação experimental entre ruído medido e o TPA}

A figura 4.27 compara o ruído medido em pista, pelo microfone interno na posição DOE, com o ruído calculado pelo TPA. Como pode ser visto, há pequenas diferenças ao entre as curvas, principalmente em torno de $130 \mathrm{~Hz}$ e $270 \mathrm{~Hz}$. Contudo, no geral, para a faixa de frequência de 80 a $300 \mathrm{~Hz}$, onde predomina a contribuição estrutural, ambas as curvas são similares e demonstram o efeito do rumble próximo de $180 \mathrm{~Hz}$. Calculando o nível de pressão sonora total nesta faixa, o ruído real medido chega a 65,6 dB(A), enquanto que o calculado atinge $65,1 \mathrm{~dB}(\mathrm{~A})$. A correlação é satisfatória e significativa para o estudo do rumble. 


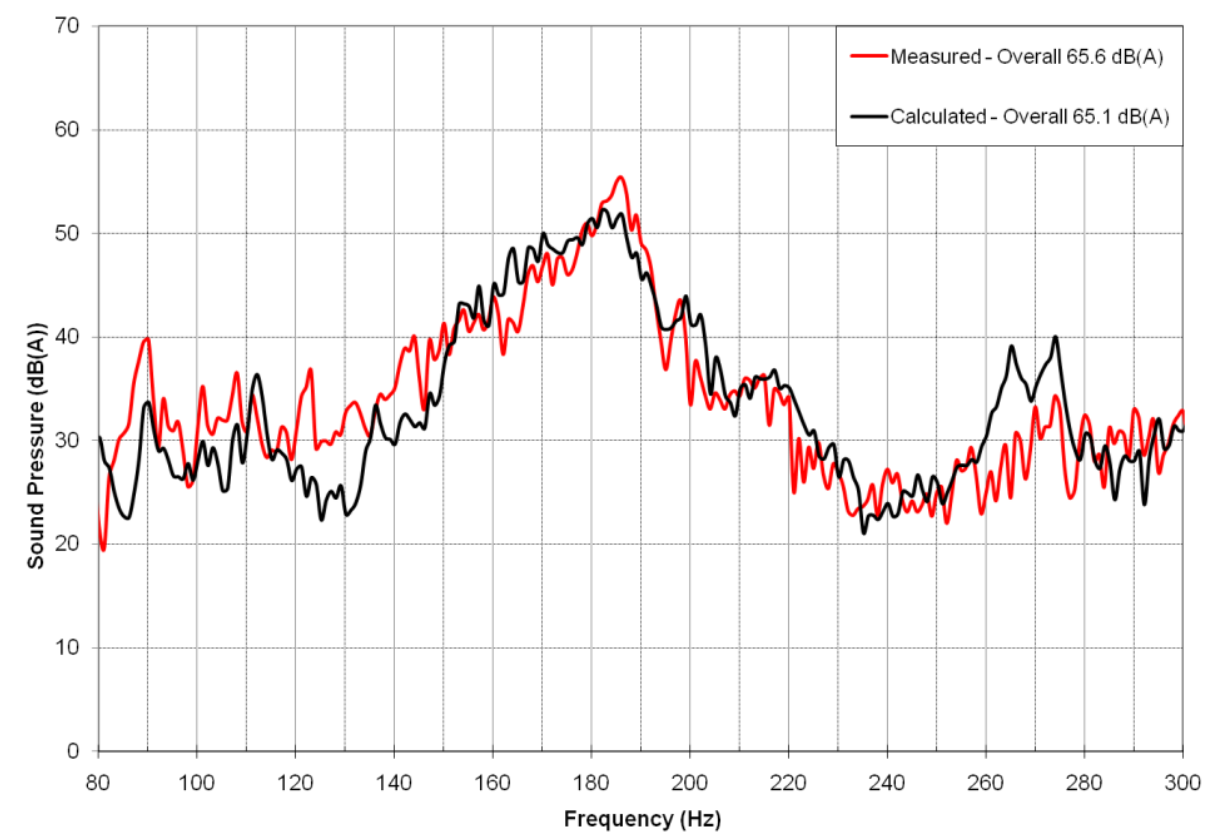

Figura 4.27:- Correlação do nível de pressão sonora medida vs. calculado, Pista Lisa @ 20 Km/h

Com o ruído calculado correlacionado, mostram-se as contribuições de cada caminho escolhido para o TPA. A figura 4.28 repete a anterior, acrescentando os ruídos nos caminhos das buchas anterior e posterior do braço de controle (pontos 3 e 4) e a bucha da torre do amortecedor, Top Mount. De acordo com as análises, a bucha anterior da bandeja da suspensão (point \#3) demonstra ser o caminho mais crítico na contribuição do rumble em $180 \mathrm{~Hz}$, seguido pelo Top Mount e por último, a influência da bucha posterior (point \#4). O valor total da faixa encontra-se na legenda.

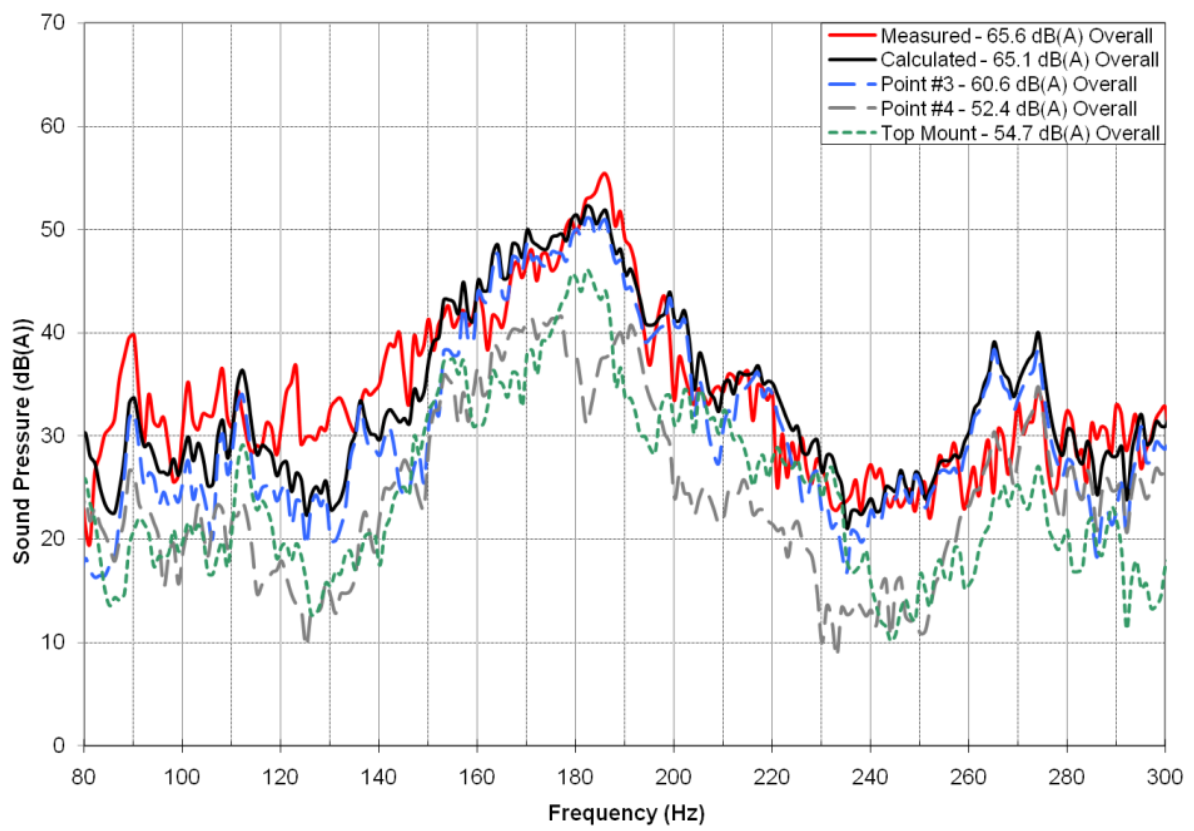

Figura 4.28: Correlação dos caminhos para o rumble, Pista Lisa @ 20 km/h 
Sobe a mesma condição de pista, a figura 4.29 mostra a correlação do rumble e os caminhos do ruído de rodagem para a $60 \mathrm{~km} / \mathrm{h}$, permanecendo o ponto 3 como o caminho mais crítico.

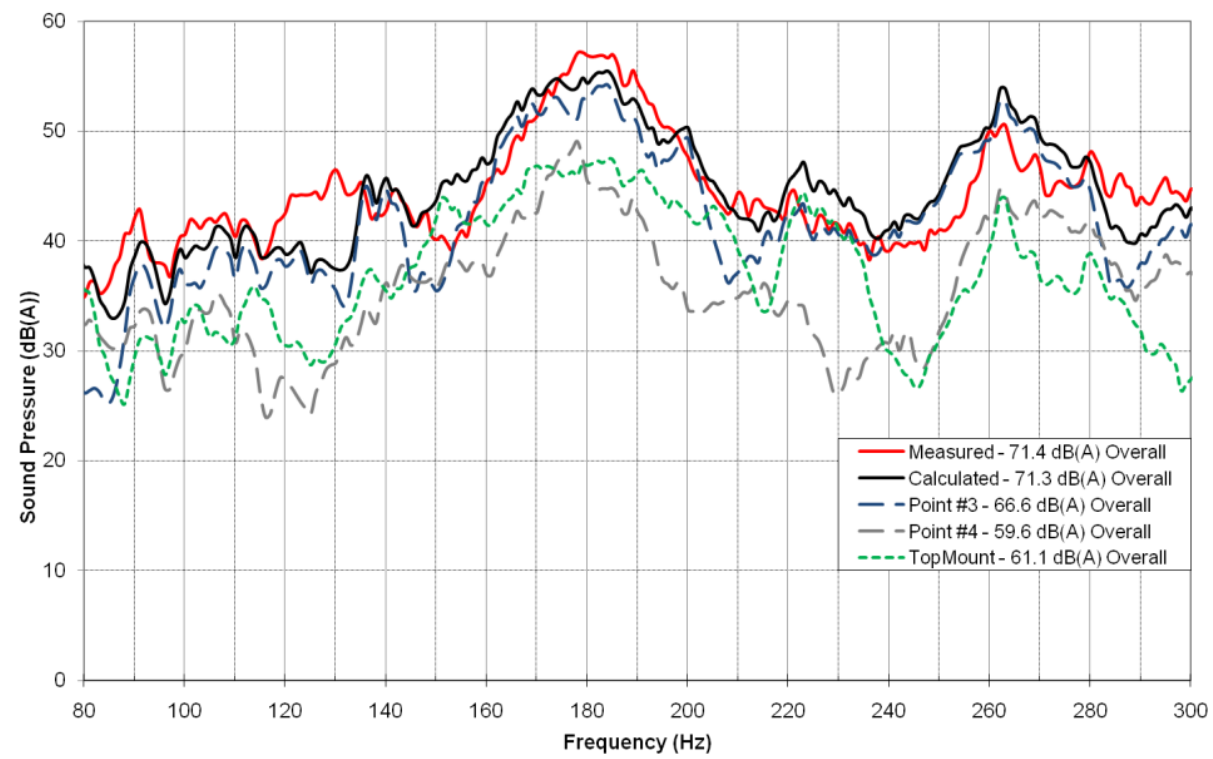

Figura 4.29: Correlação dos caminhos para o rumble, Pista Lisa @ 60 km/h

A figura 4.30 por fim mostra a correlação entre o rumble medido e o calculado, na pista áspera a $50 \mathrm{~km} / \mathrm{h}$. As pistas batizadas de Lisa e Áspera são as duas condições de textura de superfícies mais relevantes para o caso, e confirmam a correlação dos testes para o TPA e também o caminho crítico pela bucha anterior, o ponto 3 .

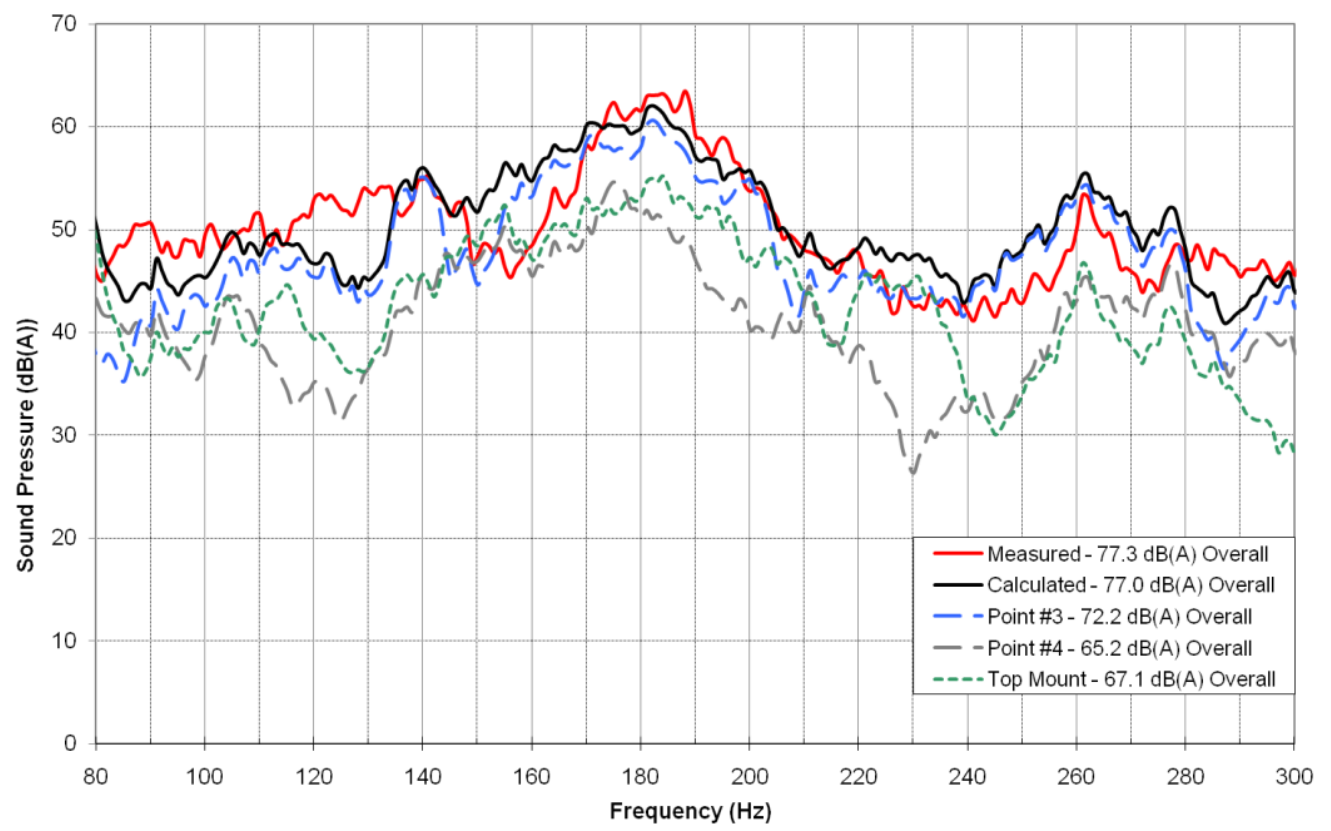

Figura 4.30: Correlação dos caminhos para o rumble, Pista Áspera @ 50 km/h 


\subsubsection{Eficiências dos caminhos na absorção de energia}

Durante a etapa de medições em pista, são aquisitadas as vibrações operacionais das buchas. São necessários somente os dados no lado passivo (carroceria), para o calculo indireto das forças de entrada, pelo o método da matriz inversa, sendo dispensados os dados de rigidez. Contudo, neste estudo, o lado ativo da conexão das buchas também é medido. A relação entre os lados ativos e passivos é usada para visualizar o quanto as vibrações causadas pelos pneus são isoladas pelas buchas da suspensão. As figuras 4.31 (a), (b) e (c) apresentam a velocidade nos três eixos e a resultante das velocidades do lado ativo e passivo, para cada bucha, em pista Lisa, a $20 \mathrm{~km} / \mathrm{h}$.

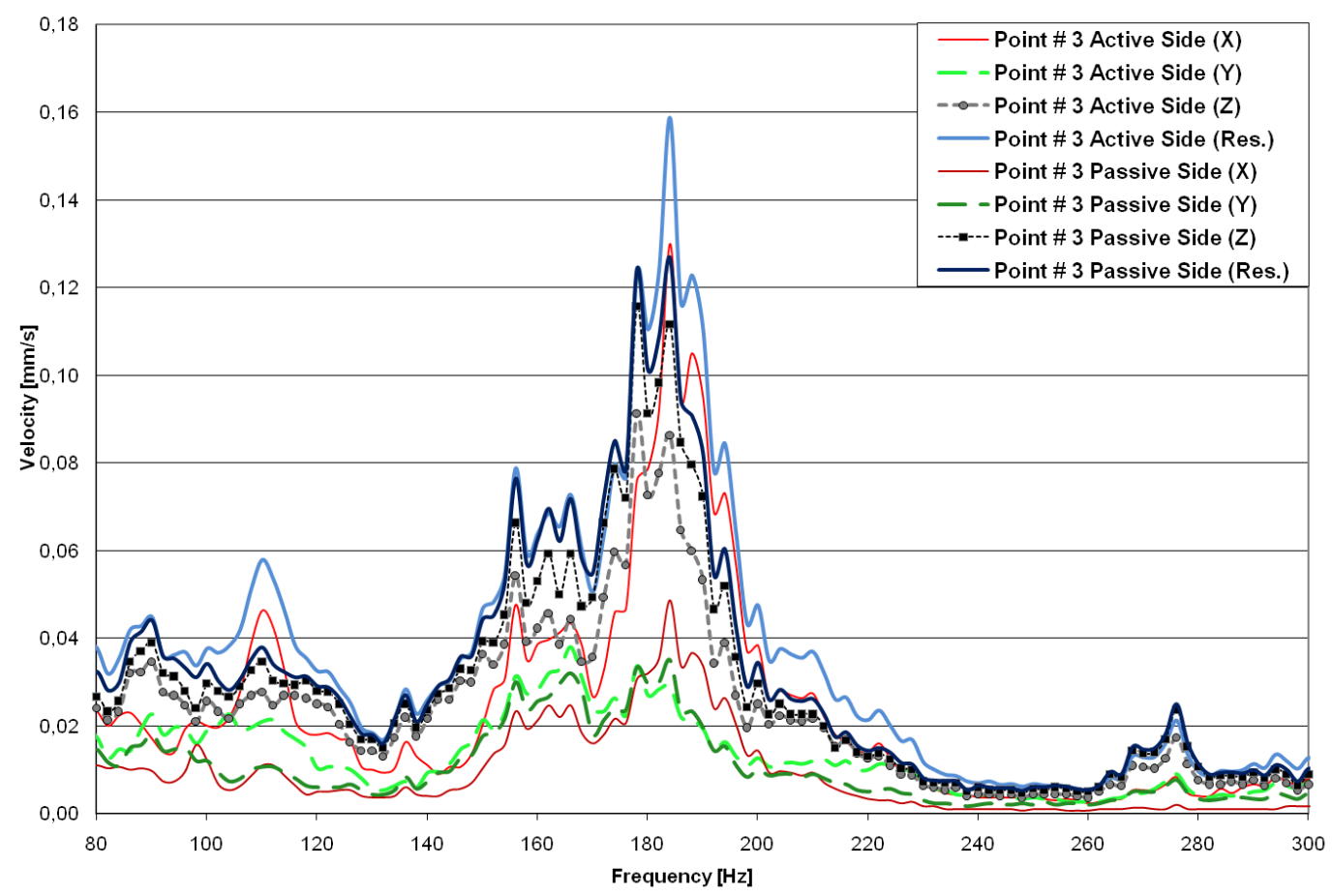

Figura 4.31 (a) 


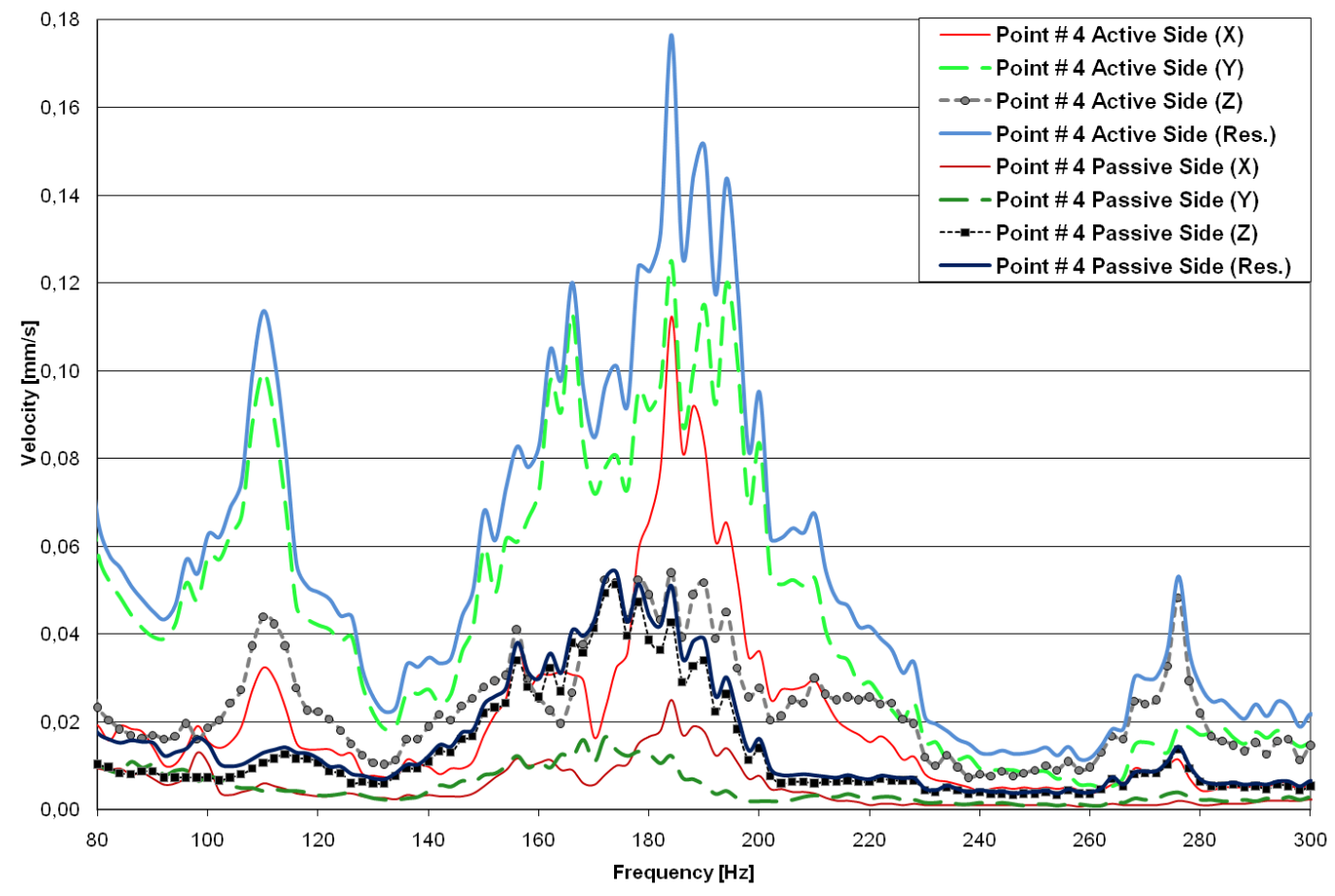

Figura 4.31 (b)

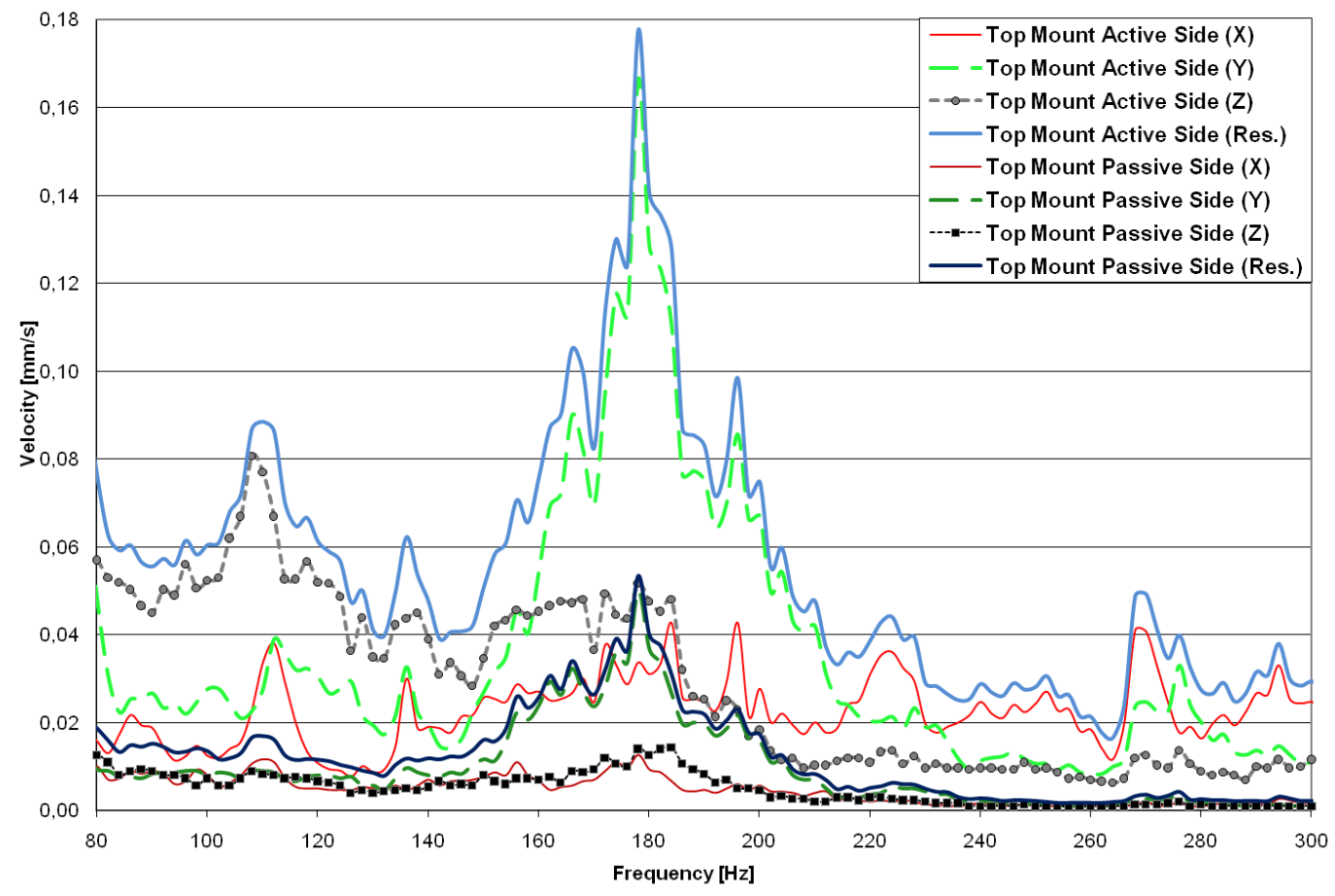

Figura $4.31(c)$

Figuras 4.31 (a), (b) e (c): Velocidades nos lados ativos e passivos medidos nas buchas ponto 3, 4 e Top Mount respectivamente.

Comparando as curvas das respostas de velocidade em cada ponto, nota-se que ambas as buchas Ponto 4 e Top Mount recebem maiores vibrações no lado ativo. Porem, olhando o lado passivo, vê-se que ambos são capazes de absorver maior energia que vem dos 
pneumáticos para a carroceria. O mesmo não ocorre no ponto 3. As curvas de velocidades no lado ativo e passivo possuem amplitudes menores, entretanto, a diferença entre as curvas também são relativamente pequenas, o que mostra uma menor eficiência no isolamento das vibrações, principalmente nas direções y e z. As figuras 4.32 (a), (b) e (c) representam a relação das velocidades ativo/passivo para melhor ilustrar o trabalho de atenuação das buchas.

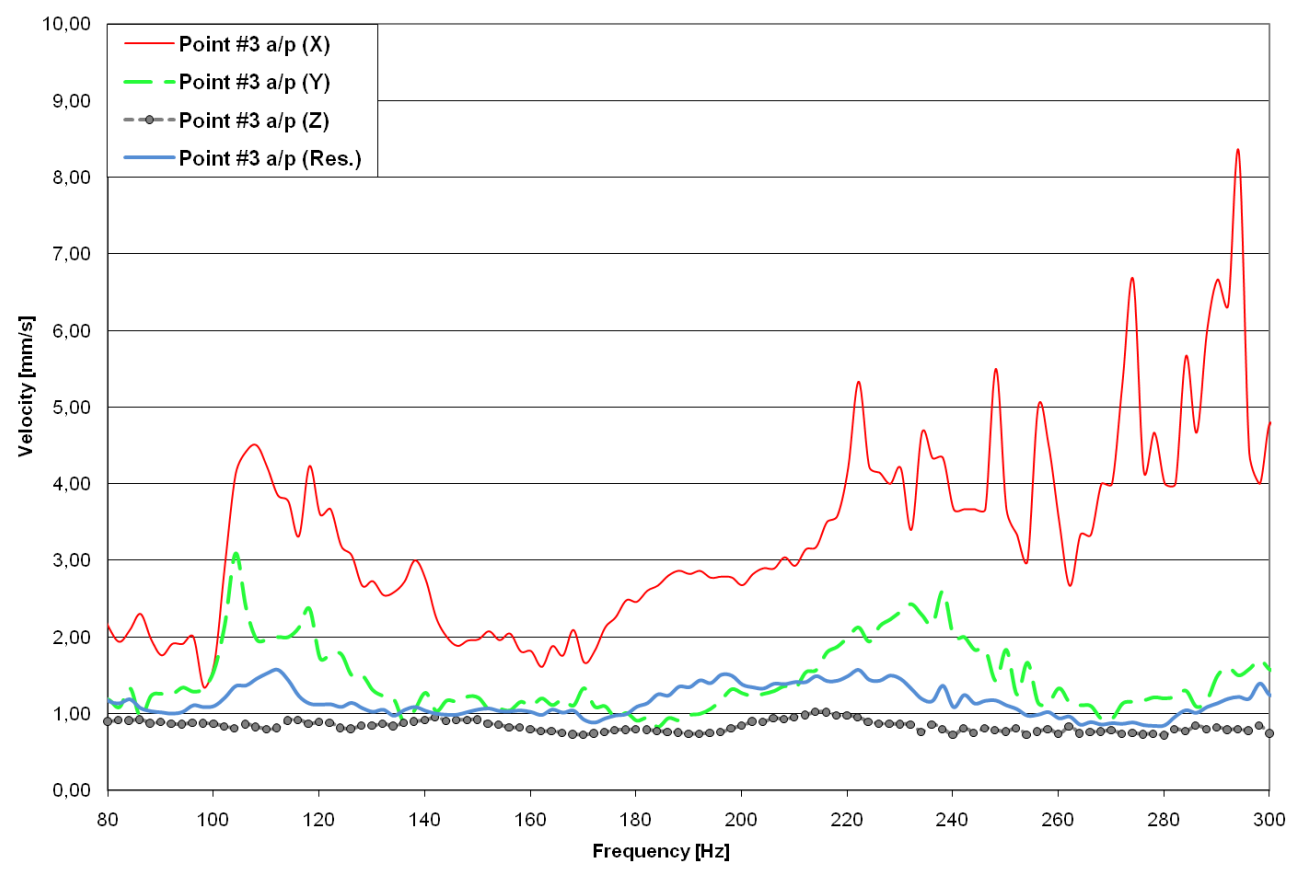

Figura 4.32 (a)

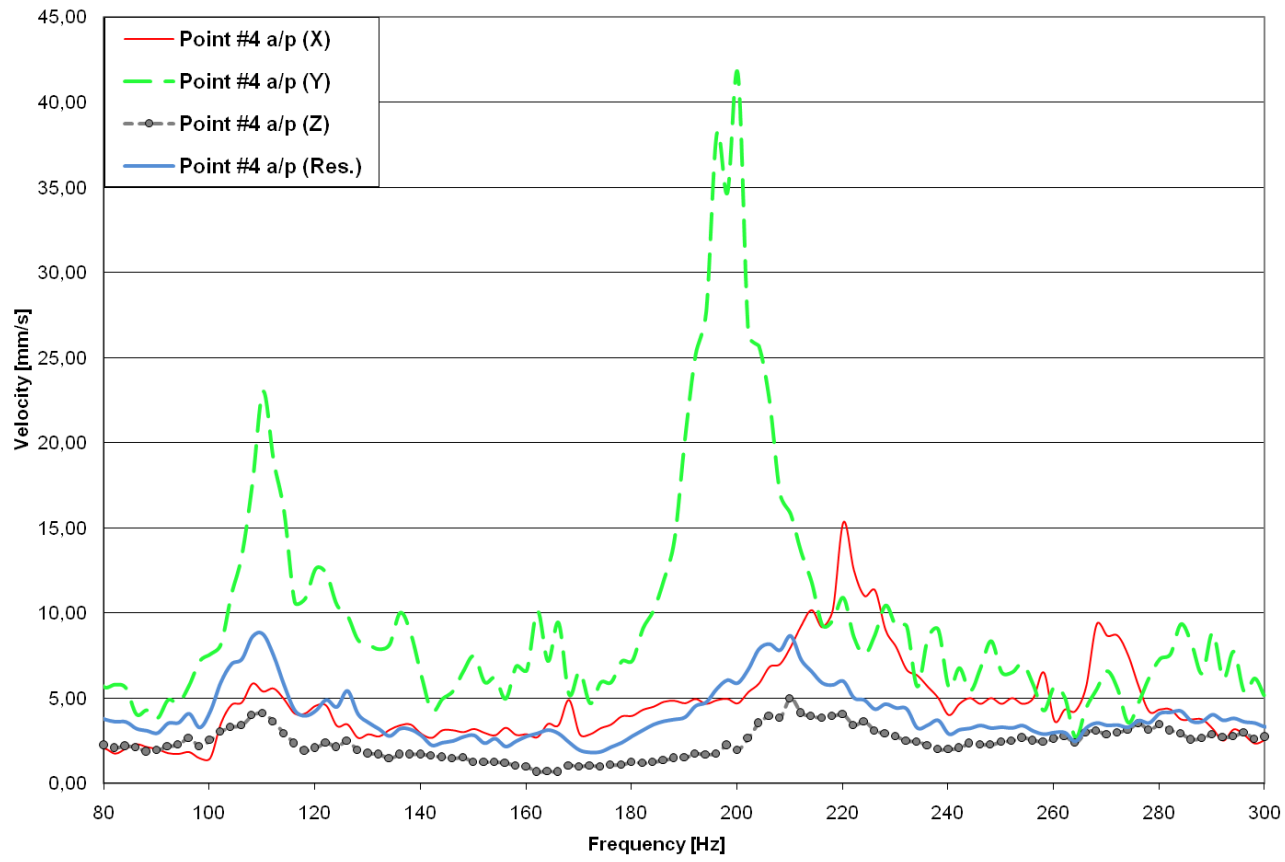

Figura 4.32 (b) 


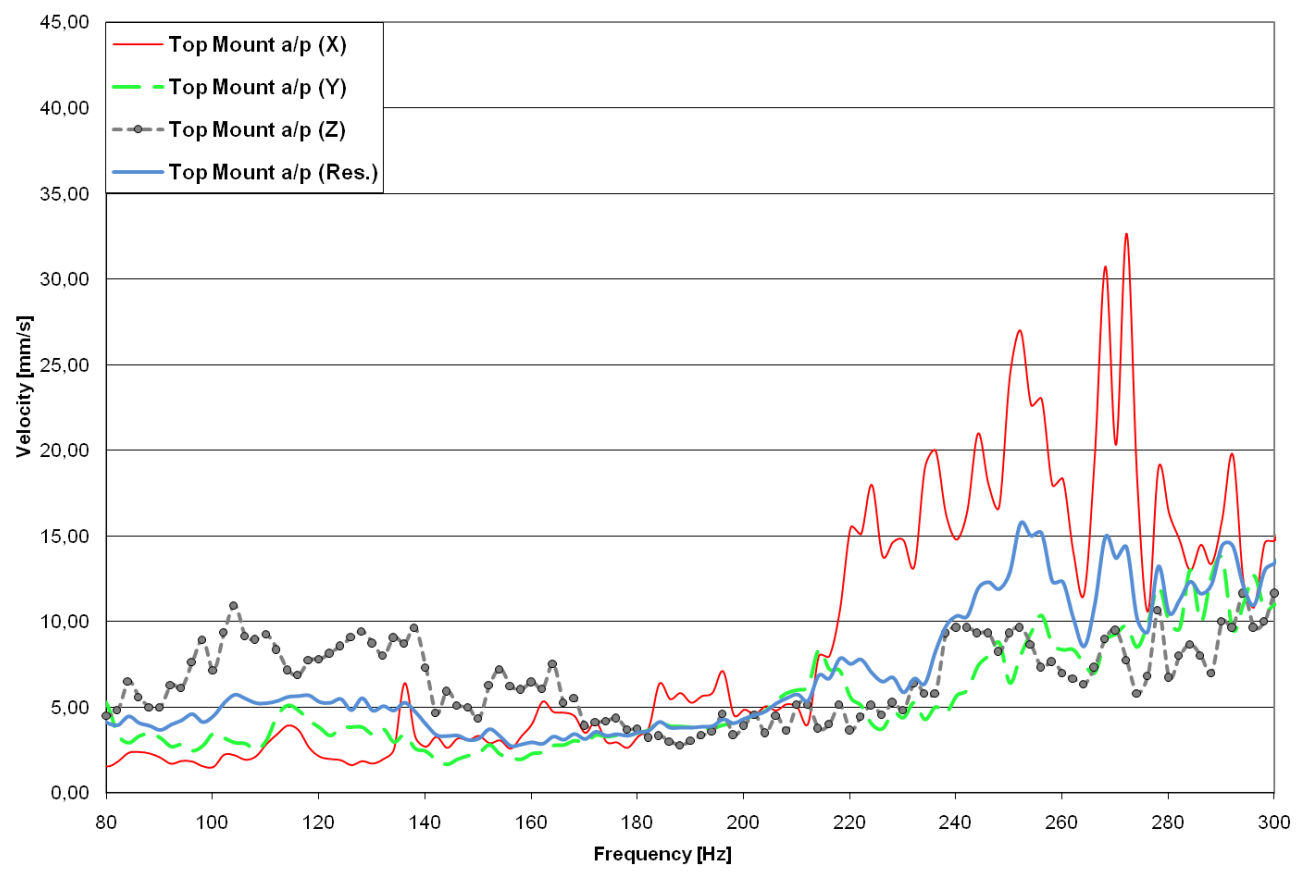

Figura 4.32 (c)

Figuras 4.32 (a), (b) e (c): Relação ativo/passivo referente o trabalho das buchas na isolação de vibrações Mais uma vez, as curvas acima mostram a menor eficiência do ponto 3 para a isolação de vibração em y e z, e previamente demonstra que a bucha anterior é o caminho mais crítico na contribuição para o rumble.

Os dados de vibrações dos lados ativos e passivos, sendo elas na unidade de velocidade ou aceleração, podem ser usados para o calculo do TPA utilizando o método da Rigidez Complexa, conforme equação (69) da revisão teórica. Faz se apenas uma ressalva ás unidades utilizadas nas vibrações de pista, podendo ser usado valores de velocidade ou mesmo deslocamento, obtidos ao integrar os dados de acelerações. O Método da Rigidez Complexa é comumente usado para investigações de TPA para configurações de coxins e motorizações. Uma recomendação deste trabalho é uma investigação mais profunda entre este método e o método da matriz inversa nos temas ligados a Road NVH.

A seguir, serão apresentados os resultados dos cálculos de forças e ruído para cada caminho investigado pelo TPA. Apesar da bucha no ponto 3 ser o mais crítico, ainda é necessário saber se o problema deve ser abordado melhorando a atenuação do carregamento no ponto ou a sua sensibilidade acústica para a carroceria. Para fins didáticos, o estudo de caso apresentará as investigações na condição mais critica ao rumble, pista Lisa a $20 \mathrm{~km} / \mathrm{h}$. 


\subsubsection{Calculo das forças de entrada no chassi}

Com os dados de vibração do lado passivo e as medições das FRFs em laboratório, para a mobilidade dos pontos (ou impedância), calculam-se as forças de entrada, devido a interação do "pneu A" na pista Lisa a $20 \mathrm{~km} / \mathrm{h}$. A figura 4.33 apresenta o carregamento estrutural total sofrido pelo lado direito de cada componente do chassi.

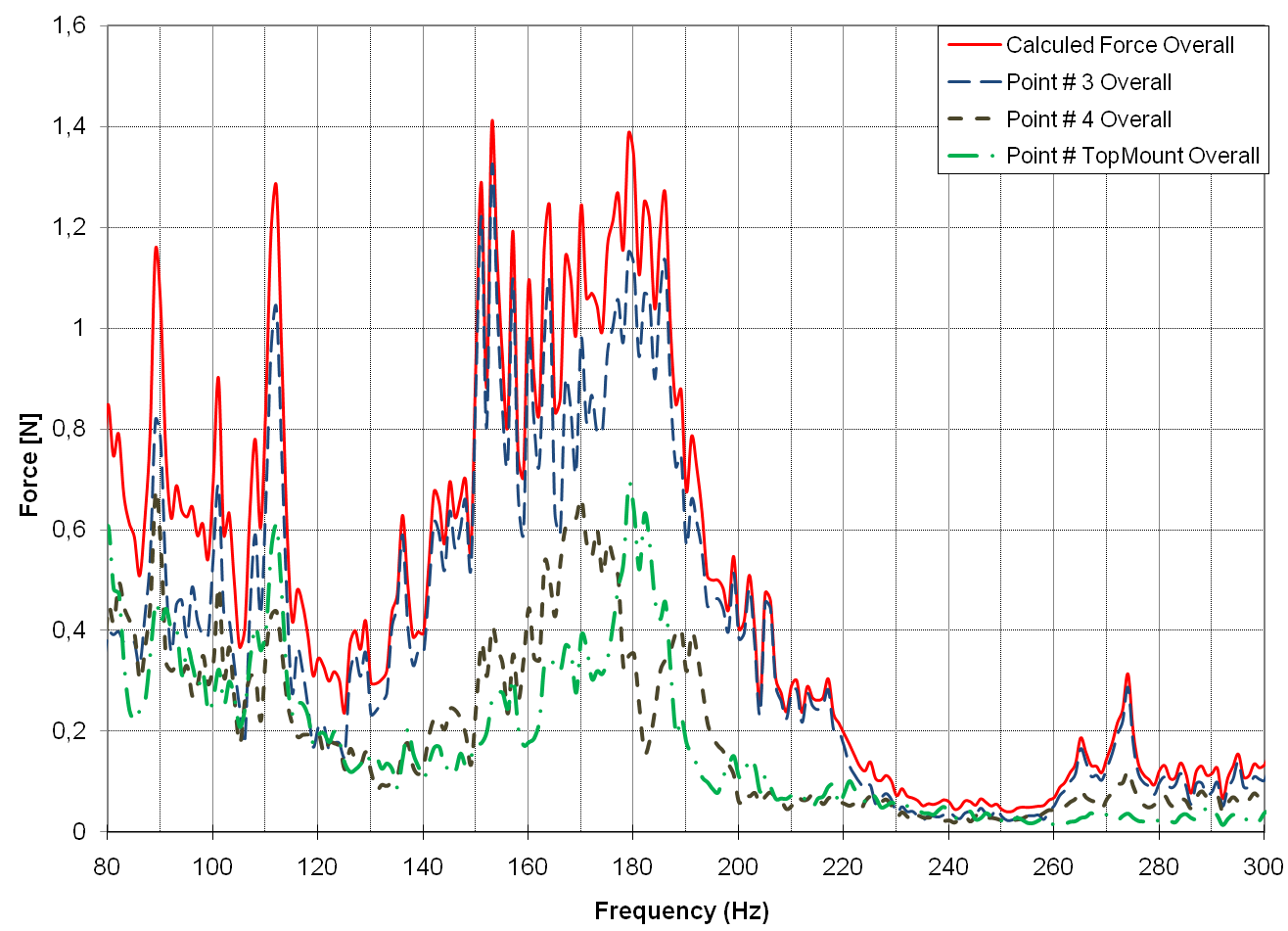

Figura 4.33: Forças de entrada medido pelo TPA

A resultante de força na bucha do ponto 3 é relativamente maior do que nos demais pontos. As figuras 4.34 (a), (b) e (c) detalham estas resultantes para todas as buchas, nos eixos $\mathrm{x}, \mathrm{y}$ e $\mathrm{z}$. 


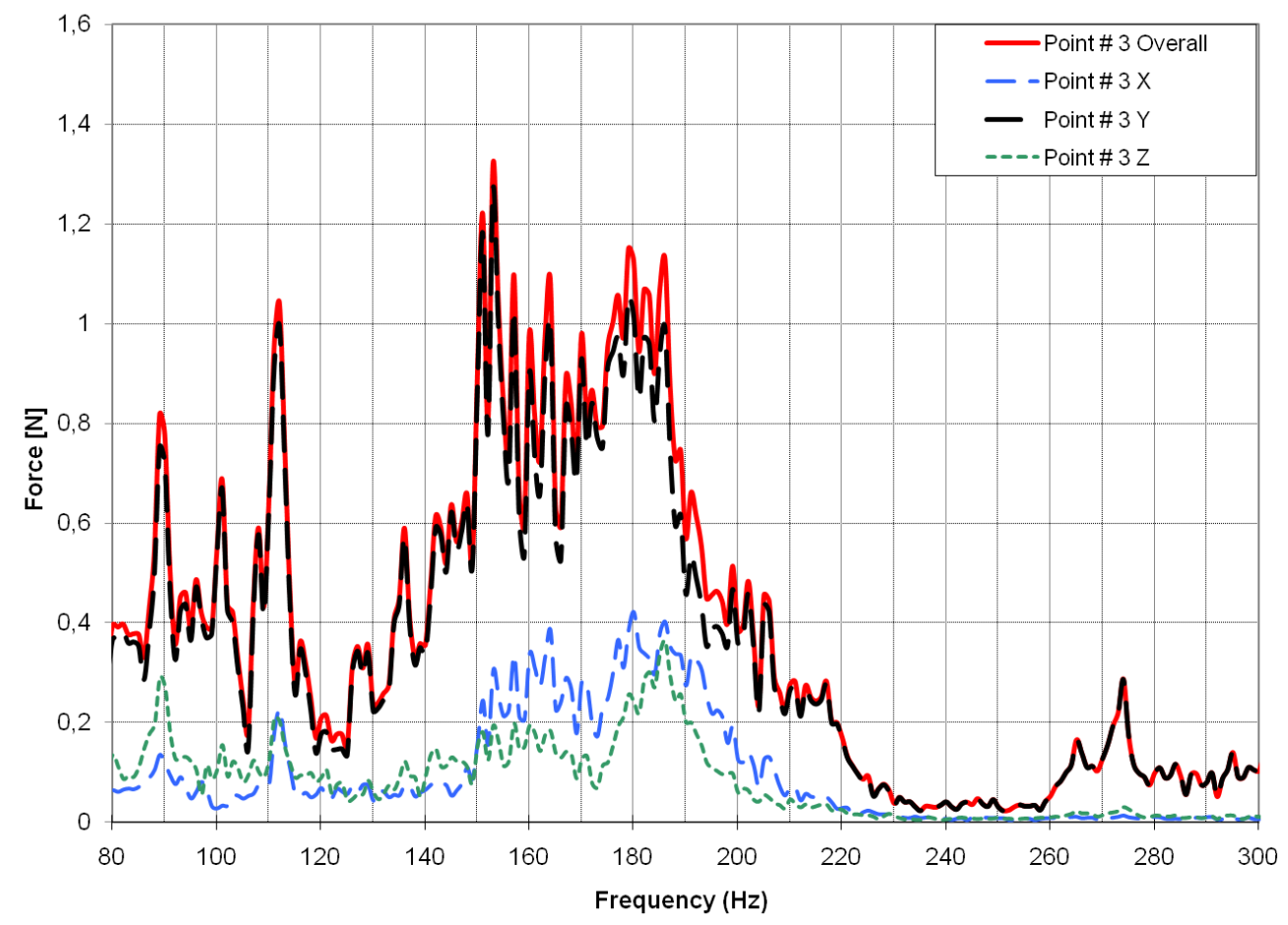

Figura 4.34 (a)

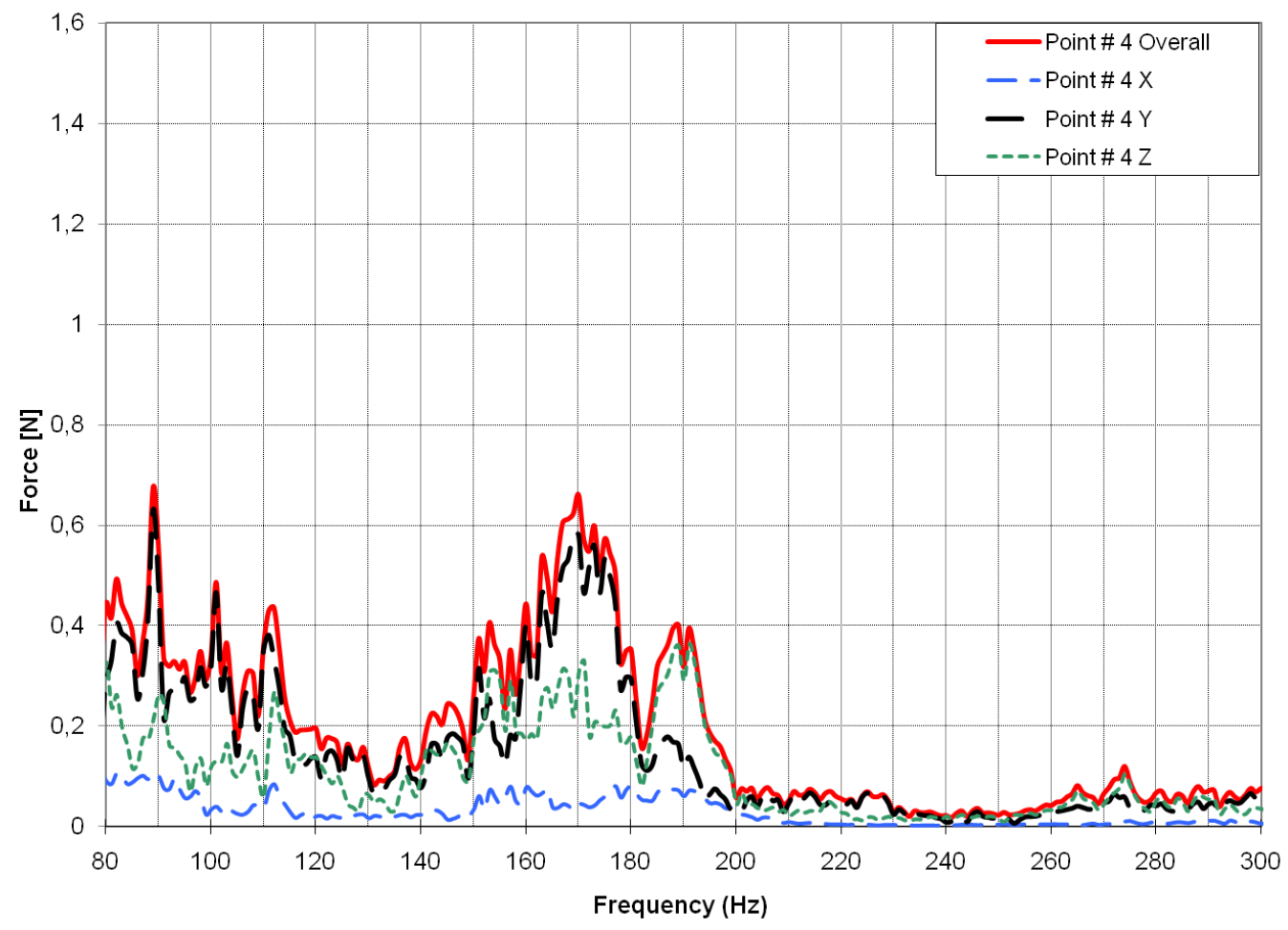

Figura 4.34 (b) 


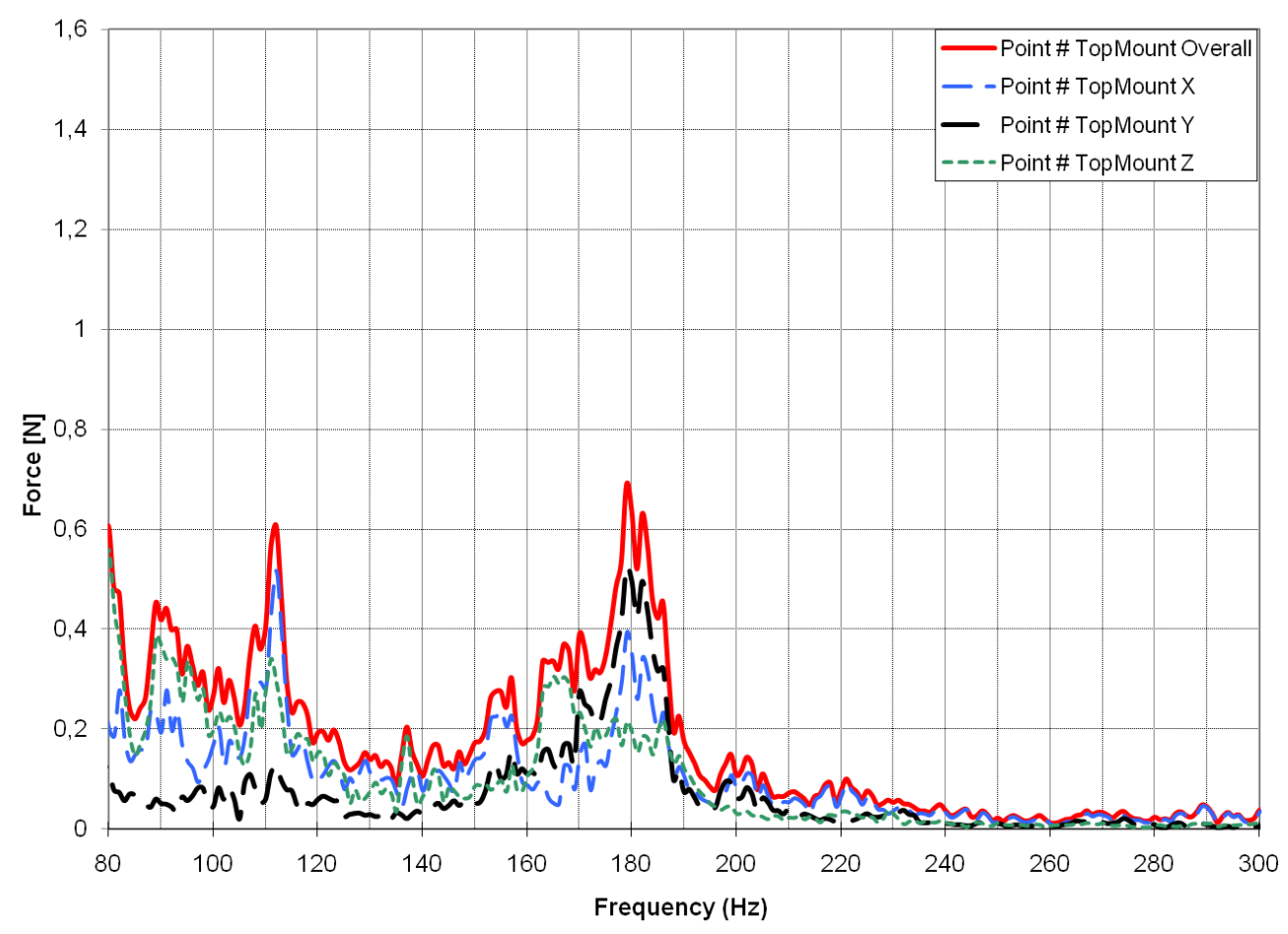

Figura $4.34(c)$

Figuras 4.34 (a), (b) e (c): Forças de entrada nas buchas da suspensão dianteira

Conforme pode ser observado nas figuras acima, a resposta da força em y, na bucha do ponto 3 é relativamente maior do que as do ponto 4 e Top Mount. Esta direção é o caminho mais crítico para formação da resultante.

\subsubsection{Calculo das respostas acústicas da carroceria}

Finalmente, com as forças calculadas e com os dados de sensibilidade acústica da carroceria (p/f) disponíveis para os três pontos de entrada de força, seguem as respostas dos níveis totais de pressão sonora, exercidos por cada caminho nas direções x, y e z, figuras 4.35 (a), (b) e (c). 


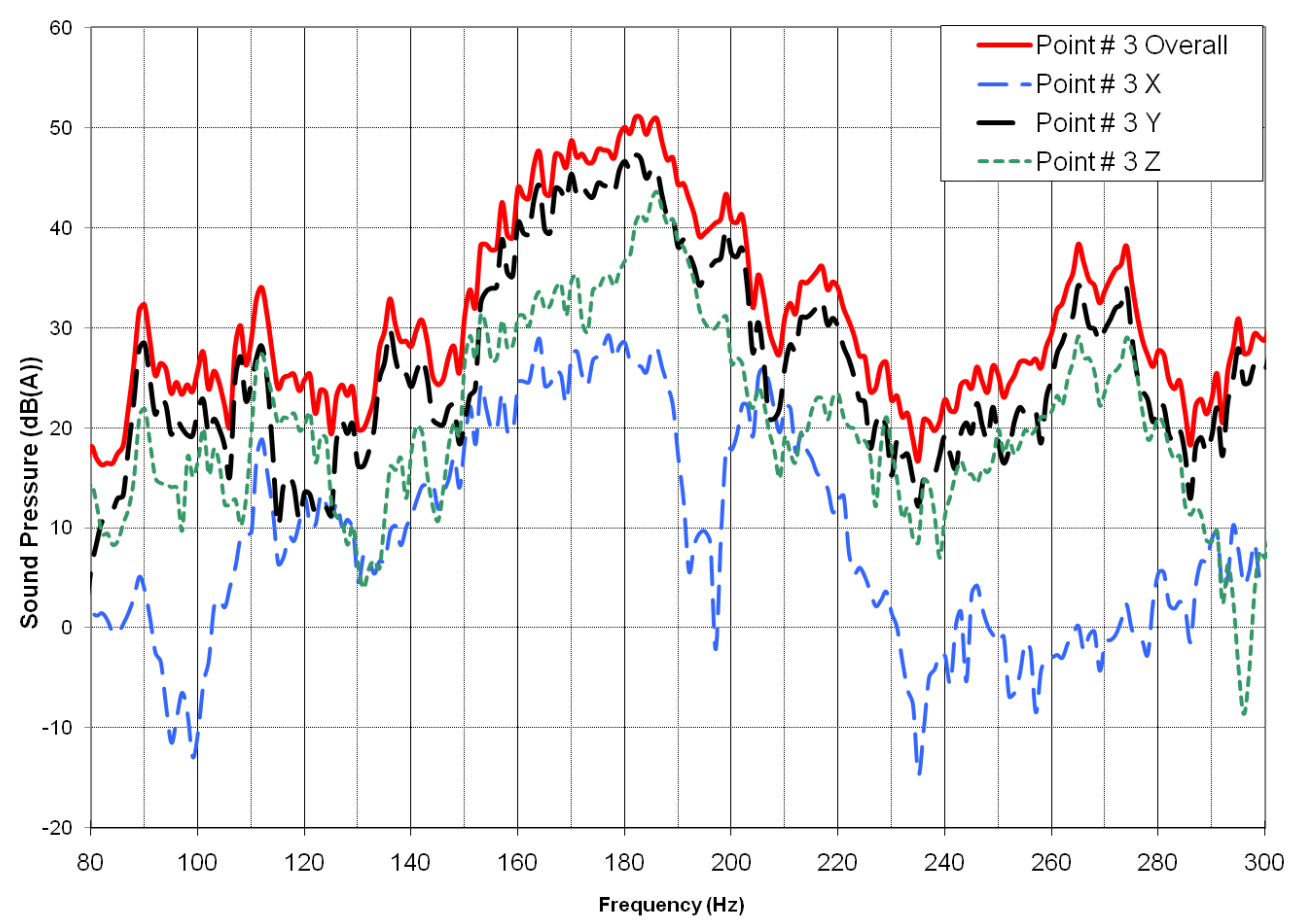

Figura 4.35 (a)

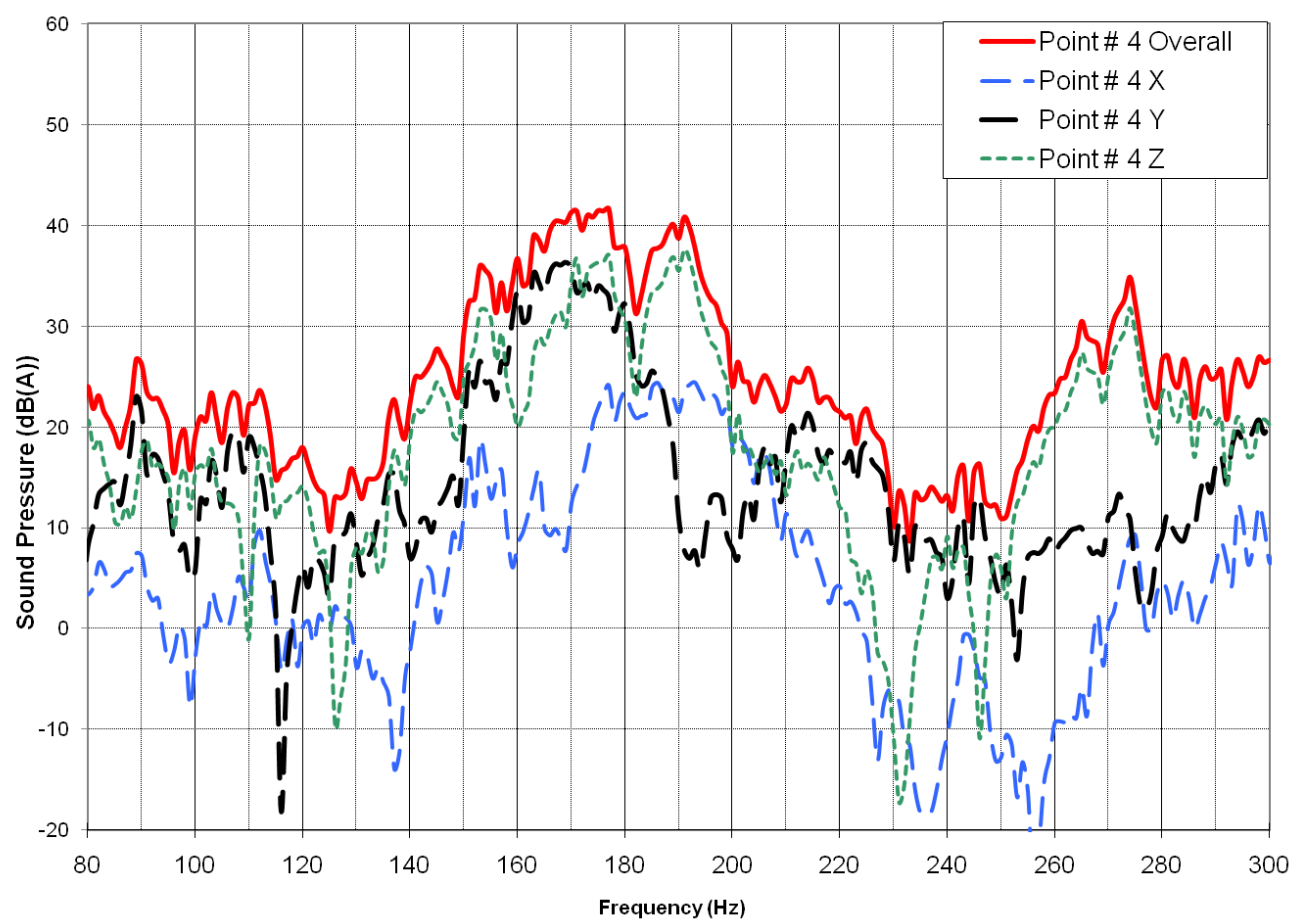

Figura 4.35 (b) 


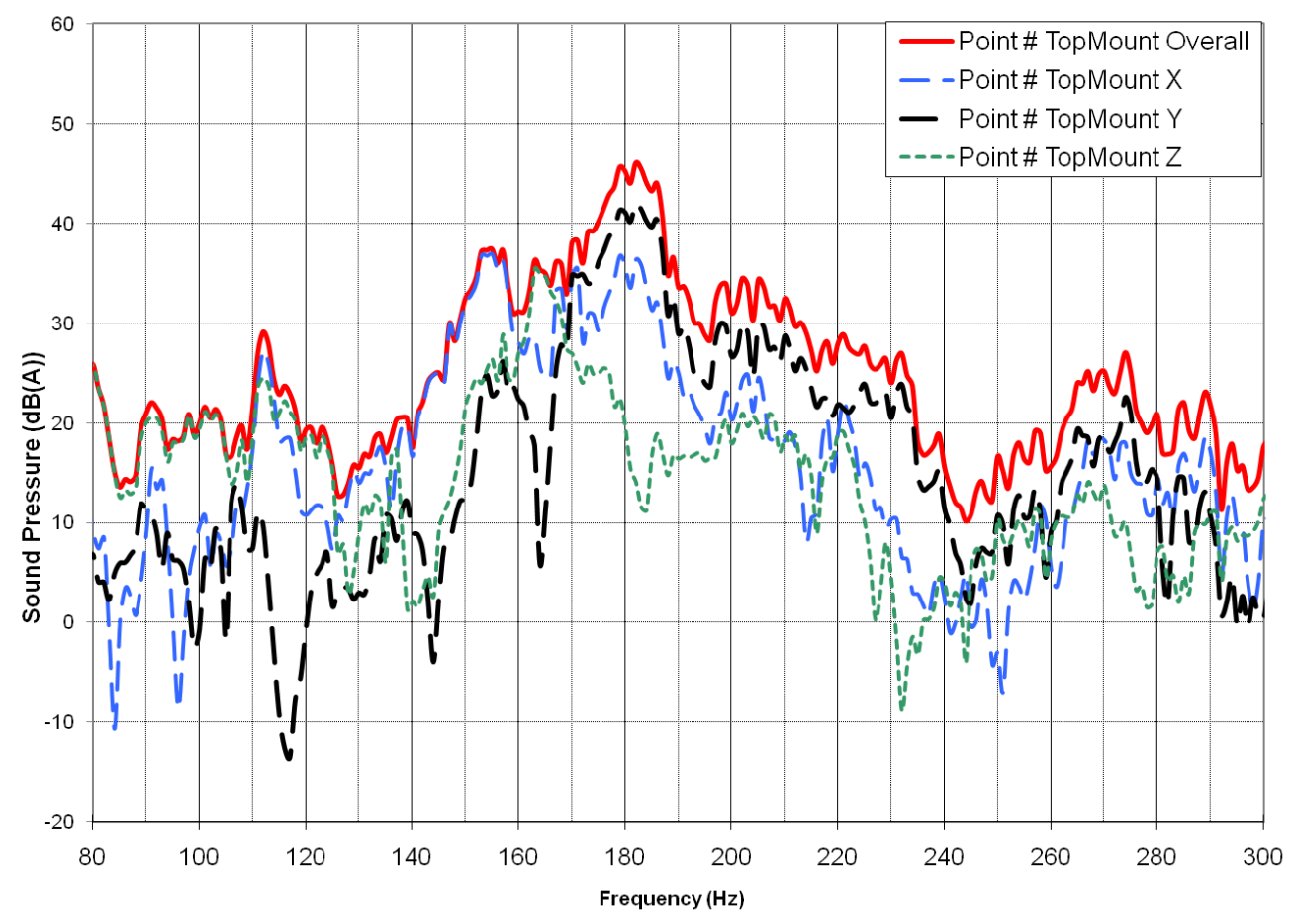

Figura $4.35(c)$

Figuras 4.35 (a), (b) e (c): Respostas acústicas dos caminhos das buchas

Na figura 4.35 (a), a bucha no ponto 3 confirma que a maior força obtido em y causa a maior contribuição de ruído na mesma direção. Vê-se também que apesar do caminho da força em z ser relativamente menor, a sensibilidade acústica para esta força é considerável em torno de $186 \mathrm{~Hz}$. Os eixos y e z, portanto, desempenham papeis relevantes na para a contribuição do rumble, sendo ambos relacionados à sensibilidade acústica e a rigidez radial da bucha anterior do braço de controle.

Graças ao TPA, a percepção do ronco pode ser descrita agora como sendo devido à baixa eficiência na isolação de vibração na direção radial da bucha e alta resposta acústica da carroceria nas direções y e z.

Conforme demonstrado, o uso do método da Matriz Inversa em sua versão reduzida (apenas a diagonal principal com FRFs), os caminhos principais em apenas um dos lados da suspensão dianteira, forneceram uma boa correlação com o ruído medido neste estudo de caso. Uma vez que a bucha anterior do braço de controle, ponto 3 , é identificado como o caminho mais crítico do ruído, duas propostas foram desenvolvidas na busca pela redução do ronco na rodagem: nova especificação de pneus e buchas do ponto 3 com nova rigidez, a serem apresentados a seguir. 


\subsection{Modificações propostas e resultados}

Importante lembrar que as ferramentas que complementam o TPA, já mencionadas no capitulo 2, tais como a análise modal e de formas operacionais de todo chassi e carroceria, são candidatas para aprimorar a convergência das soluções. Para a identificação do caminho crítico ao rumble, estas não se fizeram essenciais até o momento. Contudo, estas análises ajudam a partir de agora, na decisão para qual é a melhor solução a tomar no caminho da bucha do ponto 3: alterar design de bucha para melhorar a atenuação das vibrações e forças, ou diminuir a sensibilidade acústica da carroceria.

Encontrar a melhor solução em compromissos de desempenho dos componentes e de custo, normalmente não é uma questão simples. Mudanças no chassi afetam correlações com outros atributos como dinâmica veicular e durabilidade. O tempo total de desenvolvimento e a estratégia do retorno do investimento também precisam ser considerados.

Para concluir o estudo de caso, serão apresentados os resultados das possíveis soluções do rumble, alterando somente os componentes do chassi: reduzindo a rigidez da bucha anterior e alterando o design do modelo "A". Detalhes destas alterações não foram disponibilizados por questões éticas e profissionais.

Estas propostas exigem um cuidado maior para não alterar a dinâmica do veículo. Em tese, a alteração das buchas da suspensão afetam os atributos de Steering (Straight Ahead / Cornering Controllability e Parking Manoeuvrability), Handling (Straight Ahead / Cornering Stability) e Frenagem (Performance e Disturbios ). 


\subsubsection{Análise das forças na bucha anterior, ponto 3}

Os resultados de ambas as modificações no chassi são apresentados também em termos de força e resposta acústica no ponto 3 , medindo agora apenas as vibrações do lado passivo, para cada configuração. As FRFs de ponto (driving point / impedance) e NTF (body sensitivity) são os mesmos independentemente das configurações de pneus e buchas. As figuras 4.36 (a), (b), (c) e (d) a seguir, apresentam-se os resultados das forças de reação:

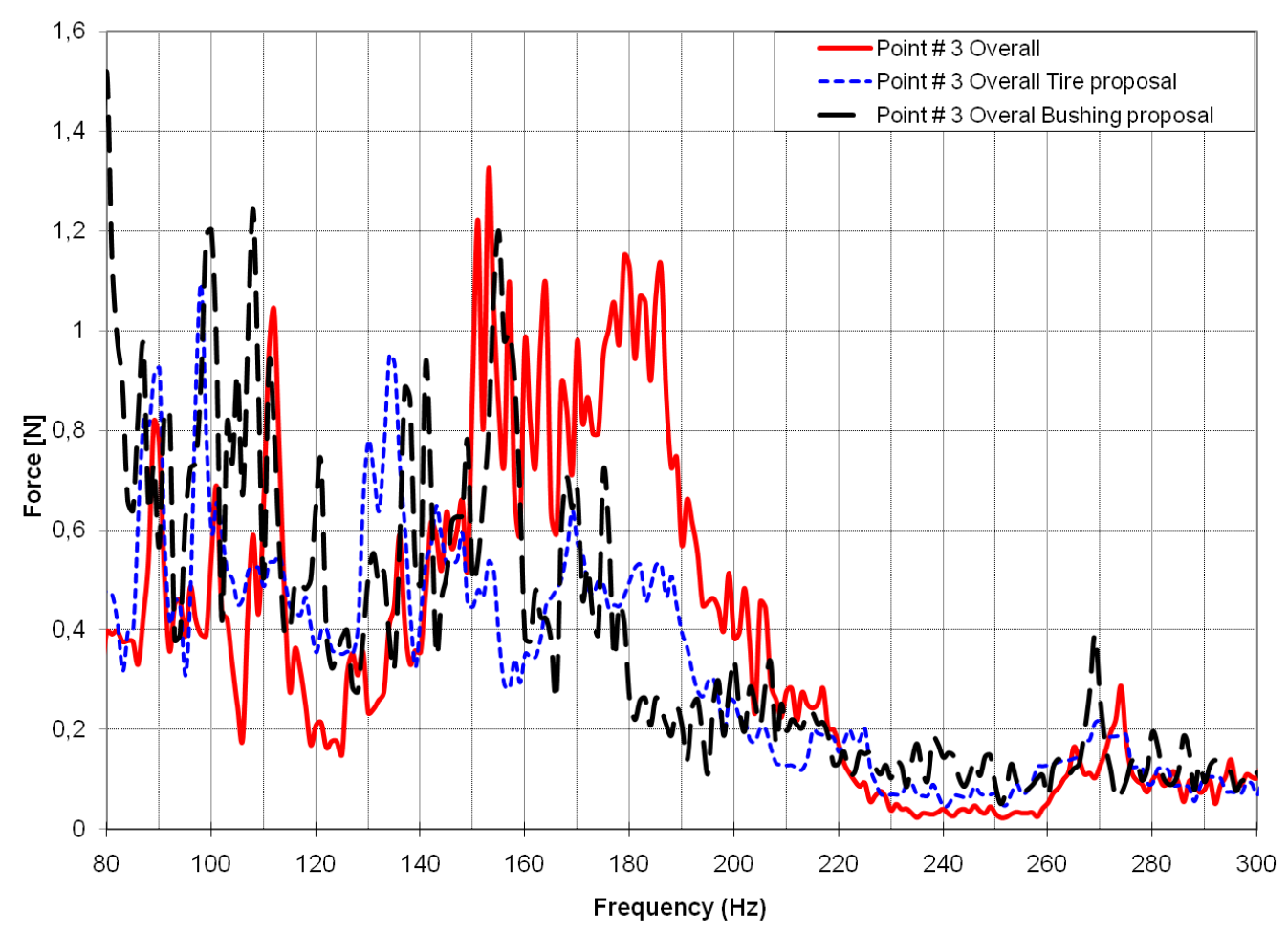

Figura 4.36 (a) 


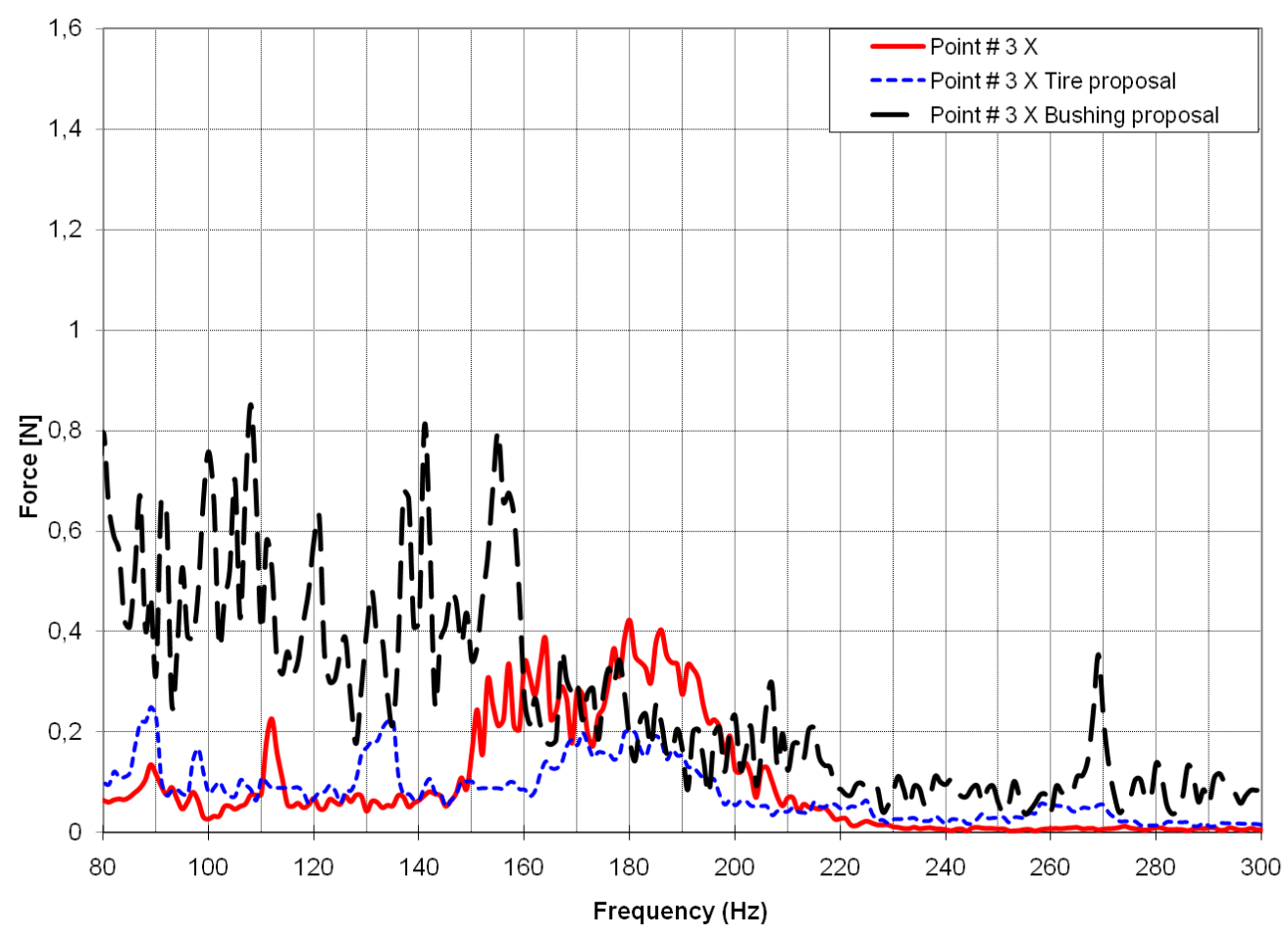

Figura 4.36 (b)

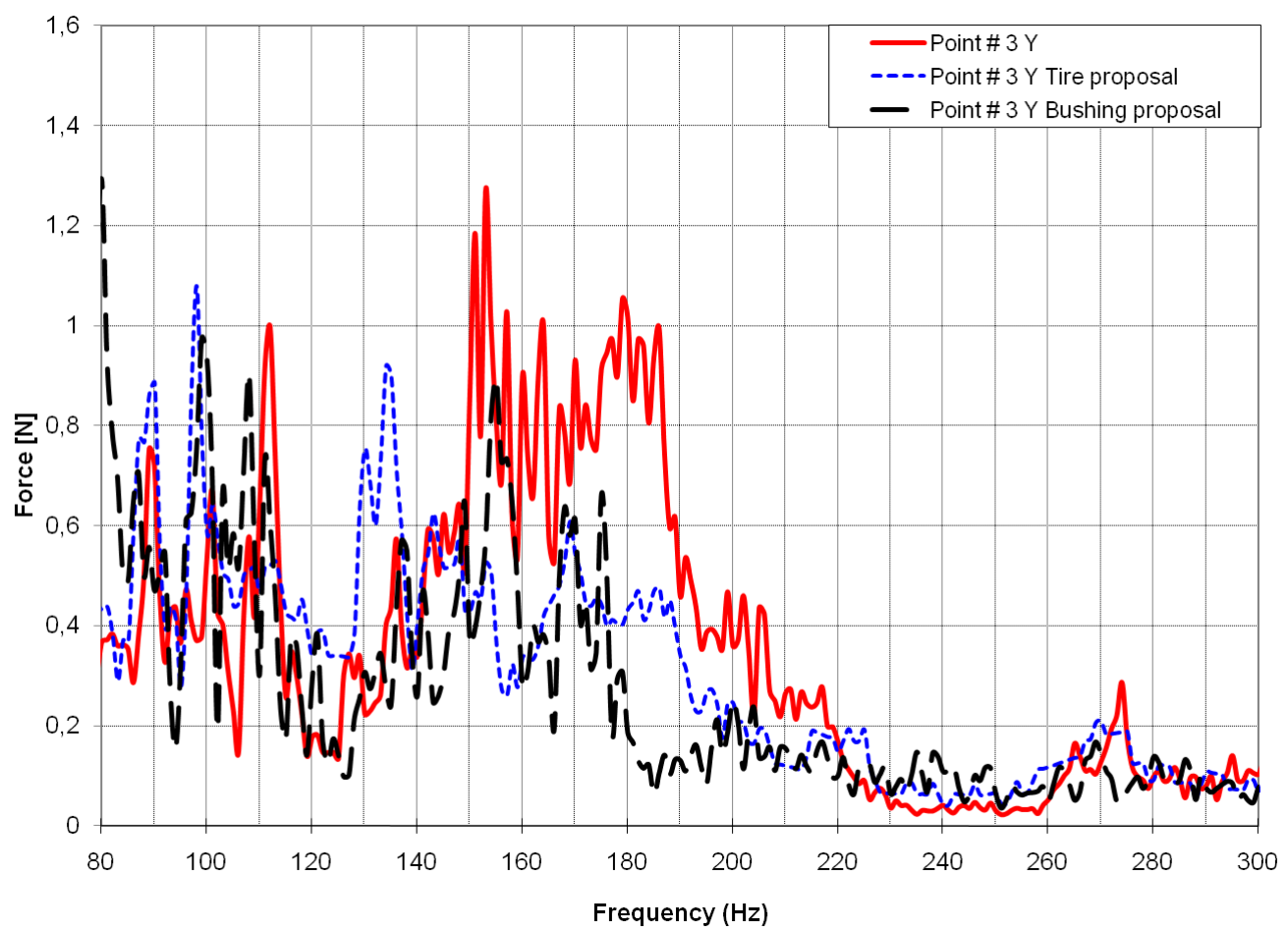

Figura 4.36 (c) 


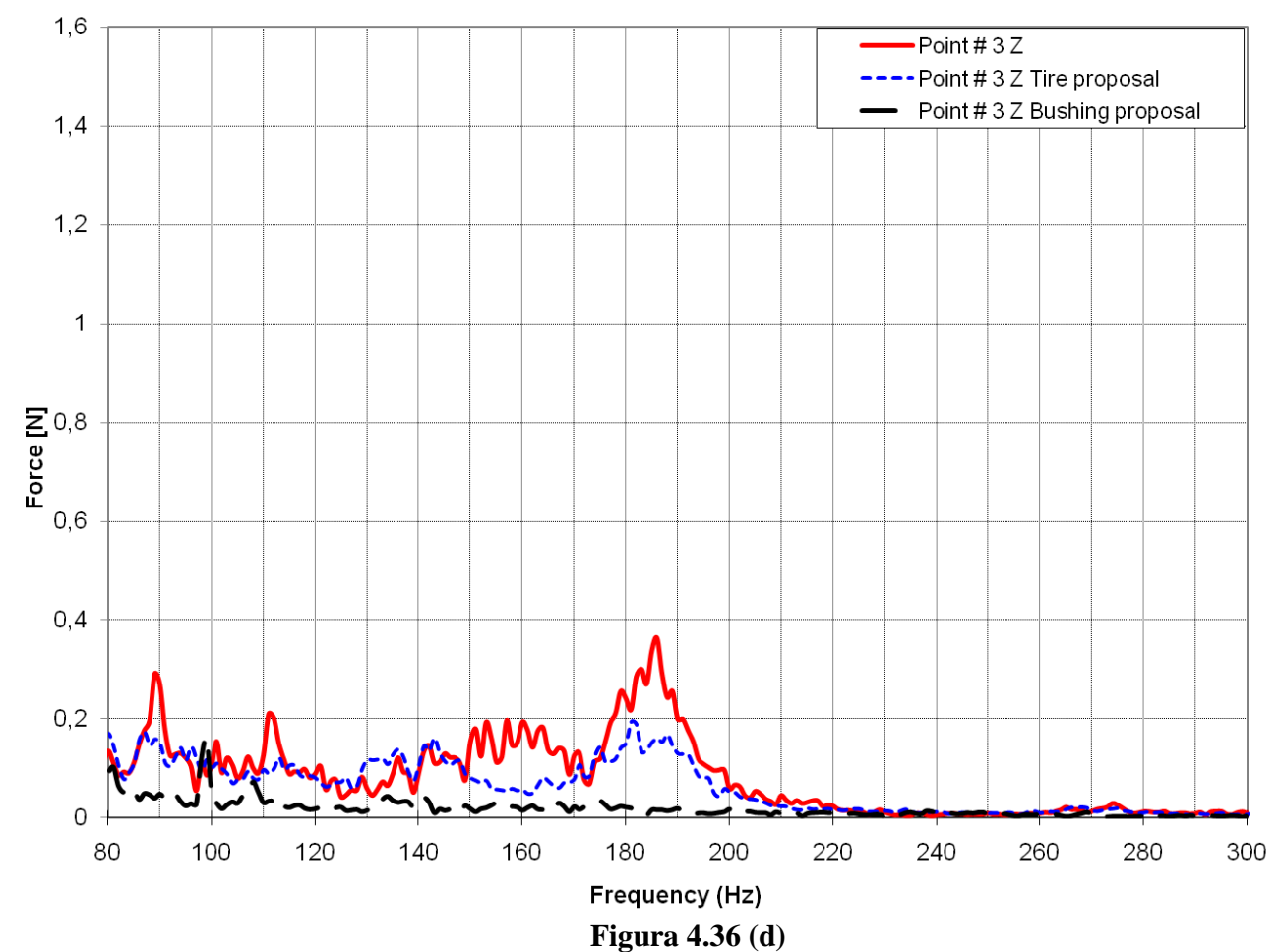

Figuras 4.36 (a), (b), (c) e (d): Comparação das respostas das forças para soluções propostas - Resultante, $x, y$ e $z$ respectivamente.

Como podem ser visto nas figuras acima, ambas as propostas obtiveram resultados positivos na atenuação da força em torno de $180 \mathrm{~Hz}$, principalmente em y. Curiosamente, também presente está um aumento de força em x para a bucha proposta, repetindo também nas direções y e z em $100 \mathrm{~Hz}$ e $110 \mathrm{~Hz}$. Estes resultados sugerem que a bucha pode estar trabalhando em faixa não linear, numa eminência de final de curso em seu batente, na direção axial.

\subsubsection{Análises da contribuição do ruído na bucha anterior,ponto 3}

Finalmente pode ser visto nas figuras 4.37 que as respostas acústicas de ambas as propostas consequentemente também são melhores que a condição inicial, em torno de $180 \mathrm{~Hz}$. Todos os resultados de forças e respostas acústicas foram satisfatórias á solução do fenômeno de ruído de rodagem chamado de rumble 


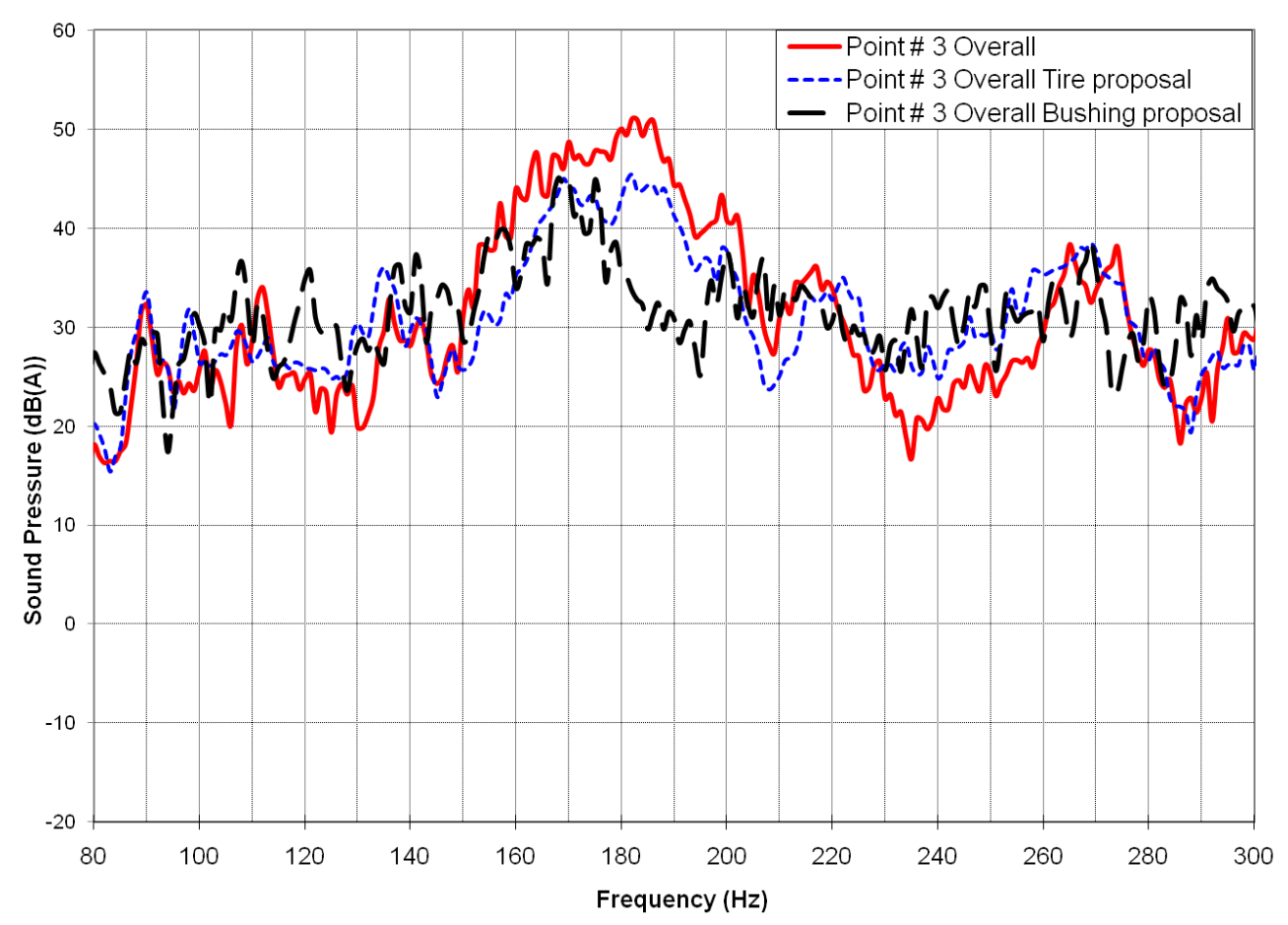

Figura 4.37 (a)

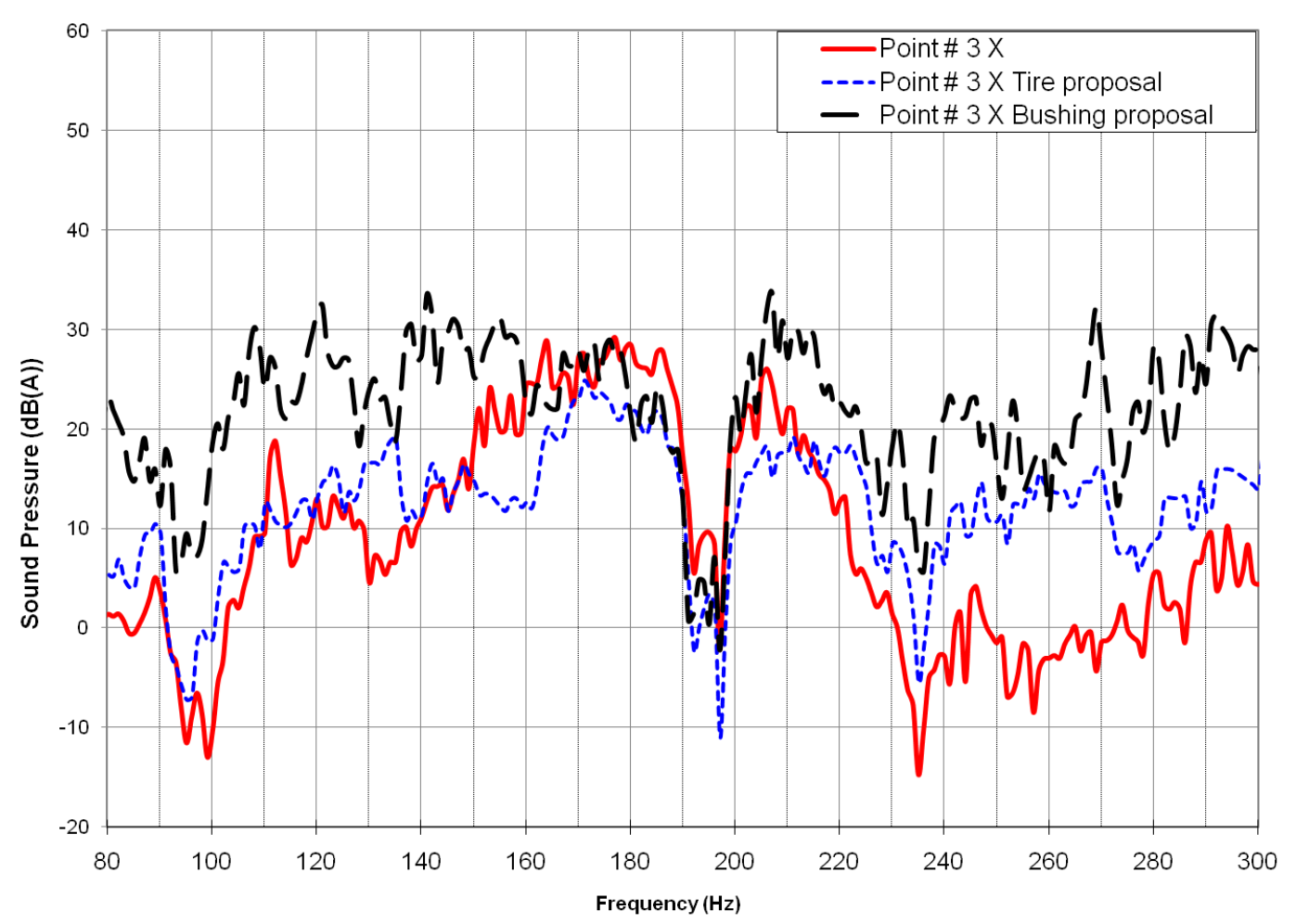

Figura 4.37 (b) 


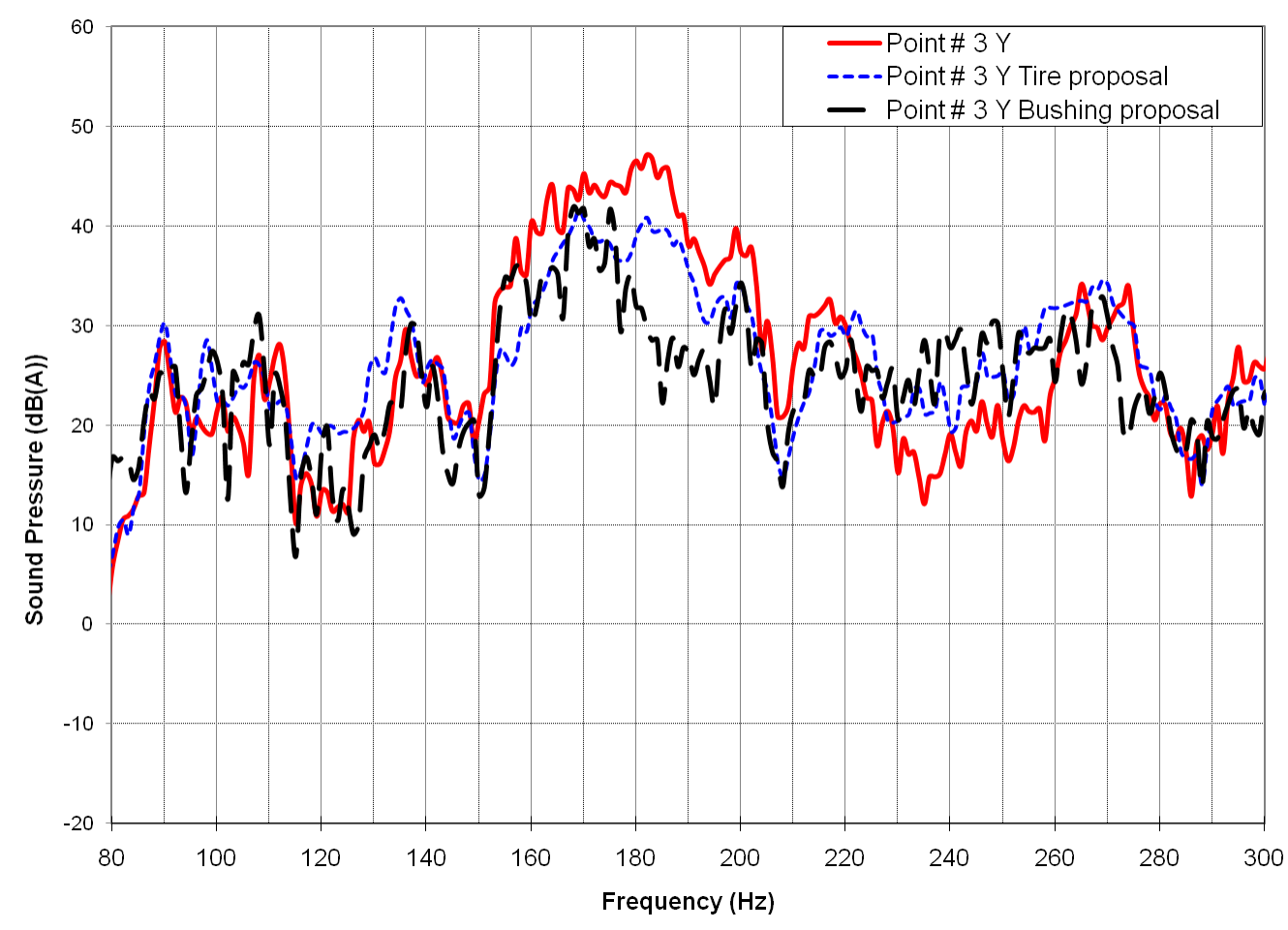

Figura 4.37 (c)

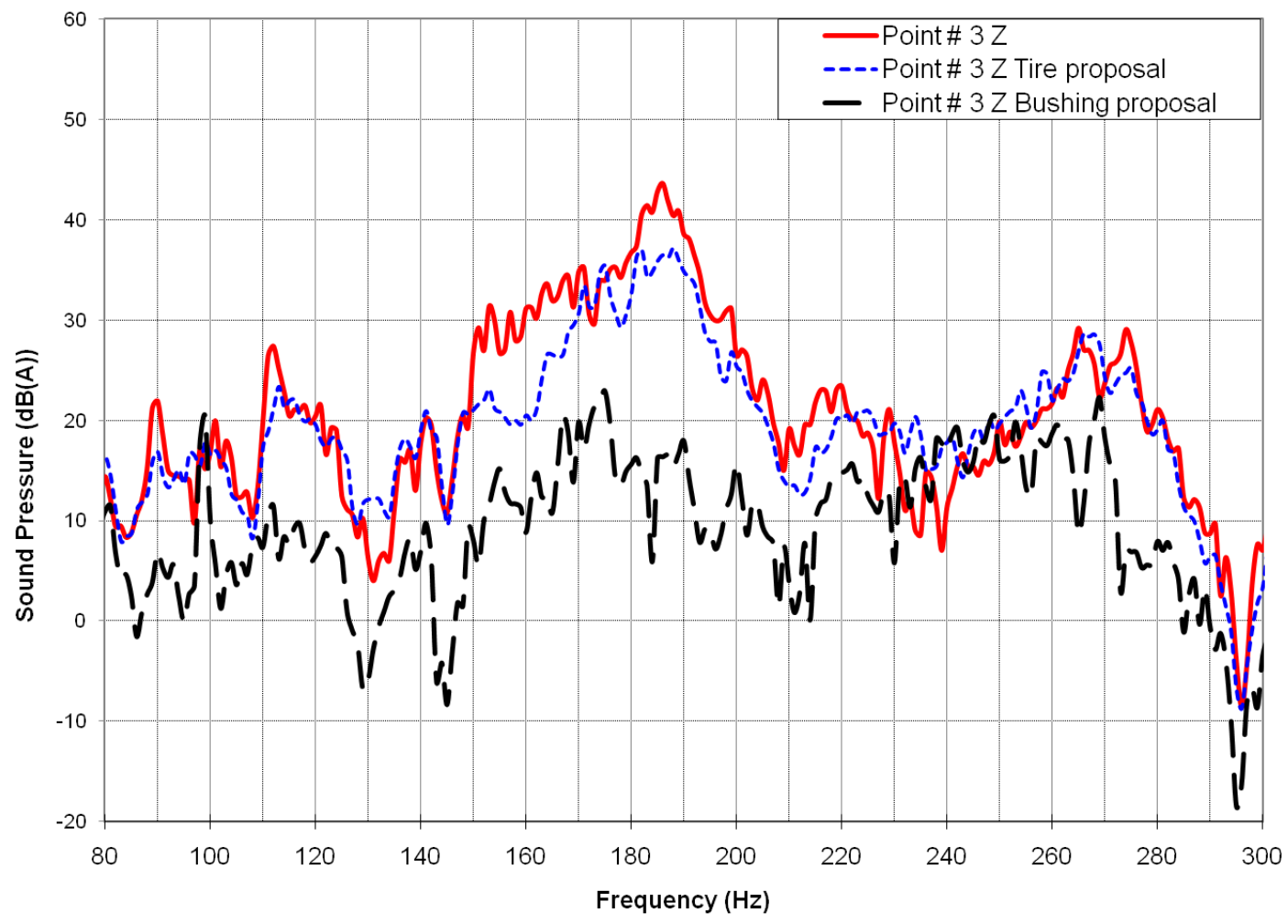

Figura 4.37 (d)

Figura 4.37 (a), (b), (c) e (d): Comparação das respostas de ruído para soluções propostas - Resultante, $z, y$ e $z$ respectivamente 


\subsubsection{Resultado final para o rumble}

Uma vez que se têm as todas as FRFs de mobilidade e sensibilidade acústica da carroceria, é possível calcular o ruído para as novas configurações de chassi, em qualquer condição operacional do protótipo, entre textura de superfícies e velocidades.

Contudo, para as novas correlações de TPA com o ruído interno medido, deve se resaltar que todos os pontos no chassi devem ter suas vibrações (ao menos no lado passivo) medidas novamente para cada proposta investigada, devido às novas distribuições de forças nos postos do chassi, e consequentemente, o novo comportamento dinâmico do protótipo.

A figura 4.38 mostra o resultado final do ruído medido para cada proposta avaliada. Juntamente os resultados apresentados para a força e o ruído calculado na bucha anterior, ambas as propostas são satisfatórias para atenuação do rumble percebido. Para trabalhos futuros, recomenda-se também a verificação da potencial melhoria do ruído interno alterando as características de carroceria.

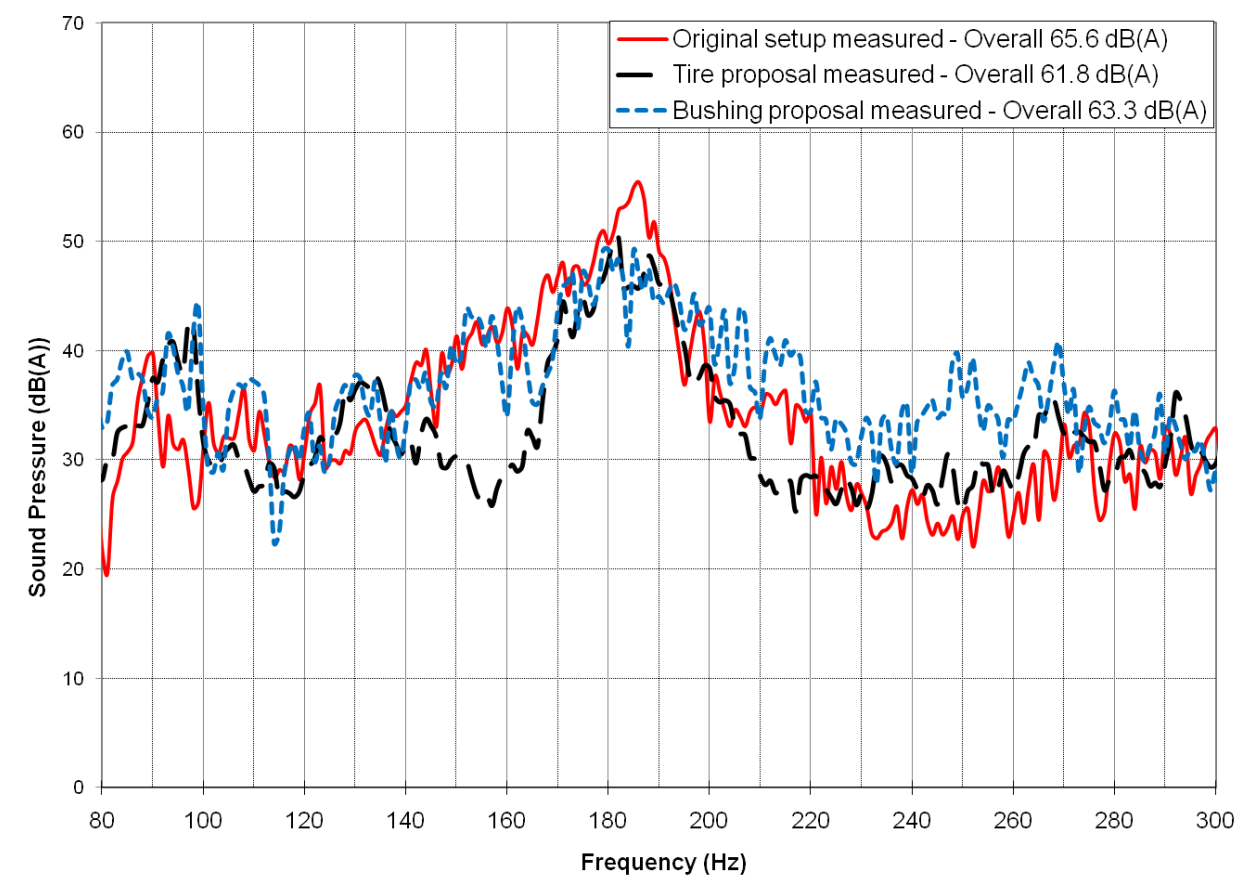

Figura 4.38: Ruído interno medido para as propostas que atenuam o rumble 


\section{Capítulo 5}

\section{Conclusões e desenvolvimentos}

\section{futuros}

Este estudo de caso apresenta a resposta do ruído de rodagem em torno de $180 \mathrm{~Hz}$ classificado como rumble, cuja fonte se origina somente de um modelo de pneu batizado de "A" e que desequilibra o balanço do ruído de rodagem entre as demais fontes de ruído de um protótipo. Buscando a melhoria deste protótipo á sensibilidade acústica, a metodologia do TPA é a melhor ferramenta da atualidade para investigar quais componentes do chassi são mais críticos para a formação do fenômeno. Os métodos clássicos e procedimentos para o TPA foram revisados e para aplicação no caso, focou-se no estudo do ruído de rodagem via contribuições estruturais.

\subsection{Conclusões do estudo de caso}

As avaliações subjetivas demonstraram que os caminhos principais do problema estão concentrados na suspensão dianteira. Assim, concluindo que maior parte do ruído de rodagem percebido, entre $80 \mathrm{~Hz}$ e $300 \mathrm{~Hz}$, é de caráter estrutural, os testes foram reduzidos para os três componentes do A-arm, do sistema Mc Pherson: buchas anterior e posterior do braço de controle e a bucha da torre da suspensão. 
Em seguida, verifica-se qual a condição mais critica para a percepção do rumble. Diversas condições operacionais, ou seja, textura de superfícies e velocidades, são avaliadas. Sendo a pior condição a pista de baixa rugosidade (lisa) e a baixa velocidade, $20 \mathrm{~km} / \mathrm{h}$. Para a didática desta dissertação, as investigações fundamentadas na teoria do TPA são apresentadas somente nesta condição.

Assim, conclui-se que o caminho mais crítico para a formação do rumble deste caso, está na bucha anterior do braço de controle da suspensão dianteira, somente ao se utilizar o modelo de pneu batizado de "A".

A resposta vibracional na direção y deste modelo "A", somado á baixa atenuação de vibrações na direção radial da bucha anterior (y e z), e á maior sensibilidade acústica da carroceria nas direções y e z, são as causas para a formação do rumble percebido no interior do protótipo.

Graças ao TPA, a percepção do ronco pode ser descrita agora como sendo devido à baixa eficiência na isolação de vibração na direção radial da bucha e alta resposta acústica da carroceria nas direções y e z.

Apesar das otimizações para a correlação do TPA, os resultados obtidos foram satisfatórios para formulação de duas possíveis propostas para atenuação do ruído: redução da rigidez na bucha anterior e mudança nos componentes do pneu "A".

Em termos práticos, diversas concessões foram feitas para realizar um TPA relativamente simples e mais rápido, comparado aos métodos clássicos, tendo em vista a redução do número de sensores e canais, bem como o tempo de instrumentação, medições e análises, em laboratório e em pistas.

Para as medições das FRF de mobilidade (a/f) do lado passivo de cada conexão das buchas, considera-se a relação de entrada de força de impacto do martelo e a saída vibração no próprio ponto apenas, desconsiderando a influência cruzada entre as direções dos eixos em um mesmo ponto e entre os demais pontos. Apesar de não se verificar os efeitos de acoplamento modal das vibrações cruzadas, o modelo obteve uma boa resposta comparada com a medição real.

No Método da Matriz Inversa para o calculo dos carregamentos estruturais do TPA, a matriz é simplificada para três pontos, com dados somente a sua diagonal principal. 
Desta maneira, somente faz se necessário inverter a relação de (f/a) para o calculo das forças.

A similaridade das FRFs de ponto para mobilidade e sensibilidade acústica entre o lado direito e esquerdo da suspensão dianteira é apresentado como satisfatória para a continuidade dos cálculos neste TPA. Da mesma maneira, assume-se a simetria para as vibrações operacionais entre os lados direito e esquerdo, realizando as instrumentações para pistas e análises apenas no lado direito. Sendo o TPA para Road NVH basicamente um problema de múltiplas referências, com quatro fontes não coerentes, mas parcialmente correlacionadas, este estudo de caso é abordado como um TPA de uma única fonte apenas, adicionando a segunda fonte, o lado esquerdo, artificialmente ao dobrar o ruído não coerente (somando $3 \mathrm{~dB}(\mathrm{~A})$ ), sem a análise de correlação entre as fases.

Assim, exemplifica-se a aplicação do TPA em seu aspecto energético para formação do ruído, uma vez que a soma dos caminhos de contribuição para o ruído final foram calculadas sem utilizar um sinal de referência, entre as fontes e a correlação com o ruído interno medido.

Conforme visto na teoria as informações das fases são importantes para o TPA uma vez que irão informar vetorialmente as respostas de ruídos e forças, também de como as vibrações agirão e reagirão para cada caminho e conexões estudadas. No estudo de caso em questão, a soma das energias foi suficiente para demonstração da causa do problema e as suas possíveis soluções, entretanto recomenda-se o uso das fases para refino da quantificação destas contribuições.

Portanto, esta análise otimizada e reduzida do TPA pode ser considerada como uma abordagem razoável para apontar caminhos críticos, bem como uma metodologia confiável para as visualizações das contribuições de ruído de cada componente da suspensão, no caso ruído via estrutural. 


\subsection{Próximos passos}

Com a experiência adquirida nestas investigações e dissertação, recomenda-se o estudo dos seguintes passos:

- Investigar um novo problema considerando as contribuições aéreas dos pneus;

- Utilizar sinal de referência para análises, trabalhando assim com o efeito de fase nos próximos modelos.

- Investigar o em espectro cruzado entre as direções e pontos selecionados para o TPA.

- Estudar modelos em TPA que considerem as demais fontes de ruído, motorização e de vento, via estrutural e aéreo.

\subsection{Tendências para Road TPA}

Os esforços contínuos para redução do consumo de combustível estão associados a diversas tecnologias de construção automotiva, entre as principais: a diminuição da resistência ao rolamento dos pneus e peso do veículo.

As relações entre a melhor eficiência de rolagem contra os comportamentos dinâmicos e respostas de $N V H$, ficam em evidência devido às novas condições de entrada de forças. Da mesma maneira, a evolução no design de carrocerias subsistemas e componentes, devem atender a pré-requisitos de peso e aerodinâmica e também devem ser cada vez mais otimizados e eficientes quanto suas FRFs, funções de transferências vibracionais e acústicas, tanto as contribuições por vias estruturais e aéreas. 
Nesta ótica, para que a qualidade do veículo e seu ruído de rodagem não sejam prejudicados, é recomendável o aprofundamento na utilização das métodos fundamentados no TPA.

As técnicas de análises de sinais e metodologias de testes experimentais, assim como as a matemática para a simulação e tratamento numérico, aproveitamento melhor as ferramentas computacionais, são investimentos importantes para evolução dos métodos e tempo empregado para as etapas de medições e análises.

Como mencionado no trabalho, o TPA, desde sua forma clássica até mesmo em formulações hibridas via $C A E$, pode ser utilizado para resolver problemas, refinar a resposta do $N V H$ veicular e também fornecer especificações de componentes (targets), também em avançado á existência do protótipo. O direcional quanto á designs permitem o maior controle do balanço entre as fontes de $N V H$, dando base para as novas tendências de componentes e melhores produtos finais. 


\section{Bibliografia}

J.S., Bendat; A.G., Piersol. (1980). Engineering Applications of Correlation and Spectral Analysis. J. Wiley \& Sons.

Arruda, J., \& Huallpa, B. (2005). Análise Espectral de Sinais e Sistemas Mecânicos Lineares. Campinas: Unicamp.

Ballou, Glen. (2005). Handbook for sound engineers. Burlington, MA, USA: Focal Press.

Bendat e Piersol. (1986). Random Data: Analysis and Measurement Procedures. New York: John Wiley \& Sons.

Biography, Hutchinson Dictionary of Scentific. (9 de 07 de 2009). Dunlop, John Boyd. (MCTC Library) Acesso em 05 de 09 de 2010, disponível em Mcgraw-Hill AcessScience Encyclopedia os Science \& Technology Online: http://www.accessscience.com

CETESB. (2004). Biblioteca Didática de Tecnologias Ambientais. Acesso em 01 de 04 de 2011, disponível em Faculdade de Engenharia Civil, Arquitetura e Urbanismo Unicamp:

http:/www.fec.unicamp.br/ bdta/modulos/mobilidade/transportes/legislacao.htm

D., Otte. (1994). Development and Evaluation of Singular Value analysis Methodologies for Studying Multivariate Noise and Vibration Problems. PhD. K. U. Leuven .

Digimods. (s.d.). Acesso em 05 de 01 de 2011, disponível em DIGIMODS.CO.UK Computer Generated Modified Cars: http://www.digimods.co.uk/

Ejsmont, J. A. (2005). Development Of Procedures For Certifying Noise Test Equipment. Poland: GDANSK UNIVERSITY OF TECHNOLOGY PUBLISHERS. 
EUROPEAN TYRE SCHOOL. (s.d.). Acesso em 20 de 07 de 2010, disponível em http://www.tut.fi/plastics/tyreschool/teachingmodules.html

Gajdatsy, P., Gielen, L., Janssens, K., Auweraer, H. V., Mas, P., \& Desmet, W. (2009). A Novel TPA Method Using Parametric Load Models: Validation on Experimental and Industrial Cases. SAE 2009-01-2165, p. 7.

Georgano, G. N. (2000). Vintage Cars 1886 to 1930. Sweden: AB Nordbok.

Gillespie, T. D. (1992). Fundamentals of Vehicle Dynamics. Warrendale: Society of Automotive Engineers, Inc.

H. Van der Auweraer, P. M. (2007, Maio 15). Transfer Path Analysis in the Critical Path of Vehicle Refinement: The Role of Fast, Hybrid and Operational Path Analysis. SAE 2007-01-2352 .

Herlihy, D. V. (2004). Bicycle, The History. Yale University Press , 76.

J. Lambert. (2000). Report on noise exposure of the population, health risks and social welfare costs. Proceedings of the noise in Europe conference. Paris, França.

J.R.F., Arruda; E., Godoy. (1989). A Peak Classification Technique in Digital Spectral Analysis. Proceedings of IMAC 7, (pp. 1582-1586). Las Vegas, NV.

J.S. Bendat; A.G. Piersol. (1980). Engineering applications of correlation and spectral analysis. Wiley .

K. H. Ko; S. J. Heo; H. Kook. (2003). Evaluation of Road-Induced Noise of a Vehicle Using Experimental Aproach. International Journal of Automotive Technology , pp. 2130.

K. Ichiro ; U. Sagiri. (2005). Coupled Vibration Analysis of Tire and Wheel for Road Noise Improvement. SAE 2005-01-2525, 11.

K.R. Stassen; P. Collier; R. Torfs. (2008). Enviromental burden of diese due to transportation noise in Flanders (Belgium). Transportation Research Part D (13), pp. 355-358.

Kano, Noriaki. (1984, April). Attractive quality and must-be quality. Journal of the Japanese Society for Quality Control (14), pp. 39-48. 
Katrien Wyckaert, Herman Van der Auweraer. (1995). Operational Analysis, Transfer Path Analysis, Modal Analysis: Tools to Understand Road Noise Problems in Cars. SAE 951251 .

Kenneth McConnell, Paulo S. Varoto. (2008). Vibrational testing: Theory \& Pratice.

Kindt, P. (2009). Structure-borne tyre/road noise due to road surface discontinuities. Belgica: Katholieke Universiteit Leuven.

LMS. (s.d.). Fundamentals of Vibration and Modal Analysis. LMS. Fonte: LMS International: http://www.lmsintl.com/

LMS. (2010). LMS International. Retrieved 05 01, 2010, from LMS Engineering Innovation: www.lmsintl.com

LMS. (1995). The Qualification and Quantification of Vibro-acoustic Transfer Paths. Fonte: LMS International: http://www.lmsintl.com/

Marshall Brain. (2010). How Harley-Davidson works. Retrieved Outubro 06, 2010, from HowStuffWorks: http://auto.howstuffworks.com/harley3.htm

McConnell, K. G. (1995). Vibration testing: theory and practice. New York, NY: John Wiley \& Sons, Inc.

Mechanics, Society for Experimental. (s.d.). Modal Analysis. IJAEM - International Journal of Analytical and Experimental Modal Analysis .

Museun, C. S. (23 de 12 de 2006). The von Draisâ€ $€^{\mathrm{TM}}$ vehicle had two wheels but no pedals. Acesso em 05 de 09 de 2010, disponível em Baron von Draisâ€ $€^{\mathbf{T M}}$ Bicycle: http://www.sciencetech.technomuses.ca/english/collection/cicles2.cfm

P.J.G. van der Linden, Ph. Varet. (26-29 de Fevereiro de 1996). Experimental Determination of Low Frequency Noise Contributions of Interior Vehicle Body Panels in Normal Operation. SAE 960194 , pp. 61-66.

Reimpell, J. and Stoll, H. (1996). The Automotive Chassis Engineering Principles. Warrendale: SAE. 
Research for a quiter europe in 2020: Updated strategy paper of CALM network. (Setembro de 2007). Fonte: Coordination of European Research for Advanced Transport Noise Mitigation (CALM): http://www.calm-network.com

Sandberg, Ulf; Ejsmont, Jerzy A. (2002). Tyre/Road Noise Reference Book. Kisa: Informex.

Scotland, Virtual. (2009). John Dunlop - A Famous Scottish Inventor. Acesso em 05 de 09 de 2010, disponível em Virtual Scotland.co.uk: http://www.virtualscotland.co.uk/scotland_articles/famous-scots/dunlop.htm

Silva, César Helou. (2010). Customized Road TPA to Improve Vehicle Sensitivity to Rumble Noise from Tires/Wheels Lateral Forces. SAE 2010-36-0553 .

Sung-Jong Kim, Hae-In Yang, Sang-Kwon Lee. (2009). Prediction of Interior Noise Based on Hybrid TPA. SAE 2009-01-2115 , p. 9.

Sung-Jong Kim; Hae-In Yang; Sang-Kwon Lee. (2009). Prediction of Interior Noise Based on Hybrid TPA, Inha University. SAE 2009-01-2115 , p. 9.

Thomson, R. W. (1846). Patent No. No. 10,900. França.

Time. (2008). The World's Worst Traffic Jams. Time .

Vandenbroeck, W. H. (1993). Suspension Analysis in View of Road Noise Optimization. Proc. of the 1993 Noise and Vibration Conference (pp. 413-421). Traverse City: SAE P-264.

W. Hendricx; D. Vandenbroeck. (1993). Suspension Analisys in view of road noise Optimization. Noise \& Vibration Conference \& Exposition, May 1993 (pp. 647-652). Traverser City, MI: SAE International.

William S. Levine. (1996). The Control Handbook. New York: CRC Press.

Winter, R. G., \& Steinberg, A. M. (2011). Coherence. Fonte: Access Science: http://www.accessscience.com 